Flávio Marinho Vasconcelos

Método de otimização topológica aplicado a projeto de moldes utilizados em processos de sinterização por plasma 
Flávio Marinho Vasconcelos

\section{Método de otimização topológica aplicado a projeto de moldes utilizados em processos de sinterização por plasma}

Dissertação apresentada à Escola Politécnica da Universidade de São Paulo para obtenção do Título de Mestre em Engenharia Mecânica. 
Flávio Marinho Vasconcelos

\section{Método de otimização topológica aplicado a projeto de moldes utilizados em processos de sinterização por plasma}

Dissertação apresentada à Escola Politécnica da Universidade de São Paulo para obtenção do Título de Mestre em Engenharia Mecânica.

Área de concentração:

Controle e Automação

Orientador:

Prof. Dr. Emílio Carlos Nelli Silva 
Este exemplar foi revisado e alterado em relação à versão original sob responsabilidade única do autor e com a anuência de seu orientador.

São Paulo, 08 de Abril de 2013

Assinatura do autor

Assinatura do orientador

Ficha Catalográfica

Vasconcelos, Flávio Marinho

Método de otimização topológica aplicado a projeto de moldes utilizados em processos de sinterização por plasma. / F.M. Vasconcelos, Ed. Rev. São Paulo, 2013. 146 p.

Dissertação (Mestrado) - Escola Politécnica da Universidade de São Paulo. Departamento de Engenharia Mecatrônica e de Sistemas Mecânicos.

1. Topologia(Otimização). 2. Sinterização. $3 . \quad$ Gabaritos e moldes I. Universidade de São Paulo. Escola Politécnica. Departamento de Engenharia Mecatrônica e de Sistemas Mecânicos. II. t. 
Dedico este trabalho a toda a minha família, especialmente à minha Mãe, que sempre foi exemplo e referência de determinação. Que esta Dissertação sirva de inspiração para as próximas gerações da família na busca pelo conhecimento científico. 


\section{Agradecimentos}

Agradeço primeiramente a Deus pelo privilégio do acesso ao conhecimento e por me oferecer condições para o meu desenvolvimento pessoal.

À minha família por me apoiar nas minhas escolhas profissionais e pela confiança em mim depositada.

À minha linda e querida Mãe, pela compreensão, orientação, incentivo e amor incondicional oferecidos ao seu filho.

À minha linda e amada filha, por ser a razão das minhas principais escolhas não apenas na esfera profissional, como também na pessoal.

Dedico também, especial agradecimento, ao meu orientador Prof. Dr. Emílio Carlos Nelli Silva, o qual se mostrou sempre receptivo às discussões que concernem ao mundo da Engenharia e da vida acadêmica, contribuindo inestimavelmente para o meu crescimento profissional.

Aos meus amigos André Teves, Ricardo Amigo e Ruben Salas pelas discussões no âmbito acadêmico e pelos momentos de descontração que compartilhamos juntos ao longo do período do mestrado. 


\section{Resumo}

A técnica de sinterização por plasma, também conhecida como processo SPS (Spark Plasma Sintering), é um processo para consolidação e sinterização de pós, em que corrente elétrica alternada pulsada e pressão de compactação são aplicadas simultaneamente aos componentes ferramentais (molde, punções, etc.). O molde utilizado neste processo tradicionalmente é cilíndrico, composto por grafite e permite a fabricação de amostras com geometria circular. Esse processo também possibilita a sinterização de um grande número de materiais, em especial, Materiais com Gradação Funcional (MGF). Tendo em vista os aspectos de geometria e composição da amostra, um projeto de otimização de moldes pode ser desenvolvido visando a fabricação de amostras com geometrias e gradação complexas. Com isso, é possível adequar a geometria do molde ao formato e composição da amostra que se deseja sinterizar, visando uma sinterização uniforme. Portanto, o objetivo deste trabalho é o desenvolvimento de uma metodologia para projetos de moldes utilizados na sinterização por plasma. Esta metodologia consiste na implementação de um algoritmo de otimização, baseado no Método de Otimização Topológica (MOT), considerando três tipos de abordagem: a primeira abordagem, a qual visa a geometria da amostra, busca obter um molde prismático considerando amostras com geometria arbitrária, como por exemplo quadrada, triangular ou em cruz, com o objetivo de uniformizar o campo de temperaturas na amostra; na segunda abordagem, que considera moldes para a fabricação de amostras MGF, os moldes podem ser projetados de modo a produzirem um gradiente de temperatura, na direção axial, através da variação da espessura da parede do molde; a terceira abordagem considera um molde constituído por material compósito. Nesta última abordagem é proposto um novo conceito de molde, onde se busca trabalhar não apenas com a geometria, como também com a microestrutura do molde dada por um material anisotrópico. Para a implementação do algoritmo de otimização, um modelo computacional baseado no Método dos Elementos Finitos (MEF), é desenvolvido considerando o processo SPS como um problema de acoplamento eletrotérmico. Na implementação do MOT utiliza-se um modelo de material baseado no SIMP (Solid Isotropic Material with Penalization) e Programação Linear Sequencial (PLS) para resolver o problema de otimização do molde. Todo o algoritmo de otimização é implementado na linguagem própria do ambiente Matlab ${ }^{\circledR}$ e o pós-processamento, para verificação e validação dos resultados, é executado no "software" comercial Comsol ${ }^{\circledR}$. 


\section{Abstract}

The Spark Plasma Sintering (SPS) technique is a powder consolidating and sintering process, in which pulsed DC electric current and pressure loads are applied simultaneously in the tool system components (graphite die, punchers, etc.) in order to perform the sintering process. Generally, a cylindrical graphite die is used for circular samples manufacturing and through this process the sinterization of a large number of materials, including Functionally Graded Materials (FGM), is possible. Considering the geometry and sample material aspects, an optimization die design technique can be developed based on the manufacturing of samples with complex geometry and gradation. Thus, it is possible to adjust the die geometry to the sample geometry or gradation in order to achieve a uniform sinterization. Therefore, the aim of this work is the development of a methodology to be applied in the design of dies used in SPS sintering process. This methodology consists of implementing an optimization algorithm based on the Topology Optimization Method (TOM), considering three approaches: in the first one a prismatic die is designed to process a sample with arbitrary geometry, for example square, triangular and cross sample; in the second approach the change of the die wall thickness is considered to achieve a predefined temperature gradient in the gradation direction of MGF samples and in the third approach the same previous objective is considered, however the focus is the optimization of thermal conductive fibers. In the latest approach, a new die concept is proposed, where the objective is to optimize not only the die geometry but the microstructure considering a die composed by an anisotropic material. To implement the optimization algorithm a computational model based on the Finite Element Method (FEM) is developed considering the SPS process as an electrothermal coupled problem. In the TOM implementation a material model based on SIMP (Solid Isotropic Material with Penalization) is adopted and the Sequential Linear Programming is used to solve the optimization problem. The optimization algorithm is implemented using the Matlab ${ }^{\complement}$ environment and the pos-processing, for verification and validation of the obtained results is carried out by using $\mathrm{Comsol}^{\circledR}$. 


\section{Sumário}

\section{Lista de Figuras}

\section{Lista de Tabelas}

\section{Lista de Abreviaturas}

\section{Lista de Símbolos}

1 Introdução 1

1.1 Sinterização . . . . . . . . . . . . . . . . . . . . 2

1.2 Sinterização por plasma . . . . . . . . . . . . . . . . . 3

1.3 Método de Otimização Topológica . . . . . . . . . . . . . . . . . . . . 8

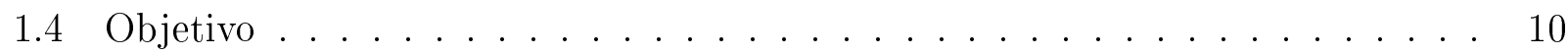

1.5 Motivação e Justificativa . . . . . . . . . . . . . . . . . . . . . . . . . . 11

2 Modelagem de Problemas Eletrotérmicos $\quad 14$

2.1 Introdução . . . . . . . . . . . . . . . . . . . . . . . . . . 14

2.2 Revisão Bibliográfica Sobre Simulações Computacionais da Sinterização SPS . 14

2.3 Modelagem Matemática . . . . . . . . . . . . . . . . . . 18

2.3.1 Problema elétrico . . . . . . . . . . . . . . . . . . . 19

2.3.2 Problema térmico . . . . . . . . . . . . . . . . 20

2.4 Formulação de elementos finitos para o problema eletrotérmico . . . . . . . . . 23

2.4.1 Problema Elétrico . . . . . . . . . . . . . . . . . . 25

2.4 .2 Problema Térmico . . . . . . . . . . . . . . . . 26 
3.1 Introdução . . . . . . . . . . . . . . . . . . . . . . . . . 30

3.2 Método de Otimização Topológica . . . . . . . . . . . . . . . . . . . . . 32

3.2.1 Conceitos teóricos da Otimização Topológica . . . . . . . . . . . . . . 32

3.2 .2 Aspectos práticos da Otimização Topológica . . . . . . . . . . . . 36

3.2 .3 Revisão bibliográfica do MOT . . . . . . . . . . . . . . . . 38

3.3 Formulação contínua do problema de otimização . . . . . . . . . . . . . . . 40

4 Implementação Numérica dos Problemas de Otimização 43

4.1 Formulação de geração interna de calor com dependência estrutural ..... 43

4.2 Análise das condições de contorno com dependência estrutural . . . . . . . . . 44

4.2.1 Modelo de convecção baseado numa função degrau . . . . . . . . . . 45

4.2 .2 Modelo de convecção baseado no SIMP . . . . . . . . . . . . . . 48

4.3 Otimização com Material anisotrópico . . . . . . . . . . . . . . . . . 49

4.4 Implementação do algoritmo de otimização . . . . . . . . . . . . . . . . . . 50

4.5 Formulação discreta do problema de otimização . . . . . . . . . . . . . . 5 51

4.6 Filtro de projeção . . . . . . . . . . . . . . . . . 55

4.7 Aproximação contínua de distribuição de material . . . . . . . . . . . . . . 56

4.8 Implementação da gradação de material em amostras MGF . . . . . . . . . . 57

4.9 Análise de sensibilidades . . . . . . . . . . . . . . . 58

4.9.1 Sensibilidade das condições de contorno com dependência estrutural . . 64

4.9 .2 Sensibilidade da matriz constitutiva . . . . . . . . . . . 65

5 Resultados e Discussão $\quad 66$

5.1 Introdução . . . . . . . . . . . . . . . . . 66

5.2 Moldes homogêneos para amostras com geometrias prismáticas arbitrárias . . . 66

5.2.1 Modelo numérico para a otimização . . . . . . . . . . . . . 66

5.3 Moldes axissimétricos homogêneos para amostras MGF . . . . . . . . . 80

5.3.1 Modelo numérico para a otimização . . . . . . . . . . . . . . . . 80 
5.3.2 Moldes para fabricação de amostra de Grafite . . . . . . . . . . . . 82

5.3.3 Moldes para fabricação de amostra de $\mathrm{Cu}-\mathrm{Ni}$. . . . . . . . . . . . . . . 90

5.3 .4 Discussão . . . . . . . . . . . . . . . . . . . . . . 96

5.4 Moldes axissimétricos compósitos para amostras MGF . . . . . . . . . . 97

5.4.1 Resultados sem a utilização da OMD . . . . . . . . . . . . . . . . 98

5.4 .2 Resultados utilizando a OMD . . . . . . . . . . . . . . 100

5.4 .3 Discussão . . . . . . . . . . . . . . . . . . 103

5.5 Pós-Processamento . . . . . . . . . . . . . . . . . . 103

6 Conclusões

6.1 Trabalhos Futuros . . . . . . . . . . . . . . . . . . 110

Referências 112

Apêndice A - Técnicas de solução do problema de otimização 118

A.1 Programação linear sequencial . . . . . . . . . . . . . . . . 118

Apêndice B - Validação do MEF e do Cálculo das Sensibilidades 121

B.1 Modelo para Molde Homogêneo Prismático . . . . . . . . . . . . . . . . . . . 122

B.2 Modelo para Moldes Axissimétricos . . . . . . . . . . . . . . . . . . 124

B.3 Propriedades dos materiais . . . . . . . . . . . . . . . . . 131

B.4 Validação do cálculo de sensibilidades . . . . . . . . . . . . . . . . . 132

Apêndice C - Método de Otimização Topológica aplicado a problemas térmicos 135

C.1 Problemas envolvendo fluxo de calor prescrito . . . . . . . . . . . 135

C.2 Problemas envolvendo geração interna de calor . . . . . . . . . . . . . . . 139

C.3 Problemas envolvendo convecção na fronteira estrutural . . . . . . . . . . . . . 141

Apêndice D - Implementação Q4/U para condução térmica 144 


\section{Lista de Figuras}

1.1 Comportamento das partículas durante a sinterização . . . . . . . . . . . . . 2

1.2 Representação esquemática do processo de sinterizaçao por plasma. . . . . . . 4

1.3 Conjunto ferramental e Máquina de SPS . . . . . . . . . . . . . . . 5

1.4 Geometrias tradicionais para molde, punção e amostra . . . . . . . . . . . . 5

1.5 Microestrutura de material MGF . . . . . . . . . . . . . . . . 6

1.6 Geometrias possíveis de serem obtidas através do MOT . . . . . . . . . . . 7

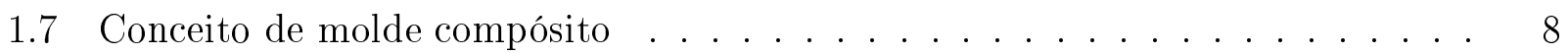

1.8 Conjunto de etapas para otimização estrutural através da OT. . . . . . . . . . 9

1.9 Exemplo de gradiente de temperatura . . . . . . . . . . . . . . . . . 10

1.10 Conceito de molde formado por material compósito . . . . . . . . . . . . . 11

2.1 Domínio bidimensional elétrico . . . . . . . . . . . . . . . . . . . . 19

2.2 Domínio bidimensional térmico . . . . . . . . . . . . . . . . . . 21

2.3 Elemento finito isoparamétrico . . . . . . . . . . . . . . . . . . 24

2.4 Sistema de coordenadas cilíndricas para formulação do problema eletrotérmico 26

3.1 Exemplo de otimização paramétrica . . . . . . . . . . . . . . . . . . . 30

3.2 Exemplo de otimização de forma . . . . . . . . . . . . . . . . . . 31

3.3 Exemplo de otimização topológica . . . . . . . . . . . . . . . . . . . . . . 31

3.4 Domínio de projeto do MOT . . . . . . . . . . . . . . . 33

3.5 Função de relaxação da distribuição de material . . . . . . . . . . . . . . . 35

3.6 Influência da penalização na solução ótima de um problema de condutividade

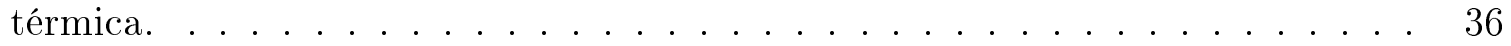

3.7 Influência do penalizador na solução ótima . . . . . . . . . . . . . . . 37

3.8 Exemplo do MOT em problema de condutividade térmica . . . . . . . . . . . 39 
4.1 Gráfico da função $H(\rho) \ldots \ldots \ldots$. . . . . . . . . . . . . . . 46

4.2 Fronteira estrutural identificada pela função $H(\rho) \ldots \ldots$. . . . . . . . . . 47

4.3 Modelo de convecção inspirado no SIMP . . . . . . . . . . . . . . . . . . . 48

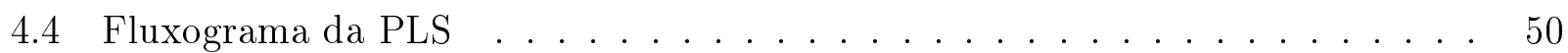

4.5 Exemplo para análise da difusividade . . . . . . . . . . . . . . . . . . 52

4.6 Discretização da amostra . . . . . . . . . . . . . . . . . . . . . . 53

4.7 Gradiente de temperatura proposto . . . . . . . . . . . . . . . 54

4.8 Técnica de Projeção . . . . . . . . . . . . . . . . . . . 55

4.9 Formulação ACDM . . . . . . . . . . . . . . . . . . . . . 56

4.10 Ilustração de uma amostra com gradação funcional. . . . . . . . . . . . . . . . 57

4.11 Gradação da propriedade característica $E \ldots \ldots \ldots$. . . . . . . . . 58

4.12 Ilustração da discretização de uma amostra com gradação funcional. . . . . . . 58

5.1 Modelo numérico para otimização de acordo com a geometria da amostra . . . 66

5.2 Geração de calor ao longo da direção radial para amostras de grafite e alumina 67

5.3 Corte e planta do molde axissimétrico original . . . . . . . . . . . . . . 68

5.4 Campo de temperaturas e fluxo de calor obtidos através do modelo computacional desenvolvido no COMSOL, considerando radiação não-linear, para estimativa das condições de contorno a serem utilizadas no problema de otimização dos moldes homogêneos prismáticos. . . . . . . . . . . . . . . . 68

5.5 Influência da discretização da malha e restrição de volume na topologia final do molde, considerando projeção desativada e $V_{\max }=60 \%$. . . . . . . . . 70

5.6 Influência da discretização da malha e restrição de volume na topologia final do molde, considerando projeção desativada e $V_{\max }=70 \%$. . . . . . . . 70

5.7 Resultados para molde prismático com restrição de volume de $V_{\max }=100 \%$, malha 50x50 e considerando projeção desativada. . . . . . . . . . . . . 70

5.8 Resultados para molde prismático com amostra quadrada - $V_{\max }=60 \%$ - Malha $50 \times 50$.

5.9 Influência da discretização da malha e restrição de volume na topologia final do molde, considerando projeção desativada e $V_{\max }=60 \%$. . . . . . . . . 
5.10 Influência da discretização da malha e restrição de volume na topologia final do molde, considerando projeção desativada e $V_{\max }=70 \%$. . . . . . . . 72

5.11 Resultados para molde prismático com amostra quadrada - $V_{\max }=50 \%$ - Malha $50 \times 50$

5.12 Influência da discretização quando da redução de $\dot{q}_{m}$ para molde prismático com amostra quadrada $-V_{\max }=60 \%, \dot{q}_{m}=1,0 \times 10^{3} \mathrm{~W} / \mathrm{m}^{3} \ldots \ldots . \ldots 73$

5.13 Perfil de temperatura apenas na região da amostra para topologia da Figura

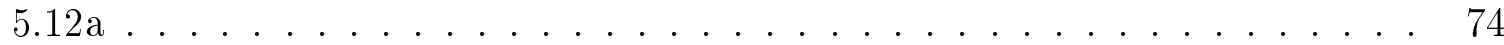

5.14 Resultados para uma amostra quadrada inserida num molde cilíndrico . . . . . 74

5.15 Resultado para amostra quadrada e não-condutora . . . . . . . . . . . . . 75

5.16 Distribuição de temperatura - Molde para amostra triangular - malha 80x80 . 76

5.17 Distribuição de temperatura - Molde para amostra triangular - malha 100x100 76

5.18 Curva de convergência e histórico do volume da estrutura - Molde para amostras triangulares ............................. 76

5.19 Resultados para amostra em cruz - Malha 80x80, $V_{\max }=50 \%$ e sem projeção .77

5.20 Resultados para amostra em cruz - Malha $80 \times 80, V_{\max }=55 \%$ e sem projeção .78

5.21 Resultados para amostra em cruz - Malha 80x80, $V_{\max }=60 \%$ e sem projeção .78

5.22 Problema eletrotérmico considerado para avaliar o processo SPS . . . . . . . . 80

5.23 Indicação da região dos moldes axissimétricos onde os gradientes de temperatura são avaliados. . . . . . . . . . . . . . . . . . . . . . . 83

5.24 Gradiente Inicial para $\rho_{0}=1 \ldots \ldots$. . . . . . . . . . . . . . . . . 83

5.25 Solução ótima para molde axissimétrico homogêneo. Malha 20x20, $w=1,0$ e sem projeção. Amostra de grafite . . . . . . . . . . . . . . . . . . . . . 84

5.26 Solução ótima para molde axissimétrico homogêneo. Malha 20x20, $w=0,8$ e sem projeção. Amostra de grafite . . . . . . . . . . . . . . . . . . 85

5.27 Solução ótima para molde axissimétrico homogêneo. Malha 20x20, $w=0,6$ e sem projeção. Amostra de grafite . . . . . . . . . . . . . . . . . . 85

5.28 Solução ótima para molde axissimétrico homogêneo. Malha 20x20, $w=0,3$ e sem projeção. Amostra de grafite . . . . . . . . . . . . . . . 
5.29 Solução ótima para molde axissimétrico homogêneo. Malha 20x20, $w=0$ e sem projeção. Amostra de grafite . . . . . . . . . . . . . . . . 86

5.30 Curvas de convergência e histórico de volume na otimização de moldes para amostra de grafite . . . . . . . . . . . . . . . . 86

5.31 Solução ótima para molde axissimétrico homogêneo. Malha 20x20, $w=0,3$ e com projeção $\left(r_{\min }=2 L_{e}\right)$ - Amostra de grafite . . . . . . . . . . . 87

5.32 Solução ótima para molde axissimétrico homogêneo. Malha 20x20, $w=0$ e com projeção $\left(r_{\text {min }}=2 L_{e}\right)$ - Amostra de grafite. . . . . . . . . . . . . 87

5.33 Solução ótima para molde axissimétrico homogêneo. Malha 20x20, $w=0,3$ com projeção parcial $\left(r_{\text {min }}=2 L_{e}\right)$ - Amostra de grafite. . . . . . . . . 87

5.34 Solução ótima para molde axissimétrico homogêneo. Malha 20x20, $w=0$ com projeção parcial $\left(r_{\min }=2 L_{e}\right)$ - Amostra de grafite.

5.35 Solução ótima para molde axissimétrico homogêneo. Malha 20x20, $w=0.3$ com projeção parcial $\left(r_{\min }=L_{e}\right)$ - Amostra de grafite.

5.36 Solução ótima para molde axissimétrico homogêneo. Malha 20x20, $w=0$ com projeção parcial $\left(r_{\min }=L_{e}\right)$ - Amostra de grafite.

5.37 Curvas de convergência e histórico de volume na otimização com projeção parcial de moldes para amostra de grafite

5.38 Solução ótima para molde axissimétrico homogêneo após 120 iterações. Malha $20 \times 20, w=0,3$ com projeção parcial $\left(r_{\min }=L_{e}\right)$ - Amostra de grafite. . . . 90

5.39 Gradação linear e exponencial das propriedades por camada no MGF Cu-Ni. . 91

5.40 Solução ótima para molde axissimétrico homogêneo. Malha 20x20, $w=0,8$ e sem projeção. Amostra Cu-Ni . . . . . . . . . . . . . . . . . . . . . . . 91

5.41 Solução ótima para molde axissimétrico homogêneo. Malha 20x20, $w=0,6$ e

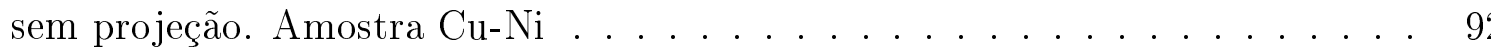

5.42 Solução ótima para molde axissimétrico homogêneo. Malha 20x20, $w=0,3$ e sem projeção. Amostra Cu-Ni . . . . . . . . . . . . . . . . . . . 92

5.43 Solução ótima para molde axissimétrico homogêneo. Malha 20x20, $w=0$ e sem projeção. Amostra $\mathrm{Cu}-\mathrm{Ni} \ldots \ldots \ldots \ldots \ldots$

5.44 Curvas de convergência e histórico de volume na otimização de moldes para amostra $\mathrm{Cu}-\mathrm{Ni}$ 
5.45 Solução ótima para molde axissimétrico homogêneo. Malha 20x20, $w=0,3$, com projeção parcial $\left(r_{\text {min }}=L_{e}\right)$ - Amostra Cu-Ni com gradação linear. . . . . 94

5.46 Solução ótima para molde axissimétrico homogêneo. Malha 20x20, $w=0$, com projeção parcial $\left(r_{\min }=L_{e}\right)$ - Amostra $\mathrm{Cu}-\mathrm{Ni}$ com gradação linear. . . . . . . . 94

5.47 Solução ótima para molde axissimétrico homogêneo. Malha 20x20, $w=0,3$, com projeção parcial $\left(r_{\min }=L_{e}\right)$ - Amostra $\mathrm{Cu}-\mathrm{Ni}$ com gradação exponencial.

5.48 Solução ótima para molde axissimétrico homogêneo. Malha 20x20, $w=0$, com projeção parcial $\left(r_{\min }=L_{e}\right)$ - Amostra $\mathrm{Cu}-\mathrm{Ni}$ com gradação exponencial. . . .

5.49 Solução ótima para molde axissimétrico homogêneo. Malha 20x20, $V_{\max }=30 \%$, $w=0,3$, com projeção parcial $\left(r_{\min }=L_{e}\right)$ - Amostra $\mathrm{Cu}-\mathrm{Ni}$ com gradação linear. 95

5.50 Solução ótima para molde axissimétrico homogêneo sem espessura mínima. Malha $20 \times 20, V_{\max }=30 \%, w=0$, com projeção parcial $\left(r_{\min }=L_{e}\right)$ - Amostra $\mathrm{Cu}-\mathrm{Ni}$ com gradação linear. . . . . . . . . . . . . . . . . . . . . 96

5.51 Curvas de convergência e histórico de volume na otimização de moldes para amostra de grafite(referente ao resultado da Figura 5.47) . . . . . . . . . . . . 96

5.52 Solução ótima para molde axissimétrico compósito. Malha 15x15, $w=0,8 \mathrm{e}$ sem filtro de projeção. Amostra Grafite . . . . . . . . . . . . . . . . . . 98

5.53 Solução ótima para molde axissimétrico compósito. Malha $15 \mathrm{x} 15, w=0,5 \mathrm{e}$ sem projeção . Amostra Grafite . . . . . . . . . . . . . . . .

5.54 Solução ótima para molde axissimétrico compósito. Malha $15 \mathrm{x} 15, w=0,3 \mathrm{e}$ sem projeção. Amostra Grafite . . . . . . . . . . . . . . . .

5.55 Solução ótima para molde axissimétrico compósito. Malha 15x15, w =0,3 e com projeção parcial $\left(r_{\min }=2 L_{e}\right)$. Amostra Grafite . . . . . . . . . . . 100

5.56 Curvas de convergência e histórico de volume na otimização de moldes axissimetricos compósitos para amostra de grafite(sem OMD) . . . . . . . . . . 100

5.57 Resultados para molde axissimétrico compósito. Malha 15x15, $w=0,3$, sem filtro de projeção e através da OMD com amostra de grafite . . . . . . . . . . 101

5.58 Resultados para molde axissimétrico compósito. Malha 15x15, $w=0,8$, sem filtro de projeção e através da OMD com amostra de grafite . . . . . . . . . . 101

5.59 Resultados para molde axissimétrico compósito. Malha 15x15, $w=0,8$, com filtro de projeção e através da OMD para amostra $\mathrm{Cu}-\mathrm{Ni}$ com gradação linear 
5.60 Resultados para molde axissimétrico compósito. Malha 15x15, $w=0,3$, com filtro de projeção e através da OMD para amostra $\mathrm{Cu}-\mathrm{Ni}$ com gradação linear 102

5.61 Curvas de convergência e histórico de volume na otimização de moldes axissimetricos compósitos para amostra $\mathrm{Cu}-\mathrm{Ni}($ sem OMD) com gradação linear . . . 103

5.62 Pós-processamento para molde axissimétrico homogêneo. Malha 20x20, $w=$ 0,3 com projeção parcial $\left(r_{\min }=L_{e}\right)$ - Amostra de grafite. . . . . . . . 105

5.63 Pós-processamento para molde axissimétrico homogêneo. Malha 20x20, $w=0$ com projeção parcial $\left(r_{\min }=L_{e}\right)$ - Amostra de grafite. . . . . . . . . . . 106

5.64 Pós-processamento para molde axissimétrico homogêneo. Malha 20x20, $w=$ 0,3, com projeção parcial $\left(r_{\min }=L_{e}\right)$ - Amostra Cu-Ni com gradação linear. . 107

5.65 Pós-processamento para molde axissimétrico homogêneo. Malha 20x20, $w=$ 0,3, com projeção parcial $\left(r_{\text {min }}=L_{e}\right)$ - Amostra Cu-Ni com gradação exponencial.108

A.1 Limites móveis . . . . . . . . . . . . . . . . . . . . . 120

B.1 Fluxograma - Validação Problema Elétrico . . . . . . . . . . . . . . . . . . 121

B.2 Fluxograma - Validação Problema Térmico . . . . . . . . . . . . . . . . . 122

B.3 Definição do problema térmico para moldes prismáticos. . . . . . . . . . . . 123

B.4 Campo de temperaturas e fluxo de calor obtidos através do modelo computacional desenvolvido no COMSOL, considerando radiação não-linear, para estimativa das condições de contorno a serem utilizadas no problema de otimização dos moldes homogêneos prismáticos. . . . . . . . . . . . . . . . . . . 12

B.5 Campo de temperaturas e fluxo de calor obtidos através dos modelos computacionais que consideram a radiação linearizada . . . . . . . . . . . . . . . 12

B.6 Comparação da distribuição de temperatura entre os três modelos para moldes prismáticos

B.7 Conjunto ferramental utilizando no modelo computacional auxiliar. . . . . . . 125

B.8 Dimensões do conjunto ferramental e condições de contorno no modelo auxiliar considerando radiação não-linear.

B.9 Resultados do modelo auxiliar axissimétrico, com radiação não-linear implementado no COMSOL, para estimativa das condições de contorno a serem adotadas no modelo axissimétrico utilizado no problema de otimização . . . 127

B.10 Modelo físico adotado e inserido no MOT . . . . . . . . . . . . . . . . . 127 
B.11 Dimensões dos componentes ferramentais no modelo axissimétrico e condições de contorno no problema eletrotérmico utilizado no processo de otimização 128

B.12 Resultados do modelo axissimétrico simulado no Comsol considerando radiação não-linear . . . . . . . . . . . . . . . . . . . . . . . . . 128

B.15 Distribuição radial de temperatura para os três modelos axissimétrico - Amostra grafite.

B.18 Distribuição radial de temperatura para os três modelos axissimétrico - amostra alumina.

B.19 Propriedades elétrica e térmica, em função da temperatura, dos materiais utilizados nos modelos computacionais .

B.20 Validação da sensibilidade - molde prismático - formulação Q4/U.

B.21 Validação da sensibilidade - molde axissimétrico homogêneo - formulação Q4/U.133

B.22 Validação da sensibilidade - molde axissimétrico Compósito (com OMD) - formulação Q4/U.

B.23 Validação da sensibilidade - molde axissimétrico Compósito (sem OMD) - formulação Q4/U.

C.1 Caso 1 para fluxo de calor prescrito . . . . . . . . . . . . . . 136

C.2 Caso 2 para fluxo de calor prescrito . . . . . . . . . . . . 137

C.3 Caso 3 para fluxo de calor prescrito . . . . . . . . . . . . . . . 138

C.4 Caso 4 para fluxo de calor prescrito . . . . . . . . . . . . . . . 138

C.5 Caso 1 de geração de calor . . . . . . . . . . . . . . . . . . . . . . . . 139

C.6 Caso 2 de geração de calor . . . . . . . . . . . . . . . . . . . . . . . . . . 140

C.7 Caso 3 de geração de calor . . . . . . . . . . . . . . . . . . . . . . . . . . . . 140

C.8 Caso 4 de geração de calor . . . . . . . . . . . . . . . . . . . . . . 141

C.9 Definição do problema para análise da convecção . . . . . . . . . . . . . . . . . 142

C.10 Caso 1 análise da convecção . . . . . . . . . . . . . . . . . . . . . 142

C.11 Caso 2 análise da convecção . . . . . . . . . . . . . . . . . . . . . . . 142

C.12 Caso 3 análise da convecção . . . . . . . . . . . . . . . . . . . . . . 143

C.13 Análise da convecção com filtro de projeção . . . . . . . . . . . . . . . . 143 
C.14 Análise da convecção com discretização refinada . . . . . . . . . . . . . . . . 143

D.2 Distribuição de temperatura obtida através análise em elementos finitos com código implementado no MATLAB e COMSOL. . . . . . . . . . . . . . . . . 145 


\section{Lista de Tabelas}

5.1 Parâmetros do problema térmico adotados da otimização de moldes homogêneos prismáticos. . . . . . . . . . . . . . . . 69

5.2 Parâmetros adotados da otimização de moldes prismáticos. . . . . . . . . . . 69

5.3 Parâmetros adotados da otimização de moldes para amostras triangulares. . 75

5.4 Parâmetros adotados da otimização de moldes para amostras em cruz. . . . . . 77

5.5 Parâmetros físicos utilizados nos problemas elétrico e térmicos. . . . . . . . . 81

5.6 Parâmetros de otimização adotados e constantes ao longo do processo de otimização dos moldes axissimétricos homogêneos. . . . . . . . . . . . . . . . . . 81

5.7 Parâmetros variáveis de otimização adotados para avaliação da sua influência na solução ótima obtida para moldes axissimétricos homogêneos. . . . . . . . . . 82

5.8 Propriedades físicas utilizadas na amostra MGF Cu-Ni. . . . . . . . . . . . 90

B.1 Valores utilizados nos modelos computacionais para validação do MEF. . . . . 123

B.2 Parâmetros adotados para validação do MEF . . . . . . . . . . . . . . . . 130

B.3 Propriedades dos materiais adotadas e utilizadas nos modelos computacionais . 132

D.1 Comparação dos resultados considerando PLS, CO e restrição de volume de $30 \% .145$

D.2 Comparação dos resultados considerando PLS, CO e restrição de volume de $60 \% .146$ 


\section{Lista de Abreviaturas}

ACDM Aproximação Contínua de Distribuição de Material

CO Critério de Optimalidade

DFE Domínio Fixo Estendido

EF Elementos Finitos

FAST Field Activated Sintering Technique

MEF Método dos Elementos Finitos

MGF Material com Gradação Funcional

MOT Método de Otimização Topológica

MRP Método dos Resíduos Ponderados

OMD Otimização de Material Discreta

OT Otimização Topológica

PECS Pulse Electric Current Sintering

PL Programação Linear

PLS Programação Linear Sequencial

PQS Programação Quadrática Sequencial

SIMP Solid Isotropic Material with Penalization

SPS Spark Plasma Sintering 


\section{Lista de Símbolos}

Os seguintes símbolos são utilizados:

\begin{tabular}{|c|c|}
\hline Símbolo & Descrição \\
\hline$a \cdot b$ & Produto escalar entre os vetores $a$ e $b$ \\
\hline$\nabla \cdot f$ & Gradiente da função $f$ \\
\hline B & Gradiente das funções interpoladoras $\mathbf{N}$ \\
\hline $\mathrm{C}(\mathrm{x})$ & Matriz constitutiva \\
\hline $\mathrm{C}_{\mathrm{E}}$ & Matriz constitutiva associada à condutividade elétrica efetiva \\
\hline $\mathbf{C}_{\mathbf{T}}$ & Matriz constitutiva associada à condutividade térmica efetiva \\
\hline $\mathbf{C}_{0}$ & Matriz constitutiva do material base \\
\hline $\mathbf{C}_{0_{\mathrm{E}}}$ & Matriz constitutiva associada à condutividade elétrica base \\
\hline $\mathbf{C}_{0_{\mathrm{T}}}$ & Matriz constitutiva associada à condutividade térmica base \\
\hline $\mathbf{C}_{\theta}$ & Matriz constitutiva numa dada orientação $\theta$ \\
\hline $\mathbf{E}$ & Campo Elétrico \\
\hline $\mathbf{F}_{\mathrm{E}}$ & Vetor global de carregamento elétrico \\
\hline $\mathbf{F}_{\mathrm{E}}^{e}$ & Vetor de carregamento elétrico num elemento $e$; \\
\hline $\mathbf{F}_{\mathrm{T}}$ & Vetor global de carregamento térmico \\
\hline $\mathbf{F}_{h}$ & Vetor global de carregamento térmico associada à convecção \\
\hline $\mathbf{F}_{q}$ & Vetor global de carregamento térmico associada à fluxo de calor \\
\hline $\mathbf{F}_{\dot{q}}$ & Vetor global de carregamento térmico associada à geração de calor \\
\hline $\mathbf{F}_{h}^{e}$ & Vetor de carregamento térmico - convecção num elemento $e$ \\
\hline $\mathbf{F}_{q}^{e}$ & Vetor de carregamento térmico - fluxo de calor num elemento $e$ \\
\hline $\mathbf{F}_{\dot{q}}^{e}$ & Vetor de carregamento térmico - geração de calor num elemento $e$ \\
\hline $\mathbf{J}$ & Vetor densidade de corrente elétrica \\
\hline $\mathbf{K}_{\mathrm{E}}$ & Matriz global de condutividade elétrica \\
\hline $\mathbf{K}_{\mathrm{T}}$ & Matriz global associada à condutividade térmica \\
\hline $\mathbf{K}_{k}$ & Matriz global associada à condução de calor \\
\hline $\mathbf{K}_{h}$ & Matriz global associada à convecção \\
\hline $\mathbf{k}_{\mathrm{E}}^{e}$ & Matriz de condutividade elétrica num elemento $e$ \\
\hline $\mathrm{k}_{\mathrm{k}}^{e}$ & Matriz associada a condutividade térmica num elemento $e$; \\
\hline
\end{tabular}




\begin{tabular}{|c|c|}
\hline Símbolo & Descrição \\
\hline $\mathbf{k}_{\mathrm{h}}^{e}$ & Matriz associada a convecção num elemento $e$; \\
\hline $\mathbf{n}$ & Vetor unitário e normal a uma superfície \\
\hline $\mathbf{N}$ & Funções interpoladoras dos graus de liberdade \\
\hline q & Vetor de fluxo de calor \\
\hline $\mathbf{R}$ & Matriz de rotação \\
\hline $\mathbf{x}$ & Coordenadas espaciais de um dado domínio \\
\hline$E(h)$ & Função de gradação das propriedades $E_{1}$ e $E_{2}$ \\
\hline$g$ & Função derivável \\
\hline$h$ & Coeficiente de transferência de calor por convecção \\
\hline$h_{a p}$ & Coeficiente de convecção aparente \\
\hline$H_{e}$ & Espaço de Sobolev de primeira ordem para potenciais elétricos \\
\hline$H_{t}$ & Espaço de Sobolev de primeira ordem para temperaturas \\
\hline$H(\rho)$ & Função de identificação de fronteiras estruturais no DFE \\
\hline$I$ & Fluxo de corrente elétrica \\
\hline$p$ & Fator de penalização das pseudo-densidades \\
\hline$q_{r_{\text {linear }}}$ & Radiação linearizada \\
\hline$q_{a p}$ & fluxo de calor prescrito aparente \\
\hline$r$ & Coordenada radial \\
\hline$T$ & Campo de temperatura \\
\hline$\widehat{T}$ & Temperatura prescrita \\
\hline$T_{0}$ & Temperatura de linearização \\
\hline$T_{s}$ & Temperatura de superfície \\
\hline$\tilde{T}$ & Campo de temperaturas virtuais \\
\hline$\dot{q}$ & Geração de calor \\
\hline$w$ & Fator de ponderação na função multi-objetivo \\
\hline$w_{i}$ & Fator de ponderação na OMD \\
\hline$x_{n}$ & Variável de projeto genérica \\
\hline$(x, y)$ & Sistema de coordenadas globais \\
\hline$z$ & Coordenada axial \\
\hline$\alpha$ & Gradiente de temperatura por camada \\
\hline$\beta_{c a l}$ & Gradiente de temperatura calculado numericamente \\
\hline$\beta_{o b j}$ & Gradiente de temperatura desejado \\
\hline$\delta$ & Constante de Stefan-Boltzmann \\
\hline$\epsilon$ & Fator de emissividade ou emitância \\
\hline$\Omega$ & Domínio bidimensional \\
\hline
\end{tabular}




\begin{tabular}{ll}
\hline Símbolo & Descrição \\
\hline$\Omega_{d}$ & Região do domínio onde há presença de material \\
$\Omega \backslash \Omega_{d}$ & Região do domínio onde não há presença de material \\
$\phi$ & Campo de potencial elétrico \\
$\phi_{e}$ & Vetor de potenciais elétricos num elemento $e$ \\
$\tilde{\phi}$ & Campo de potencial elétrico virtual \\
$\widehat{\phi}$ & Potencial elétrico prescrito \\
$\sigma$ & Condutividade elétrica \\
$\kappa$ & Condutividade térmica \\
$\gamma$ & Variável de projeto de pseudo-densidade do elemento adjacente \\
$\Gamma_{e}$ & Contorno do elemento $e$ \\
$\Gamma_{i}$ & Região do domínio onde há fluxo de corrente elétrica \\
$\Gamma_{u}$ & Região do domínio onde há potencial elétrico ou temperatura prescrita \\
$\Gamma_{q_{1}}$ & Região do domínio onde há fluxo de calor \\
$\Gamma_{q_{2}}$ & Região do domínio onde há convecção térmica \\
$\theta$ & Orientação das propriedades físicas \\
$\Theta_{e}$ & Espaço dos potenciais elétricos admissíveis \\
$\Theta_{t}$ & Espaço das temperaturas admissíveis \\
$\lambda^{\mathrm{T}}$ & Vetor adjunto \\
$\Lambda$ & Operador lógico para montagem de vetor e/ou matriz global \\
$\rho(\mathbf{x})$ & Função contínua de distribuição de material \\
$\rho$ & Variável de projeto de pseudo-densidade \\
$v$ & Variável de projeto de pseudo-orientação \\
\hline$\xi, \eta)$ & Sistema de coordenadas locais \\
\hline & \\
\hline &
\end{tabular}




\section{Introdução}

A metalurgia do pó é um dos processos metalúrgicos para fabricação de peças metálicas, ligas, cerâmicas ou materiais compósitos. Este processo pode ser definido como sendo um processo pelo qual uma massa de partículas secas, com diâmetro máximo inferior a $150 \mu \mathrm{m}$, é convertida em um componente estrutural com forma pré-definida e com propriedades que lhe permitem ser utilizados, na maioria dos casos, sem a necessidade de tratamento posterior (THÜMMLER; OBERACKER, 1993).

As operações básicas do processo tradicional da metalurgia são: produção do pó, compactação e a sinterização. A produção de pós metálicos ou cerâmicos pode ocorrer através de processamento mecânico ou químico, como por exemplo moagem, reações químicas ou de decomposição. O processo de compactação pode ser realizado por vários tipos de operações, tais como: prensagem em matrizes rígidas, prensagem isostática, compactação por laminação e extrusão de pós (CHIAVERINI, 2001). Através da compactação do pó, pode-se alcançar os seguintes objetivos:

- conformar o pó na forma projetada;

- definir as dimensões finais da peça;

- obter a densidade adequada do compactado;

- alcançar resistência mecânica necessária;

- proporcionar o contato necessário entre as partículas do pó, para assim garantir maior eficiência na operação de sinterização.

Após a etapa de compactação, realiza-se a operação final do processo: a sinterização. Como esta etapa está diretamente relacionada ao tema deste trabalho, na seção seguinte é apresentado um breve histórico sobre a sinterização e suas principais características. 


\subsection{Sinterização}

A sinterização como parte de um processo artesanal para fabricação de artefatos de metais, cerâmica e/ou porcelana, tem sua origem em antigas civilizações. Os egípcios utilizaram a sinterização para a fabricação de peças metálicas e cerâmicas há 3000 AC. Na América do Sul, os Incas utilizaram este processo para produção de joias que combinavam ouro e platina. Países como China, Grécia e outros europeus também contribuíram para o desenvolvimento da arte de sinterizar. Durante o período entre as décadas de 1920 e 1950, a sinterização como Ciência do Estado Sólido passou a ser analisada com enfoque analítico, deixando de lado métodos empíricos de análise.

Em geral, o processo de sinterização, do ponto de vista da microestrutura, pode ser dividido em três estágios conforme ilustrado na Figura 1.1 e descritos abaixo (CHIAVERINI, 2001):

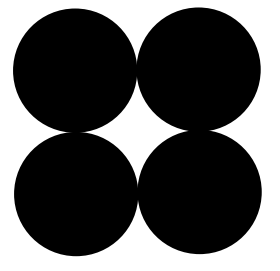

Partículas do material em pó

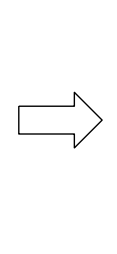

Formação de Poros

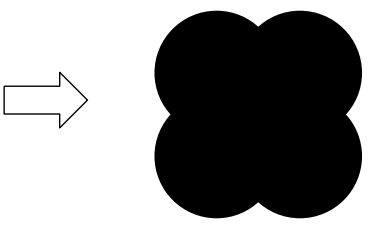

Consolidação

Figura 1.1: Comportamento das partículas de um material em pó durante o processo de sinterização.

- Inicial: Transformação dos contatos entre as partículas nos chamados "pescoços" e início do crescimento dos contornos de grão;

- Intermediário: Formação de uma rede de poros e crescimento de grão, resultando numa nova microestrutura;

- Final: Fase em que a densidade do compactado alcança valores entre 90 e $95 \%$ da densidade teórica.

Um dos meios para se intensificar as três etapas citadas acima é através do aquecimento do material em pó a medida em que o processo de compactação ocorre. Tradicionalmente, o aquecimento do material em pó, também denominado substrato ou amostra, é obtido utilizando bobinas, aquecidas por corrente elétrica, colocadas ao redor do molde onde o pó é 
inserido. Outro método para promover o aquecimento do substrato é o uso do que, na literatura, é chamado como "ativação" do processo de sinterização. Esta ativação consiste em se fazer circular corrente elétrica alternada e pulsada diretamente no substrato e componentes ferramentais durante a compactação. Devido a esta característica, na literatura é possivel encontrar denominações diferentes para este tipo de processo de sinterização (ZAVALIANGOS et al., 2004; MUNIR; ANSELMI-TAMBURINI; OHYANAGI, 2006), sendo elas:

- Sinterização de campo ativado (FAST - Field Activated Sintering Technique);

- Sinterização com corrente elétrica pulsada (PECS - Pulse Electric Current Sintering);

- Consolidação com pulso elétrico assistido (EPAC - Electric Pulse Assisted Consolidation);

- Sinterização por plasma assistido (PAS - Plasma Assisted Sintering);

- Sinterização por plasma (SPS - Spark Plasma Sintering).

\subsection{Sinterização por plasma}

A sinterização por plasma é uma técnica de fabricação que se diferencia dos métodos convencionais, tais como prensagem a quente e prensagem isostática (que utilizam bobinas de indução para aquecer o material em pó), devido a utilização de corrente elétrica para iniciar o processo de sinterização. Esta técnica apresenta diversas vantagens, incluindo a facilidade de operação, alta velocidade de sinterização, alta reprodutibilidade e menor consumo de energia, quando comparada a outros processos de sinterização. Através deste processo é possível a fabricação de materiais cerâmicos, intermetálicos, compósitos e nanocompósitos (TROMBINI et al., 2007).

No processo de SPS, o pó do material a ser consolidado é inserido num molde de grafite equipado com dois punções: um superior e outro inferior. No interior de uma câmara à vácuo, o pó é então submetido a uma carga de compressão uniaxial, a qual é transmitida pelos punções. Simultaneamente a esta compressão, uma diferença de potencial elétrico é aplicada adequadamente entre os eletrodos superior e inferior, que estão conectados aos respectivos punções. A Figura 1.2 ilustra, de maneira simplificada, a sinterização para se obter uma peça consolidada, indicando a carga de compressão que é aplicada, bem como o fluxo de corrente elétrica.

Deste modo, o sistema ferramental formado pelos punções e molde, assim como o compactado (no caso deste ser eletricamente condutivo) são afetados pela passagem de uma corrente 


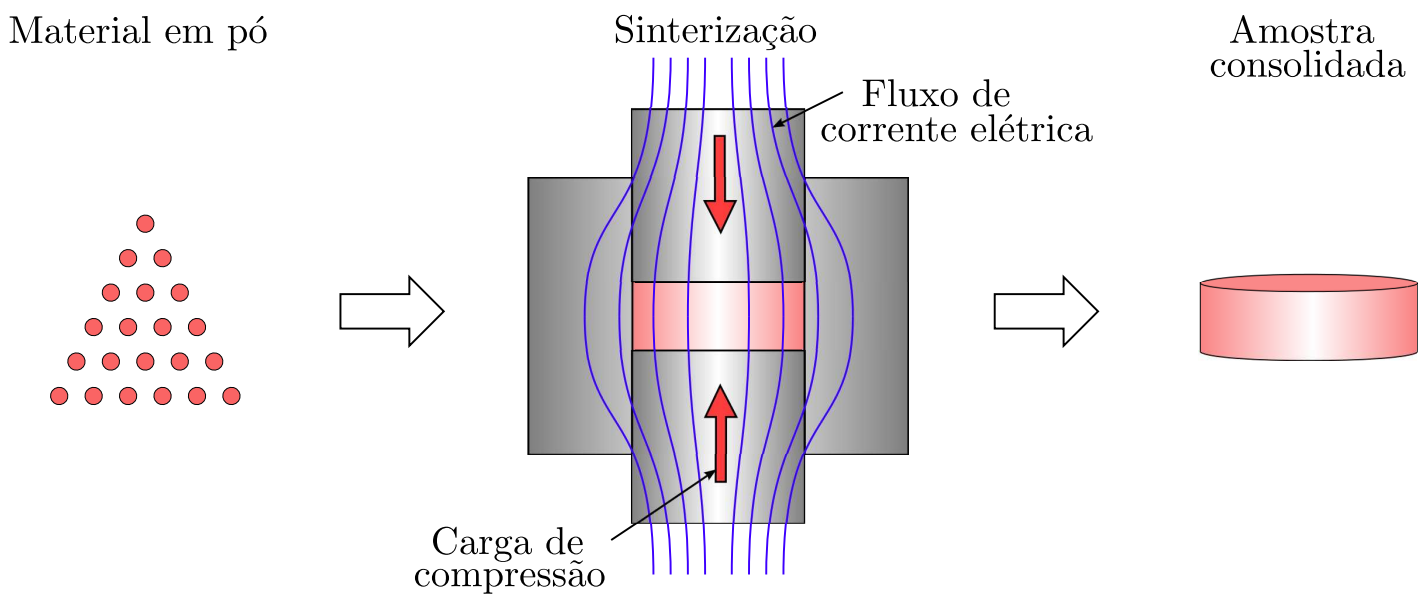

Figura 1.2: Representação esquemática do processo de sinterizaçao por plasma.

elétrica alternada e pulsada. Na Figura 1.3a é mostrado um arranjo do sistema ferramental no interior da câmara à vácuo da máquina de sinterização SPS indicada na Figura 1.3b.

Durante o processo de SPS, a passagem de corrente elétrica através dos componentes do sistema ferramental provoca uma alta taxa de geração de calor. Para amostras eletricamente condutivas, esta geração de calor ocorre diretamente na região do pó, ao passo que para amostras não condutivas a geração de calor se concentra no molde e punções que transferem calor ao material em pó. Assim, dependendo do tipo de material do compactado, a taxa de aquecimento pode afetar algumas das suas propriedades, tais como tamanho de grão e densidade final, como é o caso da alumina que apresenta redução do tamanho de grão com o aumento da taxa de aquecimento (MUNIR; ANSELMI-TAMBURINI; OHYANAGI, 2006). Além da taxa de aquecimento, outros fatores exercem influência sobre propriedades do compactado, como a taxa de compressão e o uso de corrente alternada pulsada (CHEN; ANSELMI-TAMBURINI; GARAY J. R. GROZA, 2005).

Os fenômenos pelos quais as vantagens nas propriedades do compactado são alcançadas, ainda não estão totalmente compreendidos, principalmente quanto à existência de plasma durante o processo de sinterização (CHEN; ANSELMI-TAMBURINI; GARAY J. R. GROZA, 2005). Para melhor compreender o processo SPS, diversos trabalhos têm investigado os efeitos dos campos elétrico, térmico e de tensões mecânicas na intensificação do processo de consolidação e nas propriedades finais dos materiais processados (CHEN; ANSELMI-TAMBURINI; GARAY J. R. GROZA, 2005), (ANSELMI-TAMBURINI et al., 2005), (ANSELMI-TAMBURINI; GARAY; MUNIR, 2005). A maioria dos estudos sobre o processo SPS tem se concentrado na comparação entre resultados experimentais e outros obtidos através de simulações computacionais, a partir das quais avalia-se a distribuição de corrente elétrica, temperatura e tensões mecânicas ao longo do conjunto punção-molde-compactado. Uma revisão bibliográfica sobre o processo SPS é apresentada na seção 2 . 


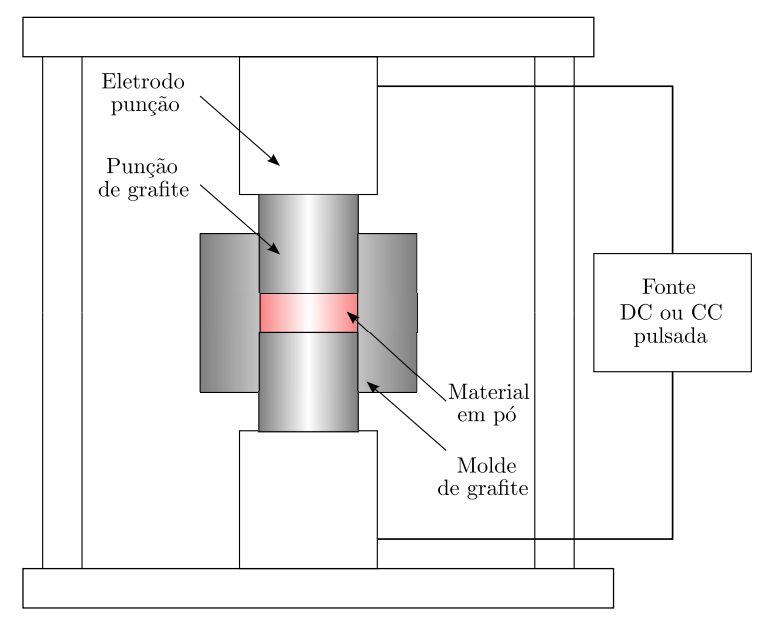

(a)

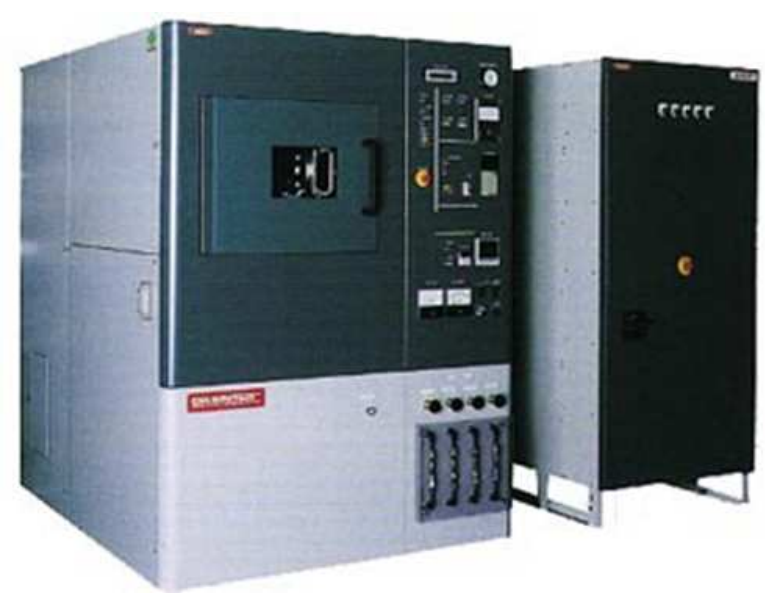

(b)

Figura 1.3: (a) - Conjunto ferramental no interior da câmara à vácuo (Adaptado de Shanckelford (2008)), (b) - Equipamento onde o processo de sinterização por plasma é realizado .

Em geral, os estudos publicados na literatura sobre este processo consideram amostras com geometria circular fabricadas a partir de moldes cilíndricos de grafite. A Figura 1.4 ilustra as atuais geometrias comumentes utilizadas para o molde, punções e amostra.

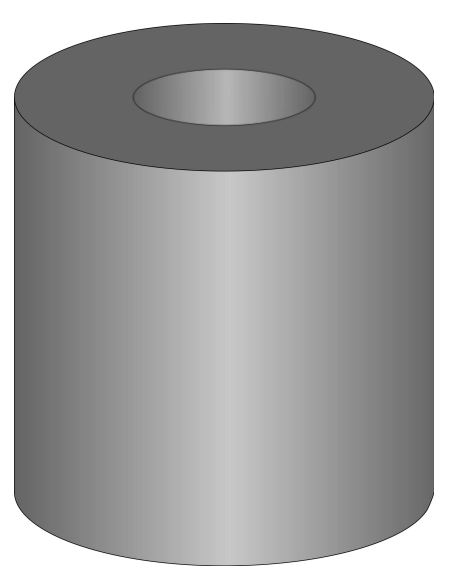

(a) Molde tradicional, cilíndrico e composto por grafite

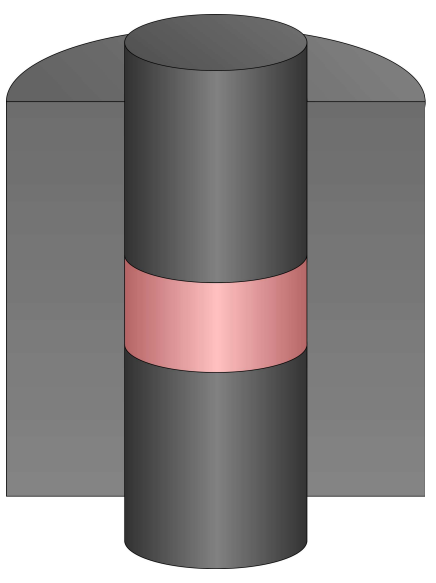

(b) Molde tradicional em corte, destancando punções e amostra

Figura 1.4: Geometrias tradicionais para molde, punção e amostra.

Com isso, diversas amostras tem sido fabricadas a partir de moldes com geometria cilíndrica, desde materiais constituídos por um único material até a combinação de dois ou mais materiais. Nesse sentido, uma das aplicações do processo SPS está no processamento de Materiais com Gradação Funcional (MGF), que consistem em materiais que apresentam mudança gradual das propriedades devido ou a uma gradação da microestrutura, ou arranjo atômico, ou ainda a uma composição química que dependa da posição. Neste último caso, o gradiente da composição química pode ser definido por uma função de transição $c_{i}(x, y, z)$ que 
descreve a concentração do componente $c_{i}$ como função da posição (KIEBACK; NEUBRAND; RIEDEL, 2003). A Figura 1.5 ilustra a microestrutura de um material MGF constituído por cerâmica e metal. A combinação desses dois tipos de materiais permite obter um produto que possui resistência mecânica (metal) aliada com uma fase de baixa condutividade térmica (cerâmica). Com a gradação da microestrutura, elimina-se a interface metal-cerâmica onde pode ocorrer concentração de tensões mecânicas (STUMP, 2006).

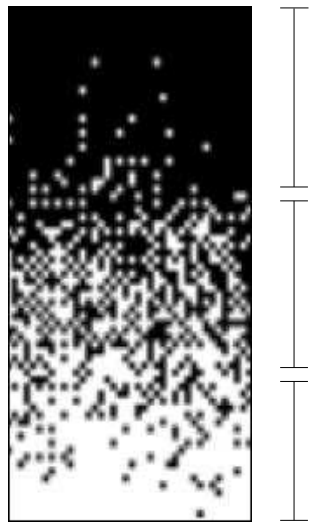

Cerâmica com

inclusões de metal

Região de transição

Metal com

inclusões de cerâmica

Figura 1.5: Microestrutura de material MGF constituído por cerâmica e metal.

Como já citado anteriormente, durante o processo de sinterização existe uma alta taxa de geração de calor nas regiões onde há fluxo de corrente elétrica. O calor gerado é então transferido para o interior da câmara essencialmente pelo mecanismo de radiação. A troca de calor entre o molde e o interior da câmara à vácuo gera na região da amostra gradientes de temperatura, nas direções radial e axial na região da amostra (YUCHENG; ZHENGYI, 2002). Esses gradientes, em alguns casos, podem não ser apropriados para o formato e tipo de material da amostra que está sendo processada. Tendo em vista amostras circulares e moldes cilíndricos, existe um gradiente uniforme de temperatura devido a simetria destes componentes. No entanto, em situações em que as amostras com geometria diferente da circular, também fabricadas com molde cilíndrico, o gradiente de temperatura pode não apresentar o mesmo comportamento uniforme. Além disso, para sinterização de amostras compostas por material MGF, a geometria cilíndrica do molde não favorece para uma adequada sinterização, uma vez que esta geometria não é capaz de produzir um gradiente de temperatura que acompanhe a gradação das propriedades no interior da amostra. A amostra, quando fabricada sob um gradiente de temperatura coerente com a gradação da composição do material, apresenta menos problemas (HONG et al., 2008). Com isso, as propriedades das amostras produzidas sem uma gradação da temperatura de sinterização podem ser negativamente afetadas, uma vez que a sinterização do pó não ocorre de maneira uniforme ao longo da direção de gradação.

Para superar essas limitações de geometria e de gradiente de temperatura, o Método de 
Otimização Topológica (MOT) pode ser aplicado para se projetar moldes que atendam às necessidades de um dado gradiente de temperatura independente da geometria da amostra e, para o caso de amostra MGF, condizentes com a gradação de propriedades. Através deste método é possível encontrar a melhor distribuição de material no molde de acordo com o tipo de amostra a ser sinterizada. A figura 1.6 ilustra geometrias possíveis de serem obtidas após um processo de otimização com foco no tipo de amostra.

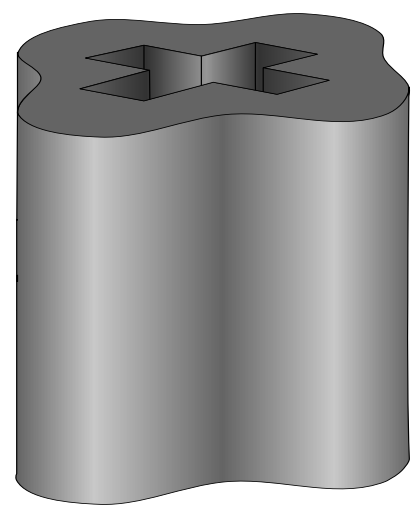

(a) Molde otimizado de acordo com a geometria da amostra.

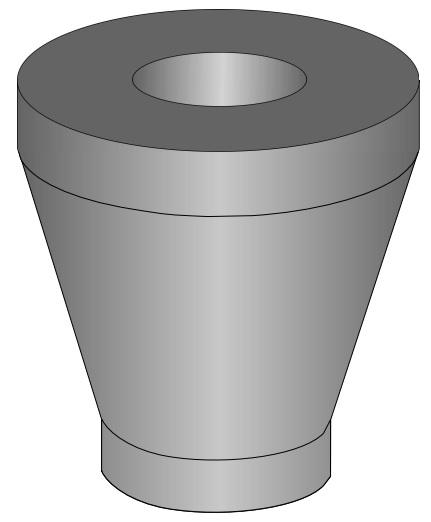

(b) Molde otimizado para amostra de MGF e com geometria circular

Figura 1.6: Geometrias possíveis de serem obtidas através do Método de Otimização Topológica.

Além do uso tradicional de moldes de grafite no processo SPS, há também a possibilidade da utilização de moldes formados a partir de materiais compósitos. Embora não sejam observadas evidências na literatura do uso de moldes compósitos no processo de sinterização por plasma, já existe a aplicação de moldes compósitos em outros processo de fabricação, como por exemplo sistemas de injeção para fabricação de materiais termoplásticos, que utilizam moldes compostos por epóxi e alumínio com o objetivo de melhorar o desempenho térmico deste componente(V.SALMORIA et al., 2008). Um conceito de molde formado por material compósito, e que é explorado neste trabalho, pode ser o uso de material anisotrópico com a finalidade de direcionar o fluxo de calor no interior no conjunto ferramental de modo a influenciar o campo de temperaturas na região da amostra. A Figura 1.7 ilustra este conceito considerando regiões do molde compostas por material ortotrópico que influenciam o campo de temperatura. Na Figura 1.7a, tem-se a distribuição de temperaturas para um molde homogêneo e isotrópico, enquanto que na Figura 1.7b tem-se um possível campo de temperaturas capaz de ser obtido através do uso de molde com material compósito. Assim, utilizando a orientação adequada de fibras condutoras é possível alterar o campo de temperatura para uma dada distribuição desejada. 


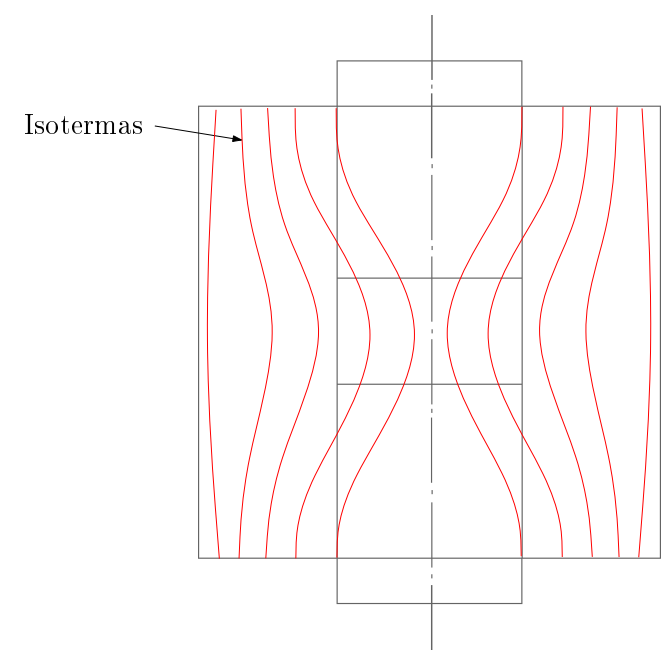

(a) Molde homogêneo

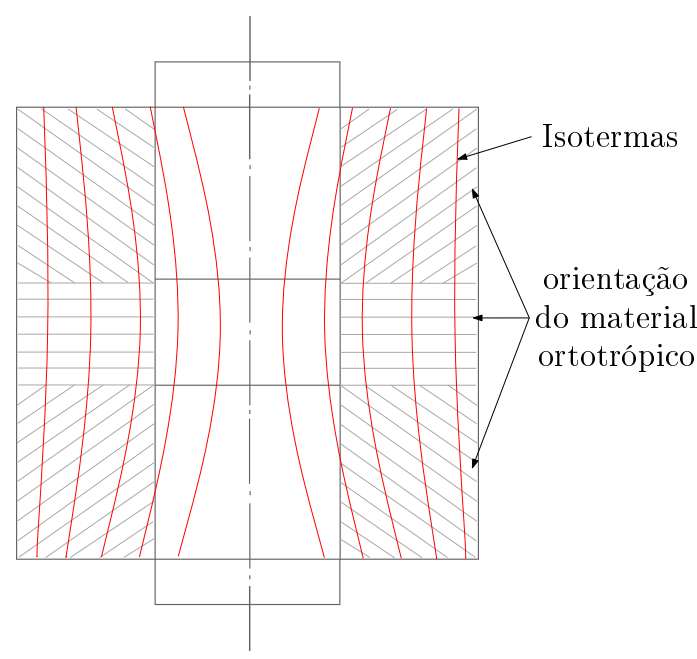

(b) Molde compósito

Figura 1.7: Conceito de molde compósito influenciando o campo de temperaturas.

\subsection{Método de Otimização Topológica}

O Método de Otimização Topológica é uma técnica que permite gerar geometrias otimizadas através da distribuição de material no interior de um domínio de projeto para uma dada estrutura. Esta distribuição ocorre a partir da combinação entre algoritmos de otimização e métodos numéricos, sendo o Método dos Elementos Finitos (MEF) o mais comumente utilizado para análise das equações de equilíbrio de um dado problema. Assim, a partir de um domínio de projeto inicialmente discretizado em elementos finitos, avalia-se o comportamento físico da estrutura e, por meio dos algoritmos de otimização, busca-se a melhor distribuição de material que atenda aos requisitos de projeto da estrutura (BENDSøE; SIGMUND, 2003).

A implementação do algoritmo MOT é baseada num conjunto de etapas necessárias para a obtenção da solução ótima e que pode ser aplicada a diversos projetos de estruturas. A sequência das etapas aplicadas ao problema de otimização é apresentada na Figura 1.8, onde é representado molde em corte longitudinal e sua seção simétrica.

A primeira etapa (Figura 1.8a) consiste em se definir o domínio fixo estendido (DFE), o qual é limitado pelos pontos de aplicação de carregamento e condições de contorno. É neste domínio que a estrutura otimizada será projetada e por isso é importante definir um DFE que contenha, no mínimo, a estrutura original que será otimizada. A segunda etapa (Figura $1.8 \mathrm{~b}$ ) é a discretização do DFE em elementos finitos. Na terceira etapa (Figura 1.8c), os dados obtidos através do MEF, juntamente com os parâmetros de otimização, são inseridos no algoritmo de otimização topológica que, iterativamente, distribui o material no interior do DFE até que a função objetivo do problema seja minimizada ou maximizada e se obtenha a solução ótima da estrutura. 


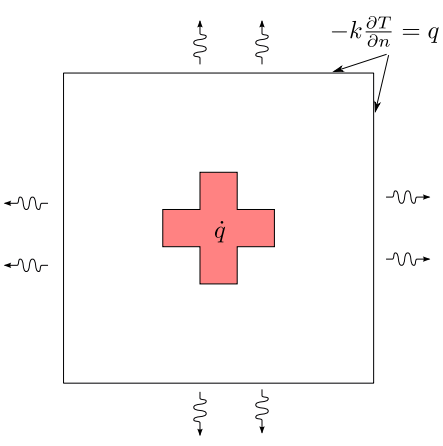

(a) Definição do domínio de projeto e das condições de contorno.

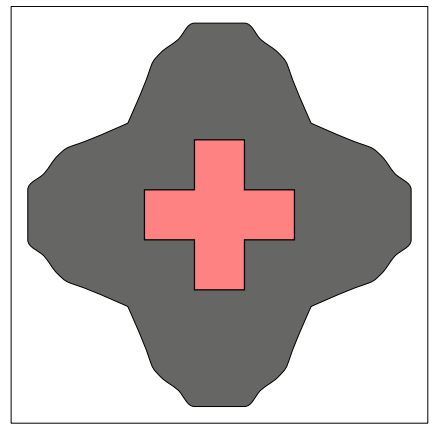

(d) Pós-processamento da solução ótima.

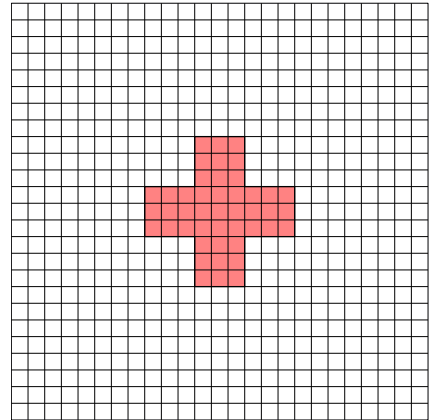

(b) Discretização do domínio de projeto em elementos finitos.

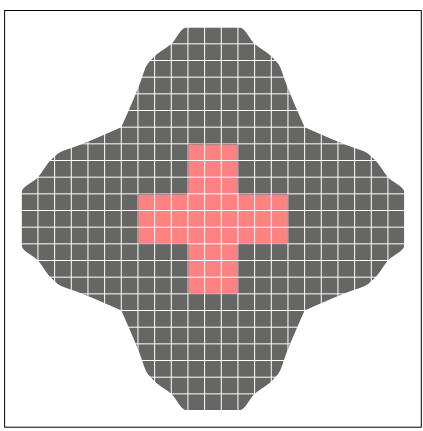

(e) Análise em software comercial.

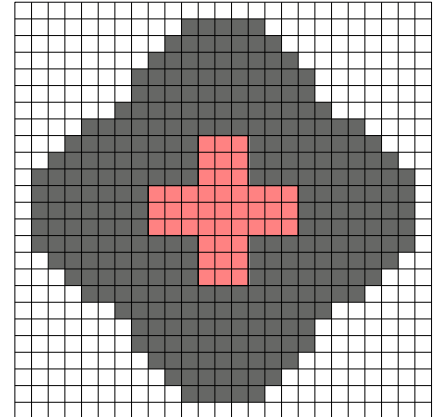

(c) Solução ótima obtida ao final do processo iterativo.

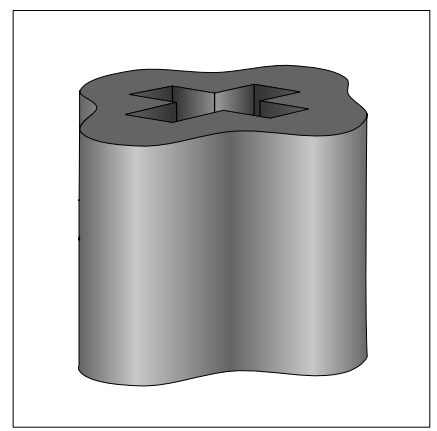

(f) Fabricação do molde otimizado.

Figura 1.8: Conjunto de etapas para otimização estrutural através da OT.

A quarta etapa (Figura 1.8d) consiste no pós-processamento da solução ótima oferecida pelo MOT. Conforme indicado pela Figura 1.8c, a solução ótima é composta por elementos em cor escura (totalmente preenchido), cores claras (ausência de material) e cores intermediárias, conhecida como "escala de cinza". Esta escala de cinza é um fenômeno que deriva da formulação adotada no MOT e deve ser minimizada para não dificultar a compreensão dos resultados, bem como inviabilizar a fabricação da estrutura. Além disso, a solução ótima pode conter regiões com distribuição de material semelhante a um "tabuleiro de xadrez", problema este conhecido como instabilidade de tabuleiro. Técnicas para contornar estes tipos de problemas inerentes ao MOT serão vistas com maiores detalhes na Seção 4. Assim, nesta etapa, o pós-processamento dos resultados pode provocar pequenas alterações na estrutura, já que os elementos que indicam materiais intermediários são eliminados.

Após o pós-processamento da solução ótima, inicia-se a quinta etapa (Figura 1.8e), que consiste na análise da topologia ótima. Nesta etapa, a estrutura sintetizada é avaliada, geralmente num programa comercial, através do MEF para se verificar a função objetivo após as alterações realizadas na estrutura durante a fase de pós-processamento. Finalmente, a última etapa consiste na fabricação da estrutura otimizada. 


\subsection{Objetivo}

O objetivo deste trabalho é o desenvolvimento de uma metodologia para projetos de moldes utilizados no processo de sinterização SPS. Esta metodologia consiste na implementação de um algoritmo de otimização, baseado no Método de Otimização Topológica, que auxilie de maneira sistemática o projeto de moldes otimizados, considerando três tipos de abordagem:

1. Amostra com geometria arbitrária;

2. Amostra circular composta por material com gradação funcional;

3. Molde de material compósito para fabricação de amostras de MGF.

Na primeira abordagem, a qual visa a geometria da amostra, busca-se obter um molde prismático considerando amostras com geometria arbitrária, como por exemplo quadrada, triangular ou em cruz com o objetivo de se uniformizar o campo de temperaturas na amostra. Para essa abordagem foi desenvolvido um modelo computacional para análise de problema bidimensional puramente térmico.

Na segunda abordagem, que considera moldes axissimétricos para fabricação de amostras MGF, os moldes podem ser projetados de modo a produzirem um gradiente de temperatura através da variação da espessura da parede do molde. Assim, ter-se-á um gradiente de temperatura adequado à gradação das temperaturas de fusao do material MGF, conforme ilustrado na Figura 1.9.

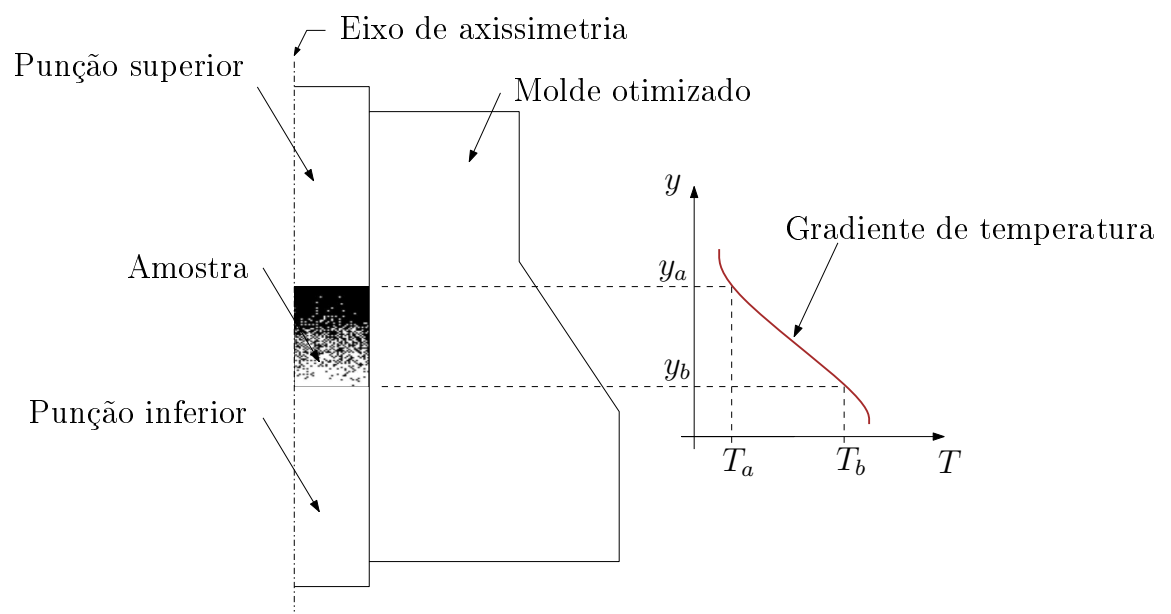

Figura 1.9: Exemplo de gradiente de temperatura fornecido pela variação da espessura da parede do molde.

A terceira e última abordagem de otimização adotada neste trabalho considera um molde constituído por material compósito para fabricação de amostras de MGF. Nesta abordagem é 
proposto um novo conceito de molde, otimizando não apenas a sua geometria, mas também a microestrutura com a qual o molde é composto. Para isso utiliza-se um de material ortotrópico, distribuído ao longo da geometria otimizada, com uma orientação que favoreça o obtenção de um gradiente axial na região da amostra, conforme ilustrado na Figura 1.10.

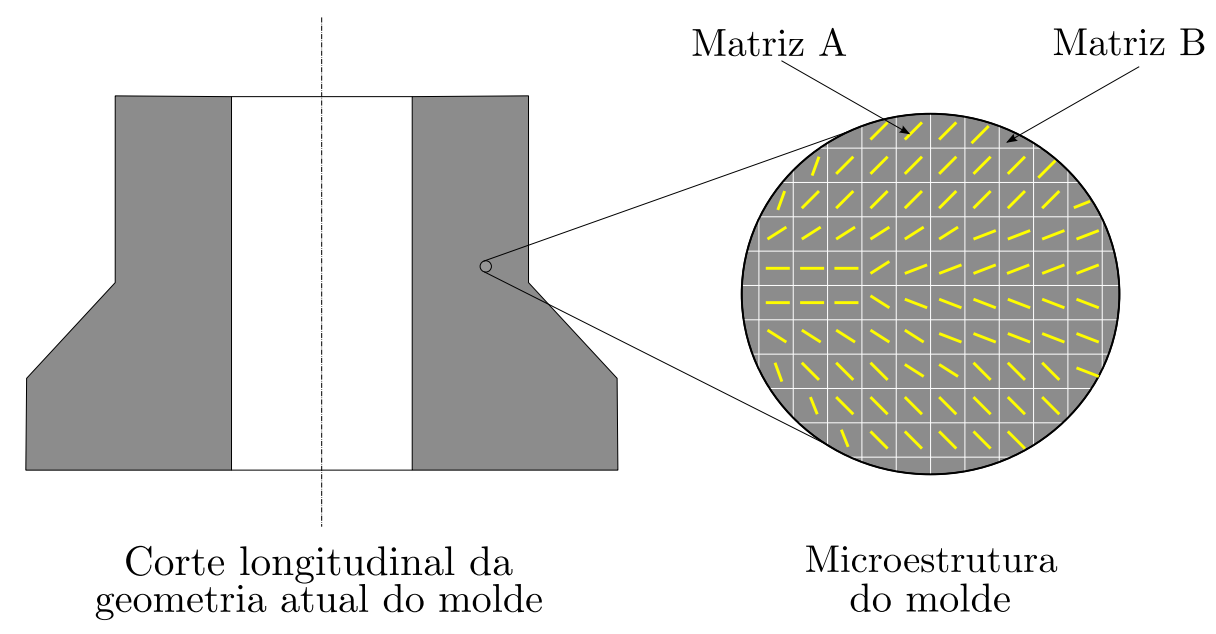

Figura 1.10: Conceito de molde formado por material compósito.

Para as segunda e terceira abordagens foi desenvolvido um modelo computacional para análise de problema eletrotérmico axissimétrico

\subsection{Motivação e Justificativa}

Apesar das vantagens em se utilizar a técnica de sinterização por plasma, vantagens essas citadas na seção 1.2, a influência da geometria do molde nas características finais das amostras praticamente não tem sido explorada pela comunidade acadêmica. Com exceção dos artigos de Hong et al. (2008) e Wei et al. (2012) que avaliam o campo de temperaturas e de tensões produzidos por moldes não-convencionais, a maioria dos estudos publicados sobre o processo de SPS estão relacionados aos procedimentos e parâmetros experimentais, tais como o efeito da corrente elétrica pulsada, temperatura de patamar, tempo de permanência nesta temperatura, dentre outros (CHEN; ANSELMI-TAMBURINI; GARAY J. R. GROZA, 2005; ANSELMI-TAMBURINI et al., 2005; ANSELMI-TAMBURINI; GARAY; MUNIR, 2005; TROMBINI et al., 2007; HUNGRÍA; GALY; CASTRO, 2009).

Como já citado, tradicionalmente utiliza-se um molde de grafite cilíndrico para fabricação de diversos tipos amostras circulares, sejam elas intermetálicas, cerâmicas ou ainda constituídas de material compósito. Assim, a motivação deste trabalho é oferecer flexibilidade de se utilizar um molde, seja ele composto por um único material, como por exemplo grafite, ou composto por material compósito, de acordo com o tipo de material ou materiais da amostra 
e também considerando a sua geometria.

Dentre as abordagens adotadas, a primeira está ligada à distribuição de temperatura na direção radial numa amostra homogênea e com geometria complexa. Para o processamento de amostras com geometria complexa, o formato cilíndrico do molde não permite obter um gradiente de temperatura uniforme ao longo da direção radial. Neste sentido, esta abordagem propõe uma otimização de molde para a fabricação de amostras com uma dada geometria, de modo a uniformizar o gradiente de temperatura na direção radial. Essa abordagem permite sinterizar amostras com uma dada geometria e ao mesmo tempo assegurar uma boa sinterização através da distribuição uniforme da temperatura. Como consequência desta abordagem, tem-se uma flexibilidade na escolha de uma geometria para a peça a ser sinterizada. Com o molde tradicional é possível, apenas, a fabricação de amostras circulares. Isso, necessariamente, exige a utilização de processos de usinagem para conferir à peça a geometria que ela precisa para a sua aplicação dentro de um mecanismo ou um dispositivo. Assim, através desta abordagem é possível reduzir ou até mesmo eliminar etapas de usinagem da amostra após a sua sinterização, reduzindo tempo e principalmente custos de manufatura tendo em vista o processo de fabricação como um todo, desde a obtenção do pó até a aplicação da peça.

No que diz respeito ao tipo de material da amostra, neste trabalho será dado ênfase aos Materiais com Gradação Funcional (MGF), os quais tem permitido a fabricação de produtos com propriedades mais eficientes e específicas para uma determinada aplicação, que pode ser aeroespacial (barreiras térmicas), militar (veículos terrestres e aeronaves), biomédica (implantes ósseos e dentários), entre outras. A qualidade de materiais MGF, em termos de propriedades mecânicas, pode ser influenciada por diversos parâmetros, dentre eles o gradiente de temperatura. Juntamente com a gradação do material, ocorre também a gradação das propriedades físicas e consequentemente a temperatura de sinterização também se altera ao longo da direção da gradação (axial). Assim, para garantir uma sinterização uniforme em toda a amostra, é desejável que exista um gradiente de temperatura na direção axial. Com essa gradação na temperatura pode-se obter excelentes propriedades mecânicas no MGF (WEI et al., 2012).

Foi com base neste gradiente de temperatura, que a segunda e terceira abordagens foram definidas. A segunda abordagem consiste numa otimização que permite obter um gradiente de temperatura através da modificação da espessura do molde ao longo da sua direção longitudinal. A terceira é uma abordagem que explora a microestrutura do molde para se alcançar um gradiente de temperatura através da otimização do arranjo de fibras condutoras, implicando num material compósito. Esta última abordagem propõe um conceito novo de molde em que é possível determinar qual a microestrutura ideal para se definir um gradiente de temperatura específico numa determinada região de um molde. 
Portanto, este trabalho busca contribuir no aperfeiçoamento da tecnologia de sinterização por plasma através do desenvolvimento de uma metodologia para se projetar moldes de acordo com o tipo de amostra a ser sinterizada. 


\section{Modelagem de Problemas Eletrotérmicos}

\subsection{Introdução}

A utilização de modelos matemáticos e computacionais que forneçam as principais características de um dado sistema são essenciais para a sua generalização e seu aperfeiçoamento. Para o caso do processo de sinterização por plasma, modelos computacionais tem sido propostos com o objetivo de melhor compreender as características deste processo e assim aproximar resultados numéricos dos experimentais.

Neste sentido, esta seção apresenta a revisão bibliográfica sobre modelagens computacionais do processo de sinterização por plasma e a modelagem matemática, na formulação contínua, adotada neste trabalho para problemas eletrotérmicos.

\subsection{Revisão Bibliográfica Sobre Simulações Computacio- nais da Sinterização SPS}

Nas publicações relacionadas com a modelagem do processo SPS, o campo de temperatura existente na região da amostra, punções e molde vem recebendo grande destaque devido, principalmente, à alta taxa de geração de calor nos componentes por onde circula corrente elétrica. Yucheng e Zhengyi (2002) estudaram o gradiente de temperatura entre o molde e amostra, combinando a solução analítica de cilindro infinito com a solução para placa infinita. Os autores destacam a existência de um gradiente na direção radial entre o centro da amostra e a parede interna do molde, que para o caso de sinterização de pó de Níquel pode variar de 130 a $900{ }^{\circ} \mathrm{C}$, aproximadamente.

Matsugi et al. (2003) realizaram um estudo para avaliar não somente o campo de temperatura, mas também a distribuição de potenciais elétricos no sistema punção-amostra-molde. Para isso, foi realizado um ensaio experimental, em regime estacionário, envolvendo dois tipos de amostra: uma de titânio (eletricamente condutora) e outra de alumina (não condutora). Os resultados experimentais foram então, comparados com resultados numéricos, os quais foram 
obtidos utilizando o método de diferenças finitas considerando a variação das propriedades físicas dos materiais com a temperatura. Segundo os autores, embora a resistividade elétrica específica seja diferente para cada amostra, a distribuição de potencial elétrico obtida é relativamente próxima, comportamento este não verificado para a distribuição de temperatura que varia de acordo com o tipo da amostra. Resultado semelhante com relação a distribuição de temperatura foi também obtido por Räthel, Herrmann e Beckert (2009) ao analisar amostras de carbeto de tungstênio e nitreto de silício, que são, respectivamente, materiais condutivo e não-condutivo eletricamente.

Outro estudo baseado na comparação entre resultados experimentais e numéricos é o apresentado por Zavaliangos et al. (2004), em que o objetivo principal é determinar uma correlação entre a temperatura da superfície do molde (coletada através de pirômetro) e a temperatura no centro da amostra. Os resultados numéricos são obtidos através de um modelo em elementos finitos (EF), para estudar o problema eletrotérmico, implementado através do pacote comercial ABAQUS ${ }^{\circledR}$ para simular o processo em regime transiente. Neste modelo os autores consideram que a troca de calor no sistema ocorre por condução até os eletrodos, refrigerados à água, e por radiação térmica nas superfícies externas do conjunto ferramental. Esta radiação é modelada considerando todas as superfícies livres do punção, molde e espaçadores, envolvendo os fatores de forma entre essas superfícies e a superfície interna da câmara de sinterização. Além disso, o modelo em EF considera as resistências de contato elétrica e térmica, existentes no sistema punção-amostra-molde, que promovem descontinuidades no campo de temperatura e potencial elétrico. Segundo os autores, as resistências de contato verticais são mais relevantes que as horizontais, já que a pressão de compactação exercida sobre os componentes tende a aproximar os contatos horizontais de contatos ideais. As simulações do processo apontaram para uma alta densidade de corrente elétrica na região dos punções e, estando a amostra e o molde essencialmente em paralelo, esta corrente elétrica atravessa os componentes de acordo com a razão de resistividade elétrica entre eles. Os autores afirmam que, devido a esta passagem de corrente elétrica, a maior parte da geração de calor ocorre na região dos punções, de modo que a amostra é indiretamente aquecida por efeito da condução térmica. Com os resultados experimentais e numéricos obtidos, os autores concluem que a diferença entre a temperatura no centro da amostra e a temperatura na superfície do molde ocorre devido a dois motivos: difusividade térmica do grafite e resistência de contato térmica na parede interna do molde.

Um estudo, semelhante ao apresentado por Zavaliangos et al. (2004), foi realizado por Vanmeensel et al. (2005). Neste estudo foi utilizada uma amostra condutora (TiN) e outra não condutora $\left(\mathrm{ZrO}_{2}\right)$ e considerado a existência de resistências térmicas de contato vertical e horizontal. Além disso, como condições de contorno, na região dos eletrodos refrigerados a 
água foi considerada condição de convecção e nas superfícies livres, a radiação (detalhes da modelagem da radiação não são apresentados). O objetivo deste trabalho foi o de analisar o gradiente de temperatura em cada amostra fabricada. $\mathrm{Na}$ amostra de $\mathrm{ZrO}_{2}$ observou-se uma diferença de temperatura na direção radial entre o centro e a extremidade de aproximandamente $30{ }^{\circ} \mathrm{C}$, ao passo que na amostra de TiN, esse gradiente foi de cerca de $100{ }^{\circ} \mathrm{C}$. Segundo os autores, gradientes elevados podem provocar uma sinterização não uniforme, refletindo na heterogeneidade das propriedades mecânicas da amostra, tais como dureza e resistência mecânica. Ainda sobre os gradiente de temperatura, os autores justificam este comportamento (gradientes elevados) através das resistências de contato e principalmente pela propriedade elétrica de cada amostra. Em amostras não condutoras a corrente elétrica circula predominantemente nos punções e molde, onde o calor gerado é conduzido rapidamente à amostra, compensando assim a perda de calor por radiação e minimizando o gradiente de temperatura. No caso de amostras condutoras, a corrente elétrica também atravessa a amostra, causando assim geração de calor na sua região. No entanto, as perdas de calor por radiação na superfície do molde não são compensadas, proporcionando uma distribuição de temperatura não homogênea na região da amostra.

Anselmi-Tamburini et al. (2005) desenvolveram estudo semelhante ao desenvolvido por Vanmeensel et al. (2005), porém não considerando a existência de resistências térmicas de contato. No modelo de elementos finitos, as temperaturas dos eletrodos foram fixadas em 300 $\mathrm{K}$, a radiação térmica foi modelada como radiação de corpo negro (emissividade igual a 1) entre a superfície do molde e o interior da câmara com temperatura constante, e corrente elétrica constante de 1000 A. Os resultados experimentais, obtidos para amostras de alumina e cobre, foram comparados e por serem próximos aos obtidos através das simulações computacionais, apontaram para a existência de gradientes de temperatura para ambos os tipos de amostras.

Outros trabalhos que seguem a mesma linha dos apresentados anteriormente tem sido publicados, como por exemplo Wang et al. (2007) que desenvolvem um modelo para tratar de um problema com acoplamento triplo (eletrotermomecânico) implementado através do "software" comercial Ansys ${ }^{\circledR}$, enquanto Tiwari, Basu e Biswas (2009) implementam um modelo em EF utilizando Matlab ${ }^{\circledR}$ e ABAQUS ${ }^{\circledR}$. Maizza, Grasso e Sakka (2009) elaboram um modelo para problema eletrotérmico considerando o movimento da malha de elementos finitos durante o processo de compactação do pó, o que influencia na densidade relativa da amostra e por sua vez nas propriedades físicas. Fazendo também esta consideração de densificação, Wang, Cheng e Zhao (2010) implementam o problema eletrotermomecânico utilizando o COMSOL ${ }^{\circledR}$ para analisar o efeito da distribuição de temperatura e tensões na microestrutura das amostras.

Outros aspectos relacionados à sinterização por plasma também tem sido investigados. Chennoufi et al. (2009) apresentam um modelo em EF para minimizar a perda de calor e 
assim contribuir para reduzir o consumo de energia na sinterização, e também sugerem uma técnica para intensificar e homogeneizar a sinterização através da eliminação de correntes de "fuga". Os efeitos da aplicação de corrente pulsada e da carga de compressão na microestrutura da amostra foram investigados na literatura por: (CHEN; ANSELMI-TAMBURINI; GARAY J. R. GROZA, 2005), (ANSELMI-TAMBURINI; GARAY; MUNIR, 2005) e (MUNIR; ANSELMITAMBURINI; OHYANAGI, 2006).

Em todos os estudos acima citados foram consideradas amostras compostas por um único tipo de material. Entretanto, diversos outros estudos tem sido publicados com o objetivo de investigar a influência de parâmetros e procedimentos experimentais na microestrutura e propriedades físicas de materiais MGF. Para citar alguns exemplos tem-se os artigos de Guo et al. (2003) que utilizaram amostras compósitas de hidróxiapatita, Feng et al. (2005) que sintetizaram amostras com gradação funcional no sistema Ti-TiB 2 -B e Watanabe et al. (2011) que fabricaram amostras gradadas composta por Titânio e polímero biodegradável. Nesses trabalhos, a sinterização dos materiais com gradação funcional foi realizada com a utilização de molde cilíndrico e com parede de espessura constante, ou seja, molde no formato tradicional.

No que se refere ao tipo de molde utilizado no processo SPS, apenas duas publicações citam o uso de moldes não-tradicionais para a fabricação de materiais MGF. Hong et al. (2008) realizaram um estudo experimental com amostra de MGF composta por $\mathrm{ZrB}_{2}-\mathrm{SiC} / \mathrm{ZrO}_{2}(3 \mathrm{Y})$ utilizando um molde de grafite que proporcionou um gradiente de temperatura na região da amostra. Este molde continha duas regiões distintas: uma no formato cilíndrico e outra no formato tronco de cone, onde a transição de uma região a outra localiza-se no centro da amostra, na direção axial. Apesar da utilização deste molde, os autores não apresentaram os critérios adotados para a definição da geometria do molde e também não é citado o uso de simulação computacional do processo de sinterização para avaliação prévia do perfil de temperatura gerado pelo tipo de molde utilizado. Semelhante aos estudos anteriores, a microestrutura e as propriedades físicas em cada camada de gradação da amostra foram investigadas. Dentre as observações citadas no estudo, os autores destacam a não existência de uma porosidade residual significante no MGF sintetizado, sugerindo uma sinterização homogênea.

O segundo estudo com molde não-tradicional foi o desenvolvido por Wei et al. (2012). Nesse estudo, um modelo computacional baseado em elementos finitos foi utilizado para simular a distribuição de temperatura e tensão mecânica durante o processo de sinterização por plasma. No modelo, além das considerações de regime transiente, acoplamento eletrotermomecânico, resistências térmicas de contato e materiais isótropos, não foi considerada condição de radiação térmica na superfície do molde. Isto por que no ensaio experimental o molde de grafite foi envolvido num feltro para minimizar perdas de calor por radiação, a qual foi desconsiderada no modelo computacional. Assim, o gradiente de temperatura é obtido através da 
densidade de corrente elétrica que circula no molde. Devido a variação na espessura do molde ao longo da direção axial, a densidade de corrente se altera e por sua vez a geração de calor ocorre de maneira mais localizada e favorece a formação de um gradiente de temperatura nesta direção. Nesse estudo foram realizados dois ensaios experimentais, um com molde tradicional e outro com molde não-tradicional para sinterizarem o mesmo tipo de amostra MGF. Para o caso do molde não-tradicional, os resultados concordaram com os numéricos, validando o modelo computacional proposto. As amostras fabricadas com os dois tipos de molde foram analisadas e os autores citam a melhora nas propriedades mecânicas da amostra sintetizada com molde não-tradicional, devido à formação de um gradiente de temperatura na direção axial.

\subsection{Modelagem Matemática}

Embora o processo de sinterização por plasma envolva um problema de acoplamento eletrotermomecânico, neste trabalho o processo SPS é analisado através de modelos computacionais que consideram um problema puramente térmico (no caso da abordagem para moldes prismáticos) e um problema eletrotérmico (no caso das abordagens de moldes com espessura variável e compósitos).

As considerações adotadas para a modelagem matemática basearam-se na revisão bibliográfica sobre simulação computacional do processo de sinterização SPS reportada na literatura. Uma das principais considerações é a não inclusão do problema mecânico, a qual resulta numa modelagem matemática incompleta, apoia-se na hipótese de que os limites de tensão mecânica podem ser alcançados através do controle de volume material do molde. Isto quer dizer que, ao final do processo de otimização, em se obtendo uma geometria de molde com parede relativamente "fina", uma medida para evitar o colapso da estrutura do molde seria aumentar a espessura da parede mantendo o seu contorno geométrico. Dessa forma, tem-se um molde otimizado e com resistência mecânica suficiente para suportar as cargas de compressão que variam de $30 \mathrm{MPa}$ a $120 \mathrm{MPa}$ dependendo da região e tipo do material sinterizado (VANMEENSEL et al., 2005; WEI et al., 2012). Além disso, o objetivo principal na otimização do molde está relacionado com o campo de temperaturas, o qual é influenciado pelo campo de densidade de corrente elétrica. Maiores detalhes sobre as considerações adotadas são apresentadas no capítulo 5 e Apêndice B. Sendo assim, apenas os problemas elétrico e térmicos são considerados na modelagem matemática.

Portanto, nesta seção é apresentada a formulação contínua dos problemas elétrico e térmico, ambos em regime permanente. 


\subsubsection{Problema elétrico}

Considerando o fenômeno elétrico, as equações governantes de um campo elétrostático podem ser escritas da seguinte forma (JIN, 2002; BASTOS; SADOWSKI, 2003)

$$
\begin{array}{cc}
\nabla \cdot \mathbf{J}=0 & \text { (Eq. da continuidade) } \\
\mathbf{J}=\sigma \mathbf{E} & \text { (Eq. constitutiva - Lei de Ohm) }
\end{array}
$$

onde $\mathbf{J}$ é o vetor densidade de corrente elétrica, $\mathbf{E}=-\nabla \phi$ representa o campo elétrico, $\sigma$ é a condutividade elétrica, $\phi$ a função escalar que representa o campo de potencial elétrico e $\Omega$ é o domínio físico da estrutura.

A partir das equações 2.1 e 2.2 a distribuição de potencial elétrico e condições de contorno em $\Omega$ são dadas pelas seguintes equações:

$$
\begin{array}{rlll}
\nabla \cdot(-\sigma \nabla \phi) & =0 & \text { em } & \Omega, \\
\sigma \nabla \phi \cdot \mathbf{n}=I & \text { em } \quad \Gamma_{i}, \\
\phi=\widehat{\phi} & \text { em } \quad \Gamma_{u},
\end{array}
$$

onde $I$ representa um fluxo de corrente elétrica cruzando a fronteira $\Gamma_{i}$ de $\Omega, \mathbf{n}$ o vetor unitário normal com sentido para fora do domínio $\Omega$ e $\widehat{\phi}$ indica um valor de potencial elétrico prescrito em $\Gamma_{u}$, conforme ilustrado na figura 2.1

As condições de contorno dadas pelas equações 2.4 e 2.5 estabelecem, respectivamente, as condições de contorno naturais e essenciais do problema elétrico (ASSAN, 2003; FISH; BELYTSCHKO, 2007).

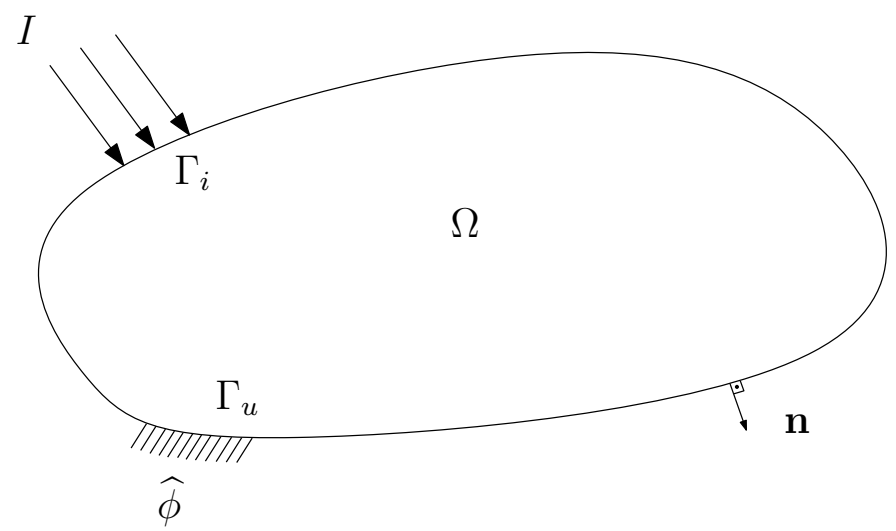

Figura 2.1: Domínio bidimensional elétrico.

Multiplicando a equação 2.3 em ambos os lados pelo potencial elétrico virtual $\tilde{\phi}$, aplicando o Teorema da Divergência ao longo do domínio $\Omega$ e utilizando as equações de contorno 2.4 e 
2.5, tem-se

$$
\int_{\Omega_{e}} \sigma \nabla \phi \nabla \tilde{\phi} \mathrm{d} \Omega=\int_{\Gamma_{i}} I \tilde{\phi} \mathrm{d} \Gamma \quad \forall \tilde{\phi} \in \Theta_{e}
$$

onde $\Theta_{e}$ é o espaço dos potenciais elétrico admissíveis dado por

$$
\Theta_{e}=\left\{\phi \in H_{e}(\Omega) \mid \phi=0, x \in \Gamma_{u}\right\}
$$

e $H_{e}(\Omega)$ é o espaço de Sobolev de primeira ordem.

As formas bilinear e linear do problema elétrico são definidas como (CHOI; KIM, 2005)

$$
a(\phi, \tilde{\phi}) \equiv \int_{\Omega} \sigma \nabla \phi \nabla \tilde{\phi} \mathrm{d} \Omega
$$

e

$$
l(\tilde{\phi}) \equiv \int_{\Gamma_{q}} I \tilde{\phi} \mathrm{d} \Gamma .
$$

Assim, a forma variacional da equação que rege o problema elétrico é expressa como

$$
a(\phi, \tilde{\phi})=l(\tilde{\phi}) \quad \forall \tilde{\phi} \in \Theta_{e}
$$

\subsubsection{Problema térmico}

$\mathrm{Na}$ análise do problema térmico, as equações governantes podem ser obtidas através da Lei de Conservação de Energia (ou primeira lei da termodinâmica) para regime permanente e pela Lei de Fourier (REDDY; GARTLING, 1994), e expressas da seguinte forma:

$$
\begin{array}{rc}
\nabla \cdot \mathbf{q}+\dot{q}=0 & (\text { Conservação da energia) } \\
\mathbf{q}=-\kappa \nabla T \quad(\text { Eq. constitutiva - Lei de Fourier })
\end{array}
$$

onde q é o vetor de fluxo de calor, $\dot{q}=\mathbf{J} \cdot \mathbf{E}$ é a geração interna de calor por unidade de volume gerada por efeito Joule (ANSELMI-TAMBURINI et al., 2005), $\kappa$ é a condutividade térmica do material e $T$ é o campo de temperatura.

Com isso, a equação de condução de calor no regime estacionário e condições de contorno em $\Omega$ (ver Figura 2.2) são dadas por:

$$
\begin{array}{rrr}
\nabla \cdot(-\kappa \nabla T)+\dot{q}=0 & \text { em } \quad \Omega, \\
\kappa \nabla T \cdot \mathbf{n}=q & \text { em } \quad \Gamma_{q_{1}}, \\
\kappa \nabla T \cdot \mathbf{n}+h\left(T-T_{a m b}\right)=0 & \text { em } \quad \Gamma_{q_{2}}, \\
T=\widehat{T} & \text { em } \quad \Gamma_{u},
\end{array}
$$




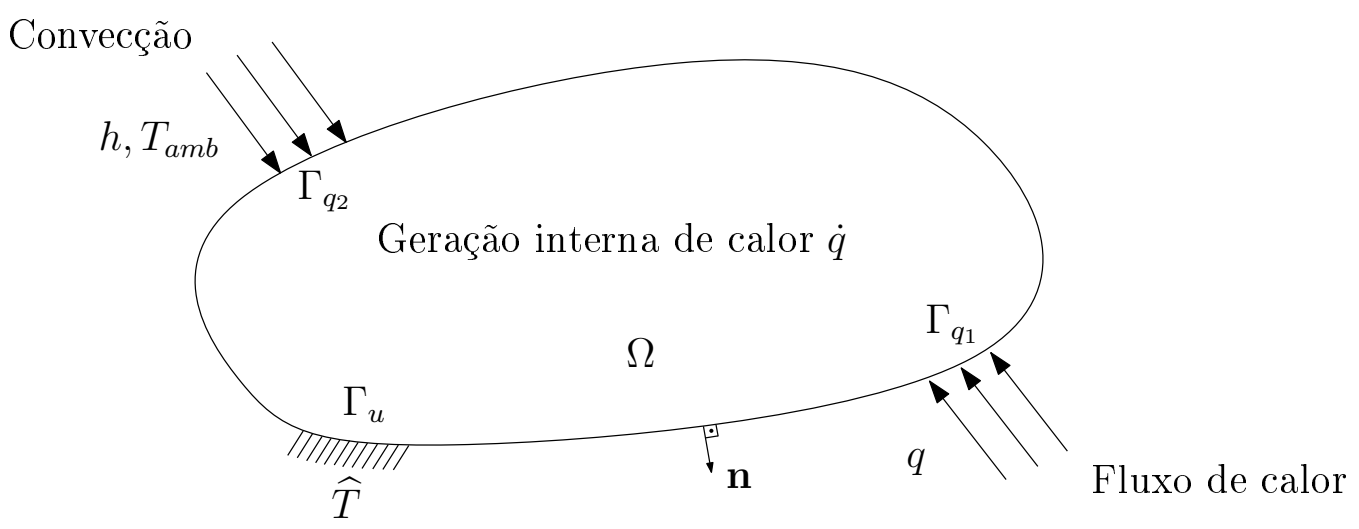

Figura 2.2: Domínio bidimensional térmico.

onde $q$ representa um fluxo de calor cruzando, na direção normal, a fronteira $\Gamma_{q_{1}}$ do domínio $\Omega$, $\widehat{T}$ indica temperatura prescrita em $\Gamma_{u}, h$ é o coeficiente de transferência de calor por convecção que ocorre em $\Gamma_{q_{2}}, T_{a m b}$ é a temperatura ambiente.

Multiplicando a equação 2.13 em ambos os lados pela temperatura virtual $\tilde{T}$, integrando por partes ao longo do domínio $\Omega$ e utilizando as equações de contorno, tem-se (FINLAYSON, 1983; LEWIS; NITHIARASU; SEETHARAMU, 2004; CHOI; KIM, 2005)

$$
\int_{\Omega} \kappa \nabla T \nabla \tilde{T} \mathrm{~d} \Omega+\int_{\Gamma_{q_{2}}} h T \tilde{T} \mathrm{~d} \Gamma=\int_{\Omega} \dot{q} \tilde{T} \mathrm{~d} \Omega+\int_{\Gamma_{q_{1}}} q \tilde{T} \mathrm{~d} \Gamma+\int_{\Gamma_{q_{2}}} h T_{a m b} \tilde{T} \mathrm{~d} \Gamma \quad \forall \tilde{T} \in \Theta_{t}
$$

onde $\Theta_{t}$ é o espaço de temperaturas admissíveis dada por

$$
\Theta_{t}=\left\{T \in H_{t}(\Omega) \mid T=0, x \in \Gamma_{u}\right\}
$$

e $H_{t}(\Omega)$ é o espaço de Sobolev de primeira ordem.

As formas bilinear e linear do problema térmico são definidas como (CHOI; KIM, 2005)

$$
a(T, \tilde{T}) \equiv \int_{\Omega} \kappa \nabla T \nabla \tilde{T} \mathrm{~d} \Omega+\int_{\Gamma_{q_{2}}} h T \tilde{T} \mathrm{~d} \Gamma
$$

$\mathrm{e}$

$$
l(\tilde{T}) \equiv \int_{\Omega} \dot{q} \tilde{T} \mathrm{~d} \Omega+\int_{\Gamma_{q_{1}}} q \tilde{T} \mathrm{~d} \Gamma+\int_{\Gamma_{q_{2}}} h T_{a m b} \tilde{T} \mathrm{~d} \Gamma
$$

Assim, a forma variacional da equação de calor pode ser expressa como

$$
a(T, \tilde{T})=l(\tilde{T}) \quad \forall \tilde{T} \in \Theta_{t} .
$$

Além das condições de contorno apresentadas acima, o termo $q$ referente a fluxo de calor também pode representar uma condição de radiação térmica, a qual é altamente não-linear com a temperatura e pode ocorrer por meio de dois tipos: radiação entre duas superfícies ou entre superfície e um ambiente. Considerando o último mecanismo, sua formulação, de acordo com 
a Lei de Stefan-Boltzmann, é dada por (ARPACI; SELAMET; KAO, 2000; INCROPERA; DEWITT, 2002)

$$
q=\epsilon \delta\left(T_{s}^{4}-T_{a m b}^{4}\right)
$$

onde

$q$ : Fluxo de calor devido à radiação;

$\epsilon \quad$ : Fator de emissividade ou emitância;

$T_{s}$ : Temperatura da superfície sujeita à radiação;

$T_{a m b}:$ Temperatura ambiente;

$\delta:$ Constante de Stefan-Boltzmann.

Para se trabalhar num problema linear de transferência de calor, porém que utilize condições de contorno que envolvam o mecanismo de radiação, $q_{r}$ pode ser linearizada através da série de Taylor. Dessa forma, a radiação linearizada adquire a seguinte forma

$$
\begin{gathered}
q_{r_{\text {linear }}}=q_{0}+h_{a p}\left(T-T_{0}\right), \\
q_{0}=\epsilon \delta\left(T_{0}^{4}-T_{a m b}^{4}\right)
\end{gathered}
$$

e

$$
h_{a p}=4 \epsilon \delta T_{0}^{3},
$$

onde

$$
\begin{aligned}
q_{0} & : \text { fluxo de calor prescrito aparente; } \\
h_{a p} & : \text { Coeficiente de convecção aparente; } \\
T_{0} & : \text { Temperatura de linearização. }
\end{aligned}
$$

Com isso, a radiação térmica linearizada é composta por dois termos: um semelhante a uma condição de contorno de fluxo de calor prescrito $\left(q_{0}\right)$ e outro semelhante a uma condição de convecção $\left(q_{a p}\right)$, sendo ambas nomeada neste trabalho como "fluxo de calor aparente" e "convecção aparente", respectivamente. Vale ressaltar que esta linearização é uma aproximação da radiação não-linear em torno de $T_{0}$ e, portanto, quanto menor a diferença $T-T_{0}$, menor é o erro nesta aproximação. Assim, a validade desta linearização, como a de qualquer outra, consiste em considerar esse erro aceitável ou não, sendo assim uma relação de compromisso. 


\subsection{Formulação de elementos finitos para o problema ele- trotérmico}

O Método dos Elementos Finitos é baseado numa formulação na forma integral das equações governantes de um dado problema.

As equações que governam os problemas elétrico e térmico, bem como as condições de contorno apresentadas na seção 2.3, estão na forma diferencial para representar o problema eletrotérmico. No entanto, para solucionar o problema eletrotérmico através do Método dos Elementos Finitos (MEF) é necessário obter a formulação na forma integral (HUGHES, 1987), a qual pode ser obtida por meio de diversos métodos, tais como métodos variacionais ou do método dos resíduos ponderados (MRP) (REDDY, 2004). Utilizando, por exemplo, o Método de Galerkin, que consiste no MRP quando se assume as funções ponderadoras como sendo iguais às funções que interpolam os valores nodais de um elemento finito (HUANG; USMANI, 1994), obtém-se a forma integral das equações governantes 2.3 e 2.13.

Assim, a formulação integral para o problema elétrico é dada por (REDDY, 2004):

$$
\int_{\Omega} \nabla \mathbf{N}^{\mathrm{T}} \mathbf{C}_{\mathbf{E}} \nabla \tilde{\phi} \mathrm{d} \Omega=\oint_{\Gamma} \mathbf{N}^{\mathrm{T}} \mathbf{C}_{\mathbf{E}} \nabla \tilde{\phi} \mathrm{d} \Gamma
$$

onde $\mathbf{N}$ representa as funções interpoladoras dos valores nodais no elemento finito, $\tilde{\phi}$ a função aproximadora do campo de potencial elétrico e $\mathbf{C}_{\mathbf{E}}$ é a matriz associada à condutividade elétrica.

Analogamente, para o problema térmico, sua formulação na forma integral é dada por:

$$
\int_{\Omega} \nabla \mathbf{N}^{\mathrm{T}} \mathbf{C}_{\mathrm{T}} \nabla \tilde{T} \mathrm{~d} \Omega=\int_{\Omega} \mathbf{N}^{\mathrm{T}} \dot{q} \mathrm{~d} \Omega+\oint_{\Gamma} \mathbf{N}^{\mathrm{T}} \mathbf{C}_{\mathrm{T}} \nabla \tilde{T} \mathrm{~d} \Gamma
$$

onde $\tilde{T}$ é a função aproximadora do campo de temperatura e $\mathbf{C}_{\mathrm{T}}$ é a matriz com as propriedade de condutividade térmica.

Com isso, a formulação em elementos finitos para o problema eletrotérmico inicia-se com a definição das funções aproximadoras que são utilizadas na formulação integral (ver equações 2.26 e 2.27), a partir da qual é possível realizar a discretização do domínio $\Omega$ e em seguida definir aproximações lineares para as variáveis primárias $\phi$ e $T$ como sendo (REDDY, 2004):

$$
\tilde{\phi}(x, y)=\sum_{i=1}^{m} N_{i}(x, y) \phi_{i}=\mathbf{N} \phi
$$




$$
\tilde{T}(x, y)=\sum_{i=1}^{m} N_{i}(x, y) T_{i}=\mathbf{N T}
$$

Nas implementações do MEF neste trabalho, optou-se pela utilização de elementos finitos bilineares isoparamétricos, conforme ilustrado na Figura 2.3.

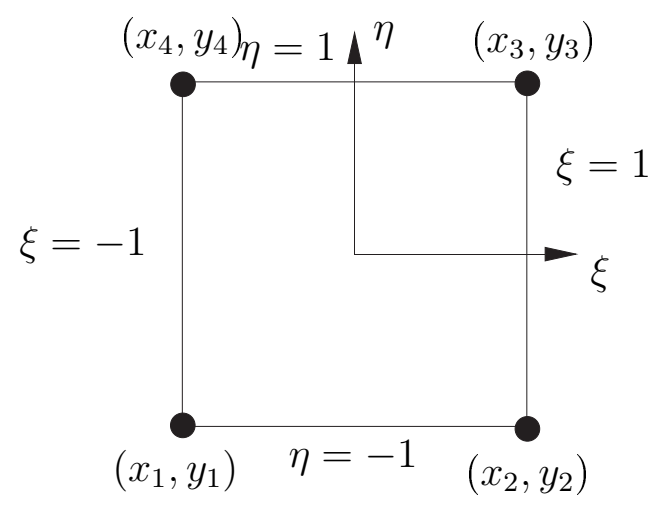

Figura 2.3: Elemento finito retangular isoparamétrico.

A partir do sistema de coordenadas locais $(\xi, \eta)$ definido no centro do elemento, as funções de interpolações são escritas da seguinte forma:

$$
\begin{aligned}
& N_{1}=\frac{1}{4}(1-\xi)(1-\eta) \\
& N_{2}=\frac{1}{4}(1+\xi)(1-\eta) \\
& N_{3}=\frac{1}{4}(1+\xi)(1+\eta) \\
& N_{4}=\frac{1}{4}(1-\xi)(1+\eta)
\end{aligned}
$$

A relação entre os sistema $(x, y)$ e $(\xi, \eta)$ de coordenadas pode ser expressa como:

$$
\begin{gathered}
x=N_{1} x_{1}+N_{2} x_{2}+N_{3} x_{3}+N_{4} x_{4}=\mathbf{N x}_{e} \\
y=N_{1} y_{1}+N_{2} y_{2}+N_{3} y_{3}+N_{4} y_{4}=\mathbf{N y}_{e}
\end{gathered}
$$

onde

$$
\begin{aligned}
\mathbf{x}_{e} & =\left[\begin{array}{llll}
x_{1} & x_{2} & x_{3} & x_{4}
\end{array}\right]^{T} \\
\mathbf{y}_{e} & =\left[\begin{array}{llll}
y_{1} & y_{2} & y_{3} & y_{4}
\end{array}\right]^{T}
\end{aligned}
$$

Para efetuar o cálculo da matriz de rigidez é necessário obter as derivadas das funções interpoladoras da maneira, resultando na seguinte matriz $\mathbf{B}$ : 


$$
\mathbf{B}=\left[\begin{array}{cccccccc}
\frac{\partial N_{1}}{\partial x} & 0 & \frac{\partial N_{2}}{\partial x} & 0 & \frac{\partial N_{3}}{\partial x} & 0 & \frac{\partial N_{4}}{\partial x} & 0 \\
0 & \frac{\partial N_{1}}{\partial y} & 0 & \frac{\partial N_{2}}{\partial y} & 0 & \frac{\partial N_{3}}{\partial y} & 0 & \frac{\partial N_{4}}{\partial y}
\end{array}\right]
$$

O sistema $(x, y)$ é um sistema de coordenadas que pode ser utilizado tanto num caso de implementação de problema bidimensional, quanto para um caso de problema axissimétrico. No caso axissimétrico as coordenadas $x$ e $y$ podem ser simplesmente substituídas por $r$ e $z$, que representam a direção radial e axial, respectivamente (ver Figura 2.4).

Durante a resolução do problema eletrotérmico é necessário calcular os gradientes do potencial elétrico $\phi$ e da temperatura $T$, em que ambos dependem da localização $(x, y)$ no interior do domínio $\Omega$. Assim, representando $\phi$ e $T$ pela variável $u$ e utilizando a regra da cadeia, tem-se:

$$
\left\{\begin{array}{l}
\frac{\partial u}{\partial \xi} \\
\frac{\partial u}{\partial \eta}
\end{array}\right\}=\left[\begin{array}{ll}
\frac{\partial x}{\partial \xi} & \frac{\partial y}{\partial \xi} \\
\frac{\partial x}{\partial \eta} & \frac{\partial y}{\partial \eta}
\end{array}\right]\left\{\begin{array}{l}
\frac{\partial u}{\partial x} \\
\frac{\partial u}{\partial y}
\end{array}\right\}=\mathbf{J}\left\{\begin{array}{l}
\frac{\partial u}{\partial x} \\
\frac{\partial u}{\partial y}
\end{array}\right\}
$$

e portanto,

$$
\left\{\begin{array}{l}
\frac{\partial u}{\partial x} \\
\frac{\partial u}{\partial y}
\end{array}\right\}=\mathbf{J}^{-1}\left\{\begin{array}{l}
\frac{\partial u}{\partial \xi} \\
\frac{\partial u}{\partial \eta}
\end{array}\right\}
$$

onde a matriz J é denominada Jacobiana da transformação de coordenadas (ASSAN, 2003; REDDY, 2004).

Assim, discretizando o domínio $\Omega$ em elementos finitos de modo a se obter $m$ valores nodais, a formulação na forma discreta para o problema eletrotérmico axissimétrico, pode ser apresentada para cada um dos problemas elétrico e térmico.

\subsubsection{Problema Elétrico}

O sistema algébrico que rege o problema elétrico, a partir da equação 2.26, é formulado na sua forma matricial como

$$
\mathbf{K}_{\mathrm{E}} \boldsymbol{\phi}=\mathbf{F}_{\mathrm{E}}
$$

onde 
$\mathbf{K}_{\mathrm{E}} \quad$ : Matriz global de condutividade elétrica;

$\mathbf{F}_{\mathrm{E}}$ : Vetor global de carregamento elétrico.

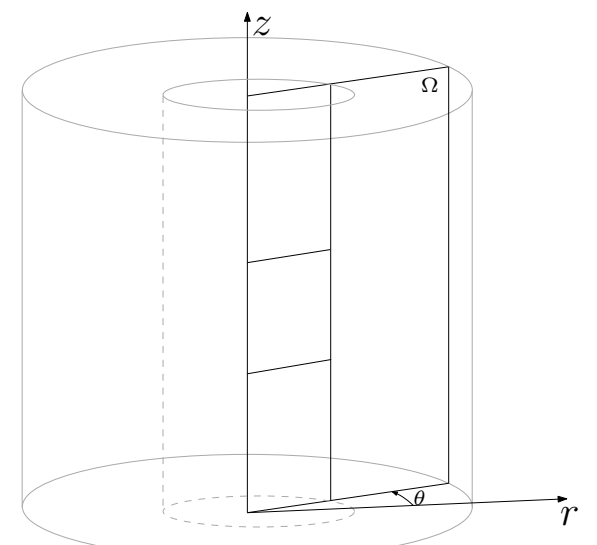

Figura 2.4: Sistema de coordenadas cilíndricas para formulação do problema eletrotérmico.

Considerando o sistema de coordenadas cilíndricas apresentado na Figura 2.4 e após a discretização do domínio $\Omega$, o sistema de matrizes e vetores globais dado pela equação 2.37 é montado a partir de um operador de sobreposição $\Lambda$, que considera a conectividade nodal dos elementos, de todas a matrizes e vetores elementais que compõem a malha de elementos finitos (HUGHES, 1987; BENDSØE; SIGMUND, 2003; ASSAN, 2003; FISH; BELYTSCHKO, 2007).

Assim, para uma discretização axissimétrica do domínio $\Omega$ em $n$ elementos finitos , a matriz global de condutividade elétrica $\mathbf{K}_{\mathbf{E}}$ e o vetor global de carregamento $\mathbf{F}_{\mathbf{E}}$ são escritos como

$$
\mathbf{K}_{\mathrm{E}}=\Lambda_{e=1}^{n} \mathbf{k}_{\mathrm{E}}^{e}=\Lambda_{e=1}^{n} 2 \pi \int_{z} \int_{r} \mathbf{B}^{\mathrm{T}} \mathbf{C}_{\mathrm{E}} \mathbf{B} r \mathrm{~d} r \mathrm{~d} z
$$

e

$$
\mathbf{F}_{\mathrm{E}}=\Lambda_{e=1}^{n} \mathbf{F}_{\mathrm{E}}^{e}=\Lambda_{e=1}^{n} 2 \pi \oint_{\Gamma_{e}} \mathbf{N}^{\mathrm{T}} \operatorname{Ir} \mathrm{d} \Gamma_{e}
$$

onde

$\mathbf{k}_{\mathrm{E}}^{e} \quad$ : Matriz de condutividade elétrica de um elemento $e$;

$\mathbf{F}_{\mathrm{E}}^{e} \quad$ : Vetor de carregamento elétrico num elemento $e$;

B : Gradiente das funções de forma $\mathbf{N}$

\subsubsection{Problema Térmico}

Através da formulação na forma integral da equação de equilíbrio do problema térmico (ver Eq. 2.21), a mesma equação escrita na forma matricial é dada por 


$$
\mathbf{K}_{\mathrm{T}} \mathbf{T}=\mathbf{F}_{\mathrm{T}}
$$

$\mathrm{e}$

$$
\left(\mathbf{K}_{k}+\mathbf{K}_{h}\right) \mathbf{T}=\left(\mathbf{F}_{\dot{q}}+\mathbf{F}_{h}+\mathbf{F}_{q}\right)
$$

onde $\mathbf{K}_{k}$ e $\mathbf{K}_{h}$ são as matrizes de rigidez térmica devido à condução e convecção, respectivamente. $\mathbf{F}_{\dot{q}}, \mathbf{F}_{h}$ e $\mathbf{F}_{q}$ são, respectivamente, os vetores de carregamento térmico devido à geração interna de calor, convecção e ao fluxo prescrito. $\mathbf{K}_{\mathrm{T}}$ representa a matriz de condutividade térmica global e $\mathbf{F}_{\mathrm{T}}$ o vetor de carregamento térmico global.

Assim, com base no sistema de coordenadas apresentado na Figura 2.4, as matrizes que compõem o sistema algébrico para o problema térmico podem ser escritas como

$$
\begin{aligned}
\mathbf{K}_{k} & =\Lambda_{e=1}^{n} \mathbf{k}_{k}^{e}=\Lambda_{e=1}^{n} 2 \pi \int_{z} \int_{r} \mathbf{B}^{T} \mathbf{C}_{\mathrm{T}} \mathbf{B} r \mathrm{~d} r \mathrm{~d} z, \\
\mathbf{K}_{h} & =\Lambda_{e=1}^{n} \mathbf{k}_{h}^{e}=\Lambda_{e=1}^{n} 2 \pi \oint_{\Gamma_{e}} \mathbf{N}_{s}^{T} h_{s} \mathbf{N}_{s} r \mathrm{~d} \Gamma_{e}, \\
\mathbf{F}_{h} & =\Lambda_{e=1}^{n} \mathbf{F}_{h}^{e}=\Lambda_{e=1}^{n} 2 \pi \oint_{\Gamma_{e}} \mathbf{N}_{s}^{\mathrm{T}} h_{s} T_{a m b} r \mathrm{~d} \Gamma_{e}, \\
\mathbf{F}_{\dot{q}} & =\Lambda_{e=1}^{n} \mathbf{F}_{\dot{q}}^{e}=\Lambda_{e=1}^{n} 2 \pi \int_{z} \int_{r} \mathbf{N}^{\mathrm{T}} \dot{q} r \mathrm{~d} r \mathrm{~d} z, \\
\mathbf{F}_{q} & =\Lambda_{e=1}^{n} \mathbf{F}_{q}^{e}=\Lambda_{e=1}^{n} 2 \pi \oint_{\Gamma_{e}} \mathbf{N}^{\mathrm{T}} q r \mathrm{~d} \Gamma_{e},
\end{aligned}
$$

onde

$\mathbf{N}_{s}$ : Funções de forma $\mathbf{N}$ no contorno do elemento;

$h_{s}:$ Coeficiente de troca de calor por convecção;

$T_{a m b}:$ Temperatura ambiente.

Na equação 2.45, o termo de geração de calor interno $\dot{q}$ estabelece o acoplamento entre os problemas elétrico e térmico. Esta geração de calor, que é causada por efeito resistivo (efeito Joule)(BASTOS; SADOWSKI, 2003) devido ao fluxo de corrente elétrica que circula em $\Omega$, é definida como (ANANTHASURESH, 2003):

$$
\dot{\mathbf{q}}=\bigwedge_{e=1}^{n} \dot{q}=\bigwedge_{e=1}^{n} \phi_{e}^{\mathrm{T}} \mathbf{B}^{\mathrm{T}} \mathbf{C}_{\mathrm{E}} \mathbf{B} \phi_{e}
$$

Além disso, as condições de contorno de fluxo prescrito e de convecção, presentes nas equações 2.43, 2.44 e 2.46, são apresentadas de modo que ao se linearizar a condição de contorno de radiação térmica, os termos $q$ e $h_{s}$ podem ser substituídos por $q_{a p}$ e $h_{a p}$. Assim, 
é possível estudar um problema que envolva o fenômeno da radiação através de um sistema de equações lineares.

Nesta seção, vale ressaltar que, a radiação térmica, como se sabe, é um mecanismo de transferência de calor não-linear. Estudar problemas térmicos envolvendo condições de contorno de radiação na sua forma explícita implica utilizar métodos numéricos específicos, como por exemplo o método Monte Carlo (YANG; TANIGUCHI; KUDO, 1995), para se abordar a nãolinearidade do problema. Outro complicador para a análise da radiação térmica é a situação em que há mais de uma superfície irradiante e/ou quando este mecanismo ocorre no interior de invólucros (enclosure radiation). Neste caso, Reddy e Gartling (1994) apresentam um algoritmo para o cálculo dos fatores de forma envolvidos no problema e esclarece que tais fatores de forma são calculados através de programas específicos que, geralmente, não fazem parte do pacote básico de um programa comercial em elementos finitos. Mais detalhes sobre as complicações da radiação térmica, bem como métodos numéricos para resoluções de problemas envolvendo este mecanismo podem ser obtidos em (SIEGEL; HOWELL, 1992).

Para o modelo compósito, a formulação em elementos finitos é a mesma já apresentada, alterando-se a definição das matrizes constitutivas $\mathbf{C}_{\mathrm{E}}$ e $\mathbf{C}_{\mathrm{T}}$ que passam a depender da orientação $\theta$ do material constituinte em relação ao sistema global de referência. Neste trabalho é adotado um material ortotrópico para otimização no molde com material compósito. Assim,

$$
\mathbf{C}_{\mathrm{E}}=\mathbf{C}_{\mathrm{E}}(\theta)=\mathbf{R}(\theta)^{T} \mathbf{C}_{0_{\mathrm{E}}} \mathbf{R}(\theta)
$$

e

$$
\mathbf{C}_{\mathrm{T}}=\mathbf{C}_{\mathrm{T}}(\theta)=\mathbf{R}(\theta)^{T} \mathbf{C}_{0_{\mathrm{T}}} \mathbf{R}(\theta),
$$

onde $\mathbf{C}_{0_{\mathrm{T}}}$ e $\mathbf{C}_{0_{\mathrm{E}}}$ podem ser escritas como

$$
\mathbf{C}_{0_{\mathrm{T}}}=\left[\begin{array}{cc}
\kappa_{x} & 0 \\
0 & \kappa_{y}
\end{array}\right] \quad \text { e } \quad \mathbf{C}_{0_{\mathrm{E}}}=\left[\begin{array}{cc}
\sigma_{x} & 0 \\
0 & \sigma_{y}
\end{array}\right]
$$

e $\mathbf{R}(\theta)$ é dada por

$$
\mathbf{R}(\theta)=\left[\begin{array}{cc}
\cos (\theta) & \operatorname{sen}(\theta) \\
-\operatorname{sen}(\theta) & \cos (\theta)
\end{array}\right]
$$

Dessa forma, basta utilizar as matrizes constitutivas com as propriedades rotacionadas para resolver o problema eletro-térmico considerando material compósito.

Além disso, como já citado na seção 1.4, dois modelos computacionais foram implementados, sendo um modelo bidimensional e outro axissimétrico. Devido a semelhança matemática 
entre as formulações em elementos finitos dos problemas elétrico e térmico no modelo bidimensional e axissimétrico, optou-se apenas pela apresentação detalhada da formulação axissimétrica. Para exemplificar essa semelhança, é apresentada na equações 2.52 a formulação das matrizes globais de condutividade térmica para o caso bidimensional, que utiliza coordenadas cartesianas.

$$
\mathbf{K}_{k}=\Lambda_{e=1}^{n} \mathbf{k}_{k}^{e}=\bigwedge_{e=1}^{n} \int_{\Omega_{e}} \mathbf{B}^{T} \mathbf{C}_{\mathrm{T}} \mathbf{B} \mathrm{d} \Omega_{e}
$$




\section{Formulação do Problema de Otimização Topológica Aplicada à Área de Transferência de Calor}

\subsection{Introdução}

O conceito de otimização está presente em diversas áreas do conhecimento, como por exemplo na Economia, Medicina, Biologia, Física, Química e principalmente nas Engenharias. Um processo de otimização consiste na busca sistemática (através de algoritmo) e racionalizada (consistente com as teorias da área aplicada) de uma solução ótima, dentro de um espaço de soluções possíveis, de modo a alcançar um ou mais objetivos e atender restrições de um problema qualquer.

Na otimização estrutural existem, basicamente, três tipos de abordagem: a paramétrica, a de forma e a topológica. Na otimização paramétrica, assume-se uma forma pré-definida para a estrutura e toma-se como variáveis de projeto um ou mais parâmetros da estrutura. A figura 3.1 ilustra este tipo de otimização para um dissipador térmico em microdispositivos, em que a área da seção transversal de cada barra é considerada como variável de projeto. Neste caso, o problema de otimização consiste na determinação dos valores ótimos da área da seção transversal de cada barra que maximizem a transferência de calor da fonte quente para a fonte fria a partir de uma restrição de volume total da estrutura.

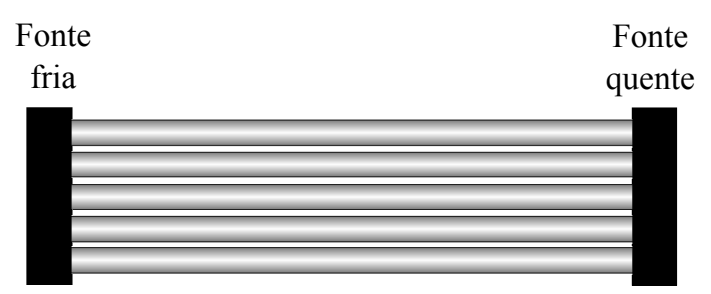

(a) Estrutura inicial.

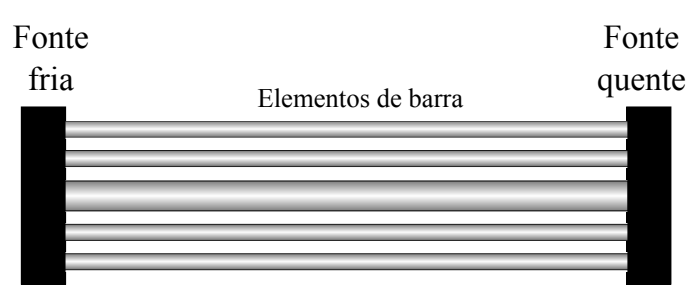

(b) Estrutura otimizada.

Figura 3.1: Otimização de forma parametrizada pela área da seção transversal dos dissipadores de calor.

Na otimização de forma, aplicada principalmente em estruturas contínuas, os contornos externos da estrutura são parametrizados por curvas, em que os parâmetros dessas curvas 
representam as variáveis de projeto na otimização. A Figura 3.2 apresenta um exemplo de otimização de forma aplicada a tubos micro-aletados utilizados para intensificação da troca de calor no interior de caldeiras (BERGLES, 2002). Trata-se de uma técnica mais genérica que a anterior uma vez que a forma externa da estrutura é alterada.

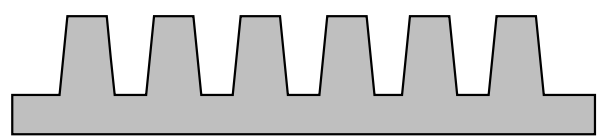

(a) Estrutura inicial.

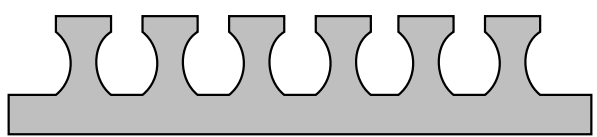

(b) Estrutura otimizada.

Figura 3.2: Otimização de forma com a qual altera-se o contorno da estrutura.

Finalmente, a última abordagem apresentada na Figura 3.3 consiste na técnica de otimização topológica. Esta técnica pode ser aplicada tanto em estruturas contínuas, quanto em discretas. Em estruturas discretas formadas por treliças ou barras, busca-se a melhor distribuição espacial destes componentes ou uma melhor conectividade entre eles. Em estruturas contínuas, busca-se a melhor distribuição de material a partir de variáveis de projeto que indicam a existência ou não de material em regiões do domínio. A Figura 3.3a exemplifica a situação de uma placa com geração uniforme de calor e com temperatura $T=0^{\circ} \mathrm{C}$ prescrita em toda fronteira do domínio. Neste problema, o objetivo é determinar a geometria da estrutura que maximiza a dissipação de calor considerando um volume máximo de material. A topologia ótima da estrutura é apresentada na Figura 3.3b, onde a região escura representa o material condutor, enquanto que a região clara indica ausência de material.

Dentre as abordagens de otimização citadas, a técnica de otimização topológica é a mais genérica, uma vez que ela não requer uma estrutura inicial ou mesmo parâmetros da geometria para fornecer uma topologia ótima.

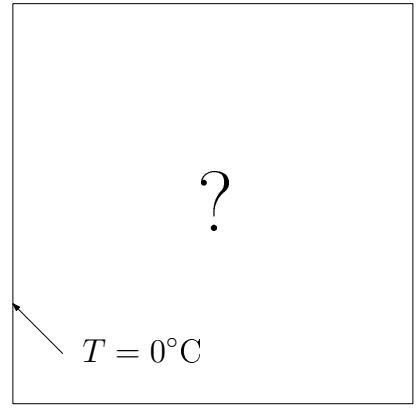

(a) Placa com geração de calor uniformemente distribuída.

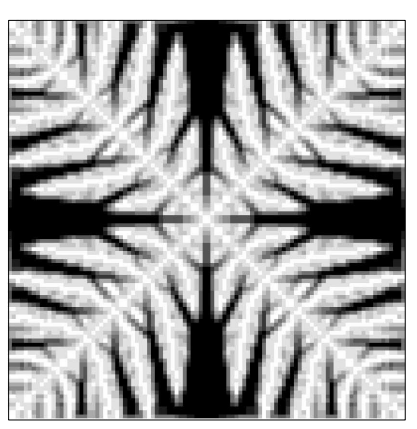

(b) Topologia ótima.

Figura 3.3: Otimização topólogia de um dissipador de calor.

Embora a Otimização Topológica (OT) tenha sua origem relacionada, principalmente, 
com os aspectos do comportamento mecânico de estruturas, como por exemplo rigidez de uma estrutura e suas frequências de vibração, esta técnica de otimização é também aplicada com critérios direcionados aos campos elétrico e térmico de uma estrutura qualquer. Neste sentido, a OT é a técnica de otimização adotada neste trabalho para se projetar moldes utilizados na sinterização por plasma, com o objetivo de se obter um determinado campo de temperatura na região da amostra sinterizada. Assim, os principais conceitos desta técnica, bem como suas aplicações na área de transferência de calor, serão vistos nas seções seguintes.

\subsection{Método de Otimização Topológica}

O conceito do Método de Otimização Topológica (MOT) reside na busca de uma distribuição ótima de material, no interior de um domínio de projeto, de maneira a extremizar (maximizar ou minimizar) uma dada função objetivo, respeitando certas restrições impostas ao problema de otimização. O material da estrutura, ao longo do processo de otimização, pode variar em cada ponto do domínio entre ar (ausência de material) e sólido (presença de material), desse modo a densidade do material pode assumir valores intermediários entre ar e sólido, de acordo com um modelo de material. No caso de problemas térmicos, a busca da distribuição ótima de material tem como objetivo a maximização da condutividade térmica da estrutura, considerando restrições de volume de material.

A procura pela distribuição ótima de material é realizada através de um algoritmo computacional que combina um método de otimização (programação linear, quadrática, método dos gradientes conjugados, etc.) com um método numérico, geralmente o Método dos Elementos Finitos (MEF), para resolver o problema físico. A partir de um domínio de projeto discretizado em elementos finitos (subdomínios), associa-se a cada elemento um valor de densidade, de modo que a distribuição de material no interior do domínio de projeto possa ser representada pelo conjunto das pseudo-densidades formado por cada elemento.

\subsubsection{Conceitos teóricos da Otimização Topológica}

A Otimização Topológica é fundamentada em dois conceitos teóricos principais: domínio fixo estendido e modelo de material, que serão descritos a seguir.

Domínio Fixo Estendido O Domínio Fixo Estendido (DFE) é a região do espaço, limitada pelas condições de contorno naturais e essenciais do problema físico, onde a estrutura otimizada será formada. Durante o processo de otimização o MOT irá remover e adicionar 
materiais no interior do DFE até que a distribuição ótima de materiais seja encontrada, definindo portanto, a geometria da estrutura.

Na implementação numérica, o domínio fixo estendido é discretizado em elementos finitos e o modelo de elementos finitos permanece constante durante o processo de otimização, sendo alterado apenas a distribuição de material em cada elemento. Com isso, as derivadas de uma função $q$ podem ser facilmente calculadas através da expressão

$$
\frac{\partial}{\partial x_{n}} \int_{\Omega} g d \Omega=\int_{\Omega} \frac{\partial g}{\partial x_{n}} d \Omega,
$$

onde $x_{n}$ representa uma variável de projeto qualquer definida após a discretização do DFE e $g$ é uma função derivável.

Modelo de material As propriedades efetivas do material em cada elemento, considerando materiais isótropos, podem ser obtidas através da expressão

$$
C(\mathbf{x})=\chi(\mathbf{x}) C_{0}
$$

onde $C_{0}$ é a propriedade básica do material a ser distribuído e $\chi(\mathbf{x})$ é uma função que permite discretizar a distribuição de material no domínio de projeto da estrutura a ser otimizada, avaliada em cada ponto $\mathbf{x}$. Matematicamente, a função $\chi(\mathbf{x})$ pode ser escrita como

$$
\chi(\mathbf{x})=\left\{\begin{array}{lll}
1, & \text { se } & \mathbf{x} \in \Omega_{d} \\
0, & \text { se } & \mathbf{x} \in \Omega \backslash \Omega_{d}
\end{array},\right.
$$

sendo $\Omega_{d}$ a região onde há presença de material, inserida num domínio $\Omega$, conforme ilustrado na Figura 3.4.

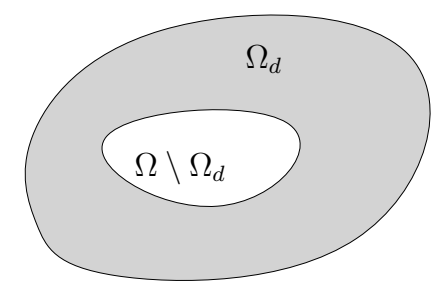

Figura 3.4: Domínio de projeto do MOT

Porém, ao se trabalhar com a função discreta $\chi(\mathbf{x})$ o problema de otimização não apresenta solução única, uma vez que esta se torna dependente da discretização do domínio de projeto $\Omega$. Dessa forma, a função discreta é substituída por uma função contínua, que faz relaxação do problema de distribuição de material e permite valores intermediários entre 0 e 1 para 
representar as propriedades do material no domínio de projeto. A princípio, propriedades com valores intermediários não teriam um significado físico, sendo apenas decorrentes de um recurso matemático para relaxação do problema. Nesse sentido utiliza-se um modelo de material que permite relaxar o problema da distribuição de material no interior do domínio de projeto, de modo que seja possível trabalhar com um problema discreto de maneira contínua. Assim, a partir de valores intermediários da variável de projeto aplicadas a um modelo de material, obtém-se as propriedades efetivas entre os materiais, que geralmente são ar (ausência de material) e sólido (presença de material).

Na literatura existem diversos modelos de materiais para o cálculo das propriedades efetivas e que podem ser implementados no MOT, sendo os principais: modelo baseado em microestruturas que envolve o método da homogeneização (HASSANI; HINTON, 1999), e modelos artificiais baseado em pseudo-densidades, como por exemplo o SIMP (Solid Isotropic Material with Penalization)(BENDSøE; SIGMund, 2003). Neste trabalho, em todas as implementações foi utilizado o modelo de material SIMP e por esta razão este modelo será brevemente discutido a seguir.

Método das densidades O método das densidades é um modelo de material que consiste numa equação que define as propriedades efetivas do material a partir de valores de pseudodensidades (variáveis de projeto) em cada ponto do domínio e das propriedades do material base. Esta equação é dada por

$$
C(\mathbf{x})=\rho(\mathbf{x}) C_{0},
$$

onde $\rho(\mathbf{x})$ pode ser interpretada como uma função de distribuição contínua de pseudo-densidades, que define a quantidade de material existente numa dada região do domínio, de modo que $0<\rho(\mathbf{x}) \leq 1$ e $\mathbf{x} \in \Omega$. Com isso, a densidade do material pode variar de um valor próximo de 0 (para evitar problemas numéricos) que indica ausência de material, até o valor 1, que indica total presença de material e que, portanto, assume as propriedades do material base.

A relaxação do problema através da ocorrência de valores intermediários para a variável de projeto $\rho(\mathbf{x})$, pode resultar em soluções com regiões formadas por materiais com propriedades intermediárias. Como citado anteriormente, valores intermediários para a variável de projeto e, por conseguinte, para as propriedades físicas do material, não apresentam um significado físico, sendo apenas consequência da formulação matemática. O excesso de valores intermediários para $\rho(\mathbf{x})$ pode dificultar a interpretação dos resultados e inviabilizar o processo de fabricação da estrutura otimizada. Dessa forma, o que se busca ao final da otimização são variáveis de projeto com valores próximos de 1 e 0 . Assim, para minimizar o excesso de valores intermediários de $\rho(\mathbf{x})$, problema conhecido como "escala de cinza", tais valores são 
penalizados da seguinte maneira (BENDSøE, 1989; ZHOU; ROZVANY, 1991; MLEJNEK, 1992)

$$
C(\mathbf{x})=\rho(\mathbf{x})^{p} C_{0},
$$

onde $p$ é o fator de penalização das pseudo-densidades intermediárias.

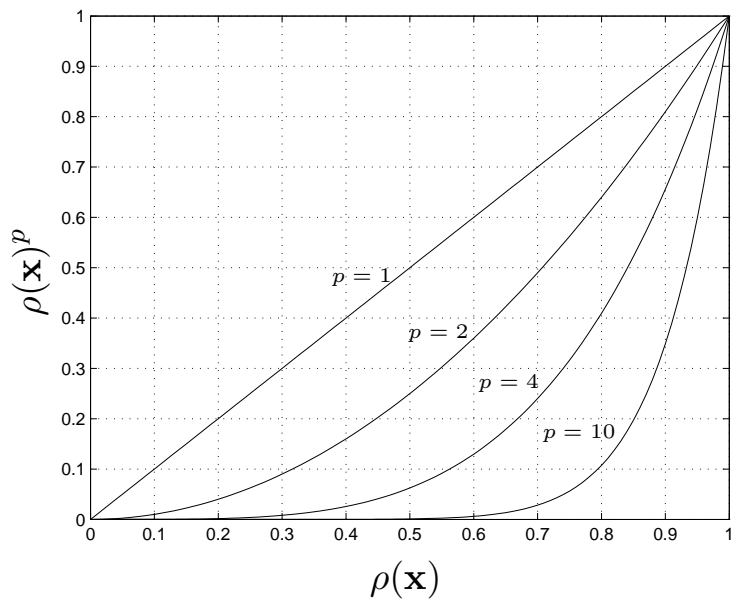

Figura 3.5: Função que define valores intermediários para as propriedades efetivas do material.

É importante notar que valores relativamente altos para o fator $p$ (ver Figura 3.5) pode aproximar o problema contínuo ao problema discreto, retornando ao problema de unicidade de solução devido à aproximação da natureza discreta da variável de projeto.

Neste trabalho, este modelo de material será utilizado tendo como $C_{0}$ as propriedades de condutividade elétrica e térmica dos materiais envolvidos no problema de otimização.

Nas implementações para molde compósito, as propriedades efetivas estão associadas a uma direção $\theta$, a qual é parametrizada pelas variáveis de projeto $v$, tal que $0 \leq v \leq 1$. Com isso a equação 3.5 pode ser rescrita como

$$
C(\mathbf{x})=\rho(\mathbf{x})^{p} C_{\theta},
$$

onde $\mathbf{C}_{\theta}=\mathbf{R}(\theta)^{T} \mathbf{C}_{0} \mathbf{R}(\theta)$ e $\mathbf{R}(\theta)$ representa a matriz de rotação descrita na seção 2.4.

A parametrização da variável de projeto $v \operatorname{com} \theta$ foi realizada de duas maneiras nas implementações. Uma utiliza $v$ atuando diretamente sobre $\theta$, tal que $\theta=v \pi$ e outra que segue o método OMD (Otimização de Material Discreta) proposto por Lund (2009) e apresentada na seção 4.3 . 


\subsubsection{Aspectos práticos da Otimização Topológica}

Com a relaxação do problema de distribuição de material dada pela equação 3.4, pode-se obter soluções que, embora matematicamente possíveis, do ponto de vista da Engenharia são inviáveis ou sem um significado físico. Assim, algumas soluções podem apresentar um padrão característico de distribuição de material classificado como: Instabilidade de tabuleiro, quando a distribuição apresenta um aspecto semelhante ao de um tabuleiro de xadrez; Escala de cinza, quando a distribuição ótima apresenta uma grande região preenchida com valores intermediários do material base da estrutura. Além disso, pode ocorrer de soluções apresentarem dependência de malha de elementos finitos, ou seja, para cada discretização obtém uma topologia diferente para a estrutura.

A instabilidade de tabuleiro, embora inerente ao MOT, é um fenômeno característico de campos tensoriais e, portanto, não verificada em problemas de campos escalares, que é o caso deste trabalho. Detalhes sobre a instabilidade de tabuleiro podem ser obtidos em (BENDSøE; SIGMUND, 2003).

As demais instabilidades, por serem decorrentes da relaxação do problema, serão vista com mais detalhes nesta seção.

Escala de cinzas Conforme citado no início desta seção, a relaxação da distribuição de material pode causar o surgimento de regiões com quantidade significativa de materiais intermediários, fenômeno este conhecido na literatura como "escala de cinza". Para minimizar a ocorrência de escala de cinza na solução ótima realiza-se a penalização de valores intermediários da variável de projeto. Essa penalização varia de acordo com o modelo de material e, no caso do modelo SIMP, a penalização é realizada pelo fator de penalidade $p$ (ver equações 3.5 e 3.6).

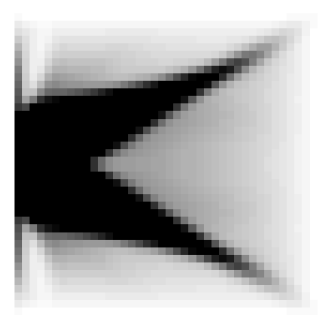

(a) $p=1,5$

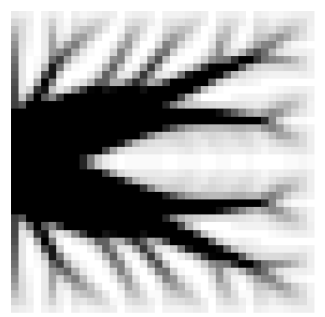

(b) $p=2,0$

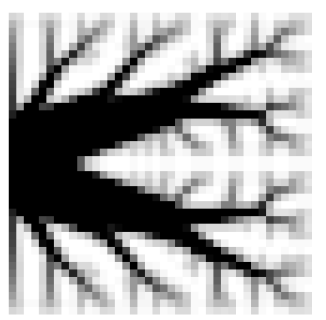

(c) $p=3,0$

Figura 3.6: Influência da penalização na solução ótima de um problema de condutividade térmica.

Com a implementação do modelo SIMP baseado na penalização dos valores interme- 
diários, soluções ótimas que representam mínimos locais podem ser encontradas (SIGMUND; PETERSSON, 1998; BENDSØE; SIGMUND, 1999), conforme exemplificado na Figura 3.6 para um problema de condutividade térmica. Para cada um dos casos apresentados na Figura 3.6, o valor de $p$ é mantido constante durante o processo de otimização. Como pode se observar, a medida em que o fator de penalização aumenta, a escala de cinza é reduzida e a distribuição de material se torna mais $\operatorname{discreta}(0-1)$.

Em geral, o método de penalização é combinado com o método da continuação que consiste em se aumentar o fator $p$ ao longo do processo iterativo (BENDSØE; SIGMUND, 2003). A principal função do método da continuação é fazer com que a solução ótima do problema de otimização esteja o mais próximo possível do mínimo global da função objetivo. A Figura 3.7 ilustra esta situação.

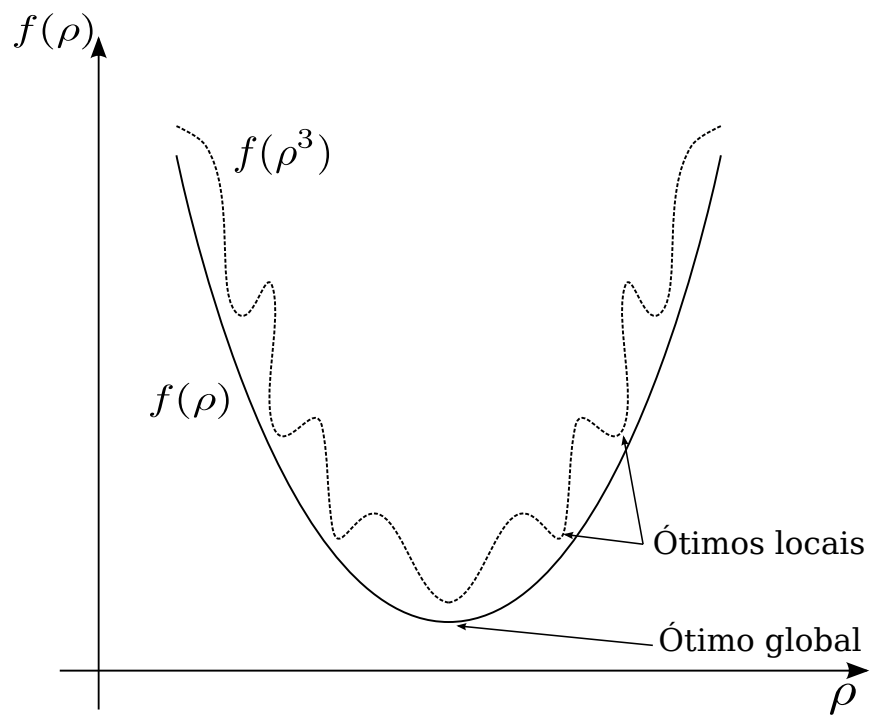

Figura 3.7: Influência do fator de penalização na função objetivo em problemas de OT.

Geralmente, no método da continuação o valor inicial de $p$ é adotado como sendo igual a 1 e aumentado gradativamente até um valor limite, que depende do tipo de problema que se deseja otimizar. É importante ressaltar que um aumento excessivo no valor de $p$ pode levar o problema a uma natureza discreta e, assim, incorrer na dependência da discretização do domínio.

Dependência da malha O problema de dependência da malha consiste na sensibilidade da solução ótima em relação a discretização do domínio fixo estendido. Em outras palavras, uma solução obtida com uma malha relativamente grosseira pode não ser obtida quando esta malha é refinada, devido a existência de múltiplos mínimos locais no problema de otimização.

Para se minimizar a dependência de malha na solução ótima, várias técnicas tem sido 
utilizadas, tais como: restrição de perímetro (HABER; JOG; BENDSøE, 1996) , filtros espaciais (BOURDIN, 2001), aumento no número de restrições do problema de otimização (RUBIO, 2005) e técnicas de projeção (BRUNS; TORTORELLI, 2001; GUEST; PRÉVOST; BELYTSCHKO, 2004).

Neste trabalho, a técnica de projeção proposta por Bruns e Tortorelli (2001) é implementada e sua formulação apresentada na seção 4.6.

\subsubsection{Revisão bibliográfica do MOT}

A técnica de Otimização Topológica foi proposta com a publicação do artigo Generating optimal topologies in structural design using a homogenization method de Bendsøe e Kikuchi (1988) em que os autores apresentam um método baseado na parametrização das propriedades do material e num domínio de projeto definido como Domínio Fixo Estendido (DFE). O desenvolvimento desta técnica foi inspirado, principalmente, no trabalho de Cheng e Olhoff (1981), quando os primeiros estudos sobre modelos de materiais baseado em microestrutura começaram a ser realizados. A utilização do conceito de microestrutura representa, no problema de otimização topológica, uma maneira de relaxação do funcional que indica se há ou não presença de material no interior de um elemento finito. Mais detalhes sobre relaxação dos funcionais em problemas de otimização estrutural podem ser encontradas nos trabalhos de Khon e Strang (1986a, 1986b, 1986c).

Com os trabalhos de Bendsøe (1989) e Rosvany, Zhou e Birker (1992), uma maneira alternativa ao modelo baseado em microestruturas é apresentada para se realizar a relaxação do variacional por meio de um modelo de material baseado na distribuição de pseudo-densidades. Este modelo, juntamente com os trabalhos de Suzuki e Kikuchi (1991) e Olhoff, Bendsøe e Rasmussen (1991), favoreceram a difusão do Método de Otimização Topológica (MOT) e motivaram a realização de diversos trabalhos acadêmicos que contribuiram para a consolidação do MOT como uma eficiente técnica de otimização estrutural.

Amplamente empregado no estudo de problemas estruturais, como por exemplo na maximização da rigidez (BENDSøE; KIKUCHI, 1988; BENDSøE, 1995; SIGMUND, 2001), o MOT também é aplicado para a resolução de problemas térmicos. A Figura 3.8 apresenta um exemplo de aplicação em problemas de condutividade térmica (BENDSøE; SIGMUND, 2003), em que se busca maximizar a condutividade térmica de um componente estrutural sujeito a geração de calor uniformemente distribuído no domínio.

Uma vez que este trabalho está fortemente relacionado com a área térmica, a revisão bibliográfica do Método de Otimização Topológica, apresentada nesta seção, é direcionada para aplicações desta técnica em problemas de condutividade térmica.

Em geral, problemas de condução térmica podem ser dividos em dois tipos. O primeiro 


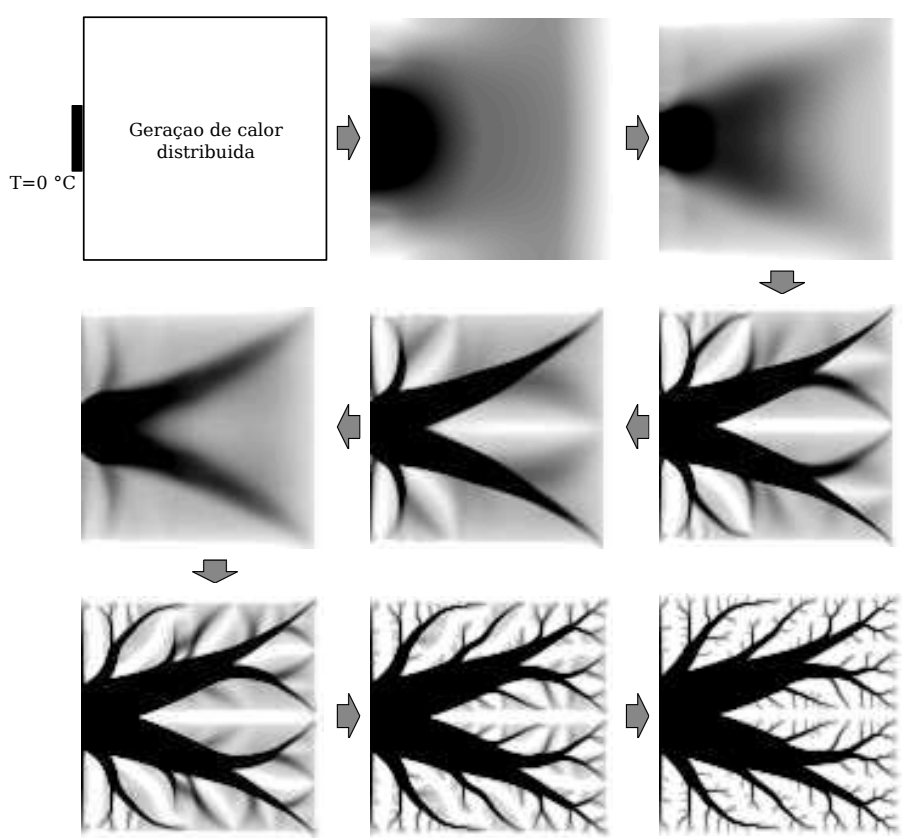

Figura 3.8: Exemplo do MOT num problema de condutividade térmica, em que se busca maximizar a dissipação térmica numa placa com geração uniforme de calor e fronteiras isoladas termicamente, exceto num trecho com temperatura prescrita.

com condições de carregamento fixas ou com independência da estrutura, ou seja, o carregamento térmico se mantém constante ao longo do processo de otimização topológica. O segundo tipo refere-se a problemas cujo o carregamento térmico é influenciado pela geometria da estrutura, como por exemplo geração de calor devido a resistividade elétrica ou condição de convecção no contorno da estrutura.

Um dos primeiros estudos voltado à características exclusivamente térmicas de uma dada estrutura é o publicado por Bendsøe e Sigmund (2003). Neste estudo, o MOT é empregado para maximizar a dissipação de energia térmica gerada de maneira uniforme, e sem dependência estrutural, sobre uma placa quadrada, em que suas laterais estão em condição adiabática, exceto em um pequeno trecho (ver Figura 3.8). Como resultado para este problema, tem-se uma estrutura com aspecto semelhante à "raiz de uma planta", resultado este comumente utilizado como "benchmark" em algoritmos relacionados com problemas de condutividade térmica. Donoso e Sigmund (2004) estudaram problemas modelados pela equação de Poisson utilizando o moldelo de material SIMP e o método das assíntotas móveis para otimizar as variáveis de projeto.

Para problemas de transferência de calor sem dependência estrutural, foram analisados dois exemplos numéricos com geração de calor semelhante ao da figura 3.8, sendo um com condições de contorno de Dirichlet (temperatura prescrita) e outro com condições de Neumman (fluxo de calor). O primeiro caso consistiu no exemplo "benchmark" de Bendsøe e Sigmund (2003) e para o segundo caso, o objetivo foi de maximixar o fluxo de calor no mesmo ponto 
onde a temperatura foi prescrita no primeiro exemplo. Ainda no mesmo exemplo numérico proposto por Bendsøe e Sigmund (2003), Zhang e Liu (2008) utilizam o SIMP e programação quadrática sequencial para resolver este exemplo, e apresentam um método para regularizar a geometria final obtida com MOT. Esta regularização da solução ótima é obtida através da combinação de técnica de suavização do contorno da estrutura com procedimentos de otimização de forma. Com isso, transforma-se a estrutura conceitual numa estrutura com aplicações na área de Engenharia.

Para problemas com dependência estrutural Iga et al. (2009) desenvolveram um método que identifica os contornos da estrutura a medida em que esta se modifica e aplica as condições de contorno que ocorrem na fronteira estrutural, como por exemplo de convecção. Esta identificação é realizada através de uma função que localiza regiões com escala de cinza, regiões estas que representam a transição de uma região sólida para uma região vazia. Neste estudo, diversos exemplos numéricos que envolvem condução, geração interna de calor e convecção térmica são analisados, considerando inclusive geração de calor com dependência estrutural. Além disso, é proposto um método para estimar o coeficiente de transferência de calor por convecção para estruturas aletadas, parametrizadas pela altura das aletas e espaçamento entre elas, considerando ainda o número de Nusselt e a equação de Dittus e Boelter.

Além dos métodos tradicionais baseado em modelo de materiais, diferentes métodos utilizados em otimização topológica tem sido propostos para avaliar problemas de condutividade térmica. Li et al. (2004) utilizam o método evolucionário para análise de problemas térmicos em regime estacionário onde se busca minimizar a temperatura num ponto qualquer do domínio, considerando o carregamento dado pela imposição de temperatura prescrita em pontos sobre a fronteira do domínio de projeto. Utilizando o mesmo conceito de método evolucionário, neste caso o BESO (bidirectional evolucionary structural optimization), Gao et al. (2008) analisam problemas térmicos com e sem dependência estrutural e comparam seus resultados com aqueles obtidos através do método tradicional que utiliza modelo de material. Os exemplos numéricos consideram a geração de calor com dependência da variável de projeto semelhante ao modelo de material SIMP, porém sem penalização. No caso dos métodos evolucionários, a remoção ou inclusão de material no domínio de projeto ocorre através de um critério baseado na sensibilidade de cada elemento. Segundo os autores, elementos com sensibilidade elevada são removidos e com baixa sensibilidade são adicionados à estrutura.

\subsection{Formulação contínua do problema de otimização}

Apesar de haver três abordagens para otimização do molde do processo de sinterização por plasma, são utilizadas neste trabalho duas formulações para os problemas de otimização. 
Na abordagem de molde prismático, o problema é o puramente térmico e com o objetivo de minimizar o potencial térmico da estrutura, o que reflete na maximização da dissipação térmica e na uniformização da distribuição de temperatura. Em geral, a função para maximizar a dissipação térmica é baseada na forma variacional da equação de calor (Equação 2.21) (IGA et al., 2009).

Assim, a formulação do problema de otimização para o molde prismático é dada por

$$
\begin{array}{ll}
\underset{\rho}{\operatorname{minimizar}} & \frac{1}{2} a(T, T)-l(T) \\
\text { tal que } & \\
& a(T, T)=l(T) \\
& \int_{\Omega} \rho(\mathbf{x}) \mathrm{d} \Omega \leq V_{\max } \\
& 0<\rho(\mathbf{x}) \leq 1
\end{array}
$$

onde $V_{\max }$ representa a restrição de volume da estrutura.

Já nas abordagens para moldes com espessura de parede variável e moldes compósitos, há o objetivo (em ambos os casos) de se obter um gradiente específico de temperatura na região da amostra. Assim, para os problemas de otimização dessas duas abordagens, a função objetivo foi definida como sendo uma combinação entre a função que minimiza o potencial térmico e uma função que busca impor um dado gradiente de temperatura na região da amostra.

Definindo $C_{1}$ como a função para a minimização do potencial térmico, ou seja,

$$
C_{1}=\frac{1}{2} a(T, T)-l(T)
$$

e $C_{2}$ como função objetivo utilizada para se obter um gradiente de temperatura desejado e definida como

$$
C_{2}=\int_{0}^{l}\left(\beta_{c a l}-\beta_{o b j}\right)^{2} \mathrm{~d} l,
$$

sendo $\beta_{\text {cal }}$ o gradiente de temperatura calculado numericamente, $\beta_{o b j}$ o gradiente te temperatura que se busca obter na região da amostra e $l$ a altura da amostra. A combinação entre $C_{1}$ e $C_{2}$ para formar a função objetivo do problema de otimização é formulada como 


$$
\underset{\rho, v}{\operatorname{minimizar}} w \ln C_{1}+(1-w) \ln C_{2}
$$

tal que

$$
\begin{aligned}
& a(\phi, \phi)=l(\phi) \\
& a(T, T)=l(T) \\
& \int_{\Omega} \rho(\mathbf{x}) \mathrm{d} \Omega \leq V_{\max } \\
& 0 \leq \rho(\mathbf{x}) \leq 1 \\
& 0 \leq v(\mathbf{x}) \leq 1,
\end{aligned}
$$

onde $w$ é o fator de ponderação entre as duas funções e $v(\mathbf{x})$ indica a orientação, em relação ao sistema de coordenadas global, do material ortotrópico adotado para otimização de molde compósito. 


\section{Implementação Numérica dos Problemas de Otimização}

Neste capítulo são apresentadas as técnicas computacionais implementadas no algoritmo de otimização para lidar com características específicas dos tipos de problemas físicos analisados. No problema elétrico ocorre a geração de calor, que é um efeito essencialmente volumétrico e é causado pelo fluxo de corrente elétrica. No problema térmico tem-se condições de contorno, tais como fluxo de calor e convecção aparentes, que atuam nas fronteiras da estrutura, a qual varia ao longo do processo de otimização. Em ambos os problemas, existem amostras que são compostas de material MGF e uma rotina para considerar a gradação das propriedades é também implementada.

Além disso, tem-se a implementação da sensibilidade da função objetivo do problema de otimização e de técnicas para contornar problemas inerentes ao MOT, tais como dependência de malha e escala de cinza.

Assim, todas as técnicas implementadas neste trabalho são descritas neste capítulo.

\subsection{Formulação de geração interna de calor com depen- dência estrutural}

A geração interna de calor é um carregamento térmico volumétrico, em que a quantidade de calor gerada é dependente da existência ou não de material em regiões do domínio de projeto e, portanto, dependente da densidade volumétrica (indicada pelas variáveis de projeto). Neste trabalho, assume-se que o carregamento térmico de geração de calor é proporcional à densidade do material. Com isso, a carga térmica de geração interna de calor é formulada, utilizando a função característica $\chi_{\Omega}$ (ver equação 3.3 ), como

$$
\int_{\Omega} \dot{q} \tilde{T} \mathrm{~d} \Omega=\int_{\Omega} \chi_{\Omega} \dot{q} \tilde{T} \mathrm{~d} \Omega
$$

onde $\dot{q}$ é a geração interna de calor em cada ponto no interior do domínio fixo estendido.

Aplicando o modelo de relaxação ao domínio de projeto, a geração interna de calor é 
expressa da seguinte forma

$$
\dot{q}=\rho_{e} \dot{q}_{0}
$$

onde $\rho_{e}$ é a função que define o valor da variável de projeto (pseudo-densidade) no interior de cada elemento e $\dot{q}_{0}$ a geração interna de calor por unidade de volume (calculada conforme equação 2.47) para um elemento totalmente preenchido, ou seja, $\rho_{e}=1$.

Com isso, o vetor de carregamento térmico devido a geração de calor, considerando dependência estrutural, é formulado como sendo

$$
\mathbf{F}_{\dot{q}}=\bigwedge_{e=1}^{n} \mathbf{F}_{\dot{q}}^{e}
$$

sendo

$$
\mathbf{F}_{\dot{q}}^{e}=2 \pi \int_{z} \int_{r} \mathbf{N}^{\mathbf{T}} \rho_{e} \dot{q}_{0} r \mathrm{~d} r \mathrm{~d} z
$$

Assim, utilizando a equação 4.4, a carga térmica de geração interna de calor é uma função da variável de projeto $\rho(\mathbf{x})$. Com esta formulação, o vetor de carregamento varia em resposta à mudança da distribuição de material ao longo do processo de otimização.

\subsection{Análise das condições de contorno com dependência estrutural}

No processo de sinterização por plasma uma das principais condições de contorno é a radiação térmica, que neste trabalho é linearizada. Como resultado desta linearização, tem-se dois termos que se assemelham matematicamente a um fluxo de calor prescrito e uma condição de convecção, conforme apresentado na seção 2.3.2. Estes dois tipos de condições ocorrem nos contornos da estrutura, a qual sofre contínua modificação durante um processo de otimização topológica. A cada iteração do processo de otimização, ocorre uma nova distribuição de material no interior do domínio de projeto, alterando a geometria da estrutura. De fato, a geometria da estrutura se modifica para atender aos requisitos da função objetivo e restrições do problema de otimização. Esta modificação na geometria é um complicador ao se trabalhar com os chamados problemas de valor no contorno, uma vez que as condições de contorno devem "acompanhar" os contornos estruturais na medida em que estes se alteram.

Para se trabalhar com problemas que envolvem condições de contorno dependentes da geometria da estrutura, alguns métodos tem sido propostos. Chen e Kikuchi (2001) apresentam um método baseado em cargas fictícias para otimização de estruturas sujeitas à pressão hidrostática. Bruns (2007), ao analisar instabilidades causadas por condições de contorno de convecção, apresenta um modelo simples que considera apenas a convecção nas face dos 
elementos finitos. Yin e Ananthasuresh (2002) estudaram micromecanismos atuados eletrotermicamente considerando condições de convecção em que o coeficiente de transferência de calor é modelado como uma propriedade do material. Iga et al. (2009) propõem um modelo baseado numa função degrau $H\left(\rho_{e}\right)$ para identificar as fronteiras estruturais que se alteram durante o processo de otimização. Essas fronteiras são identificadas pelas áreas com materiais com pseudo-densidades intermediárias (áreas com escala de cinza) que surgem entres regiões com material (pseudo-densidades próximas de 1) e sem material (pseudo-densidades próximas de 0$)$.

De um modo geral os modelos propostos para avaliar o coeficiente $h$ de transferência de calor por convecção seguem o seguinte padrão

$$
h=f(x) h_{0},
$$

onde $f$ é uma função que depende essencialmente da variável de projeto $\rho$, e $h_{0}$ é o valor de referência do coeficiente de transferência de calor. Este tipo de análise pode ser estendida para o caso de fluxo de calor, de modo a se obter

$$
q=f(x) q_{0}
$$

Neste trabalho, para lidar com as condições de fluxo de calor e convecção obtidas através da linearização da radiação térmica dois métodos foram implementados, sendo um proposto por Iga et al. (2009), porém realizando-se modificações na função $H\left(\rho_{e}\right)$ para identificar os contornos da estrutura a ser otimizada e outro um modelo que utiliza conceitos do SIMP e do modelo proposto por Yin e Ananthasuresh (2002). Ambos os modelos são apresentados a seguir.

\subsubsection{Modelo de convecção baseado numa função degrau}

Neste modelo a função $f(x)$ assume a seguinte forma

$$
f(x)=H(\rho),
$$

sendo $H(\rho)$ a função utilizada para identificar as fronteiras estruturais durante o processo de otimização e que neste trabalho é definida como 


$$
H(\rho)= \begin{cases}{\left[(\operatorname{sen})\left(\frac{\pi}{2} \frac{\rho}{\rho_{\text {inf }}}\right)\right]^{p_{h}}} & \text { se } \quad \rho<\rho_{\text {inf }} \\ 1 & \text { se } \quad \rho_{\text {inf }} \leq \rho \leq \rho_{\text {sup }} \\ {\left[(\operatorname{sen})\left(\frac{\pi}{2}\left(\frac{\rho-2 \rho_{\text {sup }}+1}{1-\rho_{\text {sup }}}\right)\right)\right]^{p_{h}}} & \text { se } \quad \rho_{e}>\rho_{\text {sup }},\end{cases}
$$

onde $\rho_{\text {inf }}$ e $\rho_{\text {sup }}$ são, respectivamente, os valores limites das variáveis de projeto $\rho$, utilizados para identificar as fronteiras estruturais onde são aplicadas as condições de contorno de transferência de calor. O parâmetro $p_{h}$ é o fator que penaliza valores de $\rho$ abaixo de $\rho_{\text {inf }}$ e acima de $\rho_{\text {sup }}$, conforme apresentando na Figura 4.1.

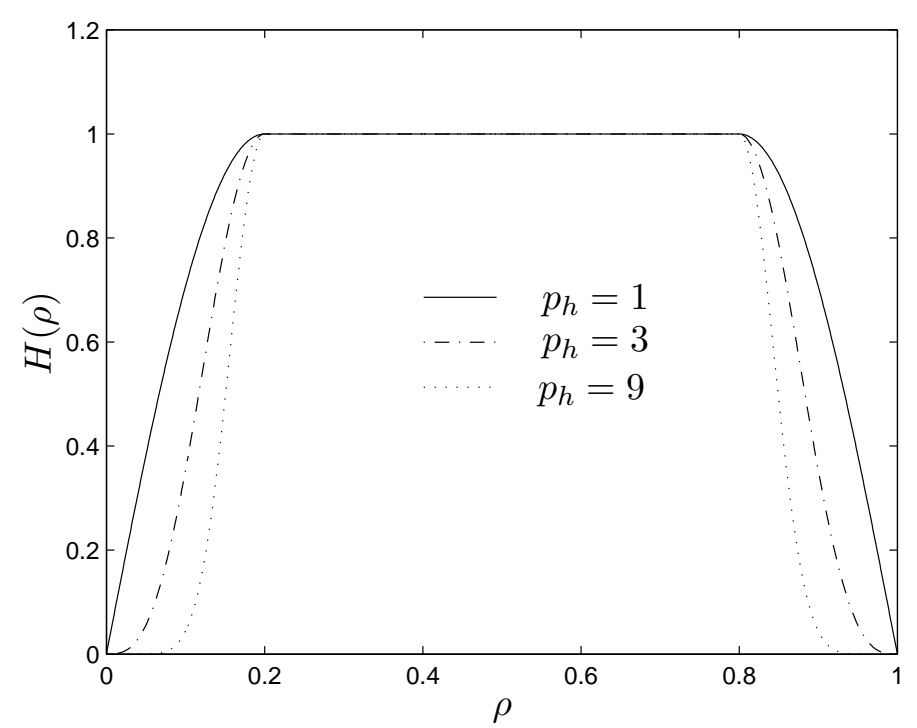

Figura 4.1: Gráfico de $H(\rho)$ para extrair as fronteiras estruturais no domínio fixo estendido considerando $\rho_{\text {inf }}=0,2$ e $\rho_{\text {inf }}=0,8$.

A Figura 4.2 ilustra a maneira pela qual as fronteiras estruturais são identificadas pela função $H(\rho)$. As condições $\rho>\rho_{\text {sup }}$ e $\rho<\rho_{\text {inf }}$ indicam, respectivamente, as regiões sólida e "vazia" do domínio de projeto, onde as condições de contorno não atuam. A região definida por $\rho_{\text {inf }} \leq \rho \leq \rho_{\text {sup }}$ é o local onde as condições de contorno irão efetivamente atuar.

Com isso, para se trabalhar com condições de contorno de convecção, inicialmente definemse coeficientes $h_{0}$ de transferência de calor para todos os nós no modelo de elementos finitos. Em seguida, utilizando a função $H(\rho)$, as condições de contorno em cada elemento podem ser extraídas a partir do valor da variável de projeto, quando esta é aplicada nos nós dos elementos (ver Equação 4.8 e seção 4.7). Assim, considerando um elemento com quatro nós, o coeficiente de transferência de calor em cada face de um elemento são aproximados da seguinte 


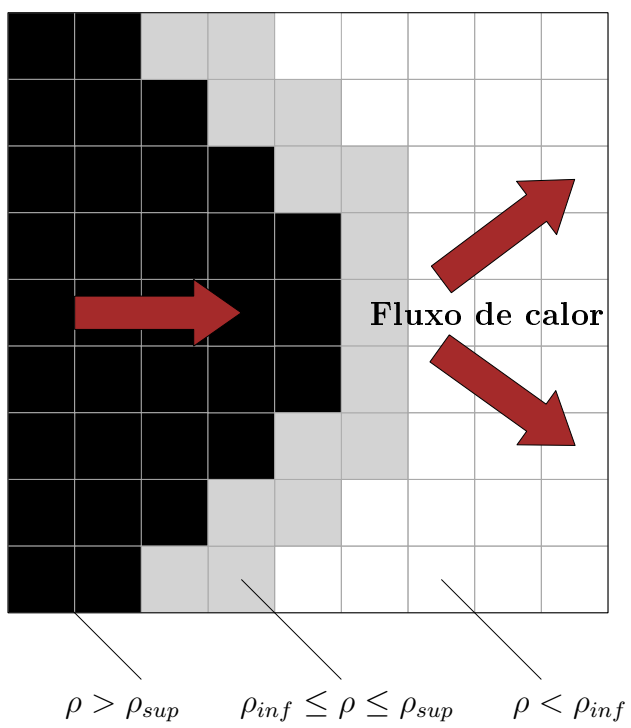

Figura 4.2: Fronteira estrutural identificada pela função $H(\rho)$.

maneira

$$
\mathbf{h}=\left[\begin{array}{cccc}
H\left(\rho_{1}\right) & 0 & 0 & 0 \\
0 & H\left(\rho_{2}\right) & 0 & 0 \\
0 & 0 & H\left(\rho_{3}\right) & 0 \\
0 & 0 & 0 & H\left(\rho_{4}\right)
\end{array}\right]\left\{\begin{array}{c}
h_{0_{1}} \\
h_{0_{2}} \\
h_{0_{3}} \\
h_{0_{4}}
\end{array}\right\}
$$

ou na forma matricial reduzida, como

$$
\mathbf{h}=\mathbf{H}(\rho) \mathbf{h}_{\mathbf{0}},
$$

onde $h$ representa o vetor de coeficientes de convecção efetiva em cada nó e $\mathbf{H}(\rho)$ a matriz da função degrau avaliada nos nós do elemento.

Com isso, as equações 2.43 e 2.44, que representam a contribuição da convecção na equação de equilíbrio do problema térmico, podem ser escritas como

$$
\begin{gathered}
\mathbf{K}_{h}=\Lambda_{e=1}^{n} \mathbf{k}_{h}^{e}\left(\rho_{e}\right)=\Lambda_{e=1}^{n} 2 \pi \oint_{\Gamma_{e}} \mathbf{N}_{s}^{\mathrm{T}}\left(\mathbf{H}\left(\rho_{e}\right) \mathbf{h}_{\mathbf{0}}\right) \mathbf{N}_{s} r \mathrm{~d} \Gamma_{e}, \\
\mathbf{F}_{h}=\Lambda_{e=1}^{n} \mathbf{F}_{h}^{e}=\Lambda_{e=1}^{n} 2 \pi \oint_{\Gamma_{e}} \mathbf{N}_{s}^{\mathrm{T}}\left(\mathbf{H}\left(\rho_{e}\right) \mathbf{h}_{\mathbf{0}}\right) T_{a m b} r \mathrm{~d} \Gamma_{e} .
\end{gathered}
$$

A mesma análise desenvolvida para a condição de convecção pode ser aplicada para a condição de fluxo de calor prescrito, de modo a se obter

$$
\mathbf{q}=\mathbf{H}(\rho) \mathbf{q}_{0} .
$$


Com isso, o vetor de carregamento térmico devido ao fluxo de calor aparente é dado por

$$
\mathbf{F}_{q_{a p}}=\Lambda_{e=1}^{n} \mathbf{F}_{q_{a p}}^{e}=\Lambda_{e=1}^{n} 2 \pi \oint_{\Gamma_{e}} \mathbf{N}^{\mathrm{T}} \mathbf{q}_{a p}^{e} r \mathrm{~d} \Gamma_{e}
$$

\subsubsection{Modelo de convecção baseado no SIMP}

No modelo baseado no SIMP a função $f(x)$ assume é expressa por

$$
f(x)=\rho_{e}^{p}(1-\gamma)
$$

sendo $\rho_{e}$ a variável de projeto penalizada pelo expoente $p$, e $\gamma$ a variável de projeto do elemento adjacente. Para se avaliar $\gamma$ é necessário realizar um mapeamento na malha de elementos finitos para se identificar os elementos adjacentes de um elemento onde se esteja analisando os coeficientes $h_{i}$ de transferência de calor, os quais são obtidos pela equação 4.16, dada por

$$
h_{i}=\rho_{e}^{p}\left(1-\gamma_{i}\right) h_{0}
$$

Com isso é possível determinar este coeficiente em cada uma da faces $i$ do elemento conforme ilustrado na Figura 4.3.

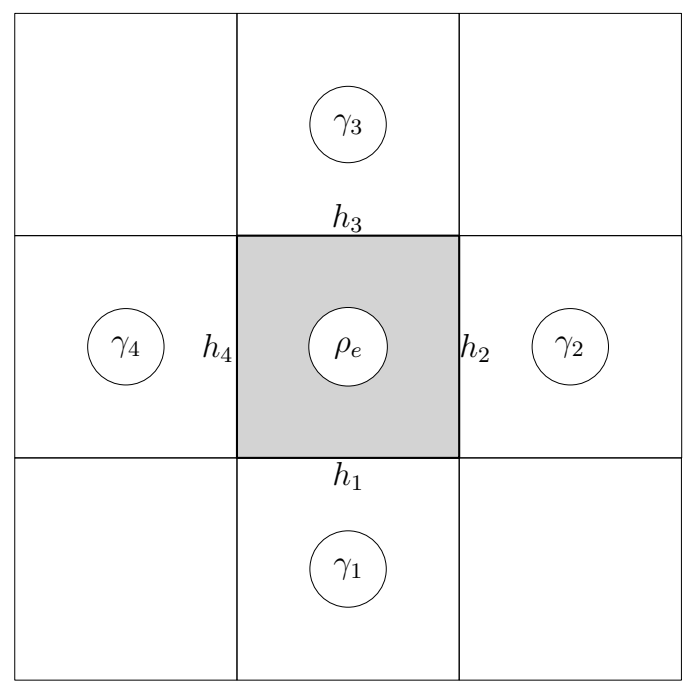

Figura 4.3: Ilustração do mapeamento sobre um elemento $e$ na malha de elementos finitos.

Com este tipo de formulação a variável $\gamma$ indica se há ou não convecção na interface entre os elementos, enquanto $\rho_{e}$ associado com $\gamma$ permite a condição de convecção parcial. Embora a convecção parcial não tenha um signifcado físico, na convergência da solução as variáveis de projeto tendem a assumir valores 0 - 1, de modo que se obtenha uma convecção total no final da otimização.

Como se verifica, ambos os modelos adotados para manter as condições de contorno atu- 
ando nas fronteiras estruturais da topologia, à medida em que esta se modifica, utilizam penalizadores. Desse modo, ao longo do processo iterativo, as condições de contorno ocorrem de maneira parcial e se intensificam quando se tem a convergência da solução e por conseguinte, uma topologia com regiões de sólido e vazios bem definida.

\subsection{Otimização com Material anisotrópico}

Para implementar a abordagem de otimização de molde compósito, foram utilizados dois modelos que envolvem a orientação das propriedades físicas do material ortotrópico adotado para compor o molde. A primeira, conforme citada na seção 3.2, é a parametrização da orientação $\theta_{i}$ pela variável de projeto $v_{i}$, tal que

$$
\theta_{i}=v_{i} \pi
$$

com $0 \leq \theta_{i} \leq \pi$ e $0 \leq v_{i} \leq 1$. Dessa maneira, a orientação das propriedades pode assumir qualquer valor entre 0 e $\pi$. O segundo modelo baseia-se no método de otimização com orientações discretas chamado Otimização de Material Discreta (OMD). Este método foi idealizado para otimização de materiais compósitos laminados empregados em estruturas em cascas (LUND, 2009; KIYONO; SILVA; REDDY, 2012). Neste trabalho, este método é utilizado para determinar a orientação das propriedades físicas em cada posição do molde empregado no processo de sinterização por plasma.

A OMD consiste num método que considera, a priori, orientações candidatas $\theta_{i}$ que definem a matriz constitutiva $\mathbf{C}_{i}$ para o material proposto. A matriz constitutiva $\mathbf{C}_{\theta}$, a qual faz parte do modelo de material descrito na equação 3.6, é obtida por meio de uma média ponderada que utiliza como pesos os fatores $w_{i}$, conforme indicado na equação 4.18.

$$
\mathbf{C}_{\theta}=\sum_{i=1}^{n_{c}} w_{i} \mathbf{C}_{i}=w_{1} \mathbf{C}_{1}+w_{2} \mathbf{C}_{2}+\cdots+w_{n_{c}} \mathbf{C}_{n_{c}}, \quad 0 \leq w_{i} \leq 1,
$$

sendo que $n_{c}$ representa a quantidade de orientações candidatas e $\mathbf{C}_{i}=\mathbf{C}_{\theta_{i}}=\mathbf{R}\left(\theta_{i}\right)^{T} \mathbf{C}_{0} \mathbf{R}\left(\theta_{i}\right)$. Os fatores $w_{i}$ são obtidos através da seguinte normalização:

$$
w_{i}=\frac{\hat{w}_{i}}{\sum_{k=1}^{n_{c}} \hat{w}_{k}}, \quad i=1, \ldots, n_{c}
$$

onde

$$
\hat{w}_{i}=\left(v_{i}^{e}\right)^{p} \prod_{j=1 ; j \neq i}^{n_{c}}\left(1-\left(v_{j}^{e}\right)^{p}\right)
$$

e $\left(v_{i}^{e}\right)$ sendo o número de variáveis de projeto atribuídas a cada elemento finito. 


\subsection{Implementação do algoritmo de otimização}

A implementação do algoritmo de otimização é realizada através do "software" Matlab, que é uma linguagem própria para o desenvolvimento de tarefas computacionais. A escolha pela implementação do MOT em ambiente Matlab se deve, não somente pela disponibilidade de licença oferecida pela Universidade de São Paulo, como também pela facilidade que esta ferramenta possui para lidar com operações matriciais, principalmente aquelas referentes à montagem e inversões de matrizes globais (na rotina do MEF). Além disso, o Matlab possui uma rotina para resolução de problemas lineares, denominada LINPROG baseada no algoritmo Simplex para otimização linear (ver Apêndice A). Esta rotina é então utilizada na implementação do MOT para resolução dos problemas lineares obtidos com a programação linear sequencial.

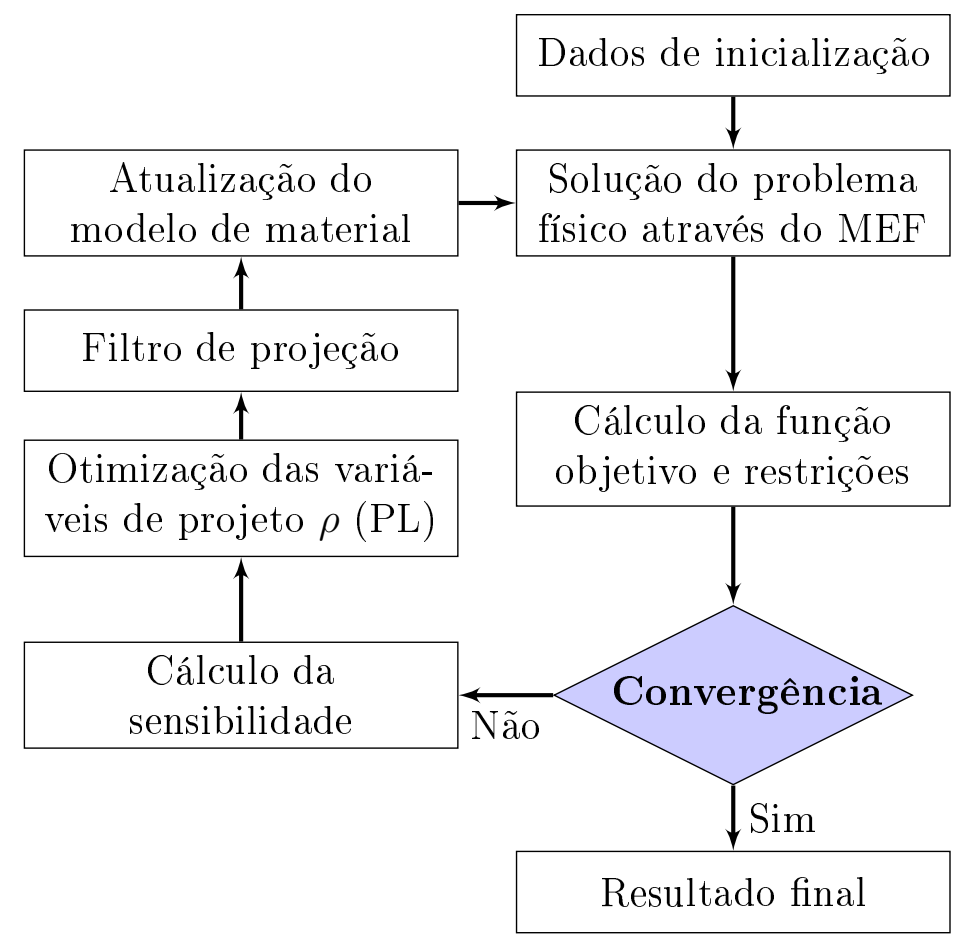

Figura 4.4: Fluxograma de implementação do algoritmo de otimização.

A implementação numérica da programação linear sequencial segue o fluxograma apresentado na Figura 4.4. Inicialmente definem-se os dados de entrada do problema de otimização, tais como: malha de elementos finitos, condições de contorno e valores iniciais das variáveis de projeto $\rho$. Em seguida, obtém-se a solução do problema físico utilizando o MEF, calcula-se a função objetivo e as restrições do problema para então, verificar a convergência da função objetivo. Se ocorrer a convergência, tem-se a solução ótima do problema de otimização, caso contrário calcula-se a sensibilidade (gradiente) da função objetivo, a qual é utilizada no otimizador (baseado na PL). Com a solução fornecida pelo otimizador, atualiza-se a distribuição de material e resolve-se novamente o problema físico. Este ciclo se repete até que a convergência 
da função objetivo seja alcançada, respeitando as condições KKT (Kharash Kuhn-Tucker), que garantem a optimalidade da solução.

\subsection{Formulação discreta do problema de otimização}

Com base nas formulações contínuas do problema de otimização apresentada na seção 3.3, a definição do problema de otimização na sua forma discreta para o molde prismático é dada como

$$
\begin{array}{ll}
\underset{\rho}{\operatorname{minimizar}} & \mathbf{T}^{\mathrm{T}} \mathbf{K}_{\mathrm{T}} \mathbf{T} \\
\text { tal que } & \\
& \mathbf{K}_{\mathrm{T}} \mathbf{T}=\mathbf{F}_{\mathrm{T}} \\
& \sum_{i=1}^{n} \rho_{i} V_{i} \leq V_{\text {max }} \\
& 0<\rho_{\text {min }} \leq \rho_{i} \leq 1,
\end{array}
$$

onde $\rho_{i}$ é a variável de projeto que representa uma densidade densidade volumétrica, $V_{i}$ é o volume associado à variável de projeto e $n$ é o total de variáveis de projeto na malha de elementos finitos. $\rho_{\min }$ é um valor próximo de zero, necessário para evitar problemas de singularidades.

Para melhor compreender o efeito da minimização do potencial térmico em problemas de otimização, considere o domínio $\Omega$ ilustrado na Figura 4.6 sujeito a uma geração constante e pontual de calor localizada no centro do domínio e temperatura igual a zero nas suas fronteiras. Deseja-se descobrir qual a melhor distribuição de um material condutor de modo a maximizar a difusividade térmica em $\Omega$. Em outras palavras, busca-se qual a distribuição de material que promova a retirada de calor do domínio de maneira mais eficiente e que, portanto, minimize a energia potencial total da estrutura. Para o problema exposto na Figura 4.6 minimizar $\mathbf{T}^{\mathrm{T}} \mathbf{K}_{\mathrm{T}} \mathbf{T}$ implica maximizar a condutividade térmica da estrutura, pois o carregamento dado por $\mathbf{F}_{\mathrm{T}}$ é constante e analisando a equação de equilíbrio do problema térmico, necessariamente tem-se a maximização de $\mathbf{K}_{\mathrm{T}}$, que é realizada com a adição de material a estrutura, ou seja, a otimização segue num caminho de aumentar o volume da estrutura.

Outra análise pode ser realizada quando tem-se a minimização num problema térmico com campo de temperatura prescrito. Nesse caso T é constante em algumas regiões do domínio e a minimização implica minimizar o carregamento térmico dado por $\mathbf{F}_{\mathrm{T}}$, que por sua vez minimiza $\mathbf{K}_{\mathrm{T}}$ e a otimização segue num caminho de retirar volume da estrutura. No caso da maximização do potencial térmico, o comportamento da otimização em termos de distribuição 


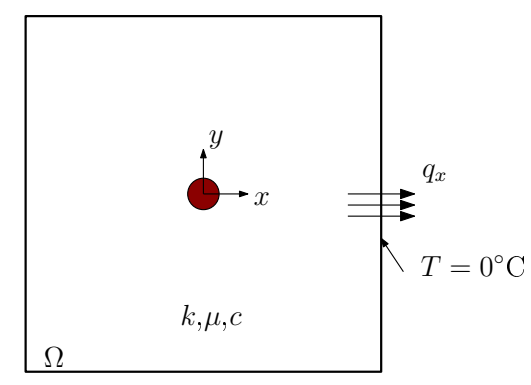

Figura 4.5: Exemplo para análise da difusividade.

de material se inverte. No primeiro caso haveria uma tendência em retirar material e no segundo de adicionar material à estrutura.

No caso dos problemas térmico e eletro-térmico abordados neste trabalho, não se sabe, a priori, qual a tendência da otimização em termos de adição ou retirada de material da estrutura, pois no problema puramente térmico o vetor de força $\mathbf{F}_{\mathrm{T}}$ varia ao longo da otimização em função do efeito da conveç̧ão aparente, enquanto que no problema eletro-térmico não há imposição de temperatura ou de carregamento térmico constante. O que ocorre neste tipo de problema é um carregamento térmico dado pela geração de calor causada pela passagem de corrente elétrica no interior do molde. Assim, optou-se por utilizar restrição de volume máximo para os problemas de otimização e, de acordo com os resultados, verificar a necessidade ou não desta restrição.

Com isso, na otimização de moldes considerando a abordagem de gradiente de temperatura na direção axial, tem-se a formulação multi-objetivo dada da seguinte forma

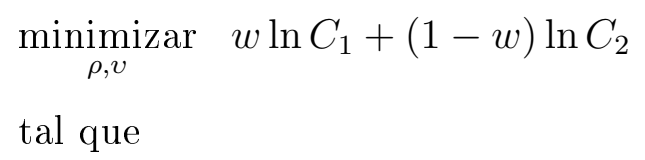

$$
\begin{aligned}
& \mathbf{K}_{\mathrm{E}} \boldsymbol{\phi}=\mathbf{F}_{\mathrm{E}} \\
& \mathbf{K}_{\mathrm{T}} \mathbf{T}=\mathbf{F}_{\mathrm{T}} \\
& \sum_{i=1}^{n} \rho_{i} V_{i} \leq V_{\text {max }} \\
& 0<\rho_{\text {min }} \leq \rho_{i} \leq 1 \\
& 0 \leq v_{j} \leq 1,
\end{aligned}
$$

sendo $v_{j}$ a variável de projeto associada à orientação das propriedades efetivas dentro do elemento finito.

Da mesma forma como foi apresentado na seção 3.3, os termos $C_{1}$ e $C_{2}$ representam, respectivamente, o potencial térmico e a função para aproximação dos gradientes axiais de temperatura calculado e especificado, e são expressos na forma discreta como 


$$
C_{1}=\mathbf{T}^{\mathrm{T}} \mathbf{K}_{\mathrm{T}} \mathbf{T}
$$

$\mathrm{e}$

$$
C_{2}=\sum_{i=1}^{p}\left(\Delta T_{i j}-\alpha\right)^{2},
$$

onde $\Delta T_{i j}=T_{i j}-T_{(i+1) j}$ é a diferença de temperatura numa região específica no interior da amostra e $\alpha$ é a diferença de temperatura que necessariamente deve haver na amostra para que o gradiente de temperatura desejado seja obtido. A Figura 4.6 ilustra a discretização na região da amostra.

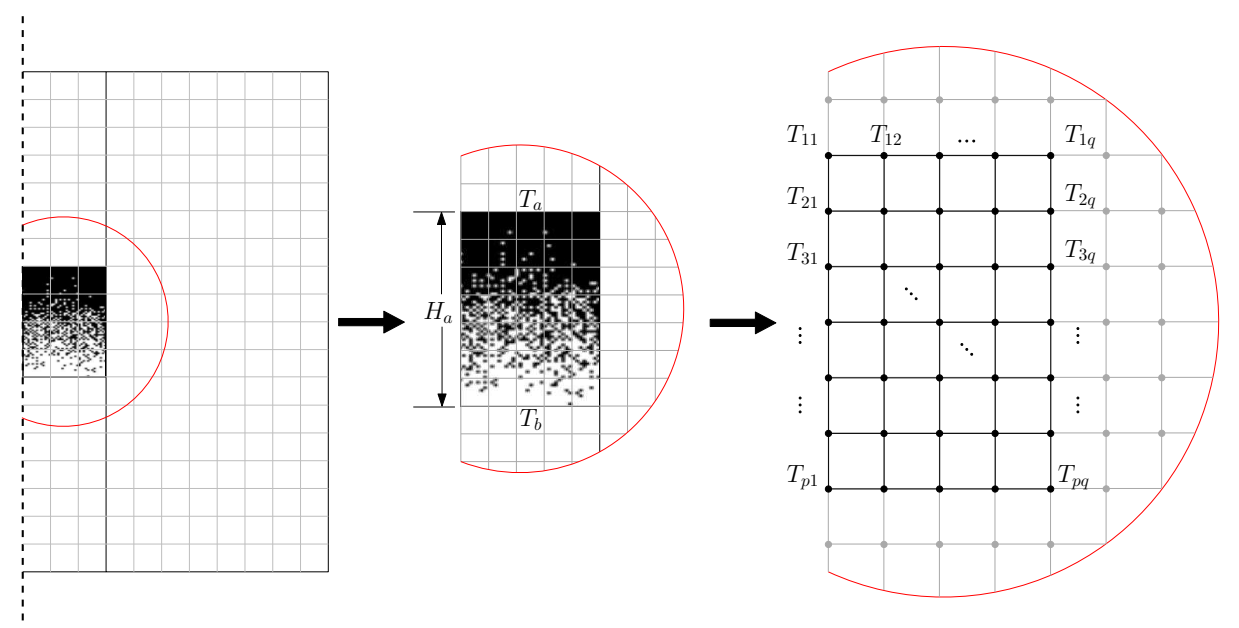

Figura 4.6: Discretização da amostra para avaliação da função objetivo referente ao gradiente de temperatura especificado.

Este tipo de implementação oferece a flexibilidade de impor um gradiente de temperatura ao longo das linhas (indicadas pelo índice $i$ ) e das colunas de nós (indicadas pelo índice $j$ ) de maneira independente. Com isso, a função objetivo pode contemplar não apenas os nós que pertencem à região da amostra, mas também os nós adjacentes pertencentes aos punções, o que pode facilitar no alcance do gradiente desejado.

Nas implementações, optou-se pela especificação de um gradiente de temperatura linear, conforme ilustrado na figura 4.7 .

A definição do gradiente de temperatura que se busca obter na amostra é baseada numa formulação parametrizada, a partir da temperatura $T_{a}$ no topo da amostra (ver Figura 4.7). Com isso, evita-se trabalhar com temperaturas pré determinadas, o que seria inviável uma vez que não se conhece, a priori, a distribuição de temperatura na região da amostra, além da mudança desta distribuição ao longo do processo iterativo.

O gradiente de temperatura é definido considerando as temperaturas nas faces superior 


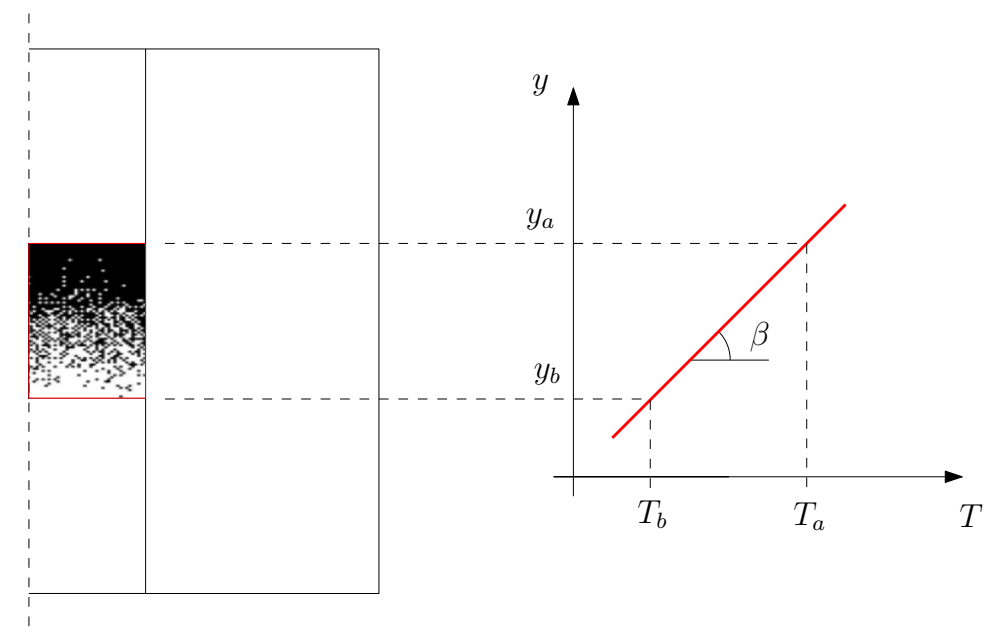

Figura 4.7: Gradiente de temperatura inicialmente proposto para otimizar o molde de grafite.

$\left(T_{a}\right)$ e inferior $\left(T_{b}\right)$, de modo que a relação entre elas é dada como

$$
T_{a}=T_{b}+T_{G}
$$

onde $T_{G}$ indica o acréscimo ou decréscimo na temperatura $T_{a}$ na face superior da amostra.

Assim, o gradiente de temperatura na amostra é dado como

$$
\beta_{o b j}=\frac{T_{a}-T_{b}}{y_{a}-y_{b}}=\frac{T_{G}}{H_{a}}
$$

onde $H_{a}$ é a altura da amostra (ver Figura 4.6).

Como o valor de $\alpha$ (Equação 4.24) está relacionado com as temperaturas nos nós do elemento, este parâmetro deve ser ajustado apropriadamente de acordo com a discretização da amostra. A relação entre $\alpha$ e as temperaturas $T_{a}$ e $T_{b}$ pode ser expressa como

$$
T_{a}=T_{b}+n_{y} \alpha \quad \Rightarrow \quad T_{G}=n_{y} \alpha
$$

e, portanto

$$
\alpha=\frac{T_{G}}{n_{y}} \quad \text { ou } \quad \alpha=\beta_{o b j} \frac{H_{a}}{n_{y}},
$$

sendo $n_{y}$ a quantidade de elementos finitos na direção $y$ presente na região da amostra. O valor de $\alpha$ também pode ser visto como um gradiente de temperatura por camada, uma vez definida a malha de elementos finitos.

Portanto, uma vez estabelecido um gradiente de temperatura $\beta_{o b j}$ para o problema de otimização, diferentes discretizações da malha não modificarão este gradiente. Neste caso, apenas o valor de $\alpha$ se altera para manter $\beta_{o b j}$ fixo. 


\subsection{Filtro de projeção}

A partir de um campo de densidades definido nos nós da malha de elementos finitos, a técnica de projeção cria um novo campo de pseudo-densidades (BRUNS; TORTORELLI, 2001; GUEST; PRÉVOST; BELYTSCHKO, 2004) definido no centroide de cada elemento. Estas pseudodensidades representam a fração de volume de cada elemento da malha e é, então, utilizada no módulo de elementos finitos inserido no MOT.

Neste trabalho, esta técnica é utilizada, porém modificando a projeção das pseudo-densidades para os nós da malha, conforme ilustrada na Figura 4.8 .

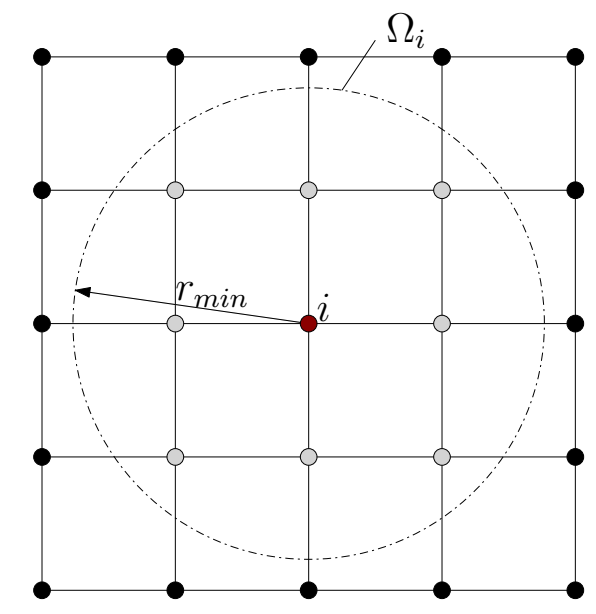

(a)

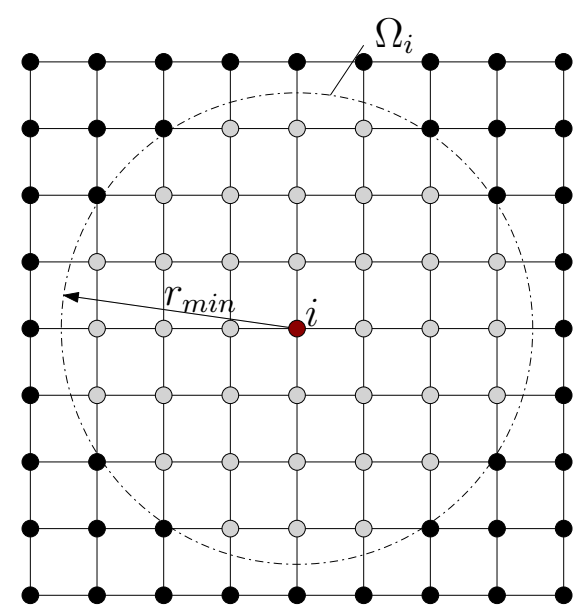

(b)

Figura 4.8: Técnica de projeção utilizada para eliminar problemas de dependência de malha.

A projeção do campo de densidades para o campo de pseudo-densidades exige dois tipos de informação:(i) o conjunto de nós incluído na projeção e (ii) a relação entre esses nós e a fração de volume nodal. O conjunto de nós é determinado através do parâmetro $r_{m i n}$, o qual define o domínio $\Omega_{i}$ que contém os nós (ver Equação 4.29) que influenciam a fração de volume do nó $i$. Esta influência ocorre pela função de ponderação (ver Equação 4.30) das distâncias $r$ entre cada nó localizado em $\mathbf{x}$ (pertencente a $\Omega_{i}$ ) e o nó $i$.

$$
\begin{gathered}
\mathbf{x} \in \Omega_{i} \quad \text { se } r \equiv\left\|\mathbf{x}-\mathbf{x}_{i}\right\| \leq r_{\text {min }} \\
f\left(\mathbf{x}-\mathbf{x}_{i}\right)=\left\{\begin{array}{cl}
\frac{r_{\text {min }}-r}{r_{\text {min }}} & \text { se } \quad \mathbf{x} \in \Omega_{i} \\
0 & \text { caso contrário }
\end{array}\right.
\end{gathered}
$$

A relação entre os nós contidos em $\Omega_{i}$ e a pseudo-densidade do nó $i$ definida por meio de uma função de projeção linear, definida como

$$
\rho_{i}=\frac{\sum_{j \in S_{i}} \rho_{j} f\left(\mathbf{x}_{j}-\mathbf{x}_{i}\right)}{\sum_{j \in S_{i}} f\left(\mathbf{x}_{j}-\mathbf{x}_{i}\right)}
$$


onde $\rho_{i}$ é a fração de volume do nó $i$ e $S_{i}$ é o conjunto dos nós contidos em $\Omega_{i}$.

De acordo com Guest, Prévost e Belytschko (2004), a técnica de projeção retira a dependência de malha devido a função de projeção ser definida independentemente de parâmetros da malha. O parâmetro $r_{\text {min }}$, no qual se baseia a função de projeção, é uma medida física que independe da malha, conforme visualizado na 4.8b. Porém, a técnica de projeção introduz, na solução ótima, regiões com escala de cinza e em alguns casos pode modificar a solução obtida sem a utilização desta técnica.

\subsection{Aproximação contínua de distribuição de material}

A implementação numérica do MOT se inicia com a definição do campo de densidades no problema de otimização. Este campo de densidades pode ser por elemento (formulação Q4/U) e, neste caso, a densidade de cada elemento representa uma variável de projeto ou por nó (formulação Q4/Q4, Q8/Q4, Q4/Q4M), onde se tem as variáveis de projeto aplicadas nos nós da malha (RAHMATALla; SWAN, 2004; PAULINO; LE, 2009).

Neste trabalho utilizou-se tanto implementação com formulação Q4/U, como a Q4/Q4 e ambas com elementos finitos isoparamétricos retangulares de 4 nós. No caso da implementação Q4/Q4, foi utilizada a técnica de aproximação contínua de distribuição de material (ACDM) proposta por Matsui e Terada (2004). A ACDM é um método que permite determinar a densidade $\rho$ no interior de um elemento finito, a partir das variáveis de projeto definidas nos nós do elemento.

A figura 4.9 apresenta, considerando um elemento finito retangular, as duas formas de parametrização do campo de densidades: a tradicional (densidade volumétrica por elemento) e a formulação ACDM, que cria um campo de densidades contínuo.

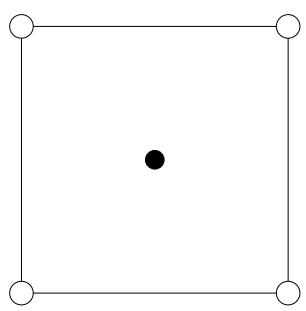

(a) Parametrização tradicional Q4/U

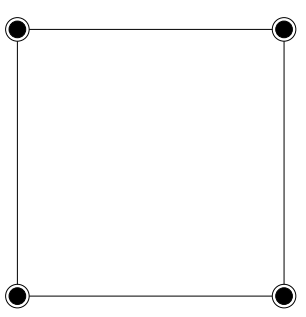

(b) Parametrização ACDM em Q4/Q4
Graus de liberdade

- Variáveis de projeto $\rho_{i}$

Figura 4.9: Representação da formulação tradicional e do ACDM.

Sua formulação é baseada nas funções de forma $N_{i}$ utilizadas para interpolar os graus de liberdade de cada elemento. Assim, a aproximação da densidade num ponto qualquer do 
elemento pode ser calculado como

$$
\rho_{e}=\sum_{i=1}^{k} N_{i} \rho_{i},
$$

onde $\rho_{e}$ e $k$ são, respectivamente, a função de densidade e o total de nós do elemento $e$ e $\rho_{i}$ é o valor da variável de projeto definida no nó $i$.

Esta abordagem, por estabelecer uma distribuição contínua de material, permite um maior controle no gradiente de densidades no interior do elemento, além de ser utilizado em problemas de distribuição de material em estruturas constituídas por MGF.

\subsection{Implementação da gradação de material em amostras MGF}

A implementação da gradação das propriedades características numa amostra MGF iniciase a partir da interpretação de uma amostra gradada conforme indicado na Figura 4.10.

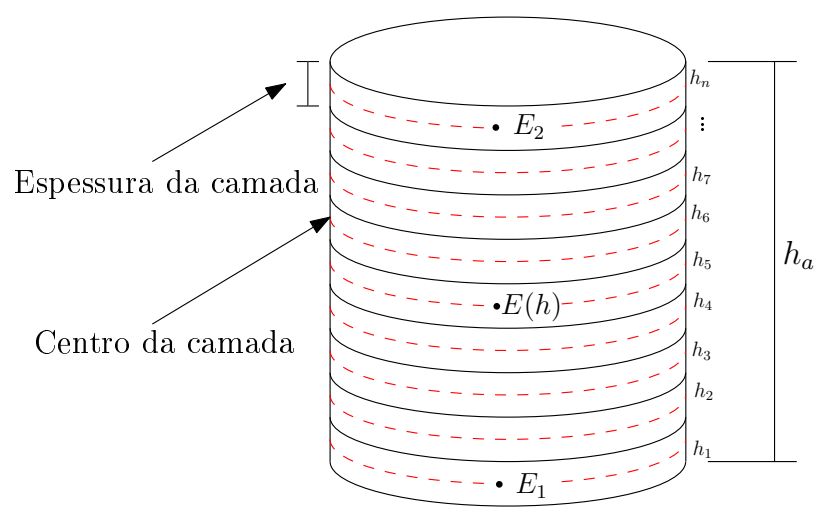

Figura 4.10: Ilustração de uma amostra com gradação funcional. $E_{1}$ e $E_{2}$ representam as propriedades características das duas matrizes que compõem a amostra e $E(h)$ é a função que define a propriedade de cada camada a partir da sua posição axial $h$.

A amostra é composta por duas matrizes de materiais em que as respectivas propriedades características $E_{1}$ e $E_{2}$ são conhecidas. A gradação é realizada considerando $E(h)$ como a função de gradação que define a propriedade de cada camada $h$, tomada na direção axial. Neste trabalho são utilizados dois tipos de função $E(h)$ para interpolar as propriedades das duas matrizes de materiais, sendo uma função para interpolação linear e outra interpolação exponencial, conforme indicado pelas equações 4.33 e 4.34, respectivamente.

$$
E(h)=\left(\frac{h-h_{1}}{h_{n}-h_{1}}\right) E_{2}-\left(\frac{h-h_{n}}{h_{n}-h_{1}}\right) E_{1}
$$




$$
E(h)=E_{1} e^{\frac{1}{\left(h_{n}-h_{1}\right)} \ln \left(\frac{E_{2}}{E_{1}}\right)\left(h-h_{1}\right)}
$$

As Figuras 4.11a e 4.11b ilustram, respectivamente, a gradação linear e exponencial das propriedades em cada camada, considerando a função de interpolação $E(h)$. Embora a função $E(h)$ seja contínua, como pode se verificar nas figuras, na implementação da gradação, as propriedades possuem valores constantes em todo interior da camada, apresentando assim um comportamento discreto de gradação das propriedades.

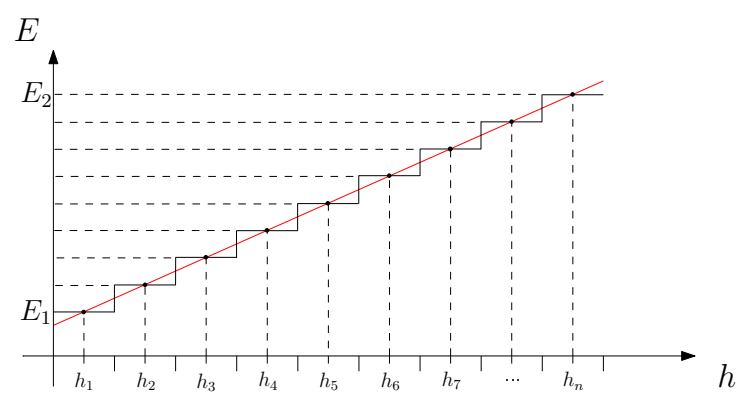

(a) Gradação linear

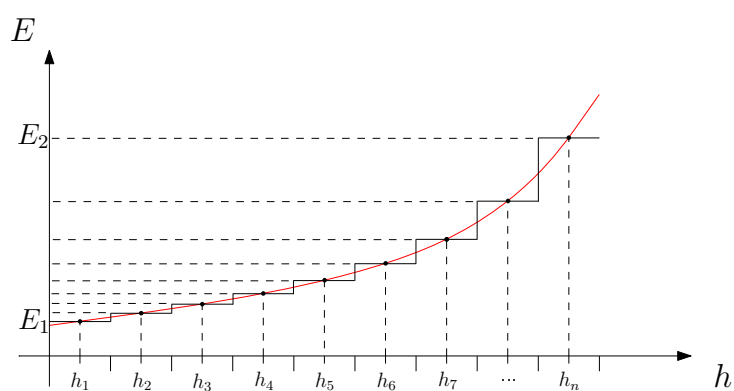

(b) Gradação exponencial

Figura 4.11: Gradação da propriedade característica $E$ ao longo da direção axial da amostra.

A quantidade de camadas numa amostra é considerada como sendo a quantidade de elementos na direção axial e que pertencem à região da amostra, conforme indicado na Figura 4.12 .

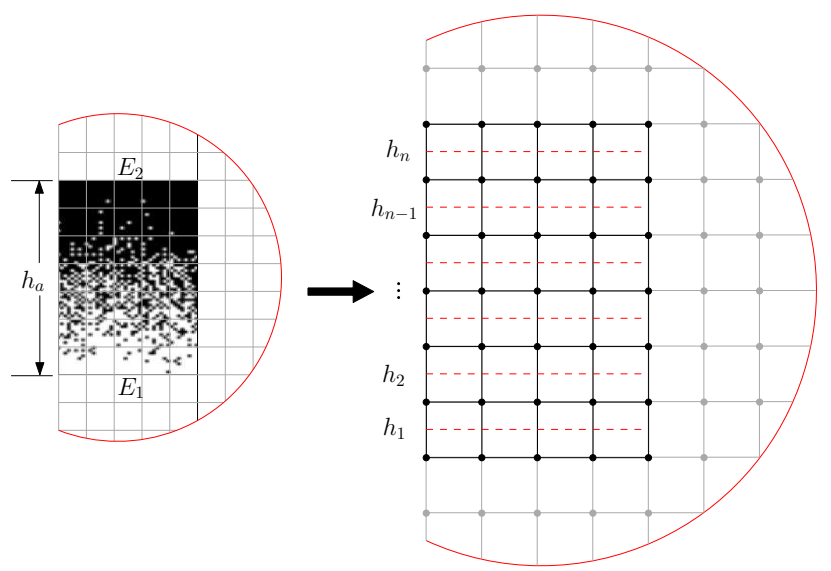

Figura 4.12: Ilustração da discretização, a partir da qual, se identificam as camadas para a utilização da função $E(h)$ para implementar a gradação funcional.

\subsection{Análise de sensibilidades}

Conforme apresentado no fluxograma da Figura 4.4, é necessário calcular o gradiente da função objetivo para ser introduzido no módulo de otimização. O cálculo desse gradiente 
indica a sensibilidade da função objetivo ao se promover pequenas mudanças em cada variável de projeto do problema em questão. Neste trabalho, foram abordados dois problemas de otimização, um com a função objetivo $\Pi_{1}$ referente ao potencial térmico da estrutura e outro com a função multiobjetivo $\Pi_{2}$ que acopla potencial térmico com gradiente de temperatura. A formulação de ambos os problemas é apresentadas na seção 4.5 e reescritas a seguir.

$$
\begin{array}{cl}
\underset{\rho}{\operatorname{minimizar}} \quad \Pi_{1}=\mathbf{T}^{\mathrm{T}} \mathbf{K}_{\mathrm{T}} \mathbf{T} \\
\text { tal que } \\
\mathbf{K}_{\mathrm{T}} \mathbf{T}=\mathbf{F}_{\mathrm{T}} \\
\sum_{i=1}^{n} \rho_{i} V_{i} \leq V_{\text {max }} \\
0<\rho_{\text {min }} \leq \rho_{i} \leq 1 \\
\underset{\rho, v}{\operatorname{minimizar}} \quad \Pi_{2}=w \ln C_{1}+(1-w) \ln C_{2} \\
\text { tal } \quad \mathbf{K}_{\mathrm{E}} \boldsymbol{\phi}=\mathbf{F}_{\mathrm{E}} \\
\mathbf{K}_{\mathrm{T}} \mathbf{T}=\mathbf{F}_{\mathrm{T}} \\
\sum_{i=1}^{n} \rho_{i} V_{i} \leq V_{\max } \\
0<\rho_{\min } \leq \rho_{i} \leq 1 \\
0 \leq v_{j} \leq 1
\end{array}
$$

Como se verifica na formulação dos problemas de otimização, existem dois conjuntos de variáveis de projeto, um referente a pseudo-densidades $\rho$ e outro relacionado à pseudoorientação $v$ das propriedades efetivas no interior do elemento finito. Nesse caso, para facilitar a análise de sensibilidades, esta será desenvolvida considerando uma variável de projeto $x$ qualquer.

Assim, iniciando pelo problema de minimização do potencial térmico dado pela função $\Pi_{1}$, tem-se

$$
\frac{\partial \Pi_{1}}{\partial x}=\frac{\partial \mathbf{T}^{\mathrm{T}}}{\partial x} \mathbf{K}_{\mathrm{T}} \mathbf{T}+\mathbf{T}^{\mathrm{T}} \frac{\partial \mathbf{K}_{\mathrm{T}}}{\partial x} \mathbf{T}+\mathbf{T}^{\mathrm{T}} \mathbf{K}_{\mathrm{T}} \frac{\partial \mathbf{T}}{\partial x}
$$

e considerando a simetria da matriz $\mathbf{K}_{\mathrm{T}}$,

$$
\frac{\partial \Pi_{1}}{\partial x}=\mathbf{T}^{\mathrm{T}} \frac{\partial \mathbf{K}_{\mathrm{T}}}{\partial x} \mathbf{T}+2 \mathbf{T}^{\mathrm{T}} \mathbf{K}_{\mathrm{T}} \frac{\partial \mathbf{T}}{\partial x} .
$$


Derivando ambos os lados da equação de equilíbrio, tem-se

$$
\begin{gathered}
\frac{\partial \mathbf{K}_{\mathrm{T}}}{\partial x} \mathbf{T}+\mathbf{K}_{\mathrm{T}} \frac{\partial \mathbf{T}}{\partial x}=\frac{\partial \mathbf{F}_{\mathrm{T}}}{\partial x}, \\
\mathbf{K}_{\mathrm{T}} \frac{\partial \mathbf{T}}{\partial x}=\frac{\partial \mathbf{F}_{\mathrm{T}}}{\partial x}-\frac{\partial \mathbf{K}_{\mathrm{T}}}{\partial x} \mathbf{T}, \\
\frac{\partial \Pi_{1}}{\partial x}=\mathbf{T}^{\mathrm{T}} \frac{\partial \mathbf{K}_{\mathrm{T}}}{\partial x} \mathbf{T}+2 \mathbf{T}^{\mathrm{T}}\left(\frac{\partial \mathbf{F}_{\mathrm{T}}}{\partial x}-\frac{\partial \mathbf{K}_{\mathrm{T}}}{\partial x} \mathbf{T}\right),
\end{gathered}
$$

e

$$
\frac{\partial \Pi_{1}}{\partial x}=-\mathbf{T}^{\mathrm{T}} \frac{\mathbf{K}_{\mathrm{T}}}{\partial x} \mathbf{T}+2 \mathbf{T}^{\mathrm{T}} \frac{\partial \mathbf{F}_{\mathrm{T}}}{\partial x}
$$

Analisando a sensibilidade da função objetivo $\Pi_{1}$ (Equação 4.40), verifica-se que seu sinal não é constante devido a efeitos associados com a dependência estrutural do vetor de carregamento térmico $\mathbf{F}_{\mathrm{T}}$. No entanto, em problemas cuja carga térmica independe de parâmetros estruturais (como por exemplo ao se prescrever temperatura em regiões do domínio) o termo $\partial \mathbf{F}_{\mathrm{T}} / \partial x$ é nulo e, portanto, a sensibilidade pode ser simplificada como

$$
\frac{\partial \Pi}{\partial x}=-\mathbf{T}^{\mathrm{T}} \frac{\mathbf{K}_{\mathrm{T}}}{\partial x} \mathbf{T}
$$

e assim, a função objetivo é minimizada monotonicamente. Este tipo de situação ocorre nos problemas apresentados no Apêndice C.

Fazendo a análise de sensibilidades da função objetivo $\Pi_{2}$, tem-se

$$
\frac{\partial \Pi_{2}}{\partial x}=\frac{w}{C_{1}} \frac{\partial C_{1}}{\partial x}+\frac{1-w}{C_{2}} \frac{\partial C_{2}}{\partial x}
$$

onde $C_{1}$ e $C_{2}$ foram definidos na seção 4.5 , equações 4.23 e 4.24, respectivamente.

O termo $\frac{\partial C_{1}}{\partial x}$ representa a sensibilidade da função potencial térmico, a qual foi desenvolvida no início desta seção e que é utilizado nos problemas puramente térmicos. Já o termo $\frac{\partial C_{2}}{\partial x}$ representa a sensibilidade da função que especifica um gradiente de temperatura na direção axial.

Inicialmente a sensibilidade da função $C_{2}$ será desenvolvida utilizando o método direto e em seguida $\frac{\partial C_{2}}{\partial x}$ será calculado através do método adjunto, que permite o cálculo desta sensibilidade de maneira computacionalmente mais eficiente que o método direto. Assim, tem-se

$$
\frac{\partial C_{2}}{\partial x}=\sum_{i=1}^{p} 2\left(\Delta T_{i j}-\alpha\right) \frac{\partial \Delta T_{i j}}{\partial x},
$$

onde $\Delta T_{i j}=T_{(i+1) j}-T_{i j}$ e portanto, 


$$
\frac{\partial \Delta T_{i j}}{\partial x}=\frac{\partial T_{(i+1) j}}{\partial x}-\frac{\partial T_{i j}}{\partial x}
$$

sendo o termo $\frac{\partial T_{i j}}{\partial x}$ a sensibilidade do campo de temperatura, que pode ser determinada a partir da equação de equilíbrio do problema térmico e é expressa da seguinte forma

$$
\frac{\partial \mathbf{T}}{\partial x}=\mathbf{K}_{\mathrm{T}}^{-1} \frac{\partial \mathbf{F}_{\mathrm{T}}}{\partial x}-\frac{\partial \mathbf{K}_{\mathrm{T}}}{\partial x} \mathbf{T}
$$

Observa-se na equação 4.45 que a sensibilidade do campo de temperatura é obtida solucionandose um sistema algébrico linear para cada variável de projeto. Com isso, para uma discretização do domínio com $n$ variáveis, o sistema da equação 4.45 deverá ser solucionado $n$ vezes.

Do ponto de vista computacional, o método direto não é vantajoso, pois a maior parte do custo computacional se concentra no processo que envolve o cálculo da matriz inversa $\mathbf{K}_{\mathrm{T}}{ }^{-1}$. Além disso, este método se aplica para os casos em que o numero de restrições é superior a quantidade de variáveis de projeto (HAFTKA; GÜRDAL, 1991).

Para se trabalhar com um problema de otimização que contenha um número relativamente alto de variáveis de projeto, utiliza-se o método adjunto para o cálculo da sensibilidade da função objetivo. Assim, para o desenvolvimento deste método, a função $C_{2}$ é reformulada da seguinte maneira

$$
C_{2}=\sum_{i=1}^{p}(\Delta \mathbf{T}-\alpha)^{2}+\boldsymbol{\lambda}^{\mathrm{T}}\left(\mathbf{K}_{\mathrm{T}} \mathbf{T}-\mathbf{F}_{\mathrm{T}}\right),
$$

onde $\boldsymbol{\lambda}^{\mathrm{T}}$ é o vetor adjunto que independe das variáveis de projeto. Nesta equação (4.46), o segundo termo do lado direito é nulo, uma vez que trata-se da equação de equilíbrio do problema térmico, a qual é uma das restrições do problema de otimização.

O vetor $\Delta \mathbf{T}$, cujos elementos são $\Delta T_{i j}$, pode ser escrito como

$$
\Delta \mathbf{T}=\mathbf{L T}
$$

onde $\mathbf{L}$ representa uma matriz de ordem $m \times n$ e $\mathbf{T}$ o vetor $n \times 1$ de temperaturas, sendo $m$ a quantidade de $\Delta T_{i j}$ presentes em $C_{2}$ e $n$ o total de nós na malha de elementos finitos.

Com isso a nova sensibilidade de $C_{2}$ é dada por

$$
\frac{\partial C_{2}}{\partial x}=2(\mathbf{L T}-\boldsymbol{\alpha}) \mathbf{L} \frac{\partial \mathbf{T}}{\partial x}+\boldsymbol{\lambda}^{\mathrm{T}}\left(\frac{\partial \mathbf{K}_{\mathrm{T}}}{\partial x} \mathbf{T}+\mathbf{K}_{\mathrm{T}} \frac{\partial \mathbf{T}}{\partial x}-\frac{\partial \mathbf{F}_{\mathrm{T}}}{\partial x}\right),
$$


que pode ser reescrita na forma

$$
\frac{\partial C_{2}}{\partial x}=\left[2 \mathbf{L T L}-2 \alpha \mathbf{L}+\boldsymbol{\lambda}^{\mathrm{T}} \mathbf{K}_{\mathrm{T}}\right] \frac{\partial \mathbf{T}}{\partial x}+\boldsymbol{\lambda}^{\mathrm{T}}\left(\frac{\partial \mathbf{K}_{\mathrm{T}}}{\partial x} \mathbf{T}-\frac{\partial \mathbf{F}_{\mathrm{T}}}{\partial x}\right)
$$

Conforme citado anteriormente, a maior parte do custo computacional está no cálculo de $\frac{\partial \mathbf{T}}{\partial x}$ (ver equação 4.45), assim o objetivo é determinar um vetor $\lambda^{T}$ para igualar a zero o primeiro termo da equação 4.49. Com isso, o vetor adjunto é dado por

$$
\boldsymbol{\lambda}^{\mathrm{T}}=2 \mathbf{K}_{\mathrm{T}}^{-1}(\boldsymbol{\alpha}-[\mathbf{L}]\{\mathbf{T}\})[\mathbf{L}] .
$$

Dando sequência à análise de sensibilidades, como visto acima, é necessário o calculo dos gradientes da matriz de condutividade e também do vetor de carregamento térmico. Lembrando que $\mathbf{K}_{\mathrm{T}}=\mathbf{K}_{k}+\mathbf{K}_{h}$ e $\mathbf{F}_{\mathrm{T}}=\mathbf{F}_{\dot{q}}+\mathbf{F}_{h}+\mathbf{F}_{q}$, a sensibilidade da matriz global de condutividade e do vetor global de carregamento térmico pode ser escrita como

$$
\begin{aligned}
\frac{\partial \mathbf{K}_{\mathrm{T}}}{\partial x} & =\frac{\partial \mathbf{K}_{k}}{\partial x}+\frac{\partial \mathbf{K}_{h}}{\partial x} \\
\frac{\partial \mathbf{F}_{\mathrm{T}}}{\partial x} & =\frac{\partial \mathbf{F}_{\dot{q}}}{\partial x}+\frac{\partial \mathbf{F}_{h}}{\partial x}+\frac{\partial \mathbf{F}_{q}}{\partial x} .
\end{aligned}
$$

Avaliando cada termo das equações 4.51 e 4.52, tem-se

$$
\begin{aligned}
\frac{\partial \mathbf{K}_{k}}{\partial x} & =\Lambda_{e=1}^{n} \frac{\partial \mathbf{k}_{k}^{e}}{\partial x}=\Lambda_{e=1}^{n} 2 \pi \int_{z} \int_{r} \mathbf{B}^{\mathrm{T}} \frac{\partial \mathbf{C}_{\mathrm{T}}}{\partial x} \mathbf{B} r \mathrm{~d} r \mathrm{~d} z \\
\frac{\partial \mathbf{K}_{h}}{\partial x} & =\Lambda_{e=1}^{n} \frac{\partial \mathbf{k}_{h}^{e}}{\partial x}=\Lambda_{e=1}^{n} 2 \pi \oint_{\Gamma_{e}} \mathbf{N}_{s}^{\mathrm{T}} \frac{\partial h_{s}}{\partial x} \mathbf{N}_{s} r \mathrm{~d} \Gamma_{e}, \\
\frac{\partial \mathbf{F}_{h}}{\partial x} & =\Lambda_{e=1}^{n} \frac{\partial \mathbf{F}_{h}^{e}}{\partial x}=\Lambda_{e=1}^{n} 2 \pi \oint_{\Gamma_{e}} \mathbf{N}_{s}^{\mathrm{T}} \frac{\partial h_{s}}{\partial x} T_{a m b} r \mathrm{~d} \Gamma_{e}, \\
\frac{\partial \mathbf{F}_{\dot{q}}}{\partial x} & =\Lambda_{e=1}^{n} \frac{\partial \mathbf{F}_{\dot{q}}^{e}}{\partial x}=\bigwedge_{e=1}^{n} 2 \pi \int_{z} \int_{r} \mathbf{N}^{\mathrm{T}} \frac{\partial \dot{q}_{e}}{\partial x} r \mathrm{~d} r \mathrm{~d} z, \\
\frac{\partial \mathbf{F}_{q}}{\partial x} & =\Lambda_{e=1}^{n} \frac{\partial \mathbf{F}_{q}^{e}}{\partial x}=\Lambda_{e=1}^{n} 2 \pi \oint_{\Gamma_{e}} \mathbf{N}^{\mathrm{T}} \frac{\partial q}{\partial x} r \mathrm{~d} \Gamma_{e} .
\end{aligned}
$$

O cálculo dos gradientes, dados pelas equações 4.53-4.57, depende do modelo de material implementado e da técnica utilizada para lidar com condições de contorno com dependência estrutural. A análise destes gradientes é apresentada nas seções 4.9.1 e 4.9.2.

O cálculo da sensibilidade do vetor de força da geração interna de calor $\mathbf{F}_{\dot{q}}^{e}$ (Equação 4.4) em relação à variável de projeto depende do tipo de problema que está sendo analisado. Num problema puramente térmico, $\partial \mathbf{F}_{\dot{q}}^{e} / \partial x$ é dado por 


$$
\frac{\partial \mathbf{F}_{\dot{q}}^{e}}{\partial x}=\frac{\partial \mathbf{F}_{\dot{q}}^{e}}{\partial \rho_{i}}=2 \pi \int_{z} \int_{r} \mathbf{N}^{\mathbf{T}} p \rho_{e}^{p-1} \dot{q}_{0} r \mathrm{~d} r \mathrm{~d} z
$$

Para o problema eletrotérmico, a geração interna de calor depende não somente do campo de densidades, como também da distribuição de potencial elétrico no interior do domínio de projeto (ver equação 2.47). Assim, a sensibilidade da geração interna de calor pode ser calculada da seguinte maneira

$$
\begin{aligned}
\frac{\partial \mathbf{F}_{\dot{q}}^{e}}{\partial \rho_{i}} & =2 \pi \int_{z} \int_{r} \mathbf{N}^{\mathbf{T}} \frac{\partial \dot{q}_{e}}{\partial \rho_{e}} \frac{\partial \rho_{e}}{\partial \rho_{i}} r \mathrm{~d} r \mathrm{~d} z, \\
\frac{\mathrm{d} \mathbf{F}_{\dot{q}}^{e}}{\mathrm{~d} \rho_{i}} & =\frac{\partial \mathbf{F}_{\dot{q}}^{e}}{\partial \rho_{i}}+\frac{\partial \mathbf{F}_{\dot{q}}^{e}}{\partial \boldsymbol{\phi}_{e}} \frac{\partial \boldsymbol{\phi}_{e}}{\partial \rho_{i}} \\
\frac{\mathrm{d} \mathbf{F}_{\dot{q}}^{e}}{\mathrm{~d} \rho_{i}} & =\left(\frac{\partial \mathbf{F}_{\dot{q}}^{e}}{\partial \rho_{e}}+\frac{\partial \mathbf{F}_{\dot{q}}^{e}}{\partial \boldsymbol{\phi}^{e}} \frac{\partial \boldsymbol{\phi}^{e}}{\partial \rho_{e}}\right) \frac{\partial \rho_{e}}{\partial \rho_{i}}
\end{aligned}
$$

onde a derivada explícita em relação a variável de projeto é obtida através da equação 4.58 e a derivada implícita é obtida da seguinte maneira

$$
\frac{\partial \mathbf{F}_{\dot{q}}^{e}}{\partial \phi^{e}}=2 \pi \int_{z} \int_{r} \mathbf{N}^{\mathrm{T}} \frac{\partial \dot{q}_{e}}{\partial \phi^{e}} r \mathrm{~d} r \mathrm{~d} z
$$

$\mathrm{e}$

$$
\frac{\partial \dot{q}_{e}}{\partial \rho_{e}}=\frac{\partial \boldsymbol{\phi}^{e \mathrm{~T}}}{\partial \rho_{e}} \mathbf{B}^{\mathrm{T}} \sigma\left(\rho_{e}\right) \mathbf{B} \boldsymbol{\phi}^{e}+\boldsymbol{\phi}_{e}^{\mathrm{T}} \mathbf{B}^{\mathrm{T}} \frac{\partial \sigma\left(\rho_{e}\right)}{\partial \rho_{e}} \mathbf{B} \boldsymbol{\phi}^{e}+\boldsymbol{\phi}_{e}^{\mathrm{T}} \mathbf{B}^{\mathrm{T}} \sigma\left(\rho_{e}\right) \mathbf{B} \frac{\partial \boldsymbol{\phi}^{e}}{\partial \rho_{e}} .
$$

O termo $\partial \rho_{e} / \partial \rho_{i}$ é decorrente da implementação em Q4/Q4 (ver seção 4.7), que considera a variável de projeto aplicada no nó (ver seção 4.7). Para a implementação em Q4/U (ver seção 4.7), este termo assume valor unitário.

Para finalizar o cálculo de $\partial \mathbf{F}_{\dot{q}}^{e} / \partial x$, é necessário obter a sensibilidade do potencial elétrico. Esta sensibilidade é representada pelo vetor

$$
\frac{\partial \phi^{e}}{\partial x}=\left[\frac{\partial \phi_{1}^{e}}{\partial x} \frac{\partial \phi_{2}^{e}}{\partial x} \frac{\partial \phi_{3}^{e}}{\partial x} \frac{\partial \phi_{4}^{e}}{\partial x}\right]^{\mathrm{T}}
$$

e pode ser obtido através da equação de equilíbrio do problema elétrico da seguinte maneira

$$
\begin{gathered}
\mathbf{K}_{\mathrm{E}} \boldsymbol{\phi}=\mathbf{F}_{\mathrm{E}}, \\
\frac{\partial \mathbf{K}_{\mathbf{E}}}{\partial x} \boldsymbol{\phi}+\mathbf{K}_{\mathrm{E}} \frac{\partial \boldsymbol{\phi}}{\partial x}=\frac{\partial \mathbf{F}_{\mathrm{E}}}{\partial x}
\end{gathered}
$$

e

$$
\mathbf{K}_{\mathrm{E}} \frac{\partial \boldsymbol{\phi}}{\partial x}=\left(\frac{\partial \mathbf{F}_{\mathrm{E}}}{\partial x}-\frac{\partial \mathbf{K}_{\mathrm{E}}}{\partial x} \boldsymbol{\phi}\right)
$$

Como a excitação no problema elétrico ocorre por meio de potenciais elétricos prescritos 
$\phi_{p}$ em $\Gamma_{u}$, tem-se

$$
\left.\frac{\partial \boldsymbol{\phi}_{p}}{\partial x}\right|_{\Gamma_{u}}=0 \quad \text { e }\left.\quad \frac{\partial \mathbf{F}_{\mathrm{E}}}{\partial x}\right|_{\Gamma \backslash \Gamma_{u}}=0,
$$

onde $\Gamma \backslash \Gamma_{u}$ indica a fronteira do domínio livre de condições de contorno e carregamento, ou seja, $\mathbf{F}_{\mathrm{E}}=0$.

Assim, a sensibilidade dos demais potenciais elétrico (graus de liberdades $\phi_{\text {livres }}$ ) pode ser obtida resolvendo seguinte problema linear reduzido (ASSAN, 2003)

$$
\mathbf{K}_{\mathrm{E}}^{\text {livres }} \frac{\partial \boldsymbol{\phi}_{\text {livres }}}{\partial x}=-\frac{\partial \mathbf{K}_{\mathrm{E}}^{\text {livres }}}{\partial x} \boldsymbol{\phi}_{\text {livres }}
$$

onde o índice livres indica a matriz ou o vetor com elementos relacionados apenas aos graus de liberdade "livres", ou seja, sem restrições.

\subsubsection{Sensibilidade das condições de contorno com dependência es- trutural}

As técnicas utilizadas para lidar com dependência estrutural estão associadas apenas às variáveis de projeto que representam pseudo-densidades, e por isso, o desenvolvimento da sensibilidade aqui exposto é feito diretamente em relação as essas variáveis.

No caso do modelo de convecção baseado na função degrau, a sua sensibilidade é calculada da seguinte forma

$\frac{\partial H(\rho)}{\partial \rho}= \begin{cases}\frac{p_{h} \pi}{2 \rho_{\text {inf }}}\left[\sin \left(\frac{\pi}{2} \frac{\rho}{\rho_{\text {inf }}}\right) \cos ^{p_{h}}\left(\frac{\pi}{2} \frac{\rho}{\rho_{\text {inf }}}\right)\right]^{\left(p_{h}-1\right)} & ; \rho<\rho_{\text {inf }} \\ 0 ; \rho_{\text {inf }} \leq \rho \leq \rho_{\text {sup }} & \\ \frac{p_{h} \pi}{2\left(1-\rho_{\text {sup }}\right)}\left[\sin \left(\frac{\pi}{2}\left(\frac{\rho-2 \rho_{\text {sup }}+1}{1-\rho_{\text {sup }}}\right)\right)\right]^{\left(p_{h}-1\right)} \cos ^{p_{h}}\left(\frac{\pi}{2}\left(\frac{\rho-2 \rho_{\text {sup }}+1}{1-\rho_{\text {sup }}}\right)\right) & ; \rho>\rho_{\text {sup }} .\end{cases}$

Para o modelo de convecção baseado no SIMP, a análise da sensibilidade é dada por

$$
\frac{\partial h_{s}}{\partial \rho}=p \rho_{e}^{(p-1)}\left(1-\gamma_{i}\right) h_{0}-\rho_{e}^{p} h_{0} \frac{\partial \gamma_{i}}{\partial \rho} .
$$

As equações 4.70 e 4.71 foram avaliadas considerando o coeficiente de convecção $h$ como grandeza física, porém a mesma análise se aplica à condição de fluxo de calor aparente, decorrente da linearização da radiação. 


\subsubsection{Sensibilidade da matriz constitutiva}

No caso de moldes prismáticos e homogêneo, o modelo de material é o mesmo e, portanto,

$$
\frac{\partial \mathbf{C}_{\mathrm{T}}}{\partial x}=\frac{\partial \mathbf{C}_{\mathrm{T}}}{\partial \rho}=p \rho^{(p-1)} C_{0}
$$

Para moldes compósitos $\mathbf{C}_{\mathrm{T}}=\mathbf{C}_{\mathrm{T}}(\rho, v)$ e nesse caso, a sensibilidade da condutividade térmica depende do método implementado para lidar com as orientações $\theta$. No método em que $\theta=v \pi$, tem-se

$$
\frac{\partial \mathbf{C}_{\mathrm{T}}}{\partial x}=\frac{\partial \mathbf{C}_{\mathrm{T}}}{\partial v}=\rho^{p} \frac{\partial \mathbf{C}_{\theta}}{\partial \theta} \frac{\partial \theta}{\partial v}
$$

e

$$
\frac{\partial \mathbf{C}_{\mathrm{T}}}{\partial v}=\rho^{p}\left(\frac{\partial \mathbf{R}^{\mathrm{T}}}{\partial \theta} C_{0} \mathbf{R}+\mathbf{R}^{\mathrm{T}} C_{0} \frac{\partial \mathbf{R}^{\mathrm{T}}}{\partial \theta}\right) \pi
$$

Na implementação do molde compósito utilizando o método OMD, tem-se

$$
\begin{gathered}
\frac{\partial \mathbf{C}_{\theta}}{\partial v_{n}^{e}}=\sum_{i=1}^{n_{c}} \frac{\partial w_{i}}{\partial v_{n}^{e}} \mathbf{C}_{i}, \\
\frac{\partial w_{i}}{\partial v_{n}^{e}}=\frac{\frac{\partial \hat{w}_{i}}{\partial v_{n}^{e}}}{\sum_{i=1}^{n_{c}} \hat{w}_{k}}-\frac{\hat{w}_{i}}{\left(\sum_{i=1}^{n_{c}} \hat{w}_{k}\right)^{2}} \sum_{k=1}^{n_{c}} \frac{\partial \hat{w}_{k}}{\partial v_{n}^{e}}
\end{gathered}
$$

e

$$
\frac{\partial \hat{w}_{k}}{\partial v_{n}^{e}}=\left\{\begin{array}{r}
p\left(v_{n}^{e}\right)^{(p-1)} \prod_{j=1 ; j \neq i}^{n_{c}}\left(1-\left(v_{j}^{e}\right)^{p}\right), \text { se } n=i \\
-\left(v_{i}^{e}\right)^{p} p\left(v_{n}^{e}\right)^{(p-1)} \prod_{j=1 ; j \neq i ; j \neq n}^{n_{c}}\left(1-\left(v_{j}^{e}\right)^{p}\right), \text { se } n=j
\end{array}\right.
$$




\section{Resultados e Discussão}

\subsection{Introdução}

Nesta seção são apresentados os resultados obtidos para cada uma das abordagens propostas neste trabalho. Na Seção 5.2 são apresentados os resultados de moldes homogêneos para a fabricação de amostras com geometria prismática arbitrária e nas seções seguintes os resultados de moldes homogêneos e compósitos para fabricação de amostras constituídas por um único material e também amostras MGF.

\subsection{Moldes homogêneos para amostras com geometrias prismáticas arbitrárias}

\subsubsection{Modelo numérico para a otimização}

Conforme ilustrado na Figura 5.1, o modelo numérico desenvolvido para avaliar a geometria do molde de acordo com a geometria da amostra consiste num domínio bidimensional $\Omega$ que representa uma seção transversal qualquer e de espessura unitária, de um molde que contém uma amostra de geometria prismática arbitrária, cujo domínio é dado por $\Omega_{a}$.

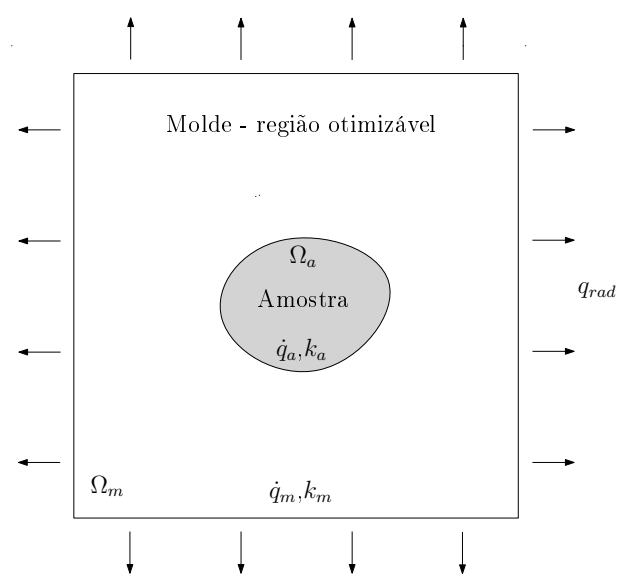

Figura 5.1: Modelo numérico para otimização de acordo com a geometria da amostra.

O carregamento térmico é indicado por $\dot{q}_{a}$ e $\dot{q}_{m}$, de modo que estes podem ocorrer simul- 
taneamente e não necessariamente iguais. Esta condição de carregamento deve-se ao fato de que ao se fabricar amostras eletricamente condutivas há fluxo de corrente elétrica predominantemente em $\Omega_{a}$, ao passo que para amostras não-condutivas, existe maior fluxo de corrente na região do molde $\Omega_{m}$. Como condição de contorno, tem-se a radiação térmica linearizada dada por $q_{\text {rad }}$.

Para se estimar os valores de geração interna de calor utilizados no modelo numérico apresentado na Figura 5.1, foi utilizado o modelo axissimétrico implementado para otimização de moldes axissimétricos homogêneos e compósitos para amostras MGF. A partir da simulação do modelo axissimétrico, verificou-se a ordem de grandeza da geração de calor ao longo da direção radial. A Figura 5.2 apresenta a geração de calor na direção radial para dois tipos de amostra: uma eletricamente condutiva composta por grafite e outra não condutiva de alumina. Como se observa na Figura 5.2, a geração de calor varia de acordo com a posição radial (ao longo da linha pontilhada indicada na Figura 5.3). No entanto, para facilitar a implementação do problema térmico apresentado na Figuras 5.1, a geração de calor dada por $\dot{q}_{a}$ e $\dot{q}_{m}$, foi uniformemente distribuída ao longo do domínio da amostra e molde.

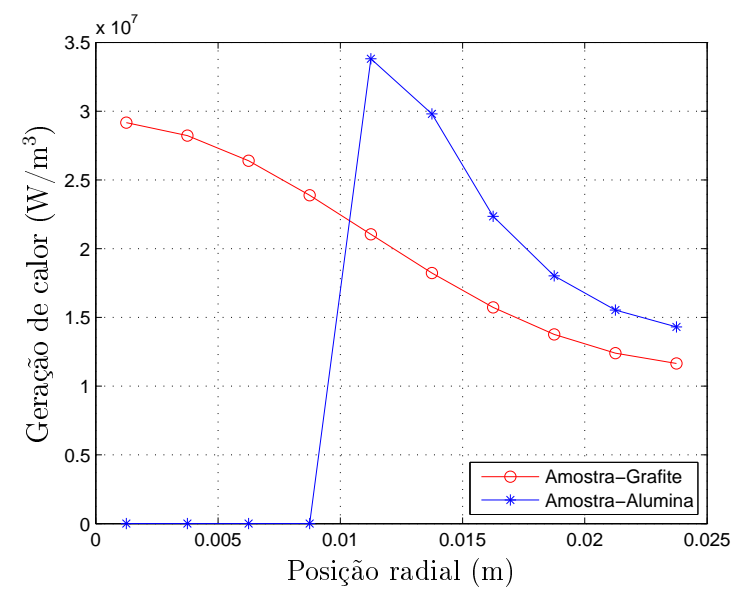

Figura 5.2: Geração de calor ao longo da direção radial do molde para amostras de grafite (eletricamente condutora) e alumina (eletricamente não-condutora).

Além da definição dos valores de geração de calor a serem introduzidos no problema de otimização, é necessário definir também a temperatura de linearização da radiação térmica. Para isso, um modelo computacional, semelhante ao modelo utilizado no problema de otimização de moldes homogêneos prismáticos, é implementado no COMSOL considerando radiação nãolinear e amostra com geometria quadrada. A partir dos resultados obtidos através do modelo COMSOL com radiação não-linear, os quais estão apresentados na Figura 5.4, a temperatura de linearização foi estimada. Assim, esta temperatura de linearização foi mantida constante em todos os processos de otimização, inclusive para nos processos envolvendo amostras com geometrias diferentes da geometria quadrada. 


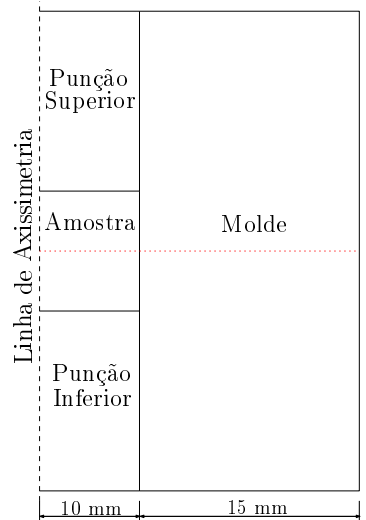

(a) Vista em Corte longitudinal

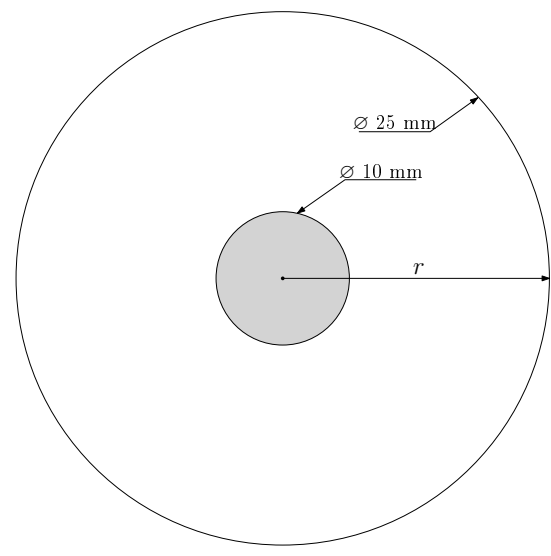

(b) Vista em planta

Figura 5.3: Corte e planta do molde axissimétrico original utilizado para estimar a geração interna de calor.

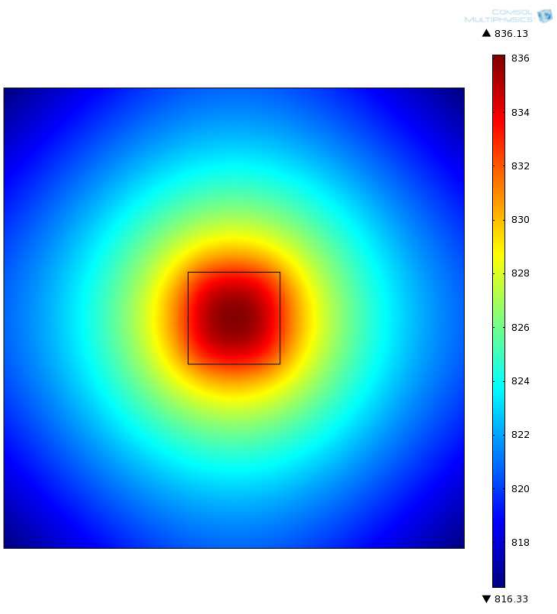

(a) Distribuição de temperatura (K)

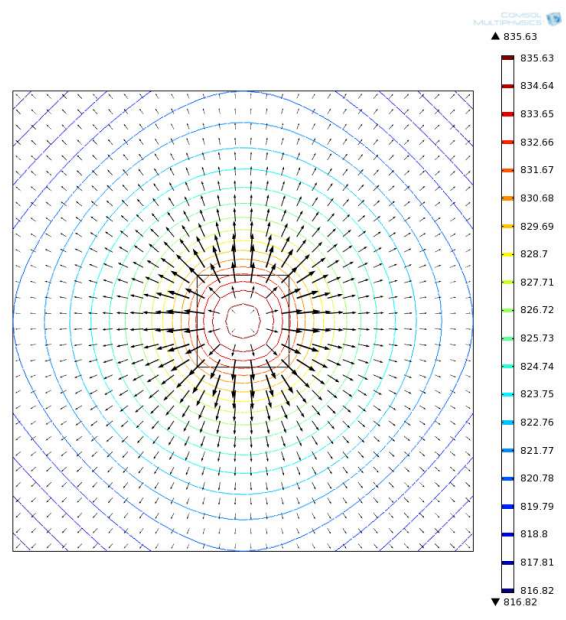

(b) Fluxo de calor e isotérmas (K)

Figura 5.4: Campo de temperaturas e fluxo de calor obtidos através do modelo computacional desenvolvido no COMSOL, considerando radiação não-linear, para estimativa das condições de contorno a serem utilizadas no problema de otimização dos moldes homogêneos prismáticos.

A Tabela B.3 apresenta os parâmetros do problema térmico, com seus respectivos valores, utilizados no processo de otimização do molde homogêneo prismático. Demais parâmetros como $\dot{q}_{a}$ e $\dot{q}_{m}$ são modificados para avaliar a influência de cada um deles na topologia ótima do molde. 


\begin{tabular}{lccc}
\hline Descrição & Parâmetro & Unidade & Valor \\
\hline Temperatura ambiente & $T_{a m b}$ & $\mathrm{~K}$ & 300 \\
Temperatura de linearização & $T_{0}$ & $\mathrm{~K}$ & 820 \\
Condutividade térmica - amostra & $k_{a}$ & $\mathrm{~W} / \mathrm{mK}$ & 50 \\
Condutividade térmica - molde & $k_{m}$ & $\mathrm{~W} / \mathrm{mK}$ & 50 \\
Total de iterações & - & - & 100 \\
\hline
\end{tabular}

Tabela 5.1: Parâmetros do problema térmico adotados da otimização de moldes homogêneos prismáticos.

Outro parâmetro definido para análise do molde homogêneo prismático foi o tamanho da amostra, avaliado pela sua área. O algoritmo de otimização foi implementado de modo que a área da amostra representasse um percentual qualquer da área do domínio $\Omega$, onde $\Omega=\Omega_{a} \cup \Omega_{m}$. Assim, para gerar os resultados da OT, foi definido que a área da amostra representa $5 \%$ da área do domínio $\Omega$, o qual tem a dimensão de $25 \times 25 \mathrm{~mm}^{2}$.

Os resultados para molde prismáticos foram obtidos através de simulações que consideraram amostras com as seguintes geometrias: quadrada, triangular e em cruz.

\subsubsection{Resultados para amostras quadradas}

A primeira análise com relação aos resultados para amostras quadradas é sobre a influência da discretização da malha e da restrição de volume na topologia final da estrutura. Os resultados obtidos são apresentados nas Figuras 5.5, 5.6 e 5.7. Estes resultados foram obtidos considerando os parâmetros indicados na Tabela 5.2.

\begin{tabular}{lccc}
\hline Descrição & Parâmetro & Unidade & Valor \\
\hline Geração de calor na amostra & $\dot{q}$ & $\mathrm{~W} / \mathrm{m}^{3}$ & $1,0 \times 10^{7}$ \\
Geração de calor no molde & $\dot{q}_{m}$ & $\mathrm{~W} / \mathrm{m}^{3}$ & $1,0 \times 10^{5}$ \\
Variável de projeto (valor inicial) & $\rho_{0}$ & - & 0,5 \\
\hline
\end{tabular}

Tabela 5.2: Parâmetros adotados da otimização de moldes prismáticos.

De acordo com os resultados das Figuras 5.5 e 5.6, verifica-se que ao refinar a malha de elementos finitos com restrição de volume de $60 \%$, obtém-se topologias que acompanham o contorno da amostra e a estrutura se mantém contínua. No entanto, para restrição de $V_{\text {max }}=70 \%$ existe uma tendência em se obter topologias com descontinuidades que refletem, de acordo com o modelo computacional, uma situação de convecção interna e que do ponto de vista do molde não é viável. A mesma variação da discretização foi realizada para restrição de volume de 100\%, o que equivale à uma análise sem restrição de volume. Os resultados 
obtidos são topologias iguais à apresentada na Figura 5.7, onde também são apresentados a distribuição de temperatura em todo o domínio de projeto e o perfil de temperatura ao longo da linha central do domínio (conforme indicado na Figura B.3).

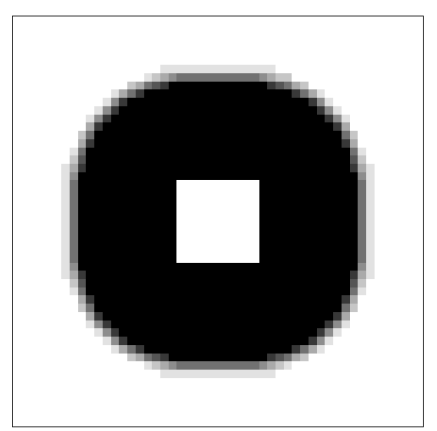

(a) Malha $50 \times 50$

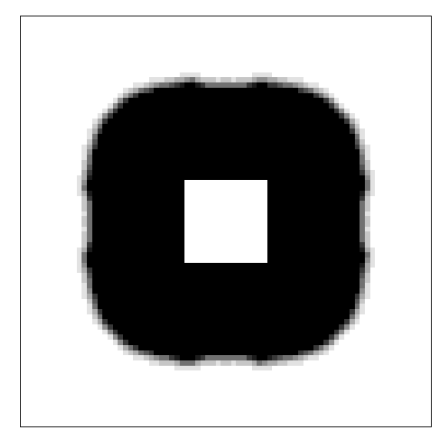

(b) Malha $80 \times 80$

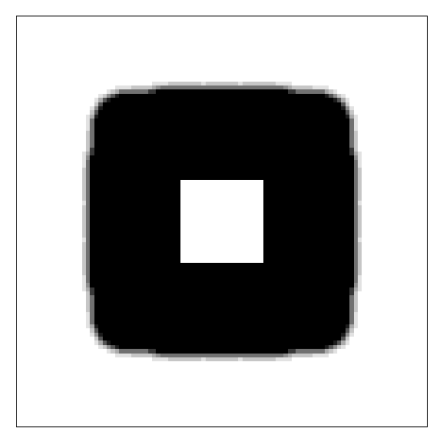

(c) Malha $100 \times 100$

Figura 5.5: Influência da discretização da malha e restrição de volume na topologia final do molde, considerando projeção desativada e $V_{\max }=60 \%$.

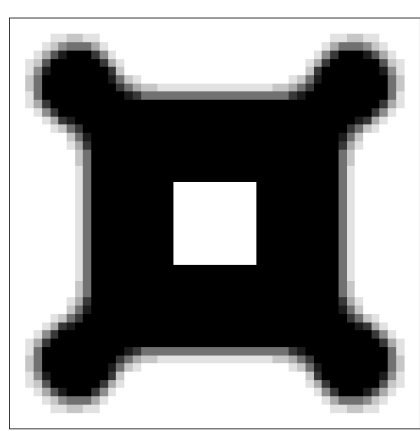

(a) Malha 50x50

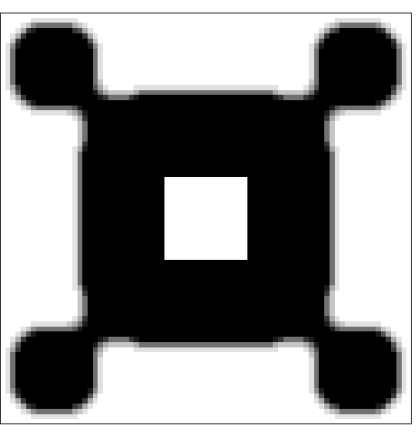

(b) Malha $80 \times 80$

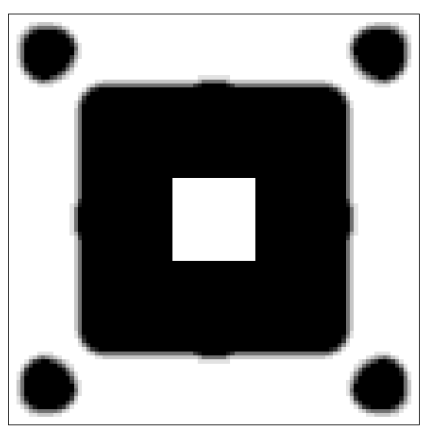

(c) Malha $100 \times 100$

Figura 5.6: Influência da discretização da malha e restrição de volume na topologia final do molde, considerando projeção desativada e $V_{\max }=70 \%$.

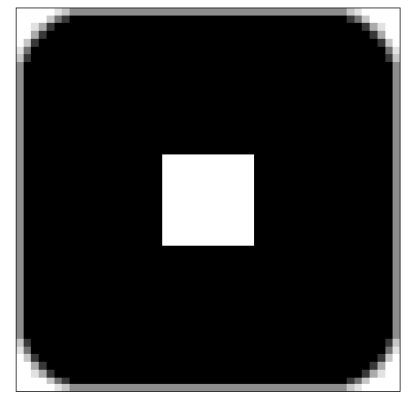

(a) Topologia

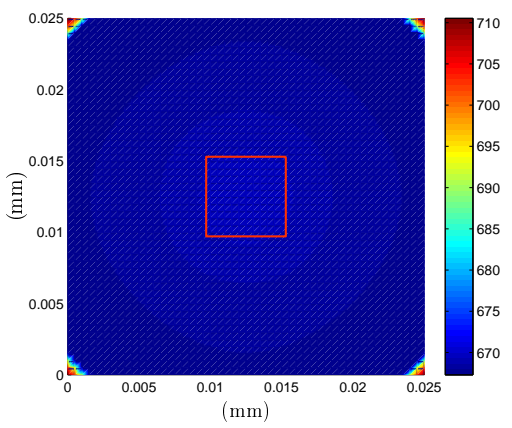

(b) Dist. Temperatura

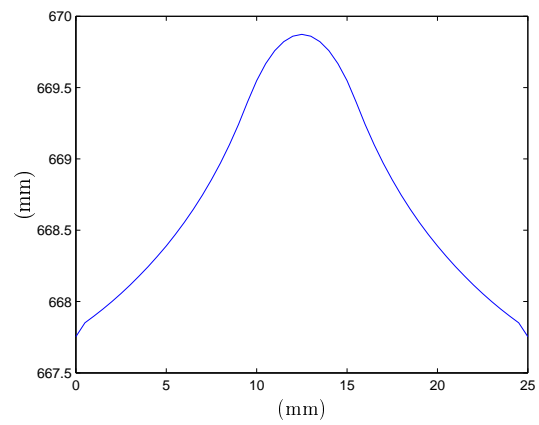

(c) Perfil de temperatura ao longo da linha central

Figura 5.7: Resultados para molde prismático com restrição de volume de $V_{\max }=100 \%$, malha 50x50 e considerando projeção desativada. 
Na Figura 5.8 são apresentados resultados de distribuição de temperatura, convergência da solução da otimização e histórico do volume da estrutura ao longo do processo iterativo. Observa-se a existência de temperaturas máximas em regiões que não apresentam material. Isto provavelmente ocorre em função da discrepância entre ordem de grandeza da geração de calor (da ordem de $10^{5}$ ) e da pseudo-densidade $\left(10^{-3}\right)$, o que permite ainda uma elevada geração de calor em regiões onde se interpreta ausência de material.

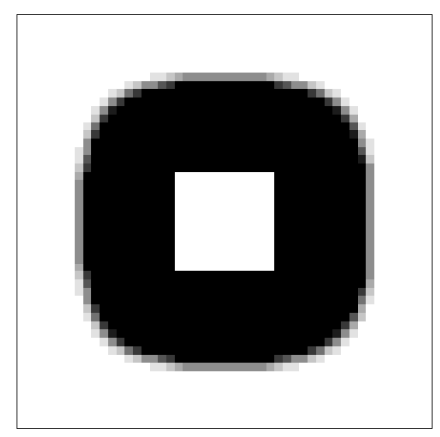

(a) Topologia

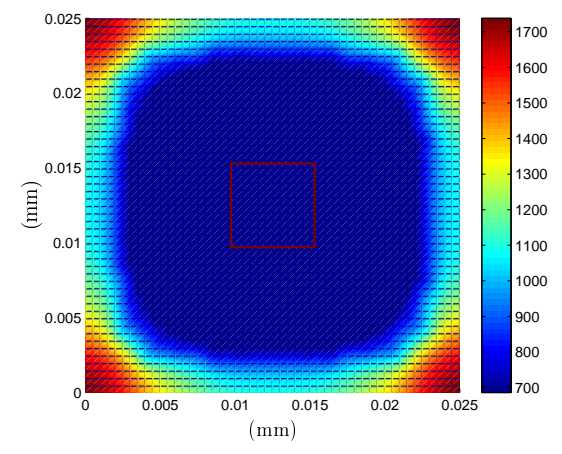

(b) Dist. Temperatura

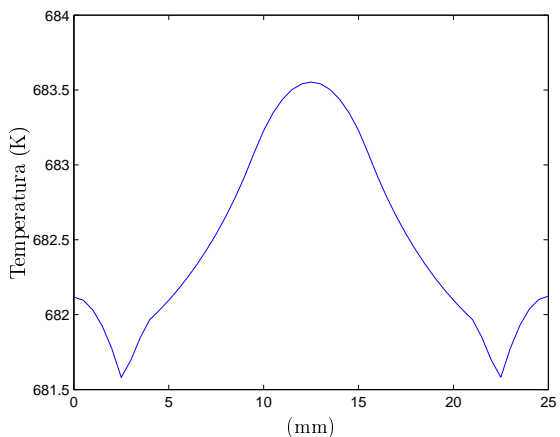

(c) Perfil de temperatura ao longo do centro do domínio

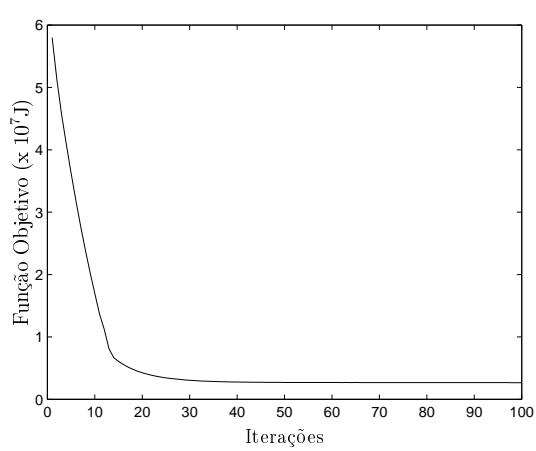

(d) Curva de convergência

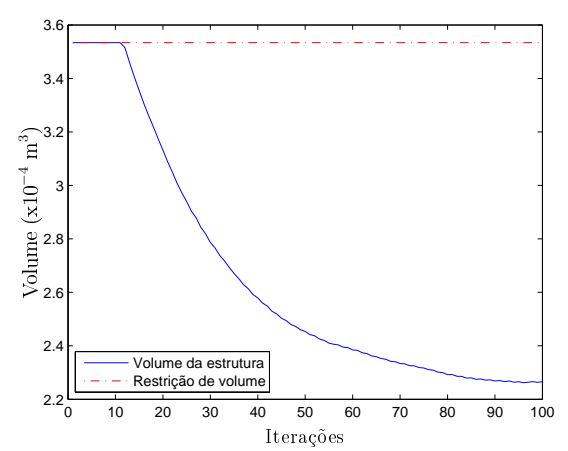

(e) Histórico do volume da estrutura

Figura 5.8: Resultados para molde prismático com amostra quadrada - $V_{\max }=60 \%$ Malha 50x50.

As Figura 5.9 e 5.10 apresentam os resultados considerando os mesmos parâmetros adotados para os resultados das Figuras 5.5 e 5.6, porém com o filtro de projeção ativado com raio de projeção igual ao dobro do lado $\left(l_{x}\right)$ de um elemento finito.

De acordo com os resultados das Figuras 5.9 e 5.10, verifica-se que a utilização de filtro de projeção induz o aparecimento de regiões com escala de cinza, principalmente para malhas com baixa discretização. A medida em que se refina a malha de elementos finitos a influência da projeção é reduzida e a estrutura tende a apresentar descontinuidades, como se verifica para o caso com restrição de $70 \%$. Isso indica a necessidade de ajustar o raio $R_{\text {min }}$ da projeção à malha de discretização para evitar este tipo de problema. No caso de $V_{\max }=60 \%$ este ajuste em $R_{\text {min }}$ não é necessário, pois mesmo refinando a malha de elementos finitos a solução obtida convergia para a topologia indicada na Figura 5.8. 


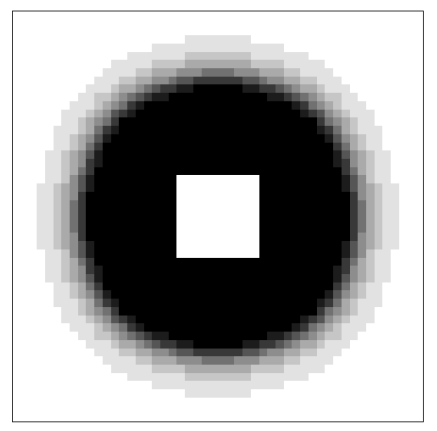

(a) Malha 50x50

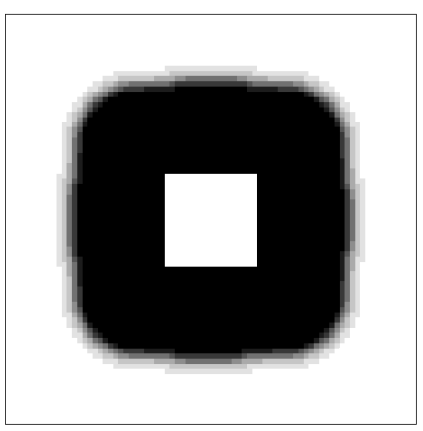

(b) Malha $80 \times 80$

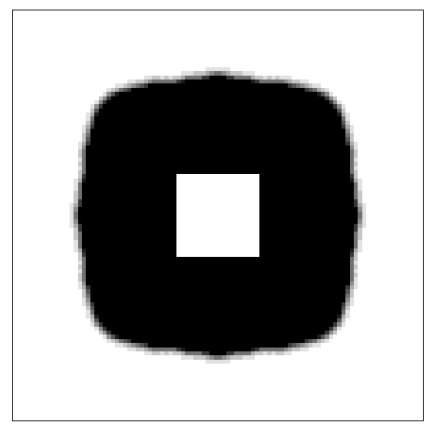

(c) Malha $100 \times 100$

Figura 5.9: Influência da discretização da malha e restrição de volume na topologia final do molde, considerando projeção ativada e $V_{\max }=60 \%$.

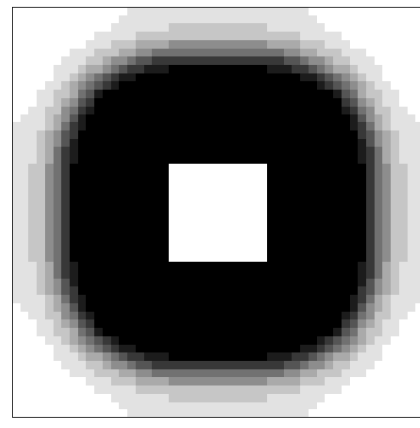

(a) Malha 50x50

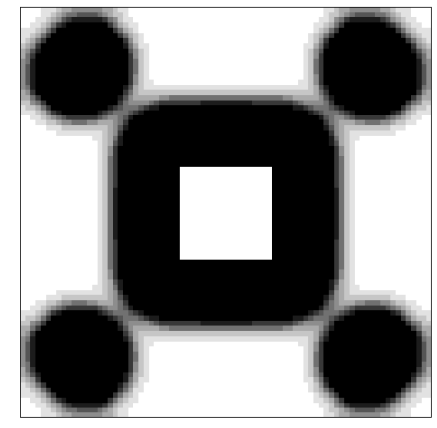

(b) Malha $80 \times 80$

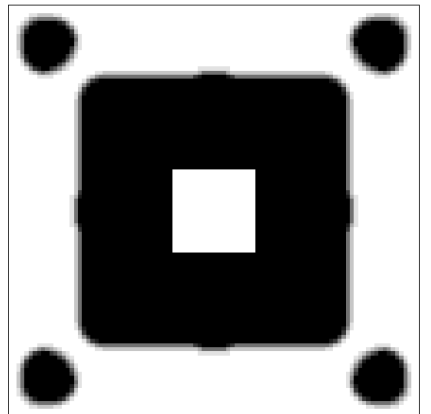

(c) Malha $100 \times 100$

Figura 5.10: Influência da discretização da malha e restrição de volume na topologia final do molde, considerando projeção ativada e $V_{\max }=70 \%$.

Além disso, simulações foram realizadas para $V_{\max }<60 \%$ e os resultados apontaram para um domínio praticamente sem material. Esta estrutura é apresentada na Figura 5.11, em que a otimização seguiu num caminho de retirar todo o material da estrutura.

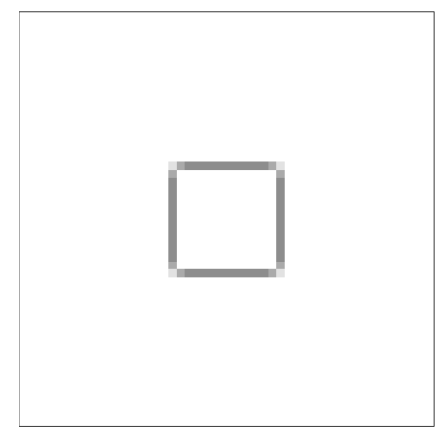

(a) Topologia

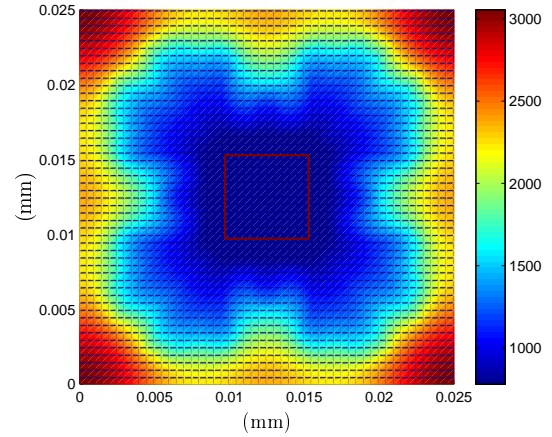

(b) Dist. Temperatura

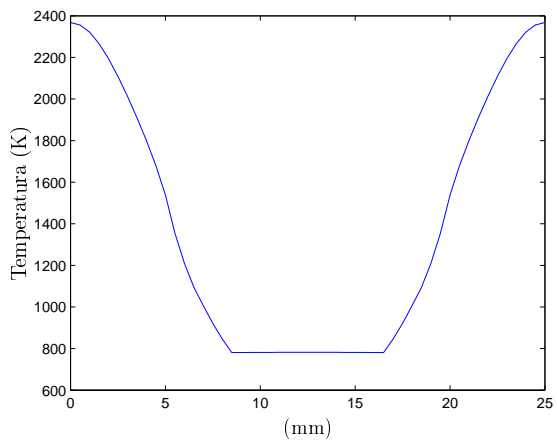

(c) Perfil de temperatura ao longo do centro do domínio

Figura 5.11: Resultados para molde prismático com amostra quadrada - $V_{\max }=50 \%$ Malha 50x50. 
Uma análise envolvendo a geração de calor no molde foi realizada, considerando a redução de $\dot{q}_{m}$ para simular uma condição de amostra com condutividade elétrica superior à condutividade do molde. Foram realizadas simulações para $\dot{q}_{m}=1,0 \times 10^{4} \mathrm{~W} / \mathrm{m}^{3}, \dot{q}_{m}=1,0 \times 10^{3}$ $\mathrm{W} / \mathrm{m}^{3}$ e $\dot{q}_{m}=1,0 \times 10^{2} \mathrm{~W} / \mathrm{m}^{3}$. Em geral os resultados foram iguais aos apresentados na Figura 5.12, que foram gerados considerando $\dot{q}_{m}=1,0 \times 10^{3} \mathrm{~W} / \mathrm{m}^{3}$, restrição de volume de $60 \%$ e variação na discretização da malha de elementos finitos. Como pode ser observado nos resultados, as topologias finais são bem próximas umas das outras, porém com mudança no campo de temperatura de acordo com a malha.

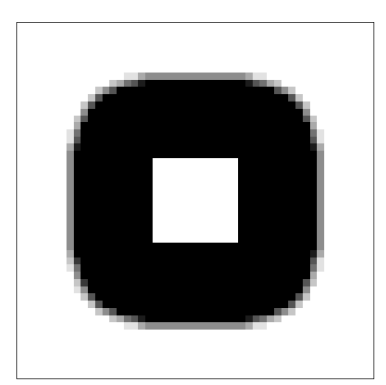

(a) malha 50x50

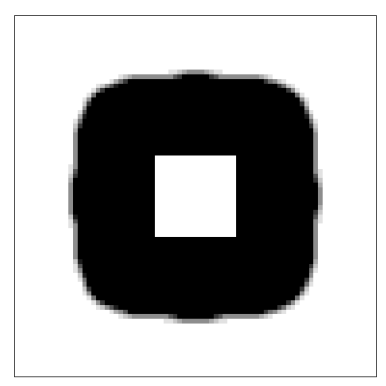

(c) malha $80 \times 80$

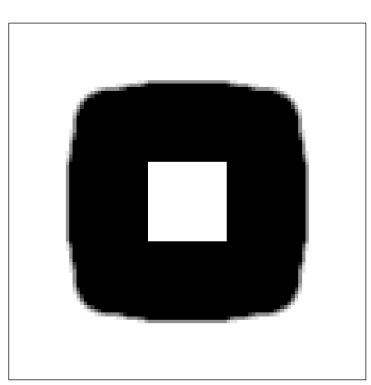

(e) malha $100 \times 100$

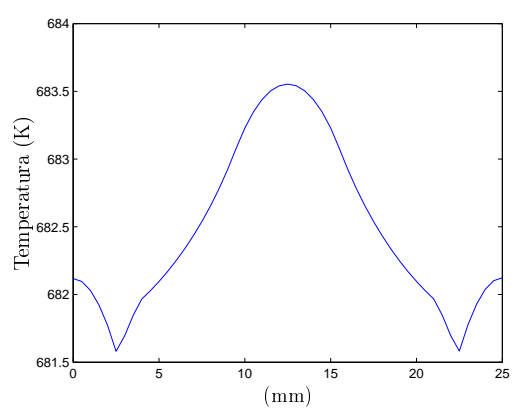

(b) Perfil de temperatura

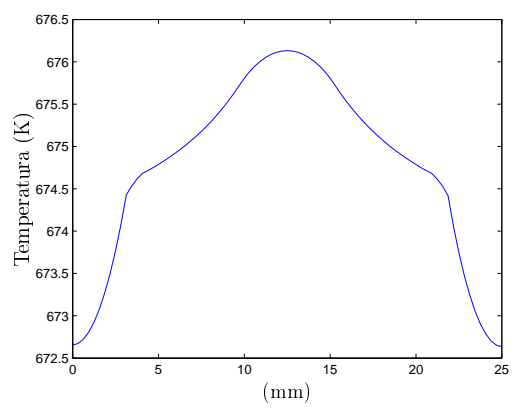

(d) Perfil de temperatura

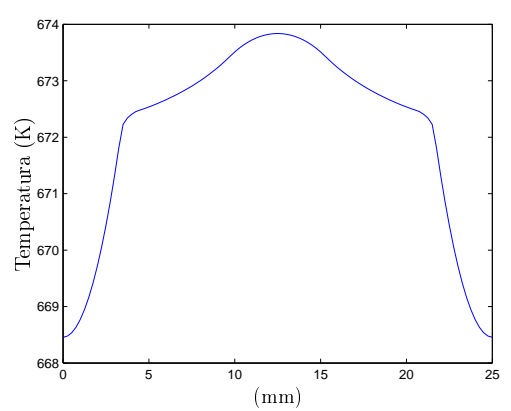

(f) Perfil de temperatura

Figura 5.12: Influência da discretização quando da redução de $\dot{q}_{m}$ para molde prismático com amostra quadrada - $V_{\max }=60 \%, \dot{q}_{m}=1,0 \times 10^{3} \mathrm{~W} / \mathrm{m}^{3}$. Topologias finais nos itens (a), (c), e (e) e respectivos perfis de temperatura nos itens (b), (d) e (f).

Na Figura 5.13 é apresentado o perfil de temperatura apenas na região da amostra para a topologia da Figura 5.12a. Este perfil de temperatura pode ser comparado qualitativamente com o perfil obtido ao utilizar uma amostra quadrada inserida num molde cilíndrico, indicado 
na Figura 5.14 e simulado no COMSOL. Verifica-se que a otimização do molde forneceu um campo de temperaturas praticamente constante na região da amostra, com temperaturas em cerca de $683 \mathrm{~K}$, ao passo que para amostra quadrada num molde cilíndrico, a amostra está sujeita a um gradiente de temperatura. Conforme se observar na Figura 5.14b, entre o centro da amostra e sua extremidade há cerca de $5 \mathrm{~K}$ de diferença.

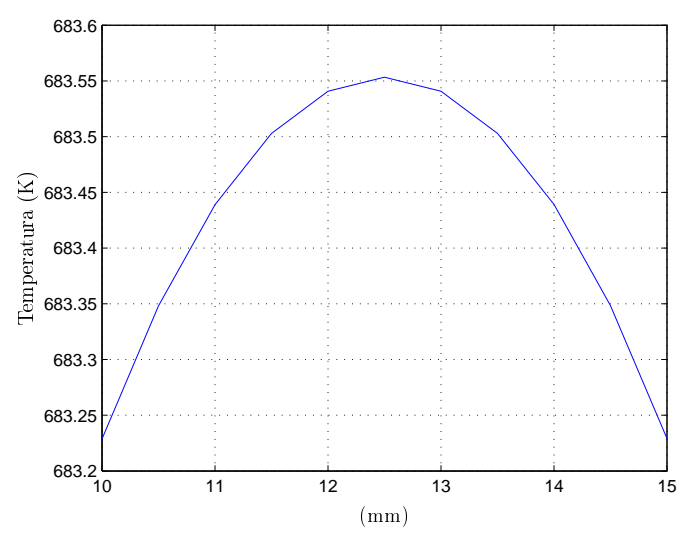

Figura 5.13: Perfil de temperatura apenas na região da amostra para topologia da Figura $5.12 \mathrm{a}$.

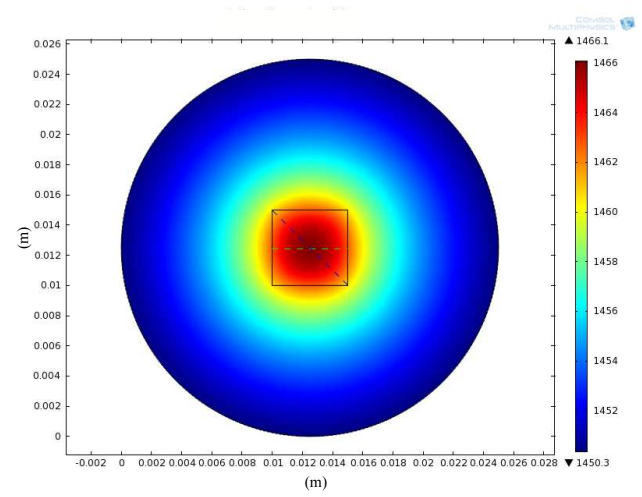

(a) Distribuição de temperatura

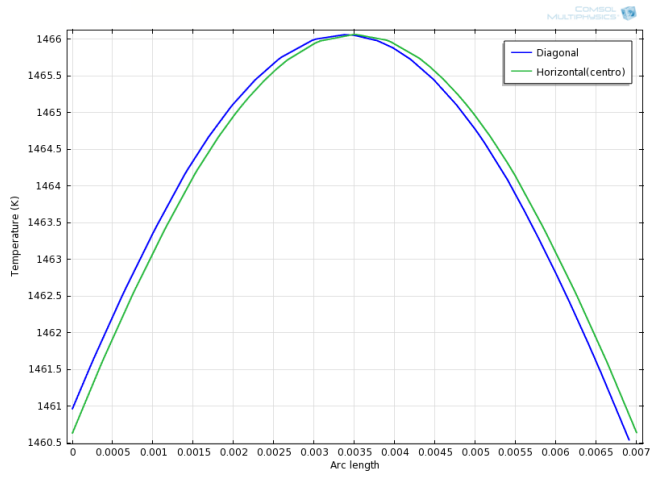

(b) Perfil de temperatura

Figura 5.14: Resultados para uma amostra quadrada inserida num molde cilíndrico

Para simular a condição de uma amostra não-condutora, a geração de calor na amostra foi reduzida ao passo que a geração no molde foi elevada. Diversas combinações de $\dot{q}_{a}$ e $\dot{q}_{m}$ foram realizadas, porém todos os resultados obtidos apontaram para uma distribuição totalmente descontínua, conforme indicado na Figura 5.15. Nesse caso, observa-se a maioria do material distribuída nas extremidades (região A na Figura 5.15a) do domínio e um "vazio" que representa conveç̧ão interna na região B da mesma figura.

A Figura 5.15b ilustra a energia potencial térmica ao longo da linha central do domínio, onde se verifica a concentração de energia em regiões onde há presença de material. A apresentação desta curva de energia térmica é uma maneira de evidenciar que não há concentração 
de energia em regiões "vazias" do domínio. Assim, se por um lado a topologia degenerada não é um resultado desejado, por outro verifica-se a consistência da estrutura com relação ao aspecto físico do problema térmico e o modelo de material implementado, que associa a condutividade térmica e geração de calor com as pseudo-densidades.

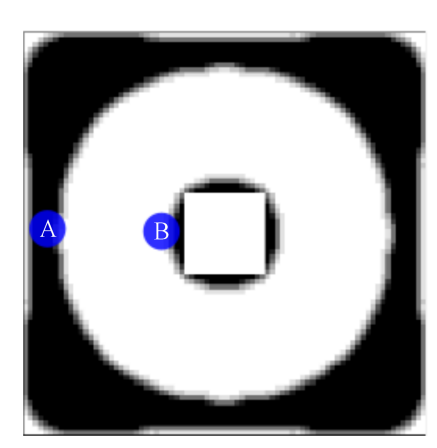

(a) Topologia degenerada

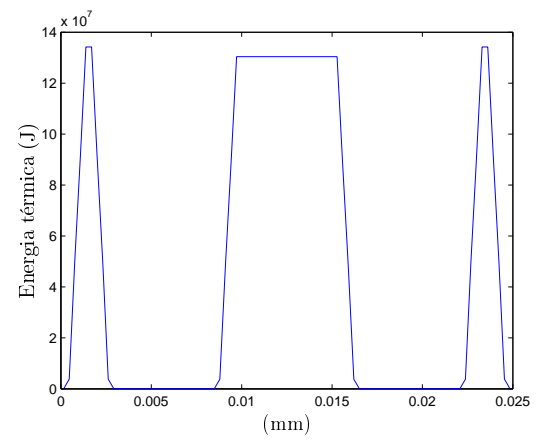

(b) Energia Potencial Térmica

Figura 5.15: Resultado para amostra quadrada e não-condutora, com $V_{\max }=60 \%$, $\dot{q}_{a}=1,0 \times 10^{5} \mathrm{~W} / \mathrm{m}^{3}$ e $\dot{q}_{m}=1,0 \times 10^{6} \mathrm{~W} / \mathrm{m}^{3}$.

Tendo em vista os resultados obtidos para as amostras com geometrias quadradas, para as demais geometrias analisadas serão apresentados apenas os resultados que apresentaram topologias coerentes para o molde.

\subsubsection{Resultados para amostras triangulares e em cruz}

Nas simulações com amostras triangulares os parâmetros da otimização estão indicados na Tabela 5.3.

\begin{tabular}{lccc}
\hline Descrição & Parâmetro & Unidade & Valor \\
\hline Geração de calor na amostra & $\dot{q}$ & $\mathrm{~W} / \mathrm{m}^{3}$ & $1,0 \times 10^{7}$ \\
Geração de calor no molde & $\dot{q_{m}}$ & $\mathrm{~W} / \mathrm{m}^{3}$ & $1,0 \times 10^{3}$ \\
Condutividade térmica - amostra & $k_{a}$ & $\mathrm{~W} / \mathrm{mK}$ & 50 \\
Restrição de volume & $V_{\max }$ & $\%$ & 60 \\
Variável de projeto (valor inicial) & $\rho_{0}$ & - & 0,6 \\
\hline
\end{tabular}

Tabela 5.3: Parâmetros adotados da otimização de moldes para amostras triangulares.

Nas Figuras 5.16 e 5.17 são apresentadas a topologia final, a distribuição de temperatura em todo o domínio de projeto e o perfil de temperatura ao longo da linha central do domínio para discretização de 80x80 e 100x100, respectivamente.

Nas simulações envolvendo amostras em cruz, foram utilizados parâmetros iguais aos aplicados para o caso de para amostras quadradas. Inclusive parâmetros como $V_{\text {max }}<60 \%$ 


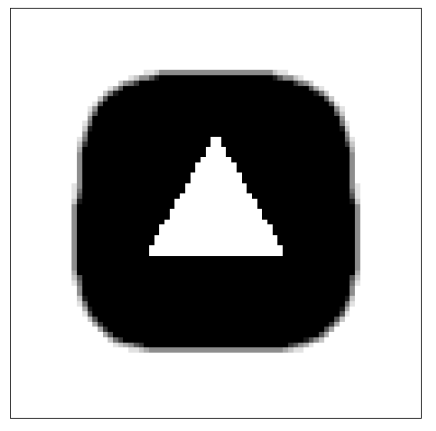

(a) Topologia

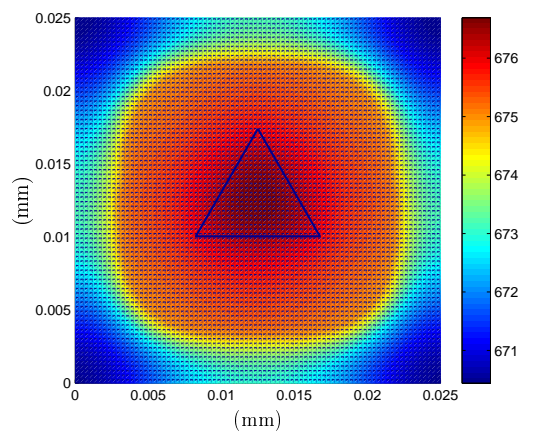

(b) Dist. Temperatura (K)

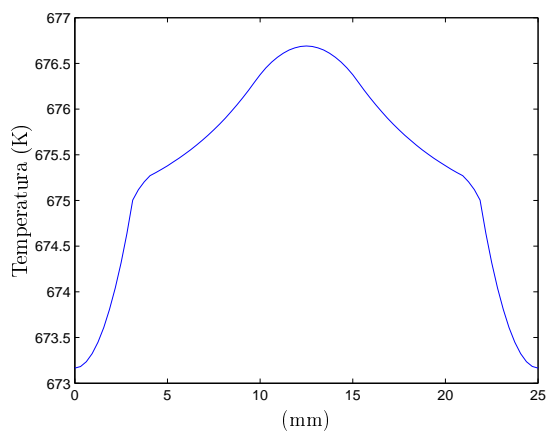

(c) Perfil de temperatura ao longo do centro do domínio

Figura 5.16: Malha 80x80 - a) Topologia final, b) Distribuição de temperatura em todo o domínio e c) Perfil de temperatura ao longo da linha central do domínio

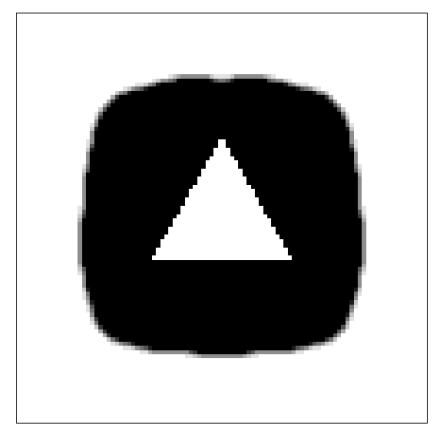

(a) Topologia

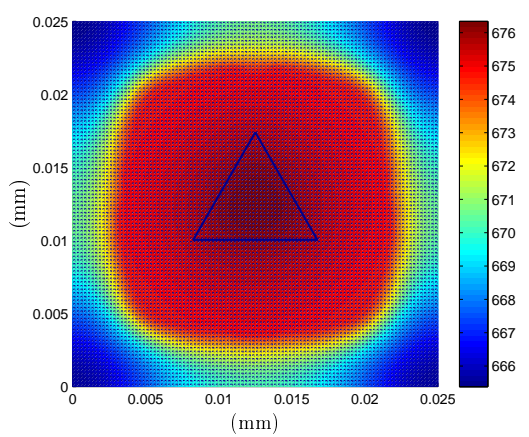

(b) Dist. Temperatura (K)

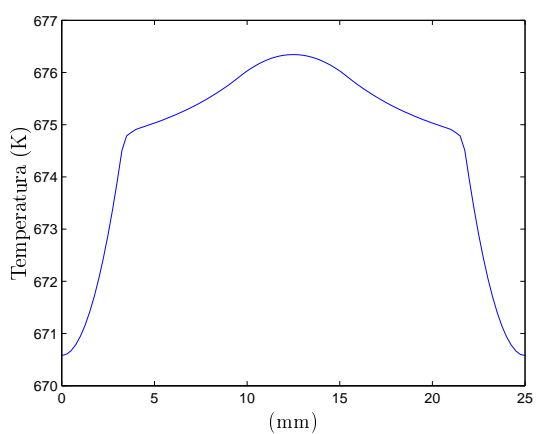

(c) Perfil de temperatura ao longo do centro do domínio

Figura 5.17: Malha 100x100 - a) Topologia final, b) Distribuição de temperatura em todo o domínio e c) Perfil de temperatura ao longo da linha central do domínio

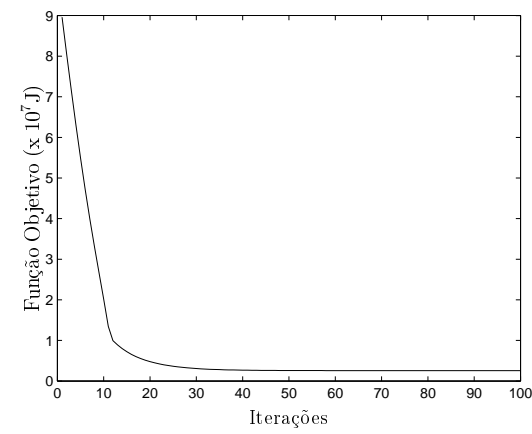

(a) Curva de Convergência

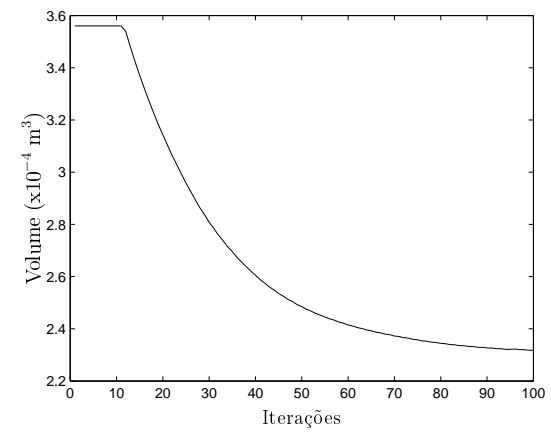

(b) Histórico do volume da estrutura

Figura 5.18: a) Curva de convergência e b) Histórico do volume da estrutura - Molde para amostras triangulares.

que resultavam em topologias inconsistentes. Neste caso, para $V_{\max }=55 \%$ e $V_{\max }=60 \%$, os resultado para amostras em cruz se mostram adequados à física do problema, ou seja, uma 
distribuição de material coerente com um molde real. Porém, para $V_{\max }=50 \%$, a distribuição de material no domínio de projeto foi praticamente nula, semelhante ao resultado com amostra quadrada, com as mesmas condições de otimização.

Os resultados para essas simulações de amostra em cruz e com restrições de volume de $V_{\max }=50 \%, V_{\max }=55 \%$ e $V_{\max }=60 \%$ são apresentados nas Figuras 5.19, 5.20 e 5.21. A Tabela 5.4 apresenta outros parâmetros de otimização utilizados nessas simulações.

\begin{tabular}{lccc}
\hline Descrição & Parâmetro & Unidade & Valor \\
\hline Geração de calor na amostra & $\dot{q_{a}}$ & $\mathrm{~W} / \mathrm{m}^{3}$ & $1,0 \times 10^{7}$ \\
Geração de calor no molde & $\dot{q}_{m}$ & $\mathrm{~W} / \mathrm{m}^{3}$ & $1,0 \times 10^{5}$ \\
Condutividade térmica - amostra & $k_{a}$ & $\mathrm{~W} / \mathrm{mK}$ & 50 \\
Variável de projeto (valor inicial) & $\rho_{0}$ & - & 0,55 \\
\hline
\end{tabular}

Tabela 5.4: Parâmetros adotados da otimização de moldes para amostras em cruz.

O objetivo de alterar o valor inicial das pseudo-densidades $\rho$, utilizando $\rho_{0}=0,55$ nas simulações para amostras em cruz, é verificar a relação entre este parâmetro e a restrição de volume. De acordo com os resultados apresentados, verifica-se que ao especificar restrições de volume abaixo do valor inicial de $\rho$, a otimização segue num sentido de retirar, praticamente, todo o material da estrutura. Ao passo que, ao especificar $V_{\max }$ acima do valor inicial de $\rho$, este comportamento da otimização não ocorre.

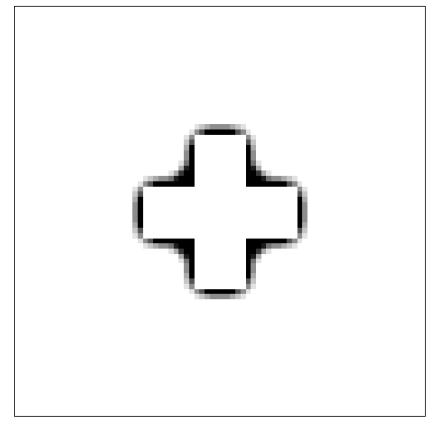

(a) Topologia

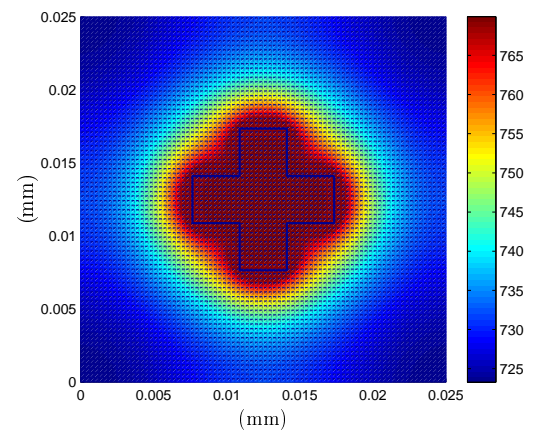

(b) Dist. Temperatura

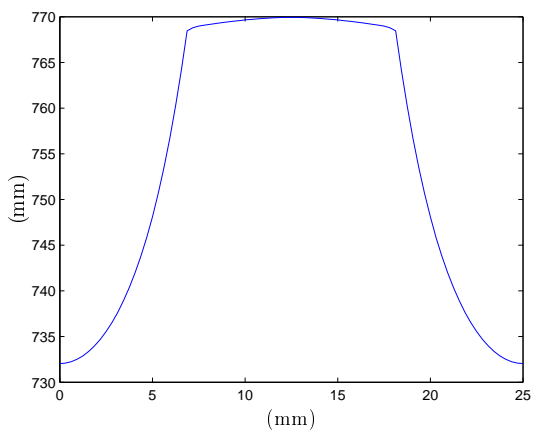

(c) Perfil de temperatura ao longo do centro do domínio

Figura 5.19: Resultados para amostra em cruz - Malha $80 \mathrm{x} 80, V_{\max }=50 \%$ e sem projeção

\subsubsection{Discussão}

Além dos resultados apresentados nesta seção, outras simulações com modelo para moldes prismáticos foram realizadas, sendo possível observar as seguintes características: 


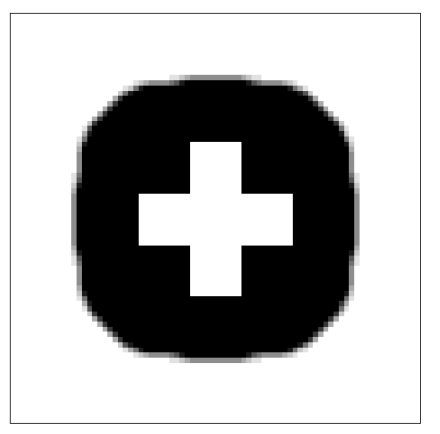

(a) Topologia

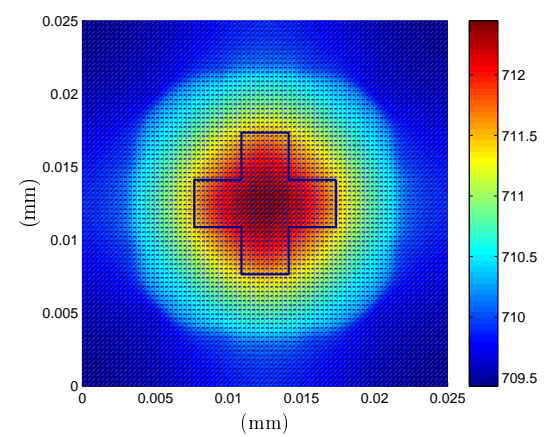

(b) Dist. Temperatura (K)

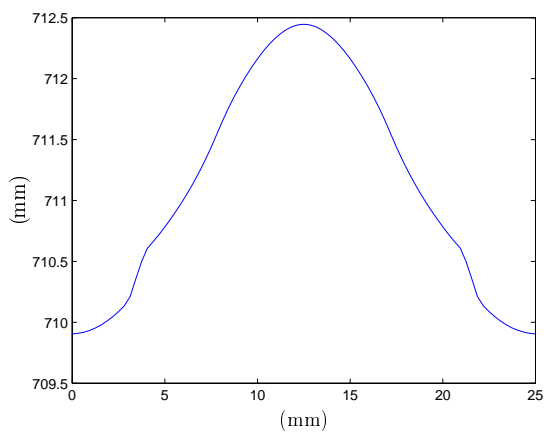

(c) Perfil de temperatura ao longo do centro do domínio

Figura 5.20: Resultados para amostra em cruz - Malha 80x80, $V_{\max }=55 \%$ e sem projeção

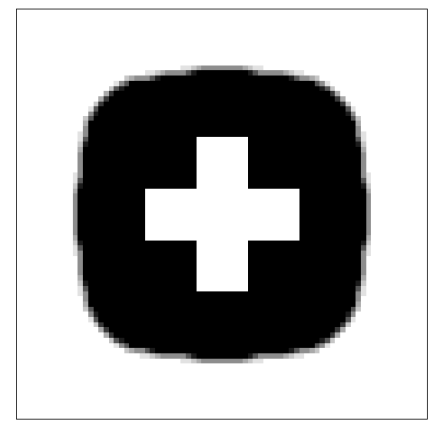

(a) Topologia

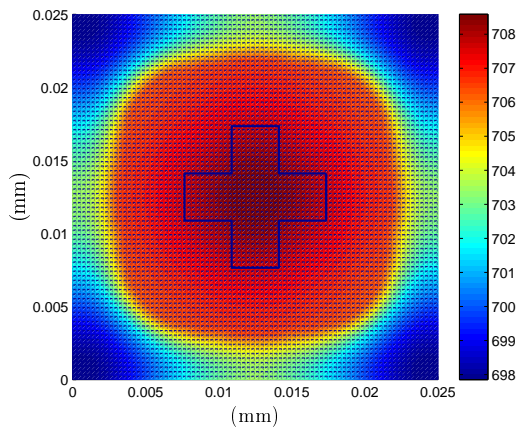

(b) Dist. Temperatura (K)

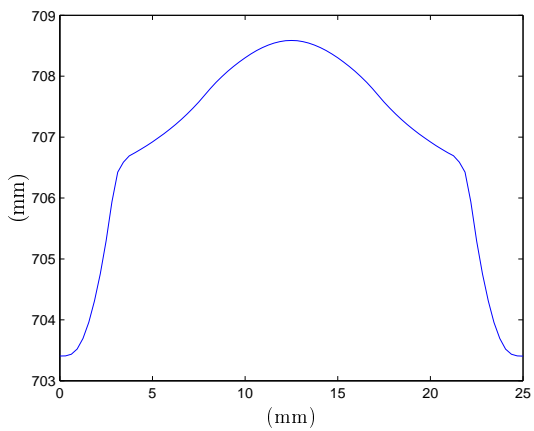

(c) Perfil de temperatura ao longo do centro do domínio

Figura 5.21: Resultados para amostra em cruz - Malha 80x80, $V_{\max }=60 \%$ e sem projeção

- Ao simular com $\dot{q}_{m} \geq \dot{q}_{a}$, os resultados obtidos não fazem sentido. A estrutura final praticamente não apresenta material no domínio e a distribuição de temperatura é também irreal, pois apresenta maiores valores nas extremidades do domínio, quando fisicamente ocorre o contrário;

- Quando $\dot{q}_{m}=\dot{q}_{a}$, o valor inicial altera sensivelmente a geometria final, mesmo esta não fazendo sentido físico;

- Resultados coerentes com o que se espera são obtidos quando $\dot{q}_{m} \leq \dot{q}_{a}$. A estrutura final apresenta material adequadamente distribuído ao redor da região da amostra, de modo a gerar um campo de temperaturas semelhante ao que ocorre no processo SPS;

Outro comportamento que deve ser ressaltado é a distribuição de temperatura quando $\dot{q}_{m} \geq \dot{q}_{a}$. Neste caso, os extremos do domínio (região A na Figura 5.15) apresentam temperaturas superiores às temperaturas da região central(região A na Figura 5.15). No início da otimização, o MEF já resulta numa região central com menores temperaturas, pois $\dot{q}_{m} \geq \dot{q}_{a}$. Com isso a otimização, que procura minimizar o potencial térmico, seguirá no sentido de 
retirar material ao redor da amostra e adicionar nos extremos do domínio do molde. Outro complicador pode ser a premissa de distribuição uniforme de geração de calor. A geração real de calor é proporcional à densidade de corrente elétrica que varia com a posição no interior do domínio. Com isso, o carregamento térmico nas extremidades do domínio é inferior ao carregamento que ocorre nas proximidades da região da amostra. No entanto, com a uniformização, as extremidades do domínio passam a ter comportamento igual a região central, com elevada geração de calor, o que na realidade não ocorre e influencia o processo de otimização.

A justificativa encontrada para as distribuições distintas quando $\dot{q}_{m} \leq \dot{q}_{a}$ e $\dot{q}_{m} \geq \dot{q}_{a}$ provavelmente se deve ao fato do modelo "enxergar" o fluxo de calor sempre da região central para a região externa. Quando $\dot{q}_{m} \geq \dot{q}_{a}$, a estrutura do molde tende a apresentar buracos (embora na literatura existam técnicas para evitar buracos ou vazios na estrutura, neste trabalho não houve implementação neste sentido). Uma vez criado um vazio no molde, o modelo interpreta este vazio como um meio externo que oferece condições para troca de calor.

Verificou-se também que a geometria do molde otimizado não sofre significativas modificações ao se alterar a geometria da amostra. Inicialmente o que se espera é um contorno do molde parecido com contorno da amostra, porém os resultados indicaram uma estrutura quadrada com cantos arredondados. Uma possível explicação para esse fato é a magnitude das grandezas físicas, tais como geração de calor e radiação térmica, que apresentam valores da ordem de $10^{7}$, enquanto que as dimensões reais do molde são da ordem de milímetros. Isso, provavelmente minimiza o efeito da geometria da amostra no campo de temperaturas que alcança valores acima de $1.000 \mathrm{~K}$ em alguns casos.

Com relação à influência da restrição de volume, verificou-se que restrição de volume com valores abaixo dos valores iniciais atribuídos às variáveis de projeto de pseudo-densidades fazem com que a topologia final tenha pouco material. Neste caso, a otimização segue num sentido de extrair todo o material inicialmente distribuído. Porém, a restrição de volume fica inativa quando da especificação desta restrição acima dos valores inicias das pseudodensidades. Neste caso, a topologia final apresenta um volume ótimo que depende do valor da restrição de volume definida acima dos valores iniciais de pseudo-densidade. Isto se verifica ao analisar as Figuras 5.5 e 5.7, onde se tem distribuições distintas para ambos os casos ainda que se tenha ao final do processo restrição de volume inativa (condição $V_{\max }=60 \%$ ). 


\subsection{Moldes axissimétricos homogêneos para amostras MGF}

\subsubsection{Modelo numérico para a otimização}

A Figura 5.22 apresenta o modelo do problema eletrotérmico e axissimétrico desenvolvido para simular o processo de sinterização SPS. Conforme indicado na figura, o processo inicia-se com a aplicação de um diferença de potencial elétrico $\Delta \phi$ entre os punções superior e inferior, de modo que o calor gerado pela passagem de corrente elétrica na estrutura é dissipado por meio da radiação $q_{\text {rad }}$ linearizada, considerando o interior da câmara como um ambiente sujeito a uma temperatura constante $T_{a m b}$. Neste modelo são consideradas as seguintes premissas: regime estacionário, propriedades físicas não dependentes da temperatura, troca térmica exclusivamente por radiação, resistências de contato desprezadas e materiais isótropos.

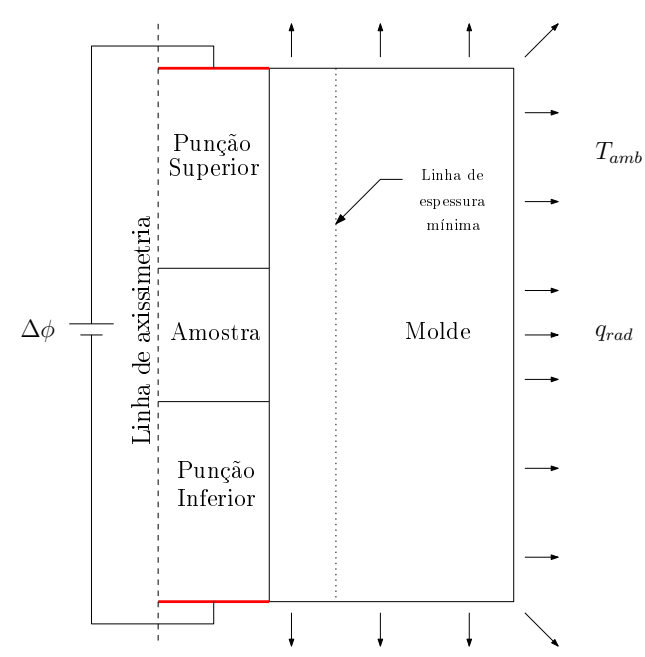

Figura 5.22: Problema eletrotérmico considerado para avaliar o processo SPS.

Com relação às considerações adotadas no modelo desenvolvido para simular o processo de sinterização SPS, as superfícies expostas à radiação no interior da câmara apresentam geometrias complexas devido à instrumentação para controle do processo e também aos aspectos construtivos de diversos componentes da câmara. Com isso o processo de radiação térmica no interior da câmara se torna de difícil modelagem, pois há diversas superfícies sujeitas à radiação térmica e nesse caso seria necessário a utilização de fatores de forma para a elaboração de um modelo preciso da radiação. Assim, para simplificar o modelo computacional, a radiação é considerada como sendo entre superfície-ambiente (emissividade igual a 1). Outra consideração importante adotada neste modelo é a ausência de resistências de contato elétrica e térmica. Conforme verificado por Vanmeensel et al. (2005), essas resistências existentes nas interfaces entre os componentes da matriz de compactação afetam a densidade de corrente elétrica, a distribuição de temperatura ao longo do conjunto ferramental e, por conseguinte, o 
gradiente de temperatura na amostra. No entanto, para simplificar a modelagem matemática, essas resistências são desprezadas, de modo que as interfaces são tomadas como um meio contínuo.

No que se refere às condições de contorno, a Tabela 5.5 apresenta os valores dos parâmetros físicos utilizados nas simulações com este modelo ao longo do processo de otimização. Maiores detalhes sobre a adoção deste modelo, bem como dos valores dos parâmetros contidos na Tabela 5.5 podem ser vistos na seção B.2 do Apêndice B.

\begin{tabular}{lc}
\hline Parâmetro & Valor \\
\hline Potencial elétrico - punção superior & 3 Volts \\
Potencial elétrico - punção inferior & 2 Volts \\
Temperatura de linearização & $1450 \mathrm{~K}$ \\
Temperatura ambiente (interior da câmara) & $300 \mathrm{~K}$ \\
\hline
\end{tabular}

Tabela 5.5: Parâmetros físicos utilizados nos problemas elétrico e térmicos.

Para o processo de otimização, os parâmetros são separados em duas tabelas. Na Tabela 5.6 são apresentados os parâmetros de otimização que são mantidos constante em todos os processos de otimização. Já na Tabela 5.7 constam os parâmetros de otimização que foram modificados para avaliar suas influências na topologia final do molde otimizado.

\begin{tabular}{lc}
\hline Parâmetro constantes & Valor \\
\hline Restrição de volume & $60 \%$ \\
Passo dos limites móveis & $10 \%$ \\
Valor inicial das variáveis de projeto & 0,5 \\
Penalizadores máximos (elétrico e térmico) & 3 \\
Gradiente de temperatura & $5 \mathrm{~K} / \mathrm{mm}$ \\
\hline
\end{tabular}

Tabela 5.6: Parâmetros de otimização adotados e constantes ao longo do processo de otimização dos moldes axissimétricos homogêneos.

Os parâmetros da Tabela 5.6 foram mantidos constantes, pois ao executar diversas vezes o algoritmo do MOT, verificou-se que ao término do processo de otimização a restrição de volume estava inativa e, uma vez obtida a convergência, a tendência do otimizador era a de retirar material da estrutura (na implementação Q4/U). Fixado o valor da restrição de volume, as variáveis de projeto foram definidas com um valor inicial igual a 0,5 , dentro do domínio viável de solução. Quanto aos penalizadores, procurou-se manter valores relativamente baixos para evitar uma transição brusca das propriedades físicas no interior do domínio, podendo 


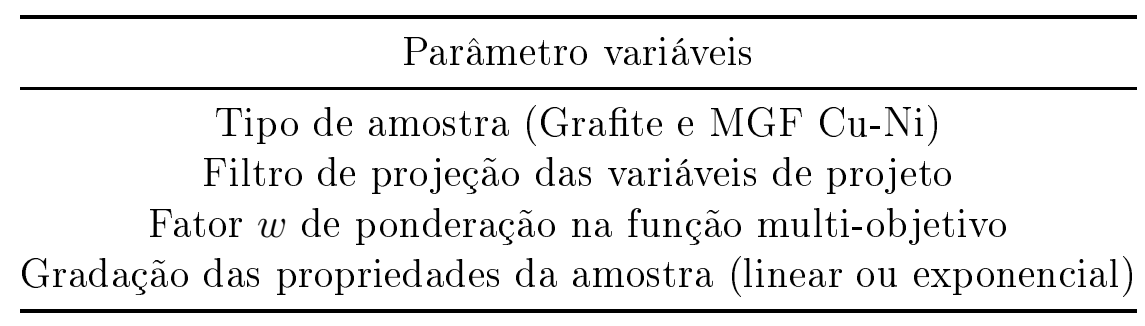

Tabela 5.7: Parâmetros variáveis de otimização adotados para avaliação da sua influência na solução ótima obtida para moldes axissimétricos homogêneos.

acarretar instabilidades numéricas na solução obtida através do MEF (BRUNS, 2007). Um estudo sobre a relação dos penalizadores no problema eletrotérmico é apresentado no trabalho de Mestrado de Varela (2012).

Além disso, nas simulações realizadas para moldes axissimétricos, foi definida uma espessura mínima (ver Figura 5.22) para a parede do molde. Nas simulações iniciais para molde axissimétrico, verificou que a distribuição de material para gerar um gradiente de temperatura se concentrava próxima a regiões dos punções e molde, criando assim uma espessura tênue para o molde. Isto ocorre, pois na formulação da função objetivo não se trabalha com valores fixos de temperatura, mas sim com gradientes, que podem ser obtidos independente da espessura da parede do molde. Diferenças na espessura impactam na intensidade do campo de temperaturas, mas não necessariamente no gradiente. Em outras palavras, um gradiente qualquer de temperatura pode ser obtido em quaisquer patamares de temperatura. Assim, definiu um valor de espessura mínima de $25 \mathrm{~mm}$, que é a espessura da parede de um molde cilíndrico real.

\subsubsection{Moldes para fabricação de amostra de Grafite}

Nesta seção são apresentados os resultados obtidos para otimização de moldes homogêneos considerando amostras de grafite. A razão da utilização de amostra de grafite consiste em avaliar o comportamento da otimização e da topologia final considerando um material com as mesmas propriedades do conjunto ferramental (molde e punções). Dessa forma, se tem a continuidade das propriedades físicas nas interfaces entre estes componentes, o que não ocorre para o caso do MGF.

Para facilitar o entendimento e comparação dos gradientes de temperaturas que são apresentados nesta e nas demais seções de resultados, a Figura 5.23 ilustra os gradientes de temperatura no início do processo de otimização, bem como a localização onde esses gradientes são avaliados.

Assim, considerando a região do molde onde os gradientes são avaliados, na Figura 5.24 são 


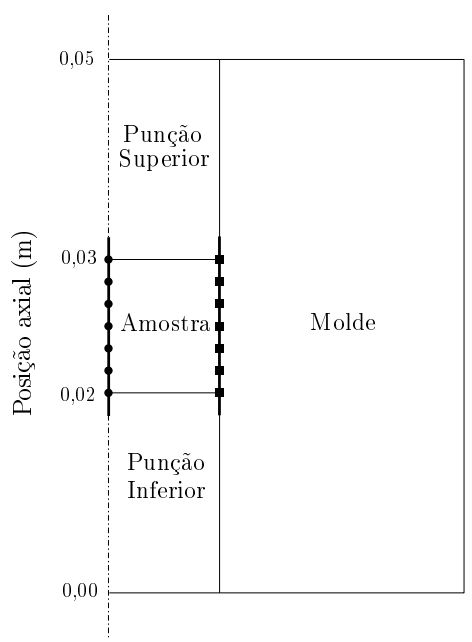

Gradientes de temperatura avaliados na direção axial

$\rightarrow$ Gradiente no centro da amostra

-..- Gradiente na interface amostra-molde

Figura 5.23: Indicação da região dos moldes axissimétricos onde os gradientes de temperatura são avaliados.

apresentados os gradientes fornecidos por um molde cilíndrico. Estes gradientes são aqueles obtidos no início do processo de otimização, quando se tem uma distribuição uniforme das variáveis de projeto (pseudo-densidades $\rho$ ). Por esta razão, tais gradientes são indicados como gradiente Inicial e apresentados, nas seções de resultados, juntos com os gradientes Especificado e Otimizado, para efeito de comparação.

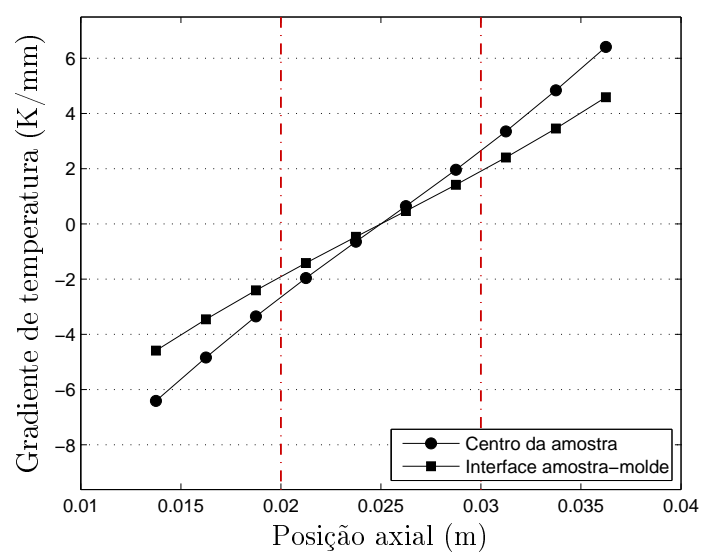

Figura 5.24: Gradiente Inicial para $\rho_{0}=1$ no início do processo de otimização.

Vale ressaltar que os gradientes apresentados na Figura 5.24 foram obtidos para variáveis de projeto com valor inicial igual um $\left(\rho_{0}=1,0\right)$. Estes gradientes são os mesmos obtidos para $\rho_{0}$ com valores diferentes de um, como por exemplo $\rho_{0}=0,5$, que é o valor adotado para iniciar o processo de otimização, conforme indicado na Tabela 5.6.

Este comportamento dos gradientes de temperatura obtidos para $\rho_{0}=0,5$ e $\rho_{0}=1,0$ serem iguais, justifica-se pelo fato dos modelos implementados considerarem as propriedades independentes da temperatura e condições de contorno lineares. Para modelos em que as 
propriedades dos materiais variam com a temperatura e as condições de contorno não são lineares, como por exemplo a radiação, tal comportamento não ocorre.

\subsubsection{Influência do fator $w$ da função multi-objetivo}

Para verificar a influência do fator $w$ na geometria do molde e no gradiente de temperatura que esta geometria é capaz de gerar, este parâmetro é variado de 1 até 0 . Na Figura 5.25 tem-se a geometria para $w=1$, que implica numa otimização que visa minimizar o potencial térmico da estrutura (ver Equação 4.22) (VASCONCELOS; MELLO; SILVA, 2010). Embora esta minimização não seja o objetivo pretendido nesta abordagem de otimização do molde, o resultado para $w=1$ é apresentado apenas para efeito de análise da influência deste fator $w$.

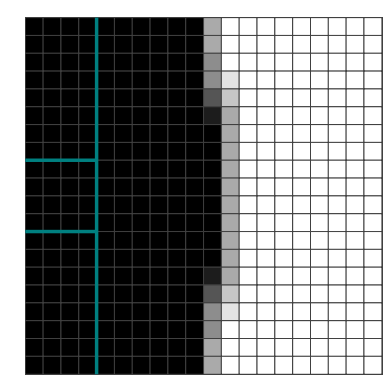

Figura 5.25: Malha 20x20, $w=1,0$ e sem projeção.

Para $w<1$, as topologias obtidas são apresentadas juntamente com os respectivos gradientes de temperatura. Nos gráficos onde constam os gradientes, tem-se as seguintes curvas: Inicial, obtida no início do processo de otimização; Otimizado, referente ao gradiente com a topologia final e Especificado, que representa do gradiente que se deseja obter ao final da otimização. Nesses gráficos, a região entre 0,02 m e 0,03 m (delimitada pelas linhas traço-ponto na vertical), refere-se à região da amostra. São apresentados os gradientes de temperatura gerados na linha central da amostra e na sua extremidade em contato com a parede interna do molde.

De acordo com os resultados das Figuras 5.26, 5.27, 5.28 e 5.29, à medida em que o fator $w$ é reduzido como uma tentativa de impor o gradiente de temperatura especificado, o gradiente de temperatura Otimizado tende a se aproximar do Especificado, apesar de para $w=0$ ainda permanecer relativamente distante. Além disso, surgiram regiões com tabuleiro de xadrez (topologias das Figuras 5.28 e 5.29), que não representam uma física real, pois considerando o modelo implementado, nas interfaces entre elementos sólidos e vazios ocorre transferência de calor por convecção, ocorrendo então uma convecção interna. 


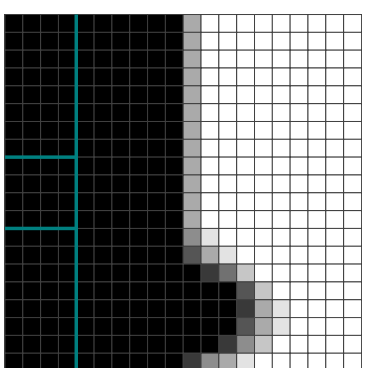

(a) Topologia

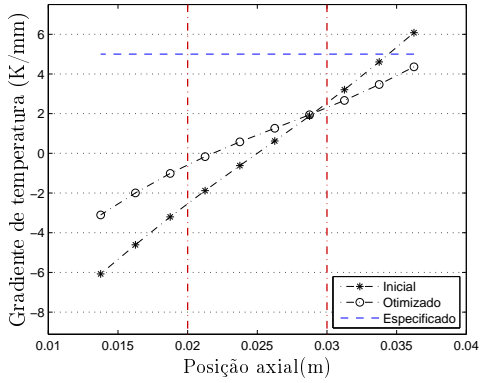

(b) Centro da amostra

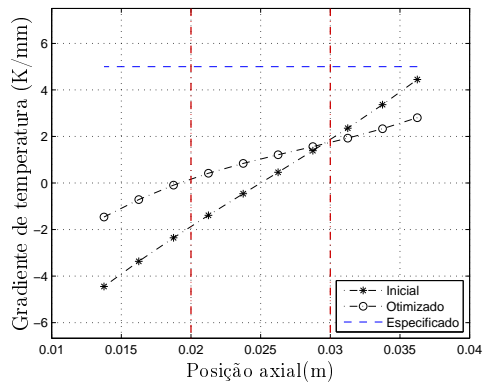

(c) Interface amostra-molde

Figura 5.26: Malha 20x20, $w=0,8$ e sem projeção.

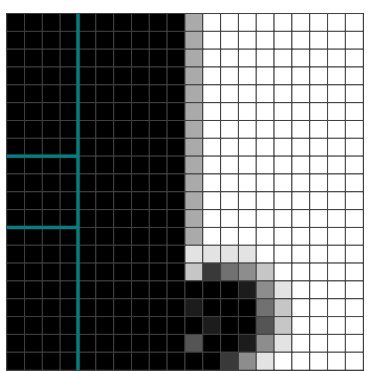

(a) Topologia

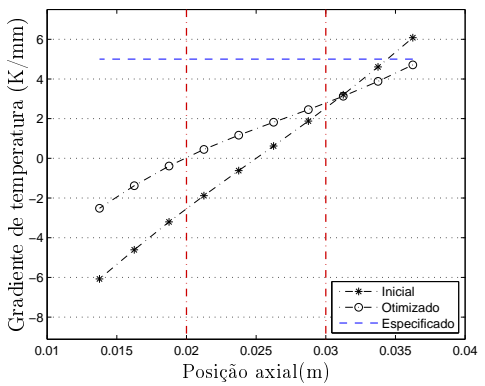

(b) Centro da amostra

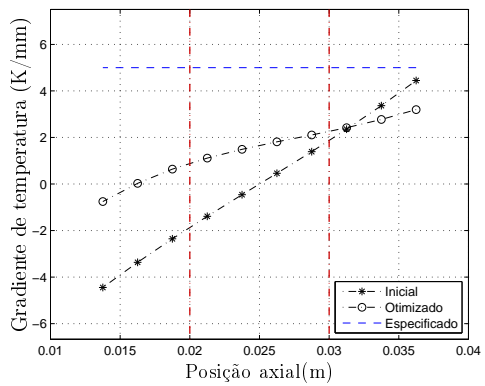

(c) Interface amostra-molde

Figura 5.27: Malha 20x20, $w=0,6$ e sem projeção.

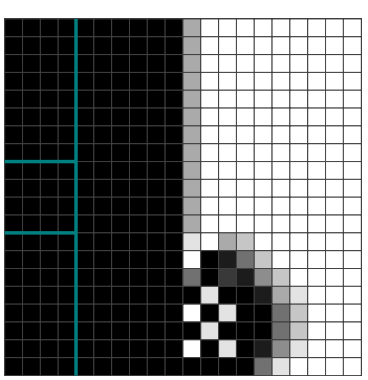

(a) Topologia

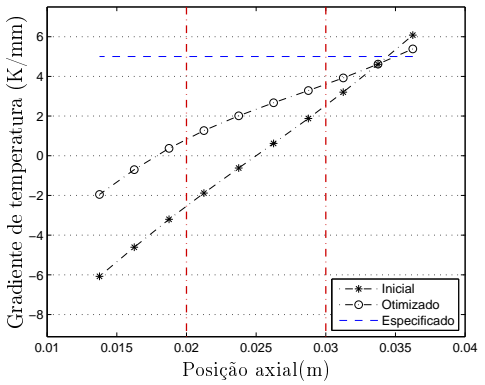

(b) Centro da amostra

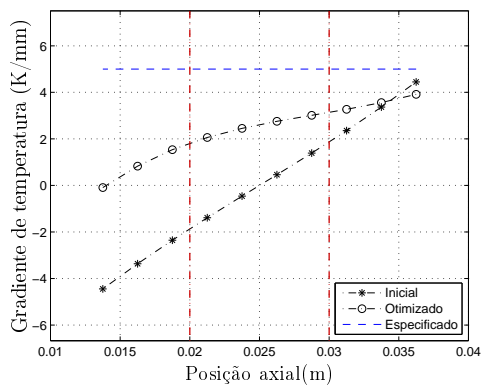

(c) Interface amostra-molde

Figura 5.28: Malha 20x20, $w=0,3$ e sem projeção.

\subsubsection{Influência do filtro de projeção}

Para evitar a ocorrência de tabuleiro de xadrez na estrutura do molde, nesta seção é verificada a influência do filtro de projeção nos casos onde esta instabilidade ocorreu.

As Figuras 5.28 e 5.29 apresentam a topologia para filtro de projeção com $r_{\min }=2 L_{e}$, onde $L_{e}$ é o comprimento do lado de um elemento finito.

De acordo com os resultados das Figuras 5.28 e 5.29, com a utilização da técnica de projeção, a instabilidade de tabuleiro de xadrez foi eliminada, conforme se observa nas Figuras 


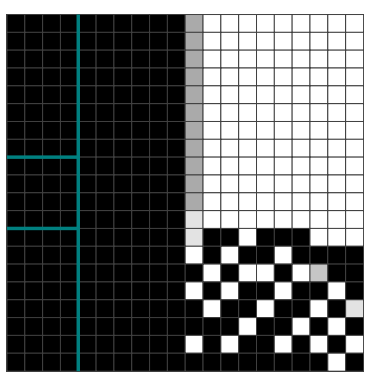

(a) Topologia

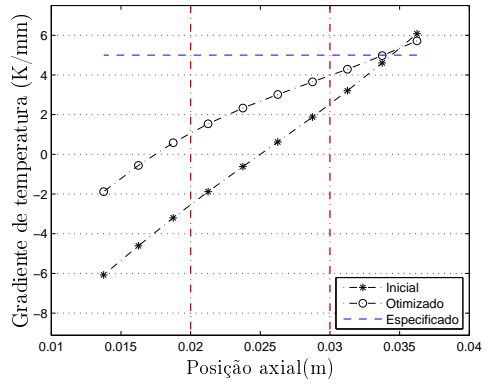

(b) Centro da amostra

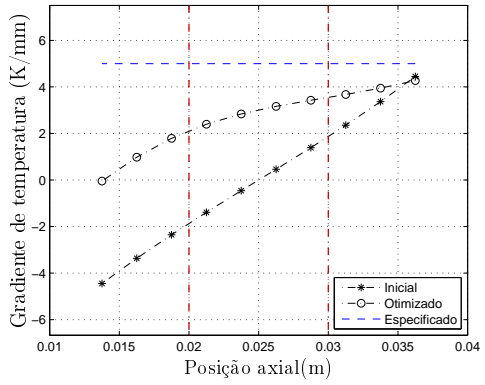

(c) Interface amostra-molde

Figura 5.29: Malha 20x20, $w=0$ e sem projeção.

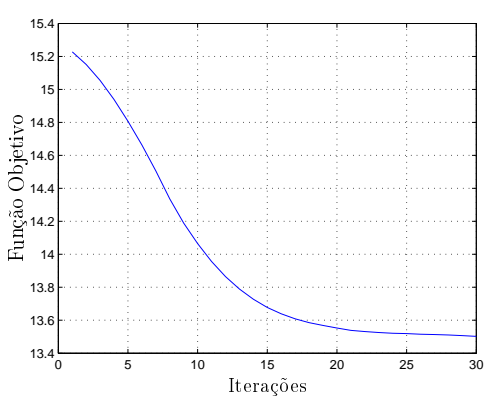

(a) Convergência

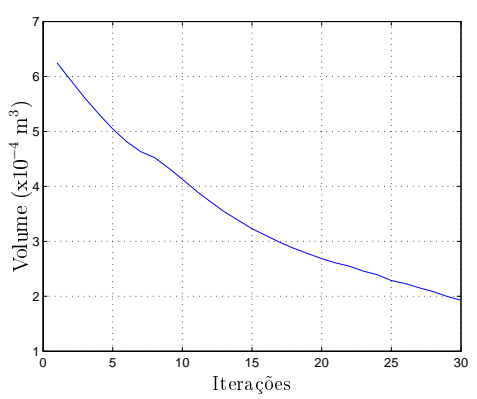

(b) Histórico do volume

Figura 5.30: Curvas de convergência e histórico de volume na otimização de moldes para amostra de grafite.

5.31 e 5.32. No entanto, em decorrência do uso da projeção, a solução apresenta regiões com escala de cinza, que também é indesejado. Para reduzir esta escala de cinza, foram realizadas simulações com projeção parcial, que consiste em manter ativa a projeção ao longo do processo de otimização e nas últimas iterações a projeção é desativada. Nessas simulações com projeção parcial, nas dez últimas iterações da otimização a projeção foi desativada. Os resultados para essas simulações são apresentados nas Figuras 5.33 e 5.34, e se verifica ainda a existência de cinza na estrutura.

Outra tentativa para minimizar a escala de cinza foi reduzir o tamanho do raio de influência dos elementos adjacentes nas pseudo-densidades. Nesse caso manteve-se a projeção parcial, porém utilizando um valor de $r_{\min }=L_{e}$. Os resultados obtidos para essas condições são apresentados nas Figuras 5.35 e 5.35.

Nas Figuras 5.35 e 5.36, verifica-se a significativa redução na escala de cinza das topologias ótimas. Além disso, é possível observar uma melhora nos gradientes de temperatura na interface amostra-molde, interface essa que representa a parede interna no molde na região da amostra. Outra consequência do uso da projeção, é a sua influência nos gradientes de temperatura. Com a projeção ativa ao longo de todo o processo de otimização, o gradiente 


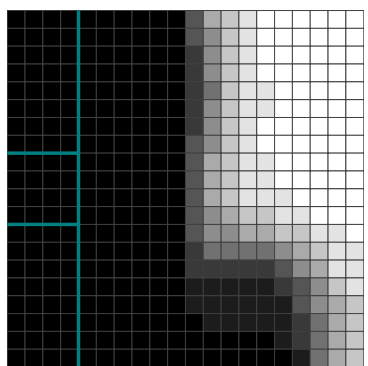

(a) Topologia

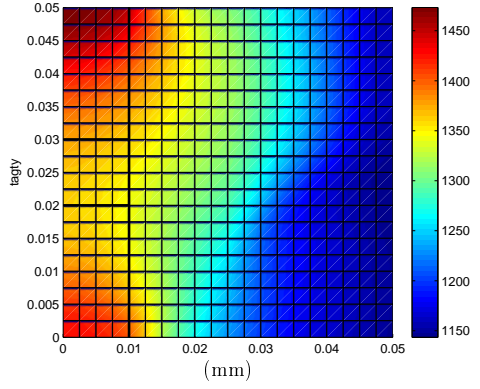

(b) Dist. Temperatura

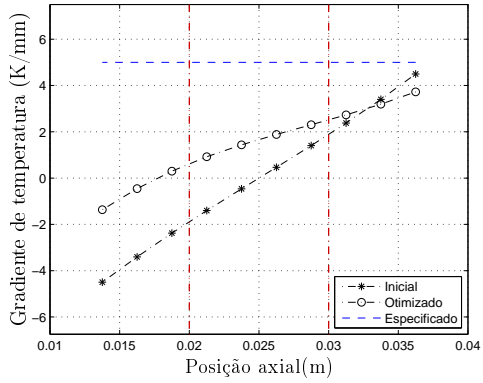

(c) Gradientes de temperatura na interface amostra-molde

Figura 5.31: Solução ótima para molde axissimétrico homogêneo. Malha 20x20, $w=0,3$ e com projeção $\left(r_{\min }=2 L_{e}\right)$ - Amostra de grafite

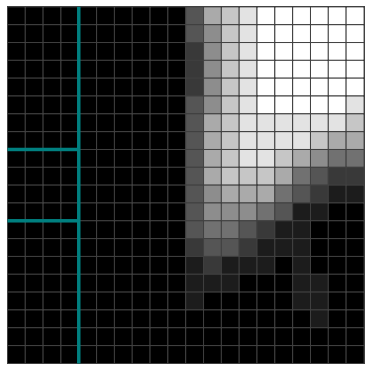

(a) Topologia

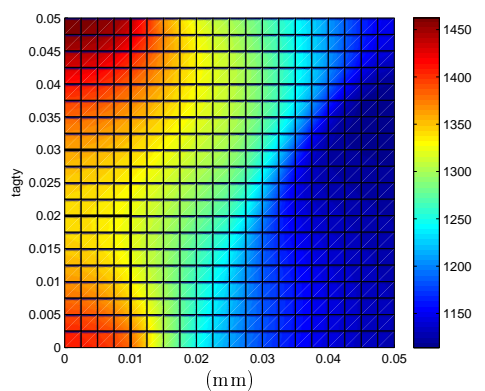

(b) Dist. Temperatura

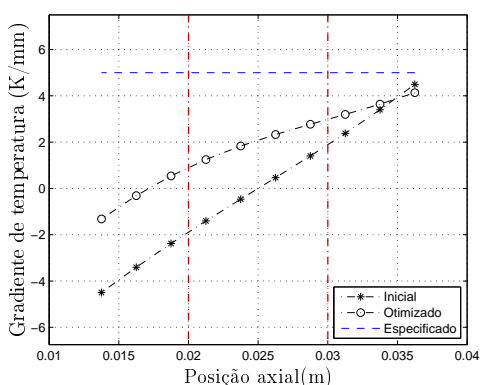

(c) Gradientes de temperatura na interface amostra-molde

Figura 5.32: Solução ótima para molde axissimétrico homogêneo. Malha 20x20, $w=0 \mathrm{e}$ com projeção $\left(r_{\min }=2 L_{e}\right)$ - Amostra de grafite.

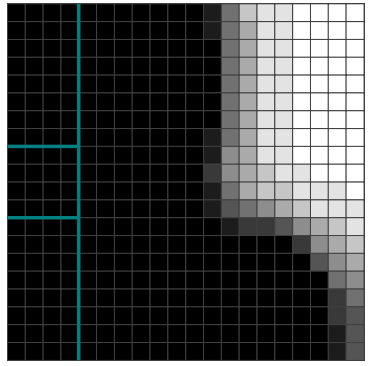

(a) Topologia

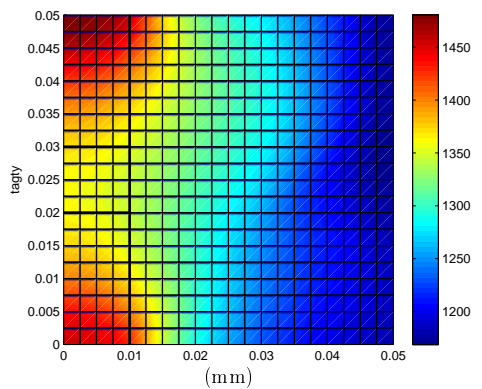

(b) Dist. Temperatura

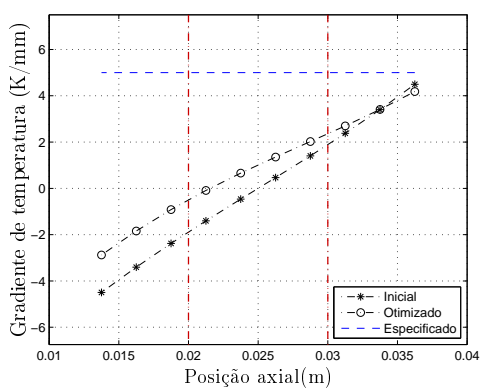

(c) Gradientes de temperatura na interface amostra-molde

Figura 5.33: Soluções ótima para molde axissimétrico homogêneo. Malha 20x20, $w=0,3$ com projeção parcial $\left(r_{\min }=2 L_{e}\right)$ - Amostra de grafite.

Otimizado é inferior ao gradiente obtido com a estrutura apresentando a instabilidade de tabuleiro, ou seja, o gradiente Otimizado fica mais distante do Especificado. Isto é facilmente verificado ao se comparar os resultados das Figuras 5.29 e 5.32. No entanto, ao se utilizar a projeção parcialmente ativa, durante a otimização, e ajustando o raio $r_{\text {min }}$, é possível obter uma topologia melhor definida e uma melhora aproximação entre os gradientes Otimizado e 


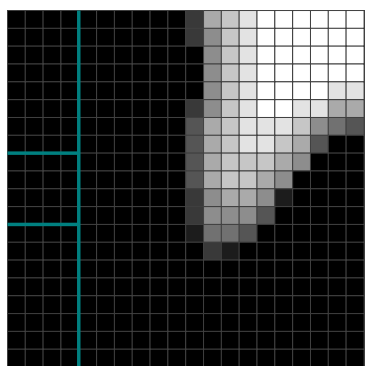

(a) Topologia

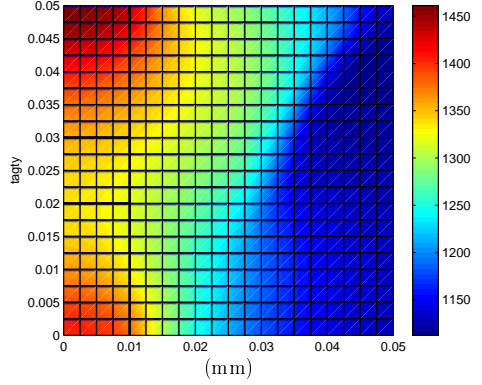

(b) Dist. Temperatura

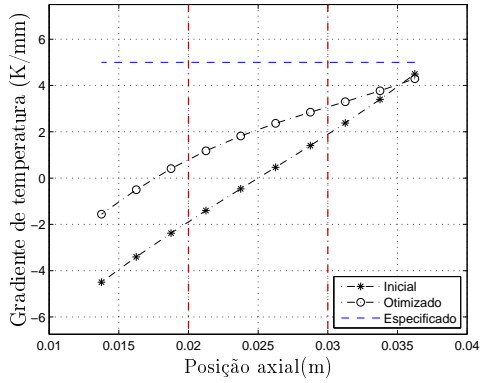

(c) Gradientes de temperatura na interface amostra-molde

Figura 5.34: Solução ótima para molde axissimétrico homogêneo. Malha 20x20, $w=0$ com projeção parcial $\left(r_{\min }=2 L_{e}\right)$ - Amostra de grafite.

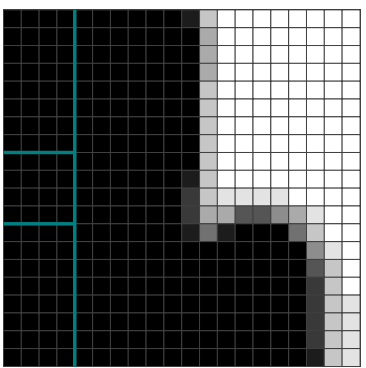

(a) Topologia

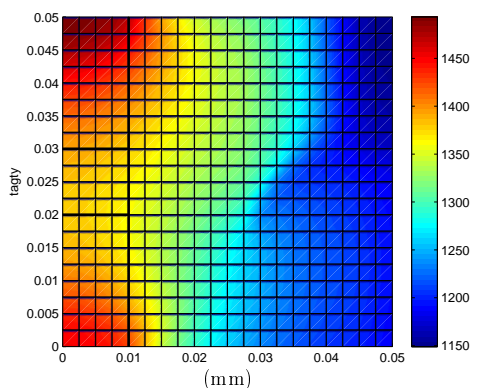

(b) Dist. Temperatura

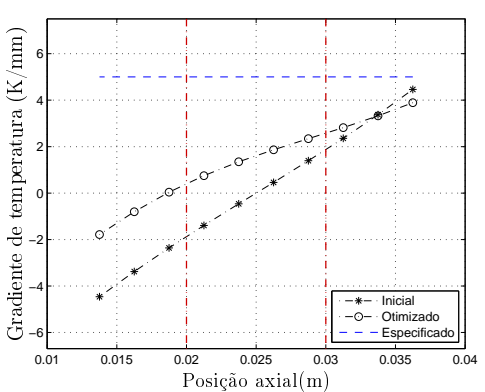

(c) Gradientes de temperatura na interface amostra-molde

Figura 5.35: Solução ótima para molde axissimétrico homogêneo. Malha 20x20, $w=0,3$ com projeção parcial $\left(r_{\min }=L_{e}\right)$ - Amostra de grafite.

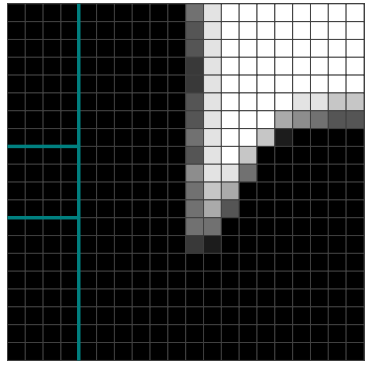

(a) Topologia

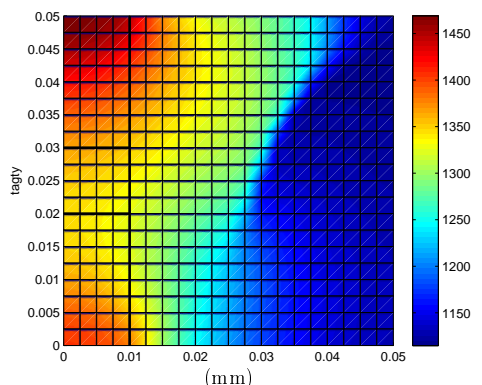

(b) Dist. Temperatura

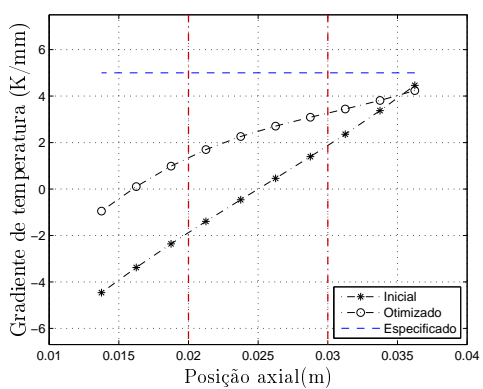

(c) Gradientes de temperatura na interface amostra-molde

Figura 5.36: Solução ótima para molde axissimétrico homogêneo. Malha 20x20, $w=0$ com projeção parcial $\left(r_{\text {min }}=L_{e}\right)$ - Amostra de grafite.

\section{Especificado.}

Com relação a convergência da função objetivo e volume da estrutura, em geral, as otimizações apresentaram mesmo comportamento quanto a esses parâmetros. Na Figura 5.37 tem-se as curvas de convergência e o histórico do volume da topologia ao longo das iterações, 
para as simulações com projeção parcialmente ativa. Verifica-se que ao desativar a projeção (iteração 50), a otimização segue num sentido de adicionar material ao domínio de projeto até que a restrição de volume seja atingida e permaneça ativa ao final do processo. Porém, também se observa (ainda na Figura 5.37) que após desativar a projeção que a função objetivo passa a assumir valores maiores.

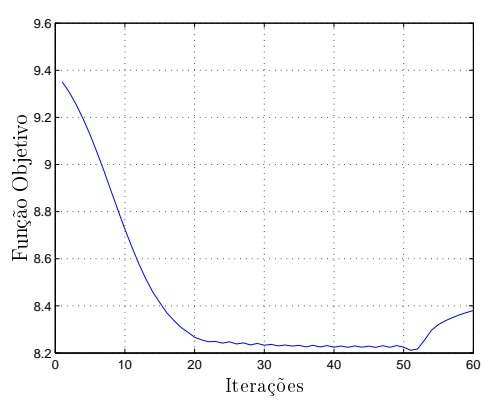

(a) Convergência

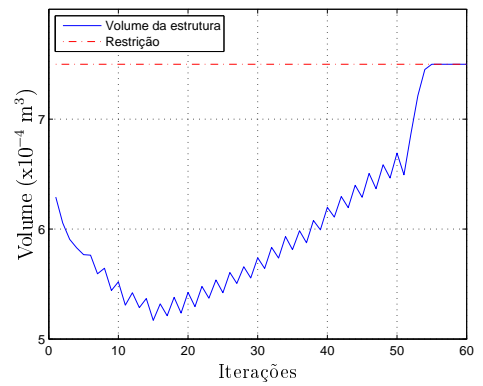

(b) Histórico do volume

Figura 5.37: Curvas de convergência e histórico de volume na otimização com projeção parcial de moldes para amostra de grafite.

Para melhor analisar o comportamento da função objetivo ao desativar a projeção, uma simulação com 120 iterações foi realizada considerando os mesmos parâmetros dos resultados obtidos na Figura 5.37, desativando a projeção a partir da iteração 50. Os resultados desta simulação são apresentados na Figura 5.38. Nesse caso, verifica-se que, prolongando o processo de otimização, um novo patamar de convergência para a função objetivo é alcançado. Este novo patamar, por estar acima daquele obtido antes da desativação da projeção, causa um impacto negativo no gradiente de temperatura Otimizado, o qual fica mais distante do Especificado, fato este facilmente observado ao se comparar as Figuras 5.38c e 5.36c. Portanto, ao desativar a projeção tem-se uma melhora na topologia da peça, que não mais possui instabilidade de tabuleiro de xadrez, porém tem-se também um prejuízo no gradiente de temperatura Otimizado. Assim, uma vez eliminado a presença de tabuleiro de xadrez na estrutura, o ideal é interromper o processo de otimização para assim não afastar ainda mais o gradiente de temperatura Otimizado do Especificado. 


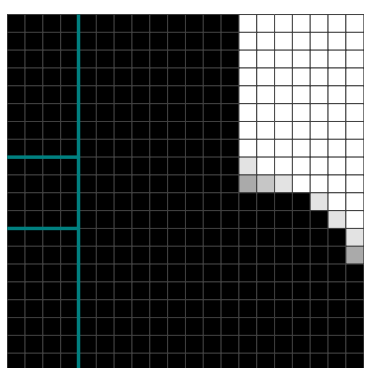

(a) Topologia

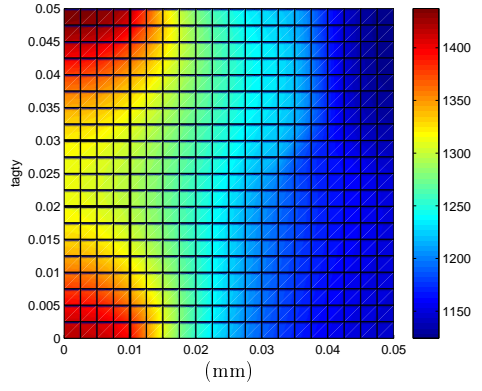

(b) Dist. Temperatura

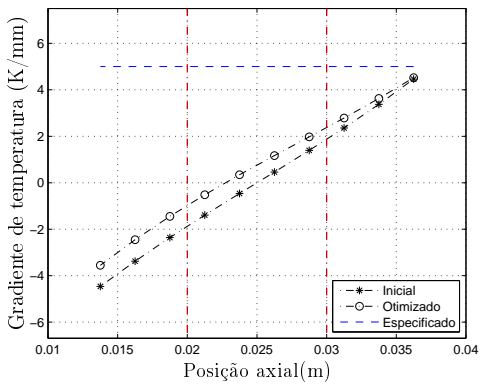

(c) Gradientes de temperatura na interface amostra-molde

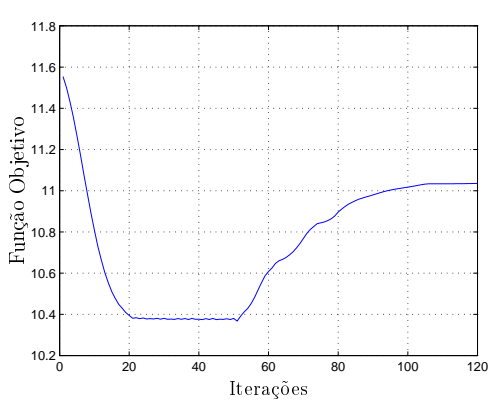

(d) Convergência

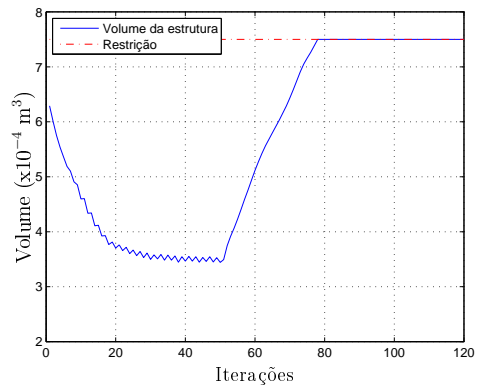

(e) Histórico do volume

Figura 5.38: Solução ótima para molde axissimétrico homogêneo após 120 iterações. Malha 20x20, $w=0,3$ com projeção parcial $\left(r_{m i n}=L_{e}\right)$ - Amostra de grafite.

\subsubsection{Moldes para fabricação de amostra de $\mathrm{Cu}-\mathrm{Ni}$}

Para otimização de moldes para fabricação de amostras de MGF compostas pelos materiais Cobre $(\mathrm{Cu})$ e Níquel(Ni), foi realizada análise semelhante à desenvolvida para amostras de grafite. Sendo inicialmente avaliada a influência do fator $w$ e em seguida, a influência da projeção parcialmente ativa, nos gradientes de temperatura. No caso dos resultados com projeção também se verificou a influência do tipo de gradação (linear ou exponencial) da propriedades As propriedades físicas dos materiais da amostra são apresentadas na Tabela 5.8. As propriedades dos materiais dos punções e molde foram adotadas como sendo as propriedades do grafite, ou seja, condutividade térmica igual a $50 \mathrm{~W} / \mathrm{mK}$ e condutividade elétrica igual a $1,0 \times 10^{5} \mathrm{~S} / \mathrm{m}$.

\begin{tabular}{lc}
\hline Propriedade do material & Valor \\
\hline Condutividade elétrica $(\mathrm{Ni})$ & $2,0 \times 10^{6} \mathrm{~S} / \mathrm{m}$ \\
Condutividade elétrica $(\mathrm{Cu})$ & $4,0 \times 10^{8} \mathrm{~S} / \mathrm{m}$ \\
Condutividade térmica $(\mathrm{Ni})$ & $64 \mathrm{~W} / \mathrm{mK}$ \\
Condutividade térmica $(\mathrm{Cu})$ & $480 \mathrm{~W} / \mathrm{mK}$ \\
\hline
\end{tabular}

Tabela 5.8: Propriedades físicas utilizadas na amostra MGF Cu-Ni. 
A partir das propriedades de cada componente do MGF tem-se a gradação das propriedades ao longo da direção axial da amostra, conforme apresentado na seção 4.8. Assim, considerando os dados da Tabela 5.8, a Figura 5.39 apresenta a gradação linear e exponencial de cada condutividade, para uma amostra com 8 camadas de gradação, sendo esse número de camadas dependente da discretização do domínio e aqui apenas exemplificada.

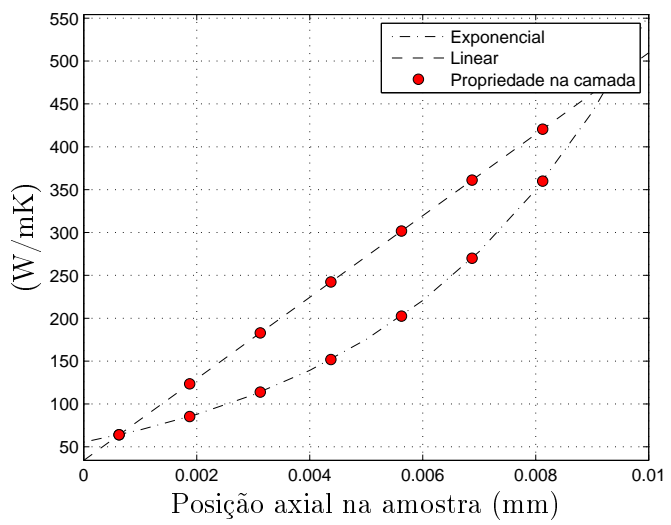

(a) Condutividade Térmica

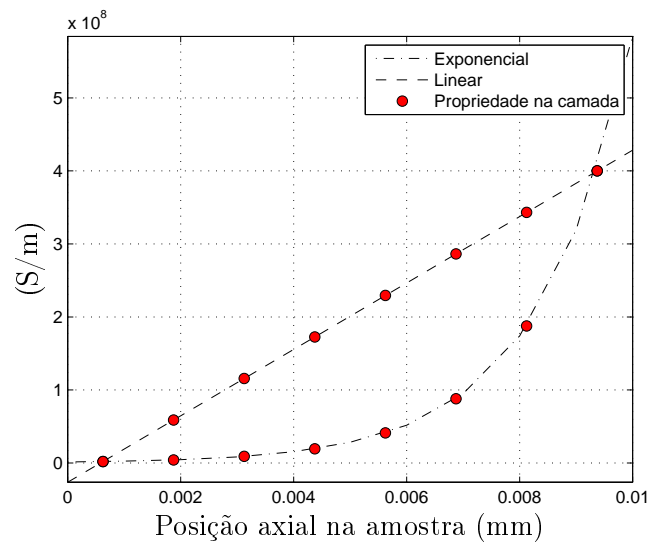

(b) Condutividade Elétrica

Figura 5.39: Gradação linear e exponencial das propriedades por camada no MGF Cu-Ni.

\subsubsection{Influência do fator $w$ da função multi-objetivo}

Ao analisar os primeiros resultados para otimização com amostras $\mathrm{Cu}-\mathrm{Ni}$, verifica-se diversas descontinuidades nas curvas de gradiente de temperatura. Isso se deve ao fato da brusca transição das propriedades elétricas e térmicas ao longo da gradação $\mathrm{Cu}-\mathrm{Ni}$ e, principalmente, nas interfaces entre a amostra e o molde. Uma discretização mais refinada conduziria a uma curva de gradiente mais suave no interior da amostra, no entanto as descontinuidades nas interfaces permaneceriam.

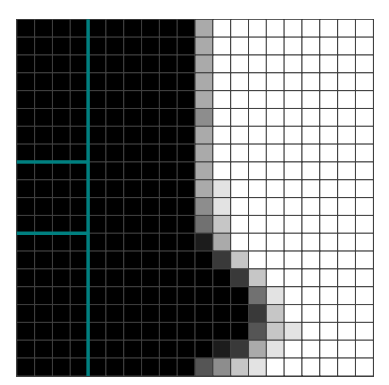

(a) Topologia

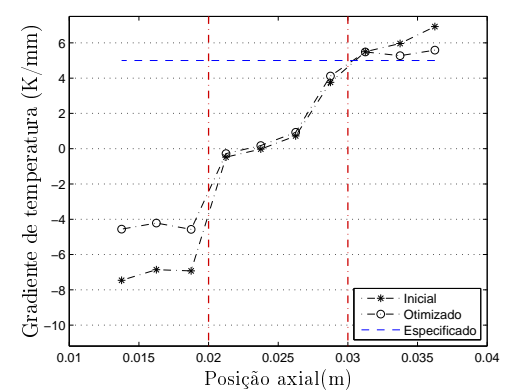

(b) Centro da amostra

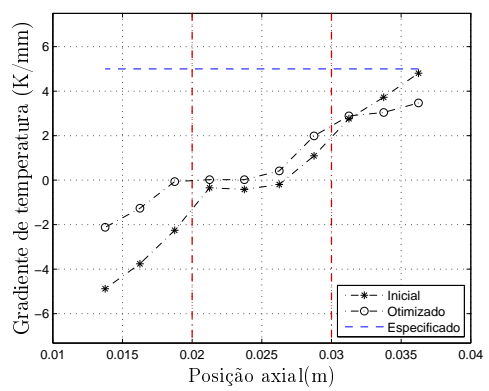

(c) Interface amostra-molde

Figura 5.40: Malha 20x20, $w=0,8$, propriedades com gradação linear e sem filtro de projeção.

Os resultados para esta amostra de MGF mostram a dificuldade em se aproximar o gra- 
diente Otimizado ao Especificado. Nota-se apenas distanciamento entre os gradientes Inicial e Otimizado nas regiões referentes ao material do molde, isto é, nas regiões abaixo de $0,01 \mathrm{~m}$ e acima de $0,03 \mathrm{~m}$.

Novamente se verifica a formação de um padrão de distribuição em tabuleiro de xadrez para $w=0,3$ (Figura 5.42) e uma forte presença desta instabilidade para $w=0$ (Figura 5.43), que de certa forma desconfigura a geometria da peça e dificulta a sua interpretação.

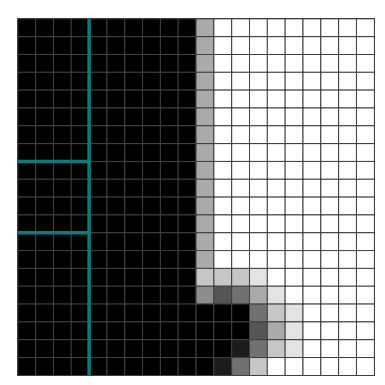

(a) Topologia

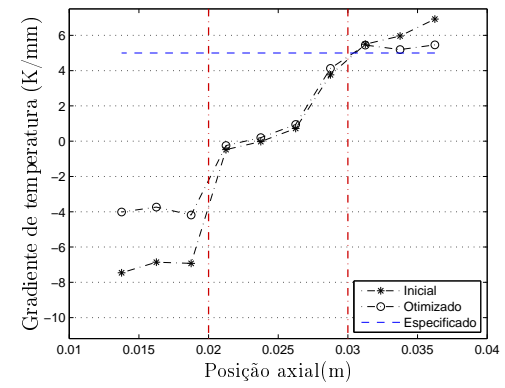

(b) Centro da amostra

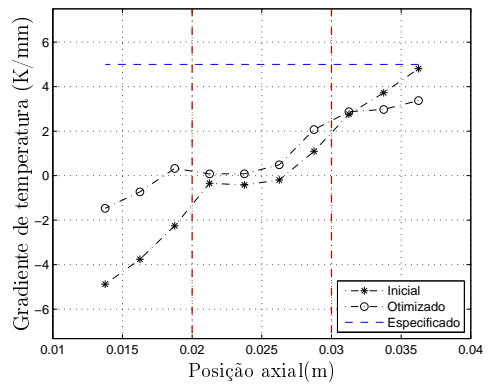

(c) Interface amostra-molde

Figura 5.41: Malha 20x20, $w=0,6$, propriedades com gradação linear e sem filtro de projeção.

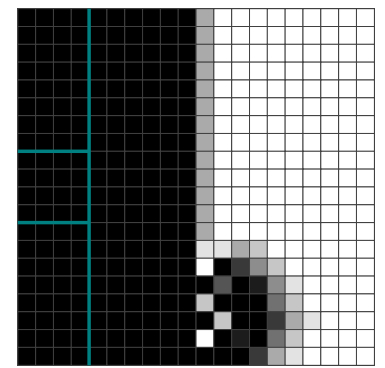

(a) Topologia

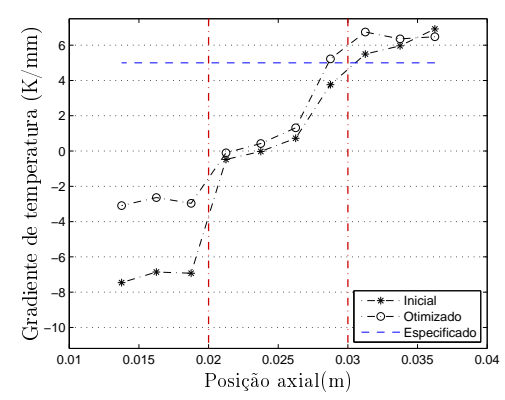

(b) Centro da amostra

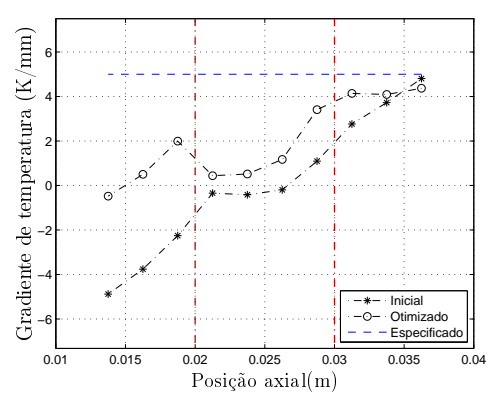

(c) Interface amostra-molde

Figura 5.42: Malha 20x20, $w=0,3$, propriedades com gradação linear e sem filtro de projeção.

Em geral, o processo de otimização para as simulações com amostra $\mathrm{Cu}-\mathrm{Ni}$, sem projeção parcial, apresentaram comportamento de convergência e histórico de volume conforme ilustrado na Figura 5.44. Há uma rápida convergência da função objetivo, porém o volume da estrutura tende a ser reduzido a cada iteração. Por esse motivo, utilizou-se no processo de otimização 30 iterações, pois mantendo o processo acima de 30 iterações, o volume é reduzido num nível em que exista apenas a espessura mínima especificada no início do processo de otimização. 


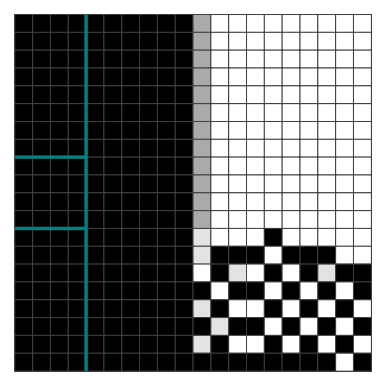

(a) Topologia

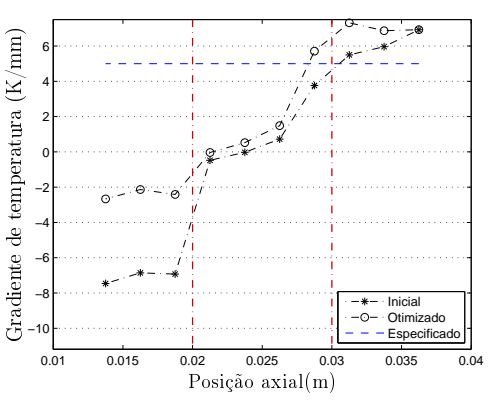

(b) Centro da amostra

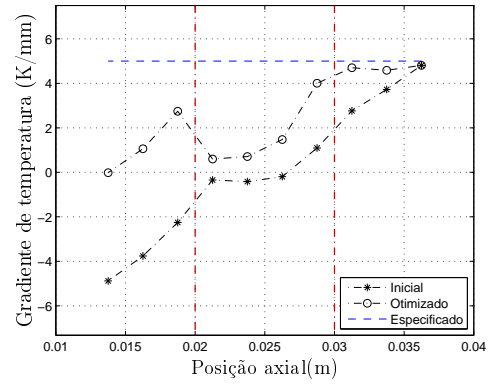

(c) Interface amostra-molde

Figura 5.43: Malha 20x20, $w=0$, propriedades com gradação linear e sem filtro de projeção.

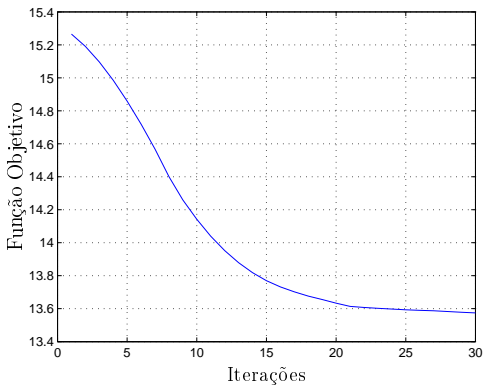

(a) Convergência

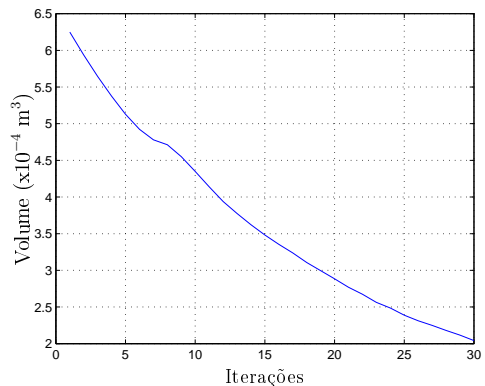

(b) Histórico do volume

Figura 5.44: Curvas de convergência e histórico de volume na otimização de moldes para amostra $\mathrm{Cu}-\mathrm{Ni}$.

\subsubsection{Influência do filtro de projeção}

Se por um lado o uso do filtro de projeção traz uma melhora no contorno do molde, apesar dos resultados apresentarem regiões com cinza, e a eliminação das instabilidades de tabuleiro de xadrez, por outro tem-se um prejuízo quanto ao objetivo de se alcançar o gradiente desejado. Praticamente não há modificação de gradiente de temperatura na região da amostra, tanto no centro quanto na extremidade.

As Figuras 5.45 e 5.46 apresentam os resultados para gradação linear entre as propriedades do Cobre e Níquel. Nesses resultados tem-se uma topologia bem definida, embora com alguns elementos em cinza, observa-se também a modificação no campo de temperaturas, porém com um gradiente Otimizado distante do Especificado.

Nas Figuras 5.47 e 5.48 tem-se os resultados para amostras $\mathrm{Cu}-\mathrm{Ni}$ com gradação exponencial. Comparando esses resultados com os obtidos para gradação linear, verifica-se que houve modificação significativa na topologia do molde para $w=0,3$, no entanto, o gradiente Otimizado de temperatura se manteve igual ao Inicial para ambas topologias (ver Figura 5.47 e 5.45). 


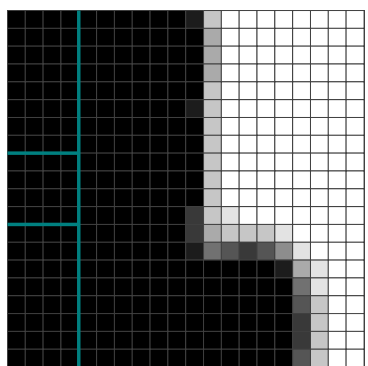

(a) Topologia

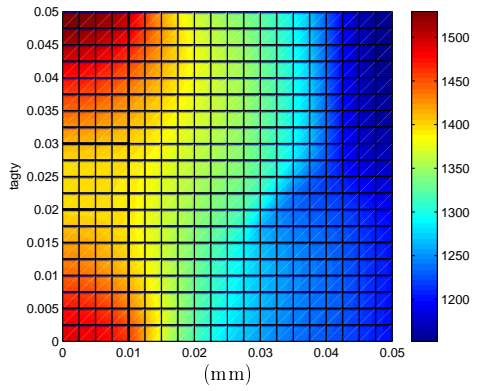

(b) Dist. Temperatura

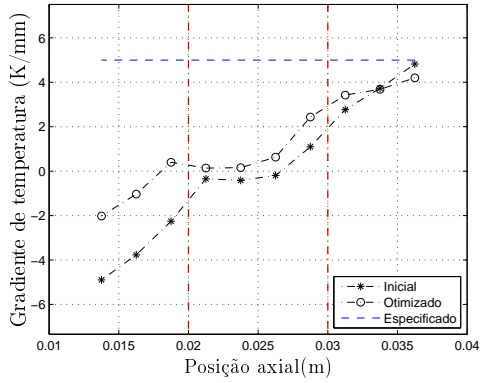

(c) Gradiente de temperatura na interface amostra-molde

Figura 5.45: Solução ótima para molde axissimétrico homogêneo. Malha 20x20, $w=0,3$, com projeção parcial $\left(r_{\min }=L_{e}\right)$ - Amostra $\mathrm{Cu}-\mathrm{Ni}$ com gradação linear.

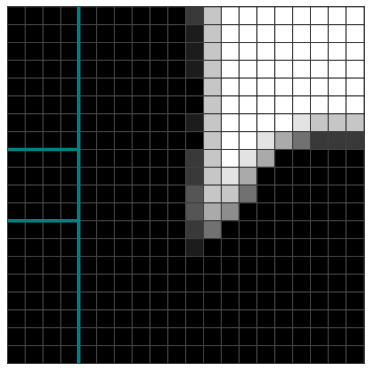

(a) Topologia

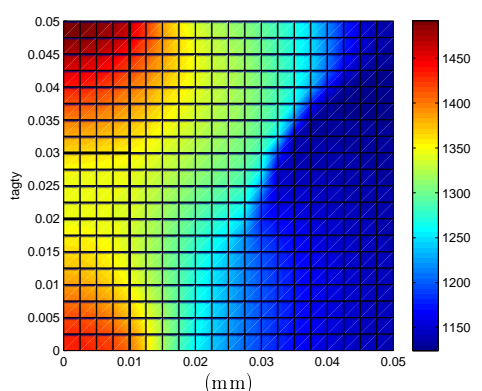

(b) Dist. Temperatura

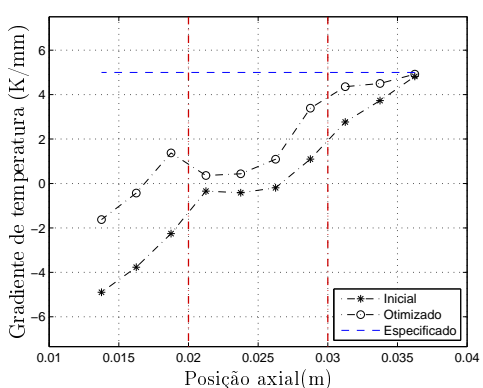

(c) Gradiente de temperatura na interface amostra-molde

Figura 5.46: Solução ótima para molde axissimétrico homogêneo. Malha 20x20, $w=0$, com projeção parcial $\left(r_{\text {min }}=L_{e}\right)$ - Amostra $\mathrm{Cu}-\mathrm{Ni}$ com gradação linear.

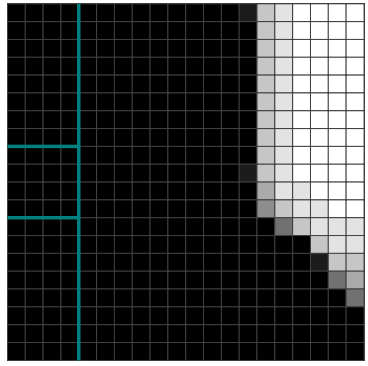

(a) Topologia

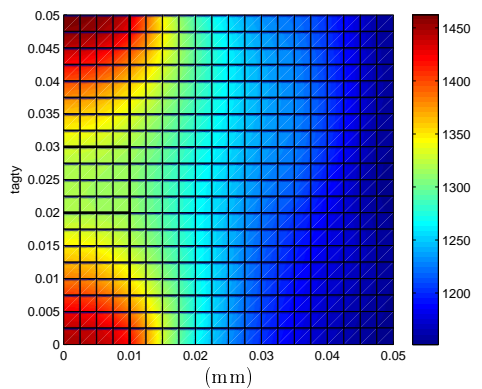

(b) Dist. Temperatura

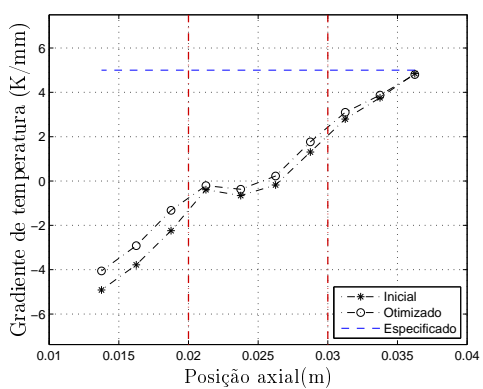

(c) Gradiente de temperatura na interface amostra-molde

Figura 5.47: Solução ótima para molde axissimétrico homogêneo. Malha 20x20, $w=0,3$, com projeção parcial $\left(r_{\min }=L_{e}\right)$ - Amostra $\mathrm{Cu}-\mathrm{Ni}$ com gradação exponencial.

Devido à restrição de volume permanecer ativa ao final do processo de otimização, quando se utiliza a projeção parcial, foi realizada um simulação com $V_{\max }=30 \%, w=0,3$, gradação linear das propriedades e $r_{\text {min }}=L_{e}$. O resultado obtido e ilustrado na Figura 5.49 é semelhante a topologia da Figura 5.45, obtido sob os mesmos parâmetros, exceto pela restrição $V_{\max }=$ $60 \%$. Neste caso, também não houve impactos nos gradientes de temperatura. 


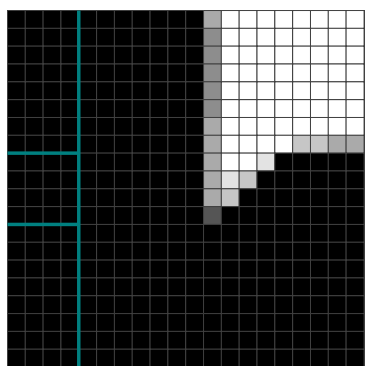

(a) Topologia

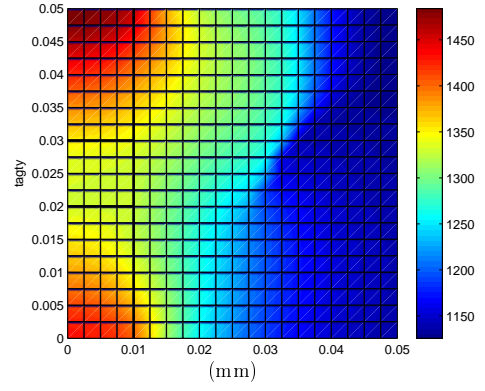

(b) Dist. Temperatura

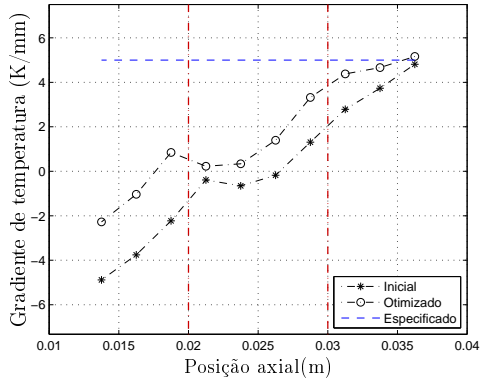

(c) Gradiente de temperatura na interface amostra-molde

Figura 5.48: Solução ótima para molde axissimétrico homogêneo. Malha 20x20, $w=0$, com projeção parcial $\left(r_{\min }=L_{e}\right)$ - Amostra $\mathrm{Cu}-\mathrm{Ni}$ com gradação exponencial.

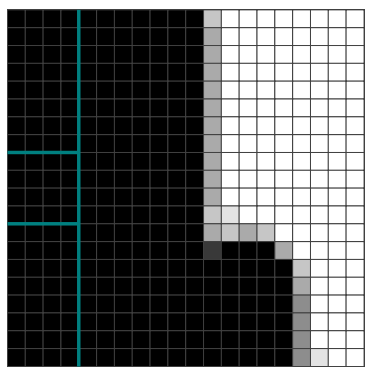

(a) Topologia

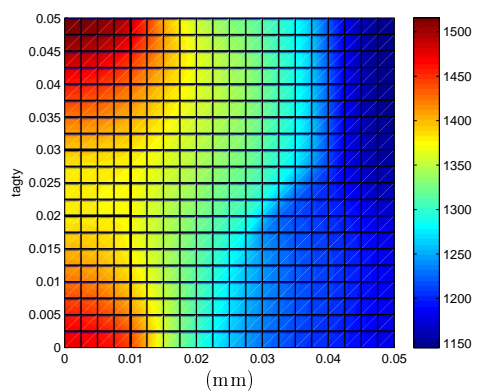

(b) Dist. Temperatura

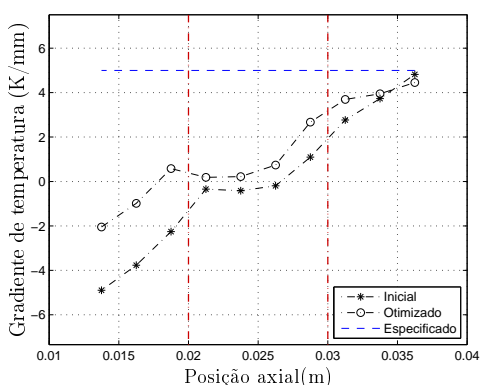

(c) Gradiente de temperatura na interface amostra-molde

Figura 5.49: Solução ótima para molde axissimétrico homogêneo. Malha 20x20, $V_{\text {max }}=30 \%, w=0,3$, com projeção parcial $\left(r_{\min }=L_{e}\right)$ - Amostra Cu-Ni com gradação linear.

Além disso, para verificar a influência da especificação da espessura mínima nos problemas de otimização do molde axissimétrico, uma simulação com espessura mínima nula foi realizada. O resultado obtido, indicado na Figura 5.50, apresenta um distribuição de material próxima às regiões dos punções, comportamento este citado no início da seção 5.3. Para este resultado, verifica-se que há uma considerável aproximação de gradiente de temperatura nas regiões próximas aos punções, fato este que não se verifica na região da amostra, onde os gradientes permanecem distantes.

Na Figura 5.51 são apresentados as curvas de convergência da função objetivo e de histórico do volume da estrutura, que em geral ocorreram nos processos de otimização envolvendo amostras $\mathrm{Cu}-\mathrm{Ni}$.

Em geral, nos resultados para as amostras de $\mathrm{Cu}-\mathrm{Ni}$, não existe gradiente de temperatura nas suas extremidades, pois as curvas Inicial e Otimizado estão aproximadamente no patamar de $0 \mathrm{~K} / \mathrm{mm}$, o que reflete um campo de temperaturas homogêneo no interior do MGF. 


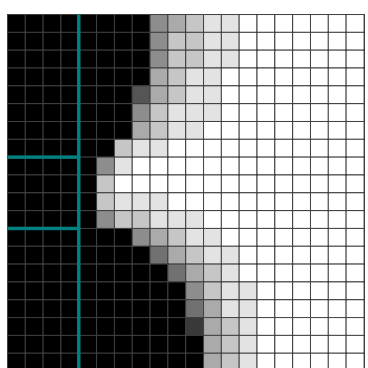

(a) Topologia

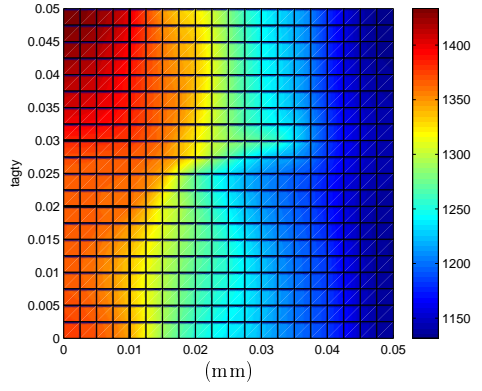

(b) Dist. Temperatura

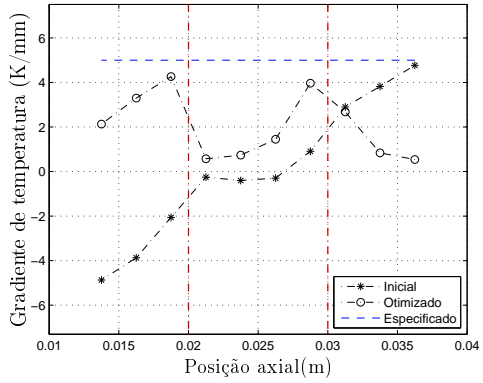

(c) Gradiente de temperatura na interface amostra-molde

Figura 5.50: Solução ótima para molde axissimétrico homogêneo sem espessura mínima. Malha $20 \times 20, V_{\max }=30 \%, w=0$, com projeção parcial $\left(r_{\min }=L_{e}\right)$ - Amostra Cu-Ni com gradação linear.

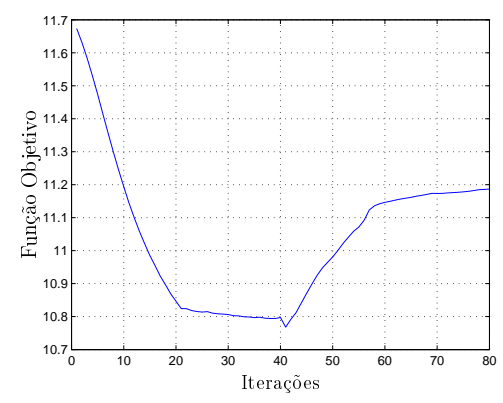

(a) Convergência

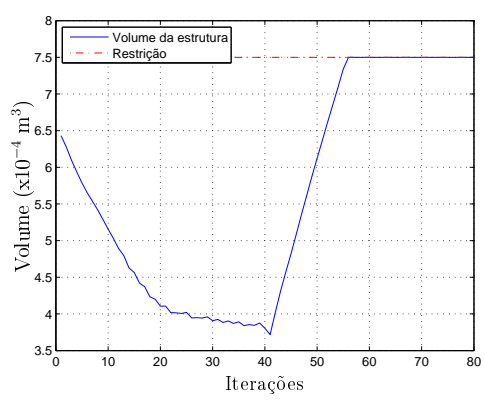

(b) Histórico do volume

Figura 5.51: Curvas de convergência e histórico de volume na otimização de moldes para amostra de grafite (referente ao resultado da Figura 5.47).

\subsubsection{Discussão}

De um modo geral, foi possível observar nos resultados obtidos para moldes homogêneos a dificuldade em se alcançar o gradiente desejado na região da amostra. Embora variando o fator $w$ de ponderação na função multi-objetivo como tentativa de "impor" um gradiente de temperatura, o gradiente Otimizado permaneceu relativamente distante do Especificado. Melhores aproximações entre esses gradientes foram obtidas para o caso de otimização com amostras de grafite, provavelmente em função da continuidade das propriedades físicas do conjunto amostra-molde-punções. No caso de otimização de amostras de MGF Cu-Ni, verificou-se as descontinuidades nas curvas de gradiente de temperatura Inicial e Otimizado, que refletem as mudanças bruscas de propriedades nas interfaces entre amostra, molde e punções.

Quanto à utilização do filtro de projeção parcial, verifica-se uma melhora na definição da topologia devido à redução da escala de cinza. Entretanto, houve um afastamento entre os gradientes Otimizado e Especificado ao comparar os resultados obtidos utilizando a projeção com aqueles obtidos sem o efeito da projeção. 
Vale ressaltar que o gradiente Inicial fornecido pelo molde no início do processo de otimização e apresentado em cada um dos gráficos referentes à gradientes, foi obtido para variáveis de projeto com valores iniciais iguais a 0,5, conforme indicado na Tabela 5.6. Assim, tem-se inicialmente um molde cilíndrico formado por um material com condutividade térmica reduzida pela metade, devido ao modelo de material implementado (ver equação 3.5). Com isso, surge a seguinte pergunta: Será que o gradiente Inicial, obtido no início da otimização, referese a um gradiente de molde cilíndrico para variáveis de projeto com valores iniciais iguais a 1 $\left(\rho_{0}=1\right)$ ? Para responder esta questão, uma simulação com variáveis de projeto unitárias e apenas um iteração foi realizada e os resultados obtidos são apresentados nas Figura 5.24a e Figura 5.24b.

Comparando os gradientes da Figura 5.24 com qualquer Figura onde constam os gradientes obtidos no início e ao final do processo de otimização, verifica-se que o gradiente Inicial é o mesmo, ou seja, o gradiente Inicial para $\rho_{0}=0,5$ é o mesmo para $\rho_{0}=1$.

\subsection{Moldes axissimétricos compósitos para amostras MGF}

Na otimização para moldes compósito, o modelo computacional utilizado é o mesmo adotado para o caso da otimização de moldes homogêneos. A diferença consiste em se ter um novo conjunto de variáveis de projeto $v$ que controlam a orientação do material ortotrópico do qual o molde compósito é constituído. Conforme citado na seção 3.2, foram implementados dois modelos para lidar com a orientação do material ortotrópico, um através da parametrização direta de $\theta=v \pi$ e outro utilizando o método OMD.

Nas simulações apenas o material do molde é ortotrópico, os punções continuam sendo de grafite, assim como no caso de moldes homogêneos. O material da amostra também não sofreu alteração. Foram realizadas simulações com amostras de grafite e de $\mathrm{Cu}-\mathrm{Ni}$.

As matrizes constitutivas térmica $(\mathrm{W} / \mathrm{mK})$ e elétrica $(\mathrm{S} / \mathrm{m})$ adotadas para o material ortotrópico que compõem o molde são:

$$
\mathbf{C}_{0_{\mathbf{T}}}=\left[\begin{array}{cc}
50 & 0 \\
0 & 10
\end{array}\right] \quad \mathbf{C}_{0_{\mathbf{E}}}=\left[\begin{array}{cc}
1,0 \times 10^{5} & 0 \\
0 & 1,0 \times 10^{2}
\end{array}\right]
$$

Inicialmente são apresentados os resultados relacionados à primeira implementação, ou seja, sem a OMD e na sequência, os resultados obtidos através da OMD. Para ambos os casos, não foi utilizado restrição de volume, isto por que ao especificar uma restrição de volume, não se obtinha uma solução viável por parte do Matlab e o processo de otimização era interrompido. 


\subsubsection{Resultados sem a utilização da OMD}

Inicialmente é verificada a influência do fator $w$ da função multi-objetivo na topologia final. Resultados com filtro de projeção parcial são avaliados para topologias que apresentaram instabilidade de tabuleiro de xadrez.

As Figuras 5.52, 5.53 e 5.54 referem-se a otimização com o fator fator $w$ igual a 0,8, 0,5 e 0,3 respectivamente, além de uma malha de discretização de $15 \times 15$ e sem a aplicação de filtro de projeção.

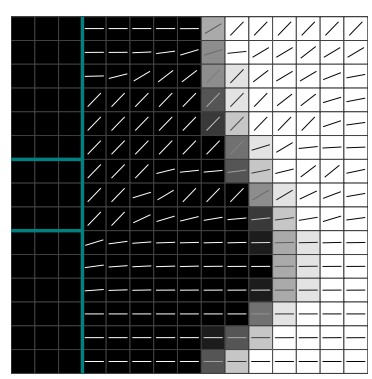

(a) Topologia final

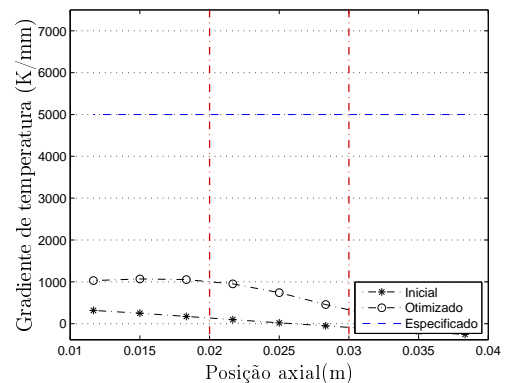

(c) Centro da amostra

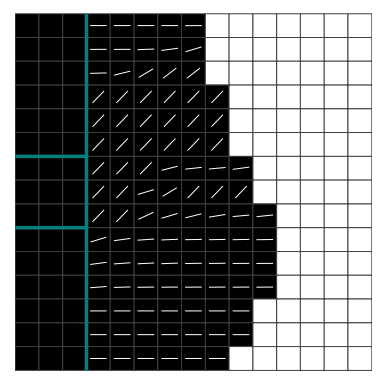

(b) Topologia interpretada $(\rho>0,6)$

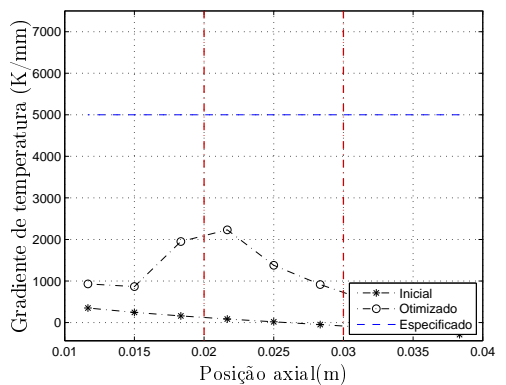

(d) Interface amostra-molde

Figura 5.52: Malha 15x15, Amostra de grafite, $w=0,8$ e sem filtro de projeção.

Na Figura 5.55 são apresentados os resultados ao se utilizar a projeção parcial para o caso de fator $w$ igual a 0,3 .

A Figura 5.56 apresenta a convergência da funções objetivo e o histórico do volume da estrutura para otimização sem a utilização da OMD. 


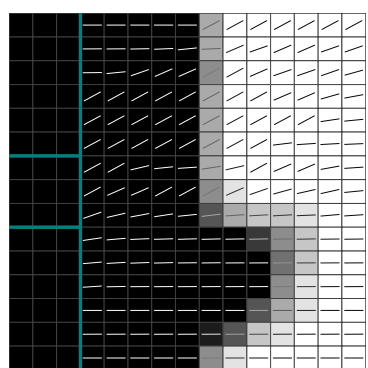

(a) Topologia final

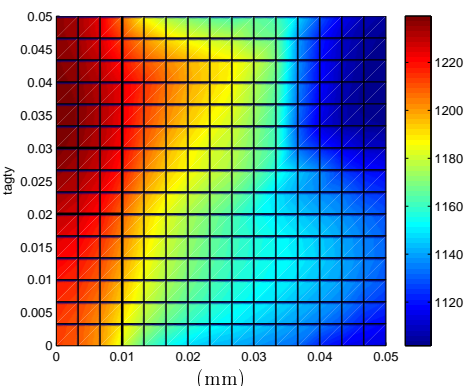

(c) Dist. Temperatura

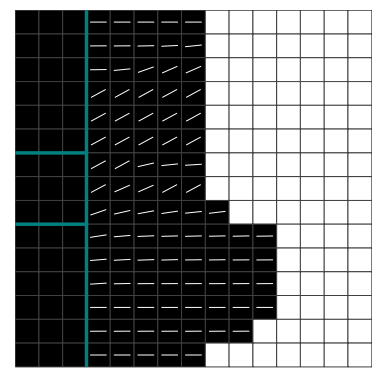

(b) Topologia interpretada $(\rho>0,6)$

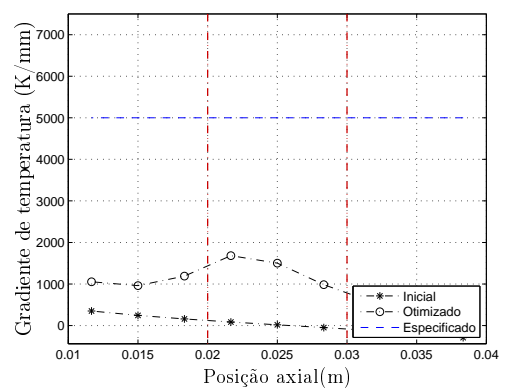

(d) Gradiente na interface da amostra

Figura 5.53: Solução ótima para molde axissimétrico compósito. Malha 15x15, Amostra de grafite, $w=0,5$ e sem filtro de projeção.

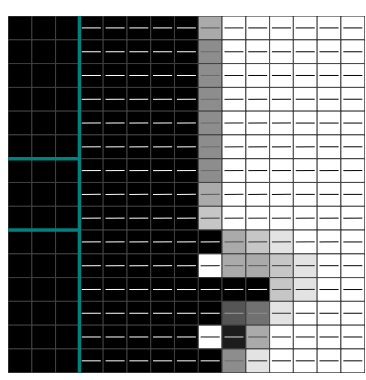

(a) Topologia final

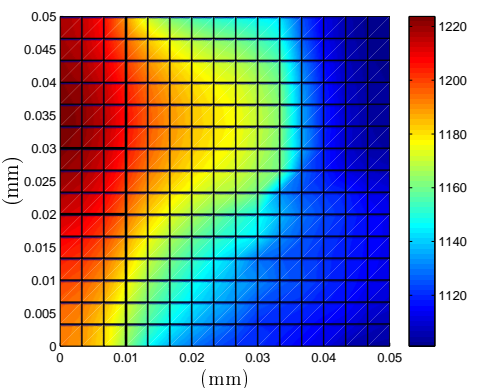

(c) Dist. Temperatura

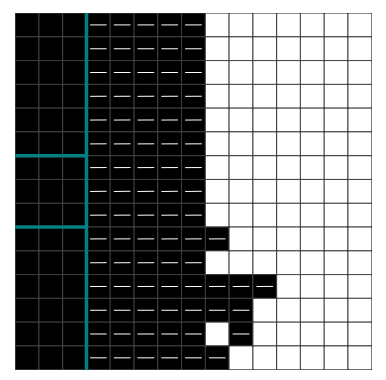

(b) Topologia interpretada $(\rho>0,6)$

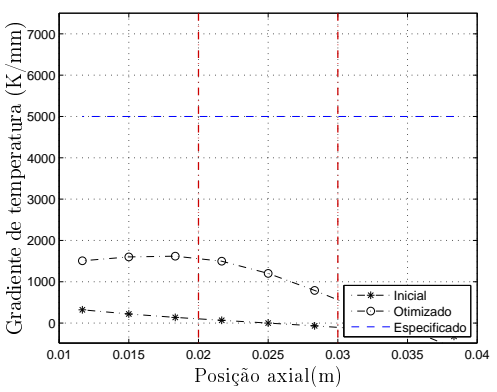

(d) Gradientes na interface amostra-molde

Figura 5.54: Malha 15x15, Amostra de grafite, $w=0,3$ e sem filtro de projeção. 


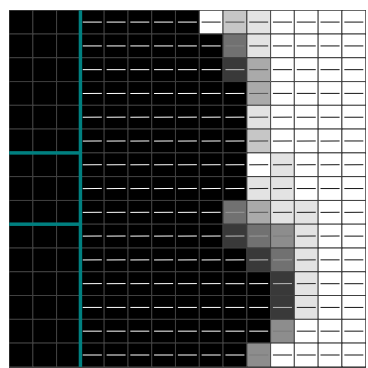

(a) Topologia final

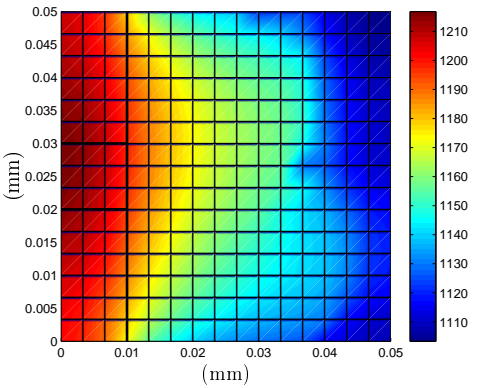

(c) Dist. Temperatura

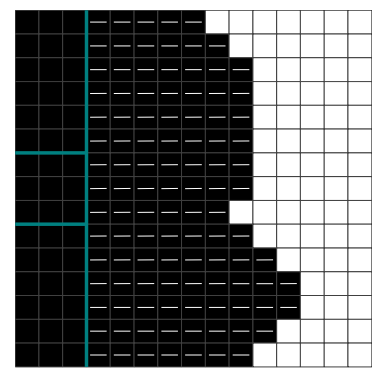

(b) Topologia interpretada $(\rho>0,6)$

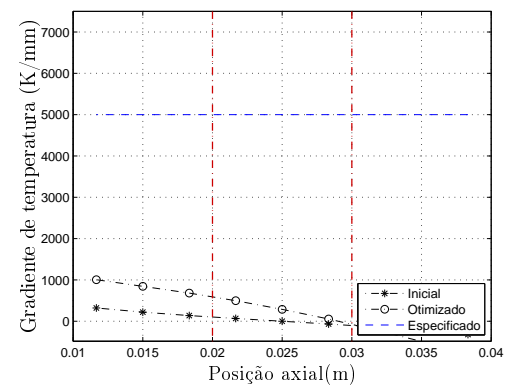

(d) Gradientes na interface amostra-molde

Figura 5.55: Malha 15x15, Amostra de grafite, $w=0,3$ e com projeção parcial $\left(r_{\min }=2 L_{e}\right)$.

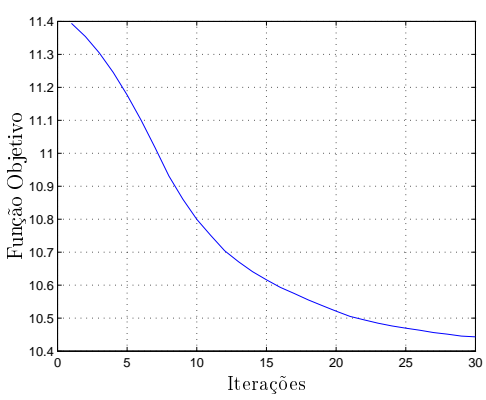

(a) Convergência

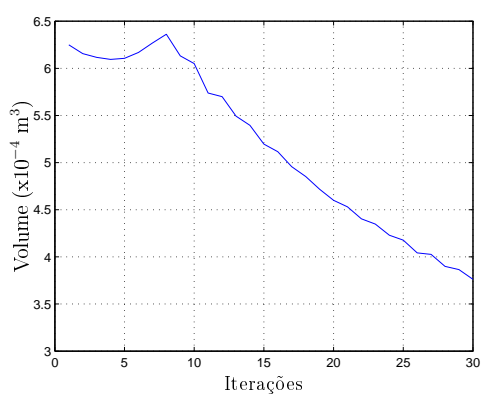

(b) Histórico do volume

Figura 5.56: Curvas de convergência e histórico de volume na otimização de moldes axissimetricos compósitos para amostra de grafite(sem OMD).

\subsubsection{Resultados utilizando a OMD}

Para a utilização da OMD (Otimização de Material Discreta) o ângulos candidatos $\theta_{i}$ adotados são igual a $0^{\circ}, \pm 45^{\circ}$ e $90^{\circ}$.

A Figura 5.61 apresenta a convergência da funções objetivo e o histórico do volume da estrutura para otimização sem a utilização da OMD. 


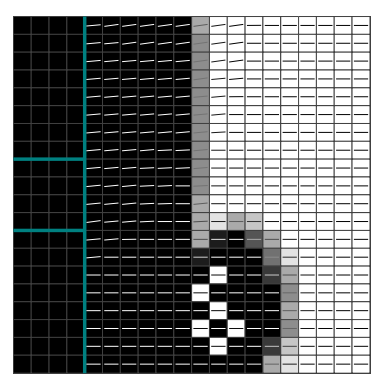

(a) Topologia e orientação do material

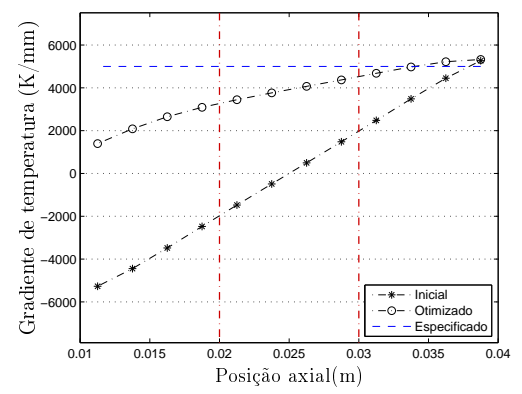

(c) Gradientes no centro da amostra - direção axial

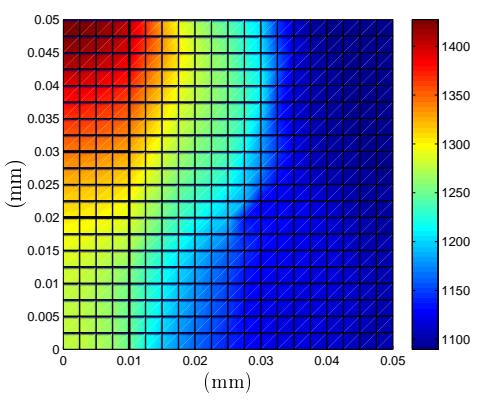

(b) Dist. Temperatura

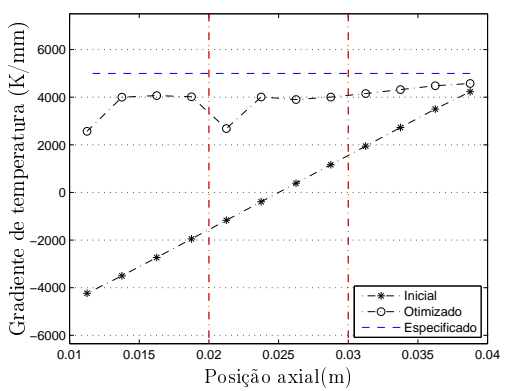

(d) Gradiente na interface amostra-molde

Figura 5.57: Resultados para molde axissimétrico compósito. Malha 15x15, $w=0$, 3, sem filtro de projeção e através da OMD com amostra de grafite.

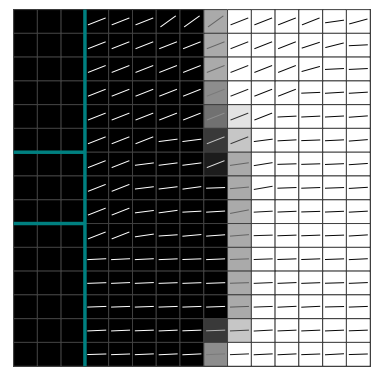

(a) Topologia e orientação do material

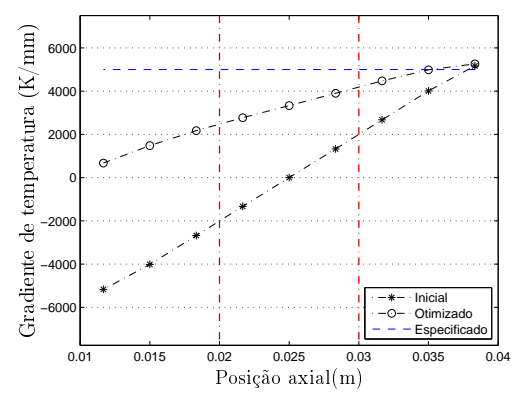

(c) Gradientes no centro da amostra - direção axial

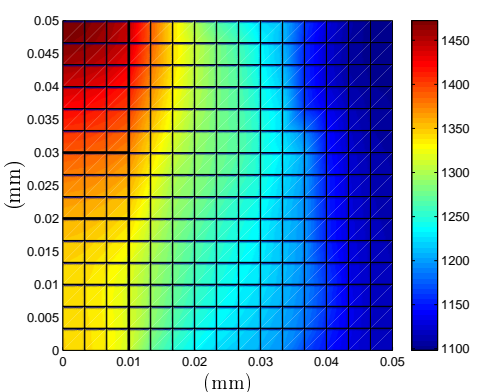

(b) Dist. Temperatura

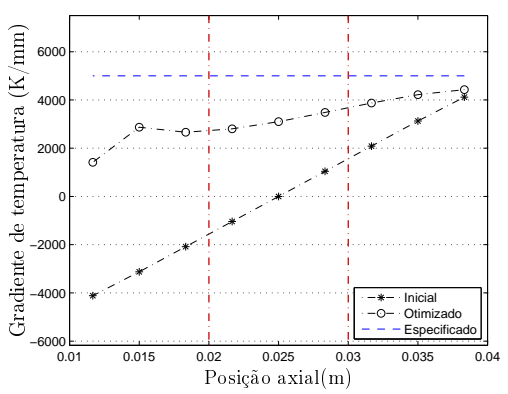

(d) Gradiente na interface amostra-molde

Figura 5.58: Resultados para molde axissimétrico compósito. Malha 15x15, $w=0$, 8 , sem filtro de projeção e através da OMD com amostra de grafite. 


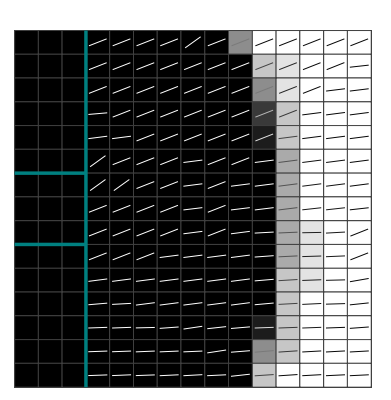

(a) Topologia e orientação do material

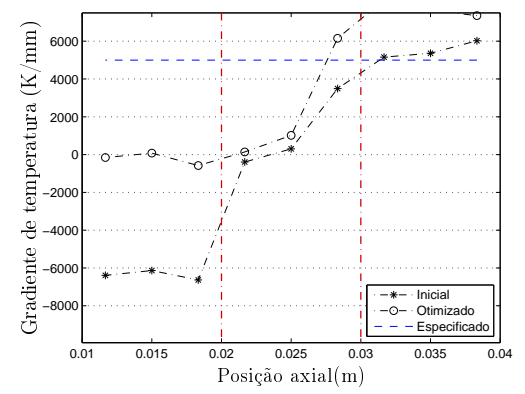

(c) Gradientes no centro da amostra - direção axial

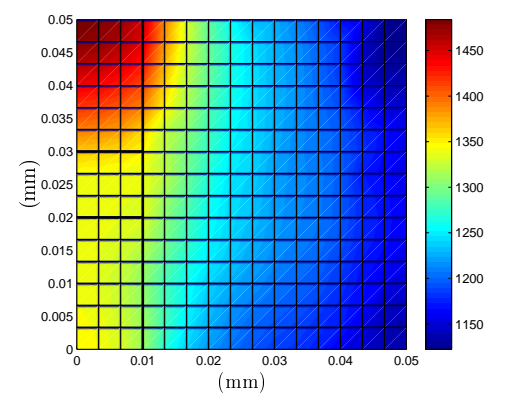

(b) Dist. Temperatura

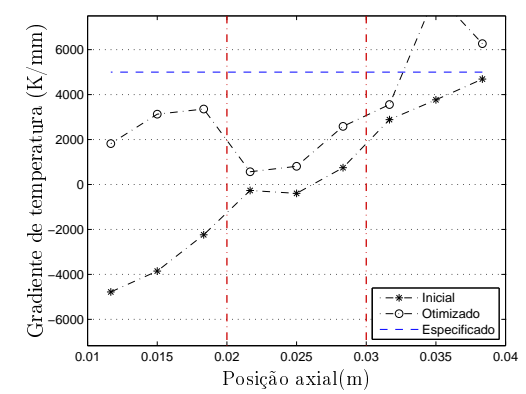

(d) Gradiente na interface amostra-molde

Figura 5.59: Resultados para molde axissimétrico compósito. Malha 15x15, $w=0,8$, com filtro de projeção e através da OMD para amostra $\mathrm{Cu}-\mathrm{Ni}$ com gradação linear.

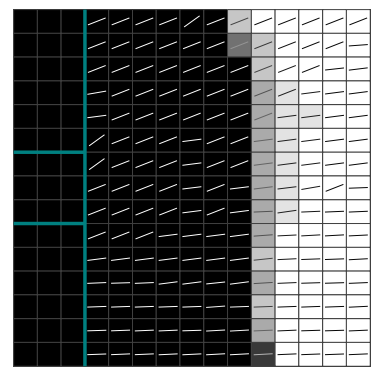

(a) Topologia e orientação do material

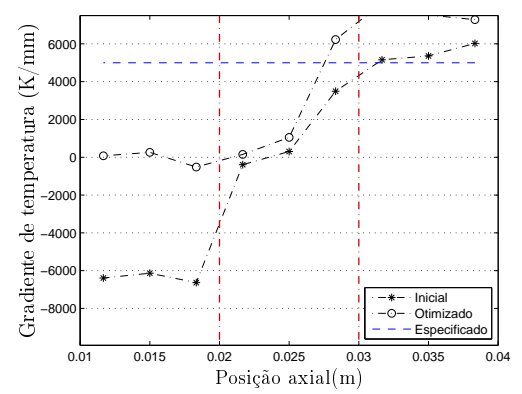

(c) Gradientes no centro da amostra - direção axial

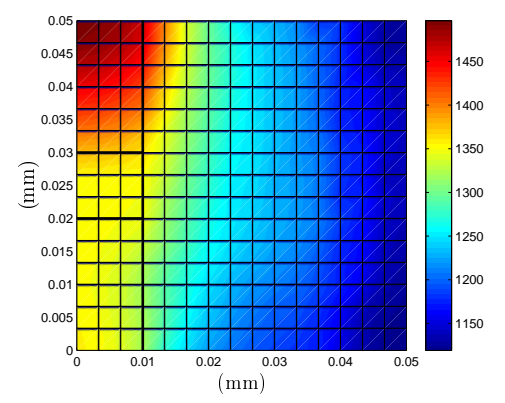

(b) Dist. Temperatura

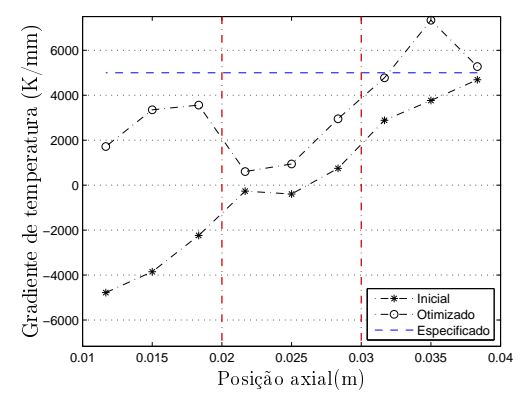

(d) Gradiente na interface amostra-molde

Figura 5.60: Resultados para molde axissimétrico compósito. Malha 15x15, $w=0,3$, com filtro de projeção e através da OMD para amostra $\mathrm{Cu}-\mathrm{Ni}$ com gradação linear. 


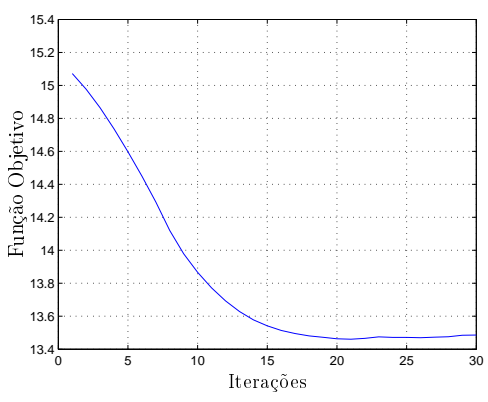

(a) Convergência

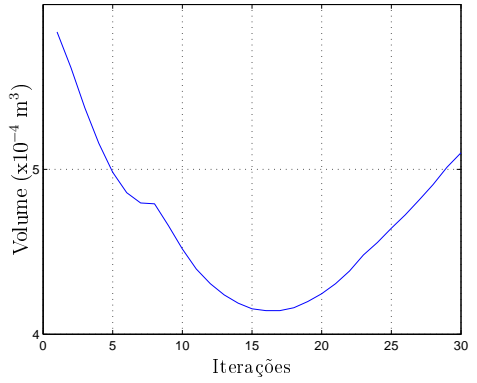

(b) Histórico do volume

Figura 5.61: Curvas de convergência e histórico de volume na otimização de moldes axissimetricos compósitos para amostra $\mathrm{Cu}-\mathrm{Ni}($ sem OMD) com gradação linear.

\subsubsection{Discussão}

De acordo com os resultados apresentados nas seções 5.4.1 e 5.4.2, verifica-se a forte aproximação entre os gradientes de temperatura Otimizado e Especificado ao se utilizar o método OMD para otimização da orientação do material do molde considerando amostras de grafite. Ao se utilizar a OMD considerando amostra $\mathrm{Cu}-\mathrm{Ni}$, verifica-se a aproximação entres os gradientes Otimizado e Especificado apenas nas regiões dos punções, na região da amostra, praticamente não houve alteração significativa entres esses gradientes. Fato esse também observado para o caso de otimização de moldes axissimétricos homogêneos.

Além disso, verifica-se a discrepância dos gradientes para a otimização sem a utilização da OMD. Uma justificativa para esse fato é a convergência deste problema para uma solução que representa um mínimo local.

\subsection{Pós-Processamento}

Após a convergência da solução ótima final do processo de otimização, a topologia gerada é pós-processada aplicando um filtro nas variáveis de projeto de pseudo-densidades para valores maiores ou iguais a 0,6. Com isso obtém-se uma topologia 0 - 1, a partir da qual interpreta-se os contornos da estrutura. Neste trabalho, a interpretação dos resultados é realizada através de pseudo densidades atribuídas aos nós. O valor da variável atribuída a um nó dependente da quantidade de elementos que compartilham este nó, assim como da "densidade" do elemento (se é sólido ou vazio) (VARELA, 2012).

Uma vez definido o contorno da estrutura, um código é gerado para ser lido no software COMSOL Multiphysics e, assim, simular a topologia pós-processada. Esta simulação no COMSOL é realizada considerando o processo de radiação térmica como um processo nãolinear e considerando as mesmas propriedades físicas dos materiais utilizadas no algoritmo de 
otimização.

Neste trabalho, o pós-processamento é realizado para as topologias obtidas do processo de otimização de moldes axissimétrico homogêneos. As topologias consideradas para análise de pós-processamento são as indicadas nas Figuras 5.35, 5.36, 5.45 e 5.47.

Os resultados do pós-processamento realizado neste trabalho são apresentados nas Figuras 5.62, 5.63, 5.64 e 5.65. Em cada figura estão indicados a topologia obtida através do MOT, o molde axissimétrico equivalente à solução ótima do MOT juntamente com a distribuição de temperaturas, o fluxo de calor e de corrente elétrica apresentados numa seção radial do molde, os gradientes de temperatura na interface amostra-molde e por fim, os gradientes de temperatura no centro da amostra(direção axial) e na interface amostra-molde (parede interna do molde) gerados pelo molde otimizado.

Verifica-se a proximidade entre os gradientes de temperatura obtidos através do MOT e aqueles obtidos após o pós-processamento. No entanto, ainda que para um pós-processamento que considera radiação não-linear, os gradientes na região da amostra estão distantes do gradiente especificado, que é de $5 \mathrm{~K} / \mathrm{mm}$ ou $5.000 \mathrm{~K} / \mathrm{m}$. 


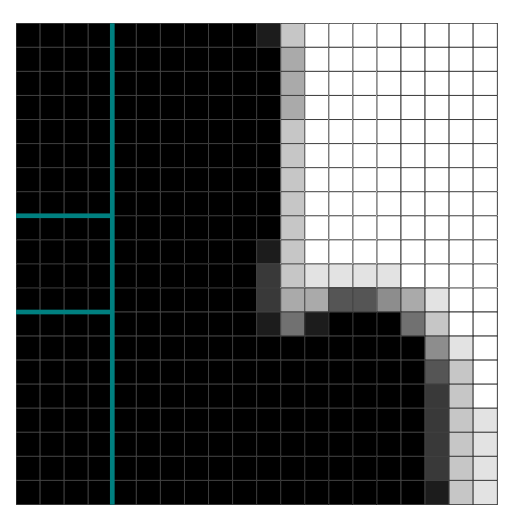

(a) Topologia otimizada

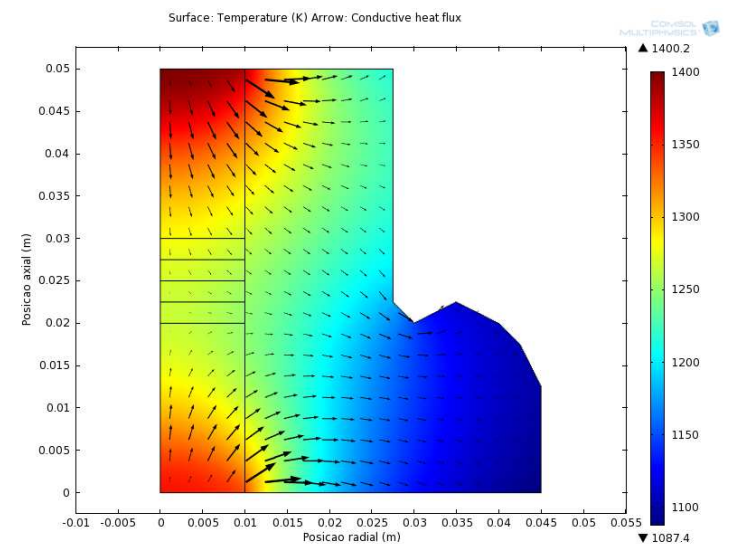

(c) Dist. Temperatura e Fluxo de calor

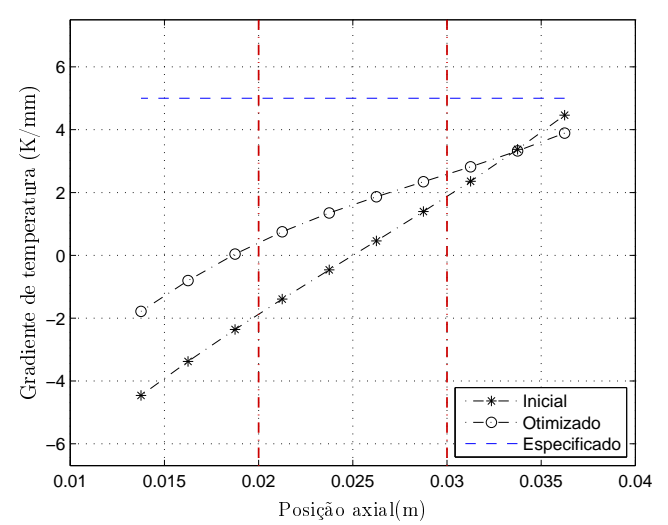

(e) Gradiente de temperatura na interface amostra-molde (OT)

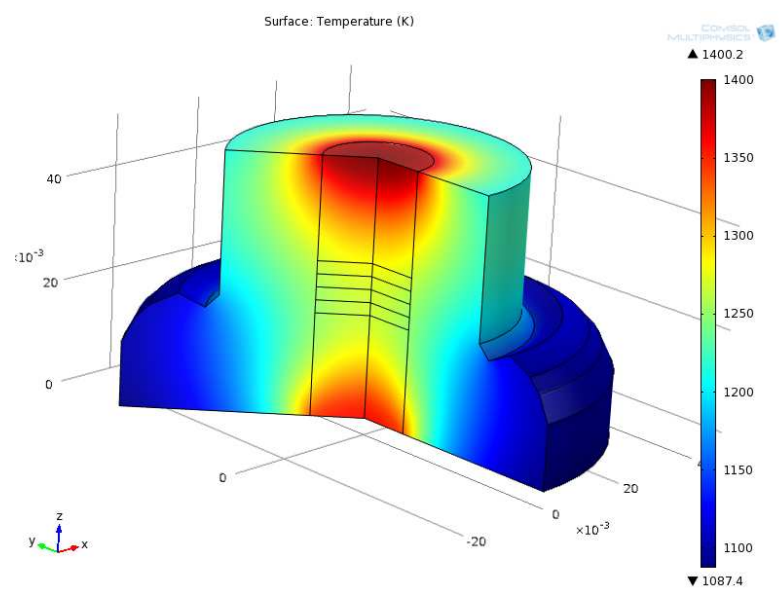

(b) Molde otimizado com a distribuição de temperatura

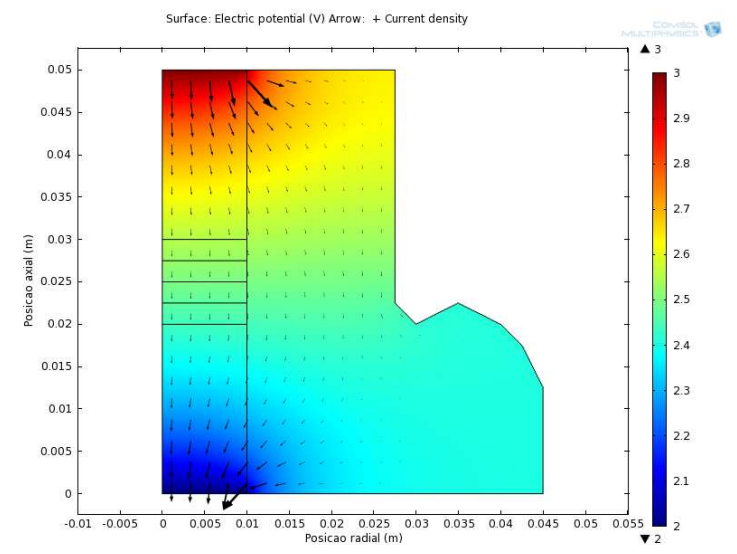

(d) Dist. Potencial elétrico e Fluxo de corrente

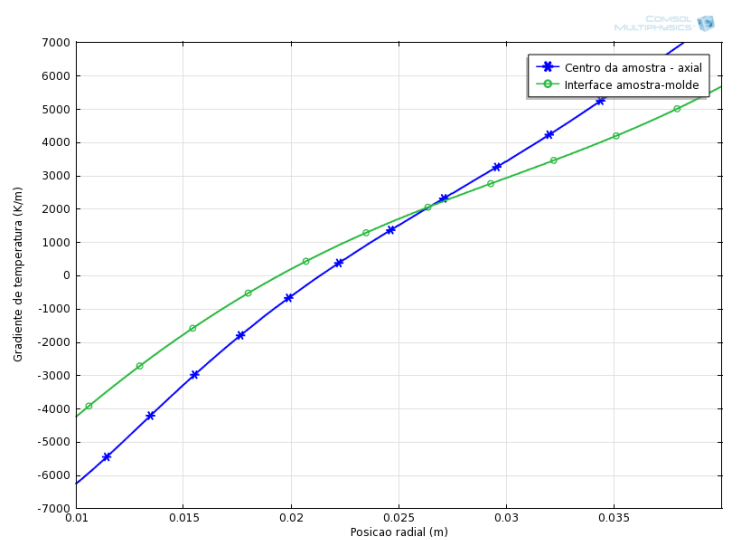

(f) Gradientes de temperatura com o molde otimizado

Figura 5.62: Pós-processamento para molde axissimétrico homogêneo. Malha 20x20, $w=0,3$ com projeção parcial $\left(r_{\min }=L_{e}\right)$ - Amostra de grafite. 


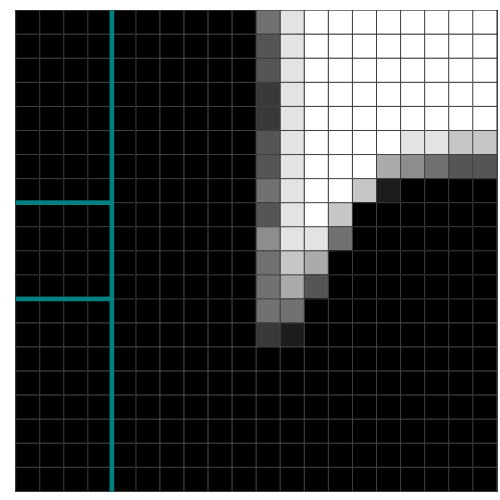

(a) Topologia otimizada

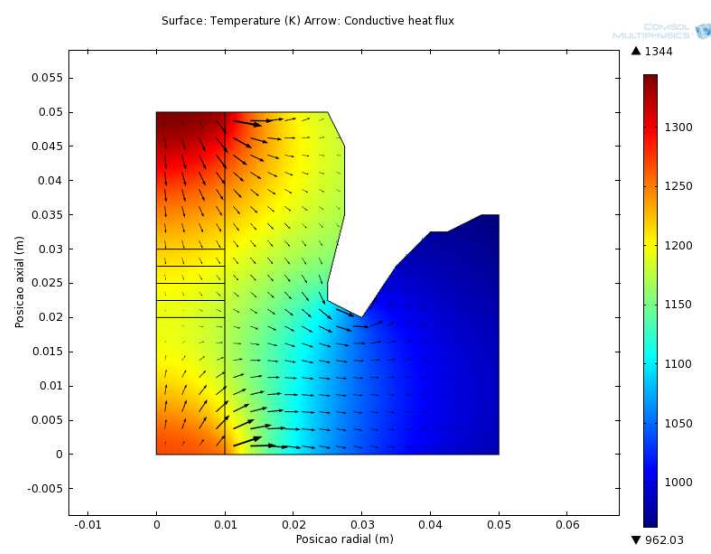

(c) Dist. Temperatura e Fluxo de calor

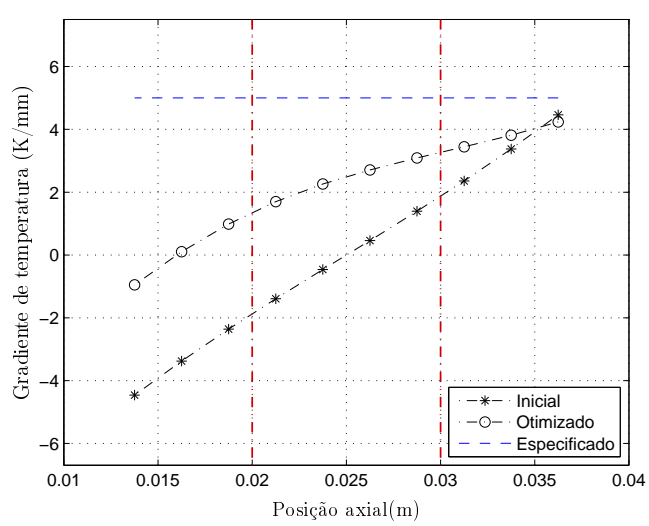

(e) Gradiente de temperatura na interface amostra-molde (OT)

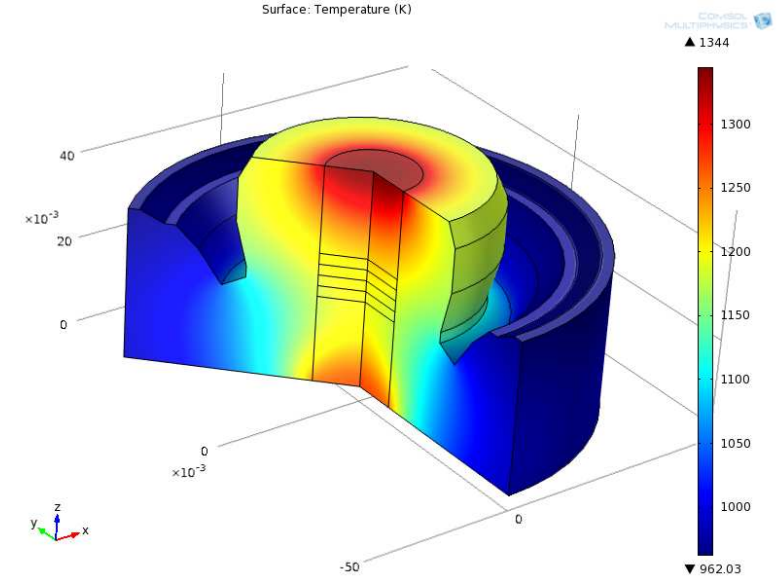

(b) Molde otimizado com a distribuição de temperatura

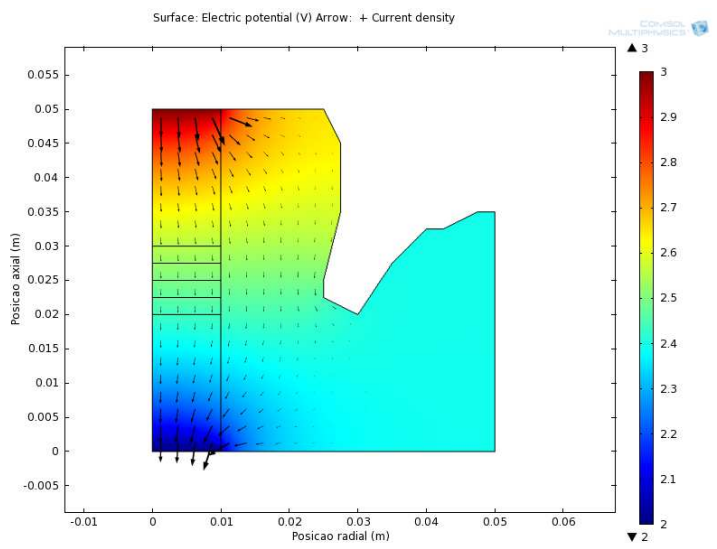

(d) Dist. Potencial elétrico e Fluxo de corrente

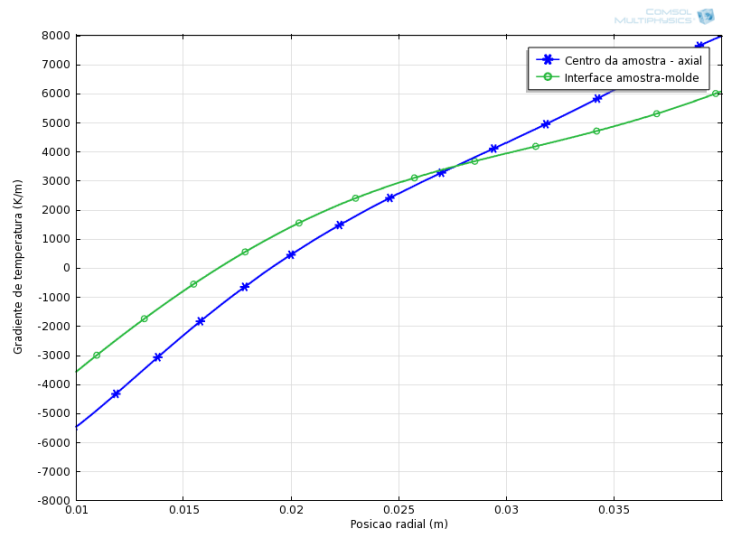

(f) Gradientes de temperatura com o molde otimizado

Figura 5.63: Pós-processamento para molde axissimétrico homogêneo. Malha 20x20, $w=0$ com projeção parcial $\left(r_{\min }=L_{e}\right)$ - Amostra de grafite. 


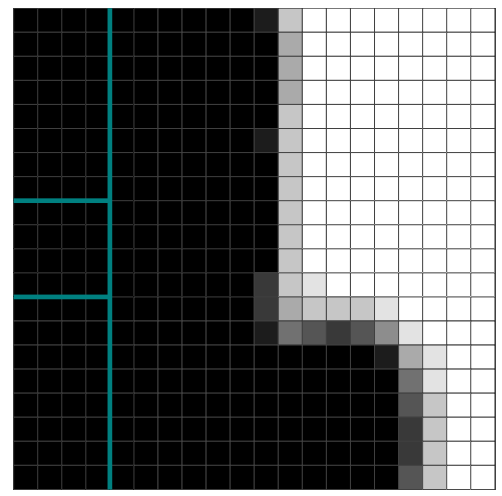

(a) Topologia otimizada

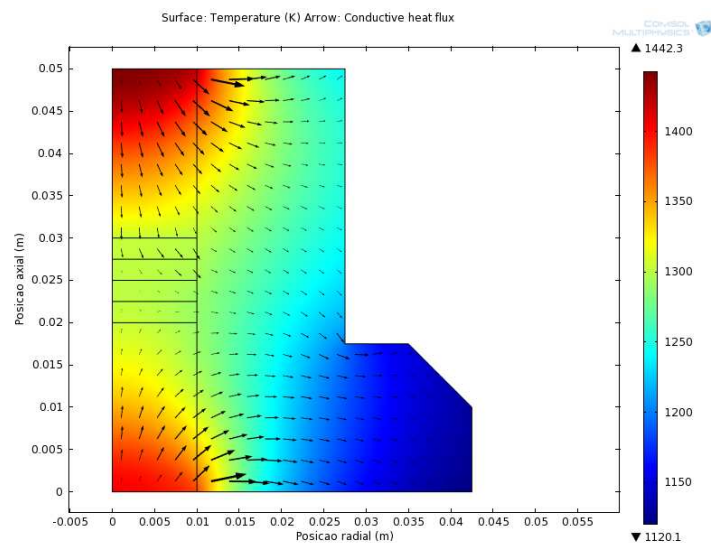

(c) Dist. Temperatura e Fluxo de calor

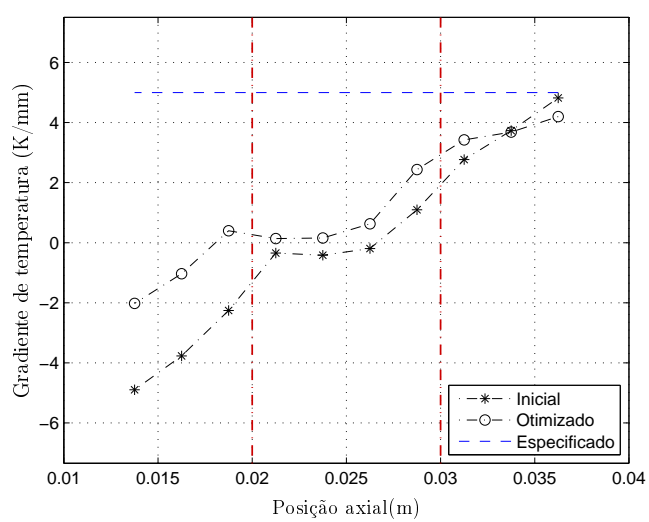

(e) Gradiente de temperatura na interface amostra-molde (OT)

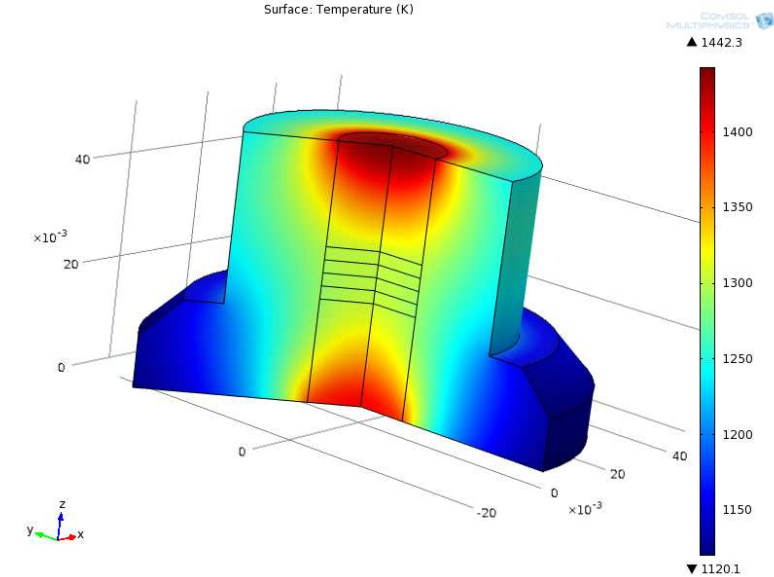

(b) Molde otimizado com a distribuição de temperatura

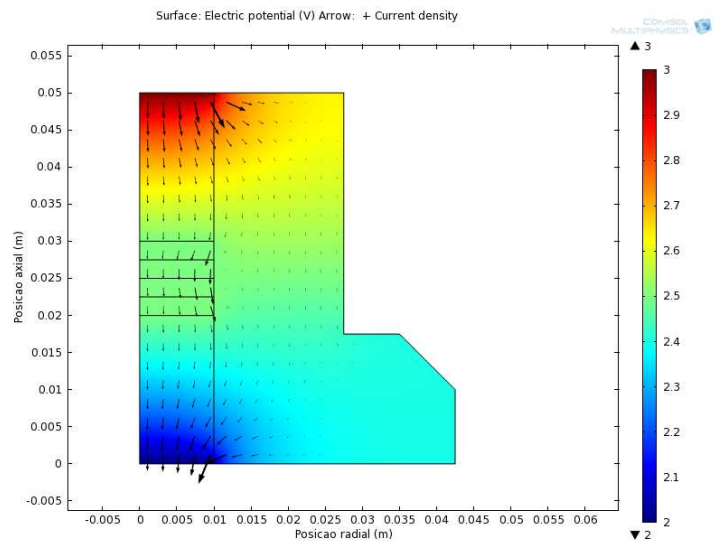

(d) Dist. Potencial elétrico e Fluxo de corrente

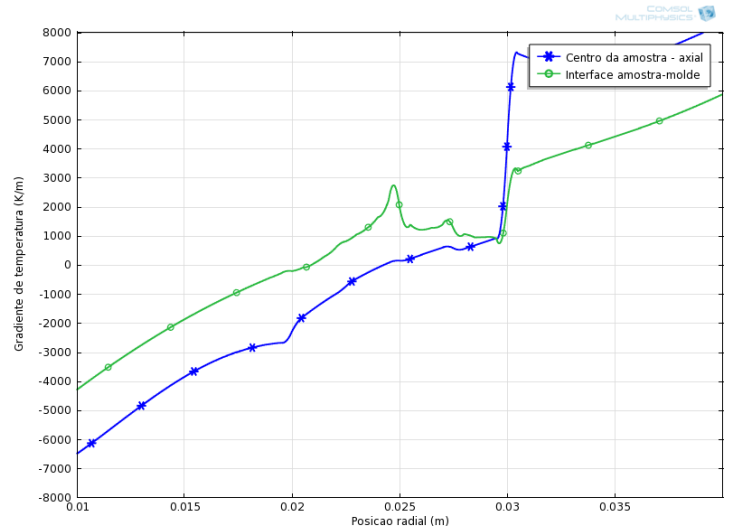

(f) Gradientes de temperatura com o molde otimizado

Figura 5.64: Pós-processamento para molde axissimétrico homogêneo. Malha 20x20, $w=0,3$, com projeção parcial $\left(r_{m i n}=L_{e}\right)$ - Amostra Cu-Ni com gradação linear. 


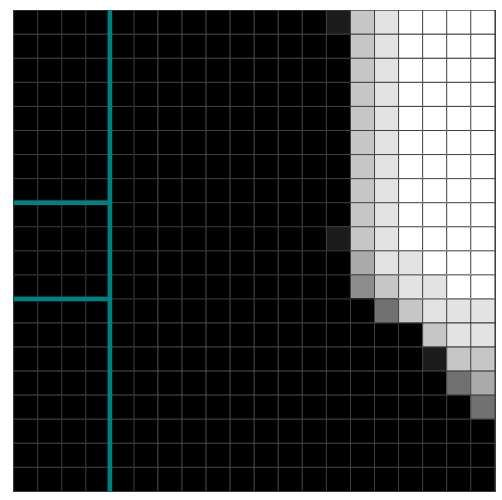

(a) Topologia otimizada

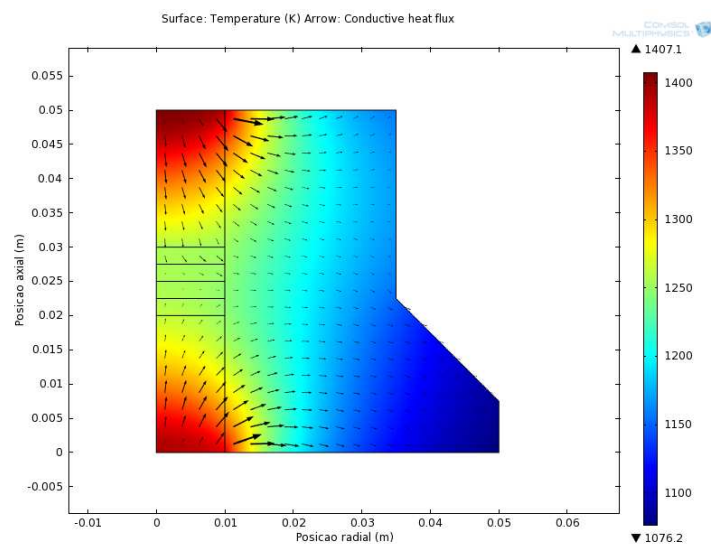

(c) Dist. Temperatura e Fluxo de calor

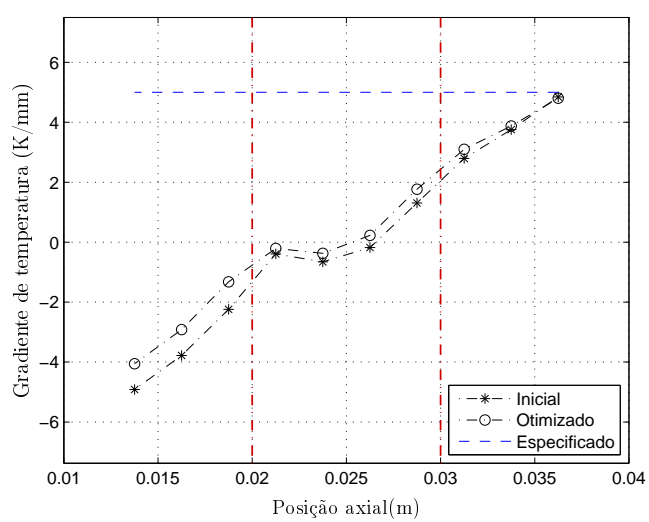

(e) Gradiente de temperatura na interface amostra-molde (OT)

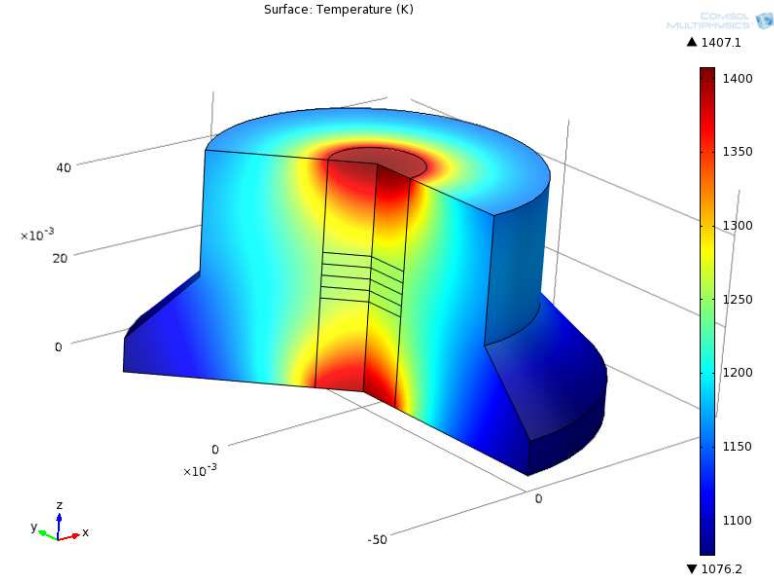

(b) Molde otimizado com a distribuição de temperatura

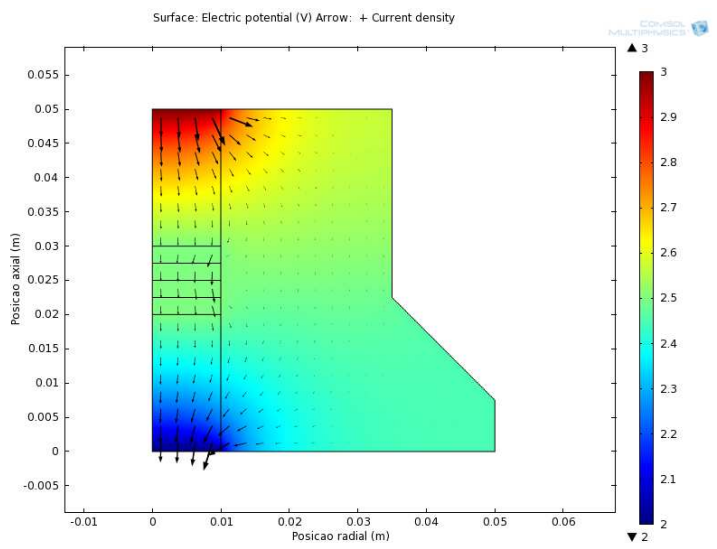

(d) Dist. Potencial elétrico e Fluxo de corrente

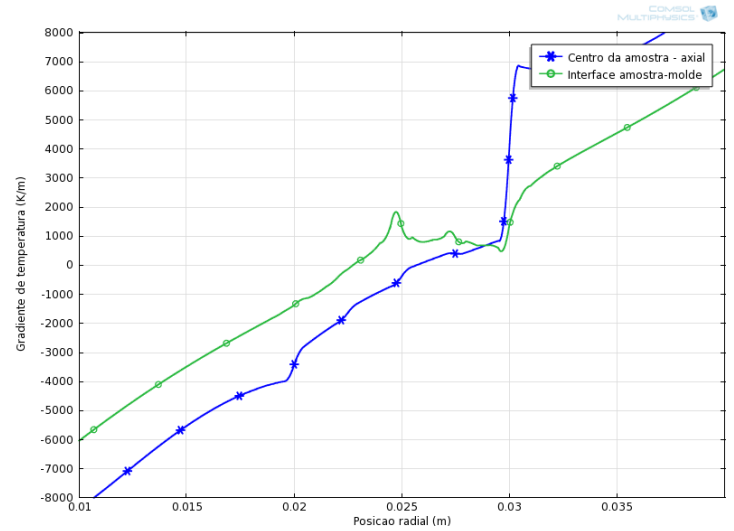

(f) Gradientes de temperatura com o molde otimizado

Figura 5.65: Pós-processamento para molde axissimétrico homogêneo. Malha 20x20, $w=0,3$, com projeção parcial $\left(r_{\min }=L_{e}\right)$ - Amostra $\mathrm{Cu}$-Ni com gradação exponencial. 


\section{Conclusões}

Com o desenvolvimento deste trabalho, o estudo com projeto de moldes utilizados no processo de sinterização por plasma pode ser visto como uma área promissora e com grandes desafios, uma vez que as condições reais do processo SPS são dotadas de diversos fatores que dificultam uma modelagem computacionalmente precisa. Os modelos computacionais implementados neste trabalho, embora considerem premissas que os afastam do comportamento real do processo SPS, permitiram uma avaliação qualitativa do campo de temperaturas ao qual as amostras sinterizadas estão sujeitas. Este campo de temperaturas, por apresentar altas temperaturas num pequeno espaço físico (dimensões da matriz de compactação da ordem de milímetros), apresenta dificuldades em se especificar um certo gradiente de temperatura. As abordagens adotadas neste trabalho para modificar este campo de temperaturas na região da amostra se mostraram viáveis e apresentaram as dificuldades em se obter um gradiente desejado.

Na abordagem para otimização de moldes homogêneos prismáticos, verificou-se a pouca influência da geometria da amostra na topologia final do molde, uma vez que os resultados obtidos indicam uma topologia aproximadamente quadrada com cantos arredondados. Fato este devido, principalmente, à magnitude das grandezas físicas envolvidas no processo de sinterização e também às premissas adotas no modelo computacional inserido no processo de otimização. Além disso, pode-se verificar que existe a necessidade de um modelo bidimensional que considere uma distribuição de geração de calor proporcional à densidade de corrente elétrica que passa pela região do molde, pois neste trabalho esta geração foi considerada uniforme, o que certamente influencia a topologia final.

As abordagens para otimização de moldes axissimétricos homogêneos e compósito apresentaram a dificuldade em se alcançar um gradiente pré-fixado. Em geral, os resultados indicaram uma geometria que busca aproximar o gradiente gerado pelo molde a um gradiente especificado. Porém, a partir dos resultados, pode se verificar que mesmo variando o contorno do molde, o impacto desta variação não reflete numa mudança significativa nos gradientes de temperatura na região da amostra. Foi possível também verificar que as descontinuidades das propriedades físicas, não apenas nas interfaces entre a amostra e os componentes ferramentais, como também no interior da amostra (no caso de amostra MGF), afetam significativamente 
os gradientes de temperatura e dificultam ainda mais a obtenção do gradiente desejado, pelo menos nas amostras simuladas neste trabalho. Os resultados envolvendo o conceito de molde compósito destacam a possibilidade da utilização de material compósito como uma maneira de se obter de gradientes de temperatura desejados. Este conceito alia a variação no contorno do molde com a orientação ótima dos materiais que o compõe. Embora não verificado para amostras MGF, na amostra de grafite utilizando da OMD, houve grande aproximação entre o gradiente Otimizado e o gradiente Especificado, ressaltando a importância deste conceito na otimização de moldes utilizados no processo de sinterização por plasma.

As vantagens em se utilizar moldes não-tradicionais para sinterização de amostras MGF já foram verificadas nos estudos experimentais realizados por Hong et al. (2008) e Wei et al. (2012). Conforme citado na seção 2.2, estes estudos não apresentaram de que maneira a geometria não-tradicional (cilíndrico com tronco de cone) dos moldes foi definida para a realização dos ensaios experimentais. Neste sentido, esta dissertação apresenta contribuições significativas no projeto de moldes para o processo de sinterização por plasma, pois apresenta técnicas e abordagens de otimização que permitem a obtenção de moldes visando a fabricação de um dado tipo de amostra, bem como apresenta resultados que evidenciam a viabilidade em se utilizar moldes otimizados. Além disso, outra importante contribuição deste trabalho é a apresentação, à comunidade acadêmica, de uma linha de pesquisa (otimização de moldes para processo SPS) que praticamente não tem sido explorada.

\subsection{Trabalhos Futuros}

Como trabalhos futuros tem-se a elaboração de um novo modelo computacional com acoplamento eletrotermomecâncio, que considere as não-linearidades às quais este processo está sujeito. Para tornar este novo modelo mais robusto, pode se considerar as propriedades dos materiais dependentes da temperatura e utilizar resistências de contato, principalmente na direção vertical. Além disso, pode-se considerar a radiação térmica como um processo não-linear ocorrendo num envólucro fechado, necessitando da utilização de fatores de forma e considerações das características construtivas do equipamentos no interior da câmara onde ocorre o processo de sinterização.

É possível também explorar novas geometrias para a amostra não apenas em modelo computacional bidimensional, mas também num modelo axissimétrico. A gradação de material em amostras MGF também é outro tema que pode ser avaliado em trabalhos futuros. Neste trabalho foi utilizada apenas gradação na direção axial, mas ela pode ocorrer em outras direções, o que requer o desenvolvimento de um modelo computacional adequado à direção da gradação. 
Com relação ao processo de otimização, pode ser utilizada restrição de tensão para a otimização de moldes uma vez que eles estão sujeitos a carga de pressão uniaxial. Podese também acoplar o MOT à uma otimização de forma como uma maneira de se obter um contorno mais definido para o molde. 


\section{Referências}

ALLEN, J. B.; WALTER, C. Numerical simulation of the temperature and stress field evolution applied to the field assisted sintering technique. International Scholarly Research Network, v. 2012, p. 9, 2012.

ANANTHASURESH, G. K. Optimal Synthesis Methods for MEMS. USA: Kluwer Academic Publishers, 2003.

ANSELMI-TAMBURINI, U.; GARAY, J.; MUNIR, Z. Fundamental investigations on the spark plasma sintering/synthesis process - iii. current effect on reactivity. Materials Science and Engineering A, v. 407, p. 24-30, 2005.

ANSELMI-TAMBURINI, U.; GENNARI, S.; GARAY, J.; MUNIR, Z. Fundamental investigations on the spark plasma sintering/synthesis process - ii. modeling of current and temperature distributions. Materials Science and Engineering, A 394, p. 139-148, 2005.

ARPACI, V. S.; SELAMET, A.; KAO, S.-H. Introduction to heat transfer. USA: Prentice -Hall, 2000.

ASSAN, A. E. Método dos elementos finitos: primeiros passos. Segunda edição. Brasil: Editora Unicamp, 2003.

BARLAK, M.; GRZES, J.; PIETRZAK, K. Fgms interlayers in diffusion bonding joints. In: INTERNATIONAL COMMITTEE OF COMPOSITE MATERIALS. Paris, France, 1999.

BASTOS, J. P. A.; SADOWSKI, N. Electromagnetic modeling by finite element methods. [S.l.]: Marcel Dekker, 2003.

BENDSØE, M. Optimal shape design as a material distribution problem. Structural Optimization, v. 1, p. 193-202, 1989.

BENDSØE, M.; SIGMUND, O. Topology Optimization Theory, Methods and Applications. Germany: Springer-Verlag, 2003.

BENDSØE, M. P. Optimization of structural topology, shape, and material. [S.l.]: Springer-Verlag, 1995.

BENDSØE, M. P.; KIKUCHI, N. Generating optimal topologies in structural design using a homogenization method. Computer Methods in Applied Mechanics and Engineering, v. 71, p. 197-224, 1988.

BENDSØE, M. P.; SIGMUND, O. Material interpolation schemes in topology optimization. Archive of Applied Mechanics, v. 69, p. 635-654, 1999.

BERGLES, A. E. Exhft for fourth generation heat transfer technology. Experimental Thermal and Fluid Science, v. 26, p. 335-344, 2002.

BOURDIN, B. Filters in topology optimization. Inter, v. 50, n. 9, p. 2143-2158, 2001. 
BRUNS, T. Topology optimization of convection-dominated, steady-state heat transfer problems. International Journal of Heat and Mass Transfer, v. 50, p. 2859-2873, 2007.

BRUNS, T. E.; TORTORELLI, D. A. Topology optimization of non-linear elastic structures and compliant mechanisms. Computer Methods in Applied Mechanics and Engineering, v. 190, p. 3443-3459, 2001.

CHEN, B.-C.; KIKUCHI, N. Topology optimization with design-dependent loads. Finite Element in Analysis and Design, v. 37, p. 57-70, 2001.

CHEN, W.; ANSELMI-TAMBURINI, U.; GARAY J. R. GROZA, Z. A. M. J. E. Fundamental investigations on the spark plasma sintering/synthesis process - i. effect of dc pulsing on reactivity. Materials Science and Engineering A, v. 394, p. 132-138, 2005.

CHENG, K. T.; OLHOFF, N. An investigation concerning optimal-design solid elastic plates. International Journal of Solids and Structure, v. 17, n. 3, p. 305-323, 1981.

CHENNOUfI, N.; MAJKIC, G.; CHEN, Y.; SALAMA, K. Temperature, current, and heat loss distributions in reduced electrothermal loss spark plasma sintering. The Minerals, Metals $\&$ Materials Society and ASM International, v. 40A, p. 2401-2409, 2009.

CHIAVERINI, V. Metalurgia do pó. 4. ed. [S.l.]: Associação Brasileira de Metalurgia e Materiais, 2001.

CHOI, K. K.; KIM, N. H. Structural Sensitivity Analysis and Optimization 1. [S.l.]: Springer, 2005.

DONOSO, A.; SIGMUND, O. Topology optimization of multiple physics problems modelled by poissonś equation. Latin American Journal of Solids and Structures, v. 1, p. 169-184, 2004.

FENG, H.; MENG, Q.; ZHOU, Y.; JIA, D. Spark plasma sintering of functionally graded

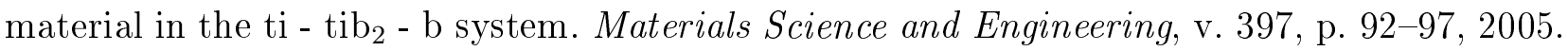

FINLAYSON, B. A. Variational Principles for Heat Transfer. [S.l.]: Hemisphere Publishing Corporation, 1983.

FISH, J.; BELYTSCHKO, T. A first course in finite elements. [S.1.]: John Wiley and Sons, 2007.

GAO, T.; ZHANG, W.; ZHU, J.; XU, Y.; BASSIR, D. Topology optimization of heat conduction problem involving design-dependent heat load effect. Finite Element in Analysis and Design, v. 44, p. 805-813, 2008.

GUEST, J. K.; PRÉVOST, J. H.; BELYTSCHKO, T. Achieving minimum length scale in topology optimization using nodal design variables and projection functions. In, v. 61, p. 238-254, 2004.

GUO, H.; KHOR, K. A.; BOEY, Y. C.; MIAO, X. Laminated and functionally graded hydroxyapatite/yttria stabilized tetragonal zirconia composites fabricated by spark plasma sintering. Biomaterilas, v. 24, p. 667-675, 2003.

HABER, R. B.; JOG, C. S.; BENDSØE, M. P. A new approach to variable-topology shape design using a constrint on perimeter. Structural Optimization, v. 11, n. 1, p. 1-12, 1996.

HAFTKA, R. T.; GÜRDAL, Z. Elements of Structural Optimization. [S.l.]: Klu, 1991. 
HASSANI, B.; HINTON, E. Homogenization and Structural Optimization: theory, practice and software. [S.1.]: Springer-Verlag, 1999.

HONG, C.-Q.; ZHANG, X.-H.; LI, W.-J.; HAN, J.-C.; MENG, S.-H. A novel functionally graded material in the $\mathrm{zrb}_{2}$-sic and $\mathrm{zrO}_{2}$ system by spark plasma sintering. Materials Science and Engineering A, v. 498, p. 437-441, 2008.

HUANG, H.-C.; USMANI, A. S. Finite Element Analysis for Heat Transfer. [S.1.]: Springer, 1994.

HUGHES, T. J. R. The finite element method. Linear Static and Dynamic finte element analysis. [S.1.]: Prentice -Hall, 1987.

HUNGRÍA, T.; GALY, J.; CASTRO, A. Spark plasma sintering as a useful technique to the nanostructuration of piezo-ferroelectric materials. Advanced Engineering Material, v. 8, 2009.

IGA, A.; NISHIWAKI, S.; IZUI, K.; YOSHIMURA, M. Topology optimization of thermal conductors considering design-dependent effects, including heat conduction and convection. International Journal of Heat and Mass Transfer, v. 52, p. 2721-2732, 2009.

INCROPERA, F. P.; DEWITT, D. P. Fundamentals of Heat and Mass Transfer. [S.1.]: John Wiley and Sons, 2002.

JIN, J. The finite element method in electromagnetics. [S.l.]: John Wiley and Sons, 2002.

KHON, R. V.; STRANG, G. Optimal-design and relaxation of variational-problems .1. Communications on Pure and Applied Mathematics, v. 39, n. 1, p. 113-137, 1986.

KHON, R. V.; STRANG, G. Optimal-design and relaxation of variational-problems .2. Communications on Pure and Applied Mathematics, v. 39, n. 2, p. 139-182, 1986.

KHON, R. V.; STRANG, G. Optimal-design and relaxation of variational-problems .3. Communications on Pure and Applied Mathematics, v. 39, n. 3, p. 353-377, 1986.

KIEBACK, B.; NEUBRAND, A.; RIEDEL, H. Processing techniques for functionally graded materials. Materials Science and Engineering A, v. 362, p. 81-105, 2003.

KIYONO, C. Y.; SILVA, E.; REDDY, J. Design of laminated piezocomposite shell transducers with arbitrary fiber orientation using topology optimization approach. International Journal For Numerical Methods In Engineering, v. 90, p. 1452-1484, 2012.

LEWIS, R. W.; NITHIARASU, P.; SEETHARAMU, K. N. Fundamental of the Finite Element Method for Heat and Fluid Flow. [S.1.]: John Wiley and Sons, 2004.

LI, Q.; STEVEN, G. P.; XIE, Y.; QUERIN, O. M. Evolutionary topology optimization for temperature reduction of heat conducting fields. International Journal of Heat and Mass Transfer, v. 47, p. 5071-5083, 2004.

LUND, E. Buckling topology optimization of laminated multi-material composite shell structures. Composite Structures, v. 91, p. 158-167, 2009.

MAIZZA, G.; GRASSO, S.; SAKKA, Y. Moving finite-element mesh model for aiding spark plasma sintering in current control mode of pure ultrafine wc powder. Journal of Material Science, v. 44, p. 1219-1236, 2009. 
MATSUGI, K.; KURAMOTO, H.; HATAYAMA, T.; YANAGISAWA, O. Temperature distribution at steady state under constant current discharge in spark sintering process of ti and $\mathrm{al}_{2} \mathrm{O}_{3}$ powders. Journal of Materials Processing Technology, v. 134, p. 225-232, 2003.

MATSUI, K.; TERADA, K. Continuous aproximation of material distribution for topology optimization. International Journal For Numerical Methods In Engineering, v. 59, p. 1925-1944, 2004.

MLEJNEK, H. P. Some aspects of the genesis of structures. Structural Optimization, v. 5, p. 64-69, 1992.

MUNIR, Z.; ANSELMI-TAMBURINI, U.; OHYANAGI, M. The effect of eletric field and pressure on the synthesis and consolidation of materials: A review of the spark plasma sintering method. Journal of Materials Science, v. 41, p. 763-777, 2006.

OLHOFF, N.; BENDSØE, M.; RASMUSSEN, J. On cad-integrated structural topology and design optimization. Compute, v. 89, n. 1-3, p. 259-279, 1991.

PAULINO, G. H.; LE, C. H. A modified q4/q4 element for topology optimization. Structural Multidisciplinary Optimization, v. 37, p. 255-264, 2009.

RAHMATALLA, S.; SWAN, C. A q4/q4 continuum structural topology optimization implementation. Stru, v. 27, p. 130-135, 2004.

RÄTHEL, J.; HERRMANN, M.; BECKERT, W. Temperature distribution for electrically conductive and non-conductive materials during field assisted sintering. European Ceramic Society, v. 29, p. 1419-1425, 2009.

REDDY, J. N. An introduction to the finite element method. Third edition. [S.1.]: Mcgraw-Hill, 2004.

REDDY, J. N.; GARTLING, D. K. The finite element method in heat transfer and fluid dynamics. [S.l.]: CRC Press, 1994.

ROSVANY, G. I. N.; ZHOU, M.; BIRKER, T. Generalized shape optimization without homogenization. Structural Optimization, v. 4, n. 3-4, p. 250-252, 1992.

RUBIO, W. M. Projeto de "MEMS" Eletrotermomecânicos Usando o Método de Otimização Topológica. Dissertação (Mestrado) — Universidade de São Paulo, 2005.

SHANCKELFORD, J. F. Ciência dos Materiais. [S.l.]: Prentice Hall, 2008.

SIEGEL, R.; HOWELL, J. R. Thermal Radiation Heat Transfer. Third. [S.1.]: Hemisphere Publishing Corporation, 1992.

SIGMUND, O. A 99 lines topology optimization code written in matlab. Structural and Multidisciplinary Optimization, v. 21, p. 120-127, 2001.

SIGMUND, O.; PETERSSON, J. Numerical instabilities in topology optimization: A survey on procedures dealing with checkerboards, mesh- dependencies and local minima. Structural Optimization, v. 16, n. 1, p. 68-75, 1998.

SILVA, E. C. N.; NISHIWAKI, S.; FONSECA, J. S. O.; KIIKUCHI, N. Optimization methods applied to material and flextensional actuator design using the homogenization method. Computer Methods in Applied Mechanics and Engineering, v. 172, p. 241-271, 1999. 
SILVA, E. C. N.; NISHIWAKI, S.; KIKUCHI, N. Topology optimization design of flextensional actuators. IEEE Transactions on Ultrasonics, Ferroelectrics, and Frequency Control, v. 47, n. 3, p. 657-671, 2000.

STUMP, F. V. Otimização Topológica aplicado ao projeto de estruturas tradicionais e estruturas com gradação funcional sujeitas a restrição de tensão. Dissertação (Mestrado) Universidade de São Paulo, 2006.

SUZUKI, K.; KIKUCHI, N. A homogenization method for shape and topology optimization. Comput, v. 93, n. 3, p. 291-318, 1991.

THÜMMLER, F.; OBERACKER, R. Introduction to Powder Metallurgy. [S.l.]: The Institute of Materials, 1993.

TIWARI, D.; BASU, B.; BISWAS, K. Simulation of thermal and electric field evolution during spark plasma sintering. Ceramics International, v. 35, p. 699-708, 2009.

TROMBINI, V.; PALLONE, E.; MUNIR, Z.; TOMASI, R. Spark plasma sintering (sps) of $\mathrm{Al}_{2} \mathrm{O}_{3}-\mathrm{ZrO}_{2}$ nanocomposites. Ceramica, v. 53, p. 62-67, 2007.

VANDERPLAATS, G. N. Numerical Optimization Techniques for Engineering Design: with Applications. New York, EUA: Mc, 1984.

VANMEENSEL, K.; LAPTEV, A.; HENNICKE, J.; der Biest, O. V. Modelling of the temperature distribution during field assisted sintering. Acta Materialia, v. 53, p. 4379-4388, 2005.

VARELA, R. A. S. Projeto de microsistemas eletrotermomecânicos(ETM) utilizando o Método de Otimização Topológica considerando resposta térmica transiente. Dissertação (Mestrado) — Universidade de São Paulo, 2012.

VASCONCELOS, F. M.; MELlO, L. A. M.; SILVA, E. C. N. Design of spark plasma sintering graphite die using topology optimization. Asociación Argentina de Mecánica Computacional, XXIX, p. 8411-8420, 2010.

V.SAlmoriA, G.; AHREnS, C. H.; VIllamizAR, F. A. Y.; NETTO, A. da C. S. Influência do desempenho térmico de moldes fabricados com compósito epóxi/aluminínio nas propriedades de pp moldado por injeção. Polímeros: Ciência e Tecnologia, v. 18, n. 3, p. 262-269, 2008.

WANG, C.; CHENG, L.; ZHAO, Z. Fem analysis of the temperature and stress distribuition in spark plasma sintering: Modelling and experimental validation. Computational Materials Science, v. 49, p. 351-362, 2010.

WANG, X.; CASOLCO, S.; XU, G.; GARAY, J. Finite element modeling of eletric current-activated sintering: The effect of coupled eletrical potential, temperature and stress. Acta Materialia, v. 55, p. 3611-3622, 2007.

WATANABE, Y.; IWASA, Y.; SATO, H.; TERAMOTO, A.; ABE, K.; MIURA-FUJIWARA, E. Microstructures and mechanical properties of titanium/biodegradable-polymer fgm for bone tissue fabricated by spark plasma sintering method. Materials Processing Technology, v. 211, p. 1919-1926, 2011. 
WEI, S.; ZHANG, Z.-H.; SHEN, X.-B.; WANG, F.-C.; SUN, M.-Y.; YANG, R.; LEE, S.-L. Simulation of temperature and stress distribution in functionally graded materials synthesized by a spark plasma sintering process. Computational Materials Science, v. 60, p. 168-175, 2012.

YANG, W.-J.; TANIGUCHI, H.; KUDO, K. Radiative Heat Transfer by the Monte Carlo Method. [S.l.]: Academic Press, 1995.

YIN, L.; ANANTHASURESH, G. K. A novel topology design scheme for the multi-physics problems of electro-thermally actuated micromechanisms. Sensor and Actuators A, v. 97-98, p. 599-609, 2002.

YUCHENG, W.; ZHENGYI, F. Study of temperature field in spark plasma sintering. Materials Science and Engineering, B90, p. 34-37, 2002.

ZAVALIANGOS, A.; ZHANG, J.; KRAMMER, M.; GROZA, J. R. Temperature evolution during field activated sintering. Materials Science and Engineering, A 379, p. 218-228, 2004.

ZHANG, Y.; LIU, S. Design of conducting paths based on topology optimization. Heat and Mass Transfer, v. 44, p. 1217-1227, 2008.

ZHOU, M.; ROZVANY, G. I. N. The coc algorithm, part ii: Topological, geometrical, and generalized shape optimization. Computer Methods in Applied Mechanics and Engineering, v. 89, p. 309-336, 1991. 


\section{Apêndice A - Técnicas de solução do problema de otimização}

Os métodos principais para solução de problemas de otimização são os métodos analíticos e numéricos. Os métodos analíticos, dentre eles o cálculo diferencial e o variacional, permitem, em geral, obter solução de problemas que envolvam geometrias simples, tais como vigas ou treliças. Já os métodos numéricos permitem resolver problemas de estruturas com geometrias complexas e são classificados em dois tipos: específicos e gerais. Um método numérico específico empregado em otimização topológica é o Critério de Optimalidade ("Optimality Criteria”) (BENDSØE, 1995; BENDSØE; SIGMUND, 2003), porém, sendo este um método com base empírica, a cada problema de otimização uma formulação específica deve ser desenvolvida, restringindo assim sua aplicação. Uma revisão sobre o critério de optimalidade pode ser encontrada em Hassani e Hinton (1999). Os métodos numéricos gerais são baseados na chamada programação matemática e permitem resolver problemas de otimização estrutural ou não. Os métodos de programação matemática podem ser classificados em métodos de programação linear, programação não-linear e métodos baseados na teoria de aproximações como a programação linear sequencial (PLS) e programação quadrática sequencial (PQS).

Neste trabalho a PLS é adotado como método de solução dos problemas de otimização apresentado na seção 4.5, já que vem sendo aplicado com sucesso na área de otimização topológica (SILVA et al., 1999; SILVA; NISHIWAKI; KIKUCHI, 2000; IGA et al., 2009).

\section{A.1 Programação linear sequencial}

A PLS é uma rotina que resolve, sequencialmente, vários subproblemas lineares. Ela pode ser aplicada a problemas de otimização com funções objetivo complexas e/ou não-lineares. Nesse caso, o problema de otimização não-linear é divido numa sequência de subproblemas lineares, sendo a solução obtida após um número suficiente de iterações (HAFTKA; GÜRDAL, 1991). Além de ser possível trabalhar com problemas não-lineares, a PLS permite trabalhar com um grande número de variáveis de projeto $\left(x_{n}\right)$ e restrições. Para isso o problema de 
otimização deve apresentar a seguinte formulação (VANDERPLAATS, 1984; HAFTKA; GÜRDAL, 1991):

$$
\underset{x_{1}, \ldots, x_{n}}{\operatorname{maximizar}} F(x)=a_{1} x_{1}+a_{2} x_{2}+\cdots+a_{n} x_{n}
$$

tal que

$$
\begin{array}{ll}
g_{i}(x)=b_{1_{i}} x_{1}+b_{2_{i}} x_{2}+\cdots+b_{n_{i}} x_{n} \leq c_{i} & \left(i=1, \ldots, m_{1}\right) \\
h_{j}(x)=b_{1_{j}} x_{1}+b_{2_{j}} x_{2}+\cdots+b_{n_{j}} x_{n}=d_{j} & \left(j=1, \ldots, m_{2}\right)
\end{array}
$$

Para funções objetivos $F(x)$ não lineares, realiza-se a sua linearização num ponto $x_{0}$ qualquer através da série de Taylor, considerando apenas os termos de $1^{\mathrm{a}}$ ordem, conforme indicado na equação abaixo:

$$
F(x)=F\left(x_{0}\right)+\frac{\partial F}{\partial x}\left(x-x_{0}\right)+\frac{\partial^{2} F}{\partial x^{2}} \frac{\left(x-x_{0}\right)^{2}}{2 !}+\cdots+\frac{\partial^{k} F}{\partial x^{k}} \frac{\left(x-x_{0}\right)^{k}}{k !}+e(x)
$$

onde $F\left(x_{0}\right)$ é o valor da função $F$ avaliada no ponto $x_{0}, k$ indica a ordem da derivada e $e(x)$ é o erro devido a aproximação da função. Para um função com múltiplas variáveis, a série de Taylor é dada como:

$$
\begin{aligned}
F\left(x_{1}, \ldots, x_{n}\right)= & F\left(x_{0_{1}}, \ldots, x_{0_{n}}\right)+ \\
& +\frac{\partial F}{\partial x_{1}}\left(x-x_{0_{1}}\right)+\cdots+\frac{\partial^{k} F}{\partial x_{1} k} \frac{\left(x_{1}-x_{0_{1}}\right)^{k}}{k !}+ \\
& +\frac{\partial F}{\partial x_{2}}\left(x-x_{0_{2}}\right)+\cdots+\frac{\partial^{k} F}{\partial x_{2}{ }^{k}} \frac{\left(x_{2}-x_{0_{2}}\right)^{k}}{k !}+\cdots+ \\
& +\frac{\partial^{k} F}{\partial x_{n}}\left(x-x_{0_{n}}\right)+\cdots+\frac{\partial^{k} F}{\partial x_{n}{ }^{k}} \frac{\left(x_{n}-x_{0_{n}}\right)^{k}}{k !}+e\left(x_{1}, \ldots, x_{n}\right)
\end{aligned}
$$

Os termos acima da primeira ordem são desprezados, obtendo a linearização da função objetivo a ser introduzida na PLS. Assim, a função objetivo $F$ linearizada assume a seguinte forma:

$$
F=F_{0}+\frac{\partial F}{\partial x_{1}}\left(x_{1}-x_{0_{1}}\right)+\frac{\partial F}{\partial x_{2}}\left(x_{2}-x_{0_{2}}\right)+\cdots+\frac{\partial F}{\partial x_{n}}\left(x_{n}-x_{0_{n}}\right)
$$

Como os termos constantes não influenciam no processo de otimização, a função linear a ser utilizada na PLS é dada como:

$$
F_{\text {linear }}=\frac{\partial F}{\partial x_{1}} x_{1}+\frac{\partial F}{\partial x_{2}} x_{2}+\cdots+\frac{\partial F}{\partial x_{n}} x_{n}
$$

A equação A.5 é linear em relação as suas variáveis de projeto $x_{i}$, em que os coeficientes da função $F_{\text {linear }}$ representam a sensibilidade da função $F$ em relação às variáveis do problema. Procedimento análogo pode ser realizado com as funções de restrição $g_{i}$.

Como citando anteriormente, a linearização é realizada para um valor qualquer de $x_{0}$. Assim, para que a linearização não apresente erros significativos na aproximação de $F$ em 
relação à $F_{\text {linear }}$ (ver Figura A.1), são definidos limites móveis para as variáveis de projeto $x$. No problema de otimização, os limites móveis representam restrições de caixa para a variável de projeto, ou seja, $x_{i}^{\text {min }} \leq x_{i} \leq x_{i}^{\text {max }}$. Os valores para os limites móveis devem ser adequados para cada trecho da função não-linear $F$, tendo como base a sua curvatura. Em regiões de pequena curvatura pode-se assumir valores relativamente altos para os limites móveis e em regiões de curvatura acentuadas assume-se valores pequenos. Com isso, o processo de convergência da solução ótima se torna mais rápido e ao mesmo tempo não se corre o risco de perder o ponto de máximo da função $F$.

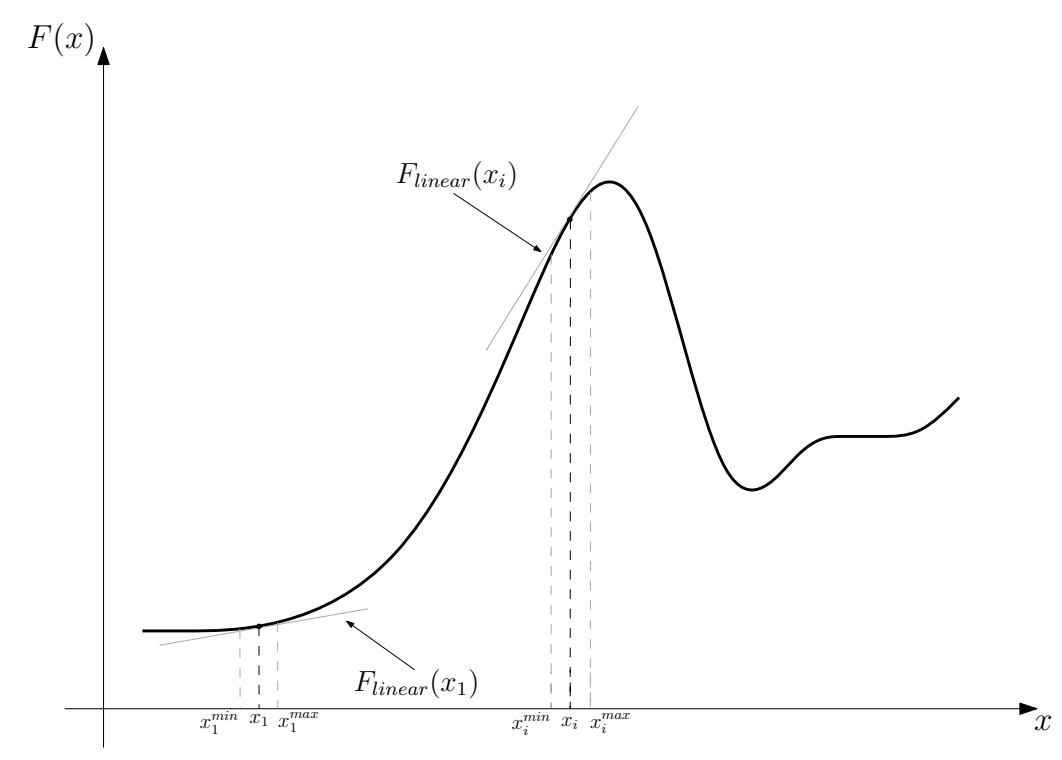

Figura A.1: Limites móveis numa função $F(x)$ unidimensional.

Em geral, adota-se para os limites móveis valores entre $5 \%$ a $10 \%$ do valor da variável de projeto em cada interação (HAFTKA; GÜRDAL, 1991). 


\section{Apêndice B - Validação do MEF e do Cálculo das Sensibilidades}

O Método de Otimização Topológica (MOT) é baseado num processo iterativo em que, a cada iteração, as equações governantes dos problemas elétrico e térmico são solucionadas através do Método dos Elementos Finitos(MEF). A correta implementação do MEF, para a resolução destes problemas, é fundamental para a eficácia do processo de otimização e confiabilidade dos resultados obtidos com o MOT. Assim, neste Apêndice é apresentado a validação dos modelos computacionais implementados no ambiente Matlab ${ }^{\circledR}$ para resolução tanto do problema elétrico, quanto do térmico. Para validar as implementações, foram desenvolvidos modelos computacionais no software comercial COMSOL ${ }^{\circledR}$ e o procedimento adotado para esta validação esta indicado nas Figuras B.1 e B.2. Além disso, é também apresentada a validação do cálculo da sensibilidade das funções objetivo dos problemas de otimização. Esta validação é feita a partir da comparação entre a senbilidade obtida analiticamente e aquela obtida através do Método das Diferenças Finitas(MDF).

Elaboração de modelo no Comsol

Elaboração de modelo no Matlab

Comparação de resultados:

Fluxo de corrente elétrica e distribuição de potencial elétrico

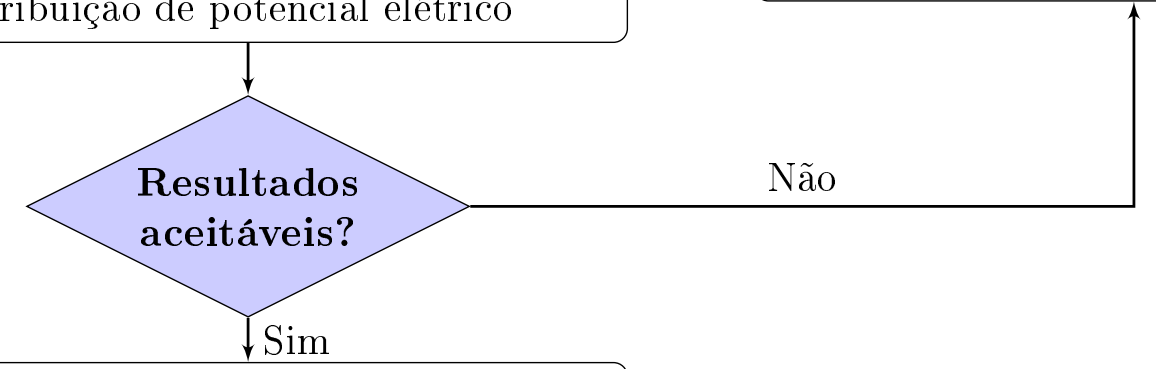

Ajuste/Correção do modelo em Matlab

Aplicar ao MOT

Figura B.1: Processo de validação da implementação do problema elétrico. 


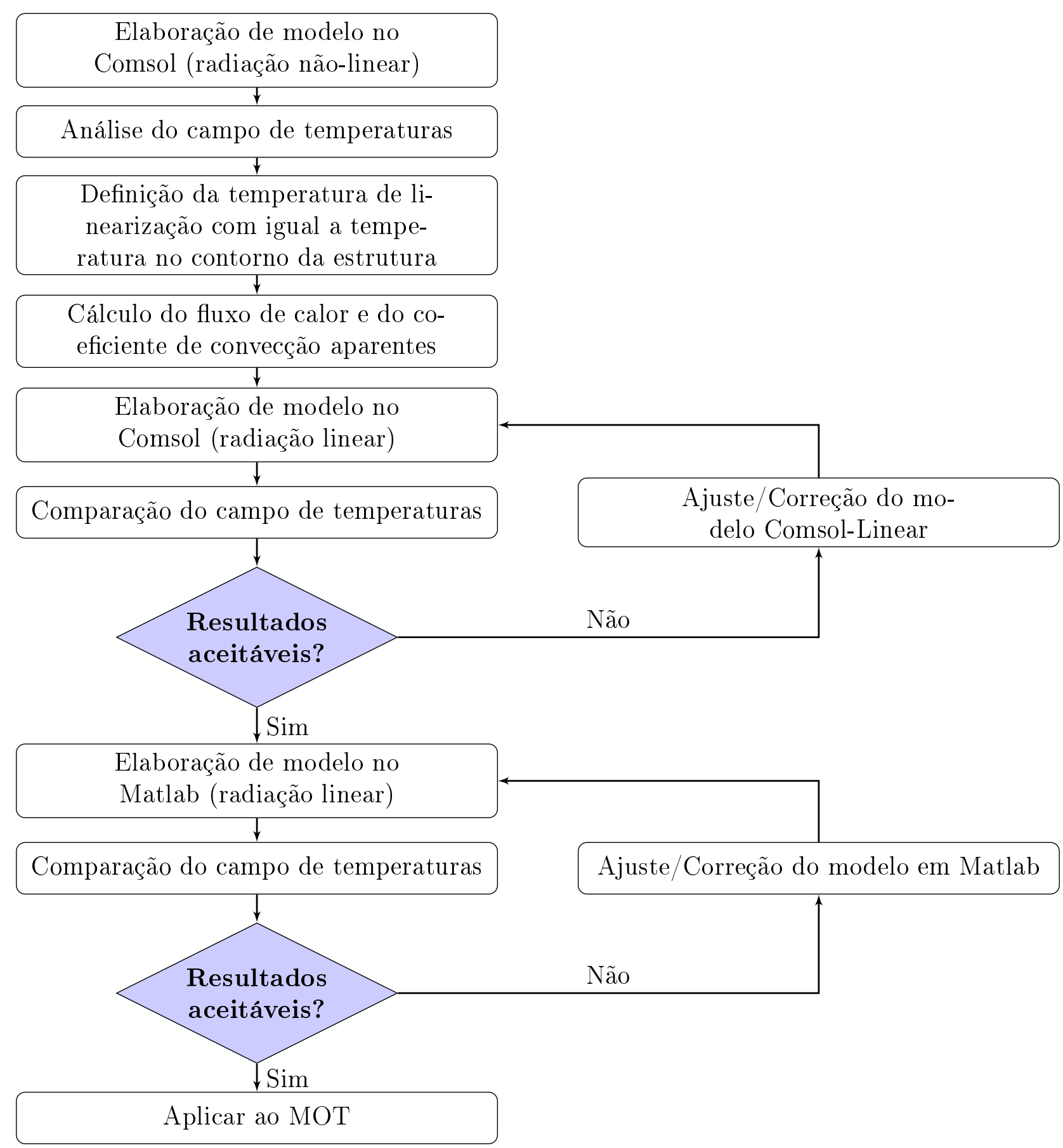

Figura B.2: Processo de validação da implementação do problema térmico.

\section{B.1 Modelo para Molde Homogêneo Prismático}

No problema de otimização para moldes prismáticos foi considerado um modelo computacional para a análise de um problema puramente térmico. Este modelo avalia a distribuição de temperatura numa placa, sujeita a um Estado Plano de Condução térmica (EPC) e de espessura unitária, com geração de calor uniformemente distribuída em regiões definidas como sendo material do molde e da amostra, conforme indicado pela Figura B.3. Em todo o contorno da placa existe uma condição de radiação térmica que, na implementação no Matlab, foi 
linearizada dando assim origem aos termos de fluxo prescrito de calor e convecção aparentes, conforme indicado pela equação 2.23 .

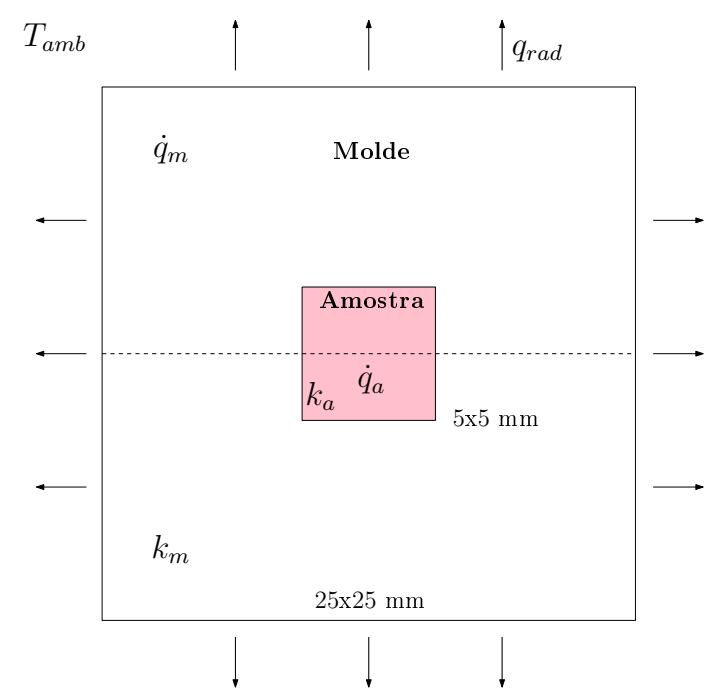

Figura B.3: Definição do problema térmico em moldes prismáticos para elaboração dos modelos computacionais

A Tabela B.1 apresenta os valores utilizados para cada uma da variáveis do problema para os caso de radiação térmica linear e não-linear. Os valores de $\dot{q}_{a}$ e $\dot{q}_{m}$ foram tomados a partir da análise do problema axissimétrico para o modelo de molde homogêneo com espessura de parede variável. Como pode se verificar na Tabela B.1, a geração de calor é maior na região da amostra, o que implica numa amostra condutiva onde há predominância do fluxo de corrente elétrica que promove a geração de calor. O termo $q_{r a d}$ é a radiação térmica que na linearização é dada por $q_{r a d}=q_{a p}+h_{a p}\left(T-T_{a m b}\right)$.

\begin{tabular}{ccc}
\hline \multirow{2}{*}{ Variáveis } & \multicolumn{2}{c}{ Radiação } \\
\cline { 2 - 3 } & Não-Linear & Linear \\
\hline$\dot{q}_{a}\left(\mathrm{~W} / \mathrm{m}^{3}\right)$ & $10^{8}$ & $10^{8}$ \\
$\dot{q}_{m}\left(\mathrm{~W} / \mathrm{m}^{3}\right)$ & $10^{4}$ & $10^{4}$ \\
$k_{a}(\mathrm{~W} / \mathrm{mK})$ & 50 & 50 \\
$k_{m}(\mathrm{~W} / \mathrm{mK})$ & 50 & 50 \\
$q_{a p}\left(\mathrm{~W} / \mathrm{m}^{2}\right)$ & - & $2,52 \times 10^{4}$ \\
$h_{a p}\left(\mathrm{~W} / \mathrm{m}^{2} \mathrm{~K}\right)$ & - & 125 \\
$T_{a m b}(\mathrm{~K})$ & 300 & 820 \\
\hline
\end{tabular}

Tabela B.1: Valores utilizados nos modelos computacionais para validação do MEF.

As Figuras B.4, B.5 e B.6 apresentam os resultados obtidos com os modelos elaborados no Comsol e com a implementação realizada no Matlab. 


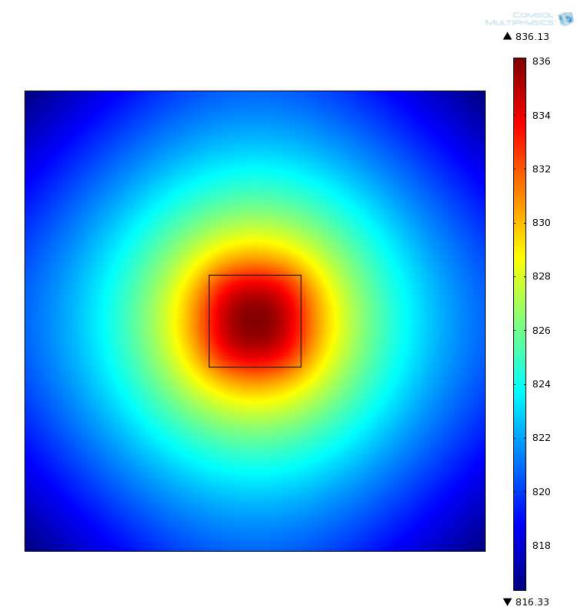

(a) Distribuição de temperatura (K)

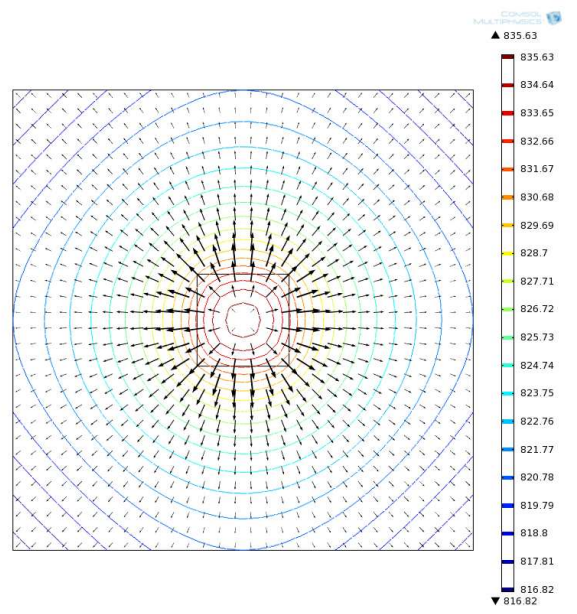

(b) Fluxo de calor e linhas isotérmicas (K)

Figura B.4: Campo de temperaturas e fluxo de calor obtidos através do modelo computacional desenvolvido no COMSOL, considerando radiação não-linear, para estimativa das condições de contorno a serem utilizadas no problema de otimização dos moldes homogêneos prismáticos.

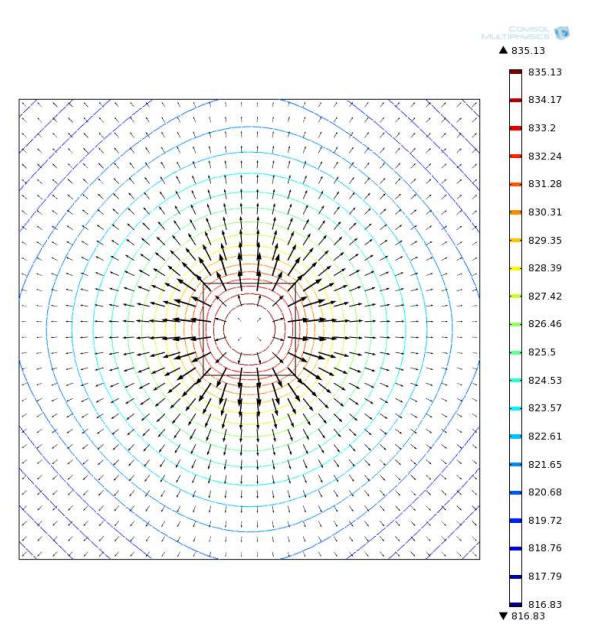

(a) Comsol: radiação linear

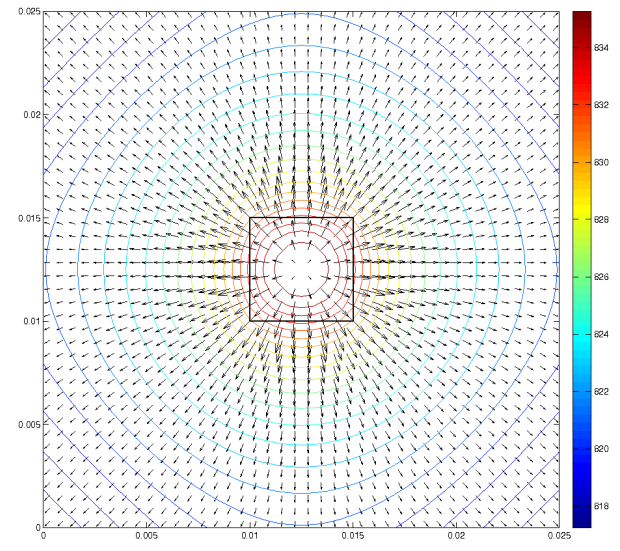

(b) Matlab: radiação linear

Figura B.5: Campo de temperaturas e fluxo de calor obtidos através dos modelos computacionais que consideram a radiação linearizada. (a) Implementação no COMSOL e (b) Implementação no MATLAB.

\section{B.2 Modelo para Moldes Axissimétricos}

Conforme apresentado na seção 5.3.1, o modelo axissimétrico adotado para otimização de moldes considera a excitação da estrutura através da aplicação de uma diferença de potencial elétrico $(d d p)$ entre os punções superior e inferior (ver Figura 5.22 ou B.10). No entanto, os modelos apresentados na literatura consideram a aplicação da ddp entre os eletrodos de grafite. Assim, inicialmente um modelo auxiliar, semelhante aos reportados na literatura foi desenvolvido com o objetivo de se determinar a $d d p$ existente entre os punções, para assim 


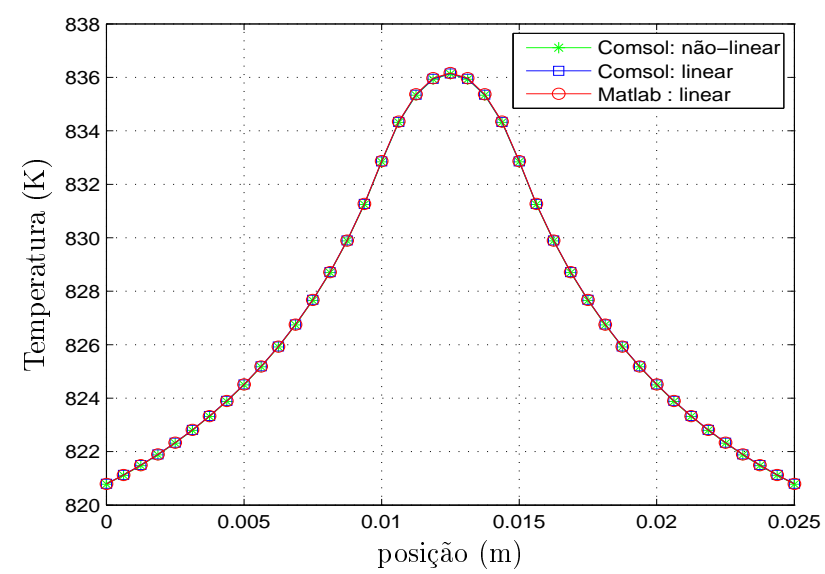

Figura B.6: Distribuição de temperatura, para os três modelos, ao longo da linha tracejada indicada na Figura B.3

utilizá-la no modelo computacional que está integrado ao processo de otimização topológica do molde axissimétrico. Este modelo auxiliar considera o conjunto ferramental indicado na Figura B.7 e se baseia no ferramental utilizado nos processos de sinterização por plasma que ocorrem na máquina SPS disponibilizada pela Escola Politécnica da USP (EPUSP) para projetos de pesquisa.

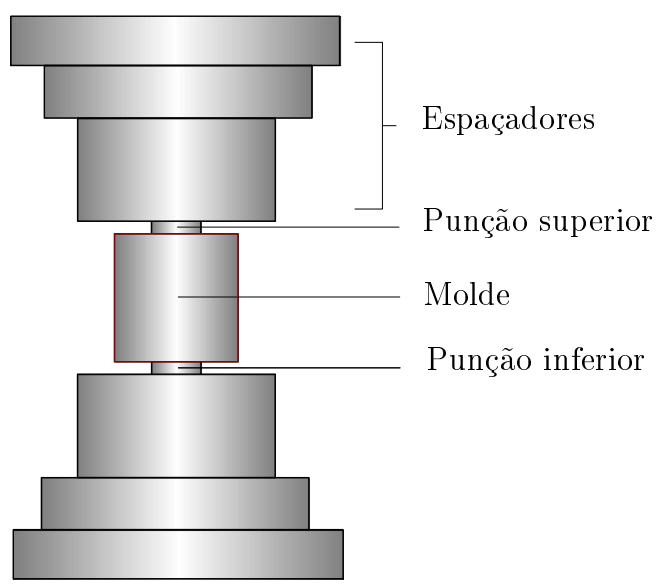

Figura B.7: Conjunto ferramental utilizado na elaboração do modelo computacional auxiliar para determinação da diferença de potencial elétrico entre os punções superior e inferior.

Neste modelo auxiliar, o processo de sinterização por plasma foi simulado no COMSOL ${ }^{\circledR}$ considerando que a transferência de calor entre o molde e o interior da câmara à vácuo ocorre através da radiação não-linear. A amostra, assim como os demais componentes (molde, punção e espaçadores) são considerados como sendo compostos por grafite (condutividade térmica de $50 \mathrm{~W} / \mathrm{mK}$ e elétrica de $\left.1,0 \times 10^{5} \mathrm{~S} / \mathrm{m}\right)$. As dimensões dos componentes ferramentais e as condições de contorno estão indicadas na Figura B.8. 


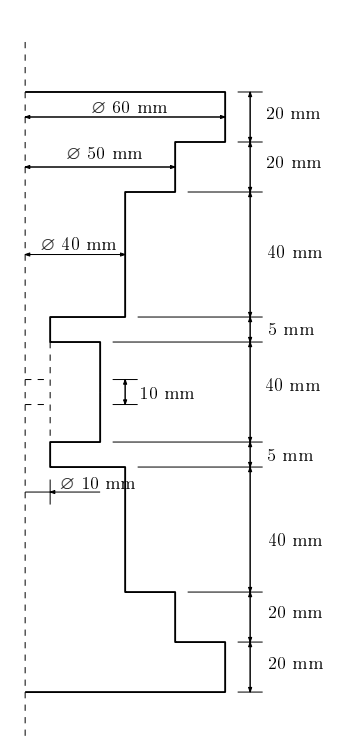

(a) Dimensões dos componentes ferramentais.

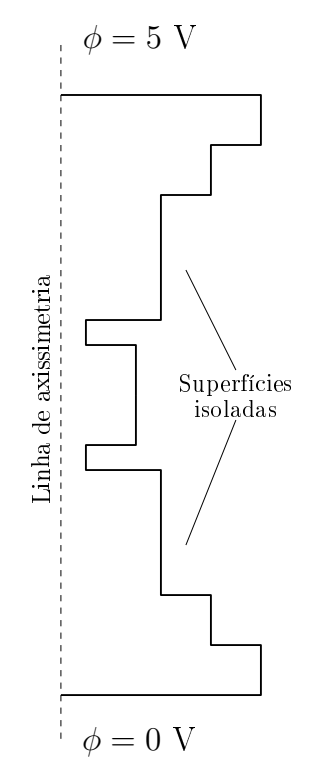

(b) Problema elétrico

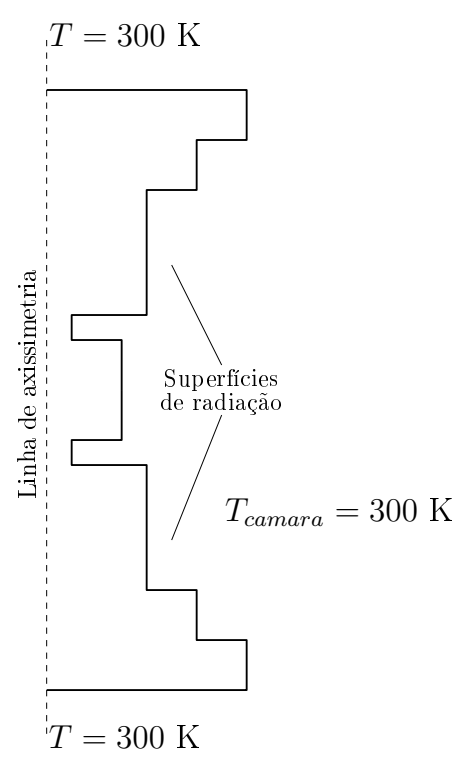

(c) Problema térmico

Figura B.8: Dimensões do conjunto ferramental e condições de contorno do problema eletrotérmico no modelo auxiliar considerando radiação não-linear.

A Figura B.9 apresenta os resultados obtidos com este modelo auxiliar, destacando a distribuição de potencial elétrico e de temperatura. Como pode-se observar, os resultados apontam para uma diferença de potencial elétrico de cerca de 1 Volt entre os punções superior e inferior. Por esta razão, está foi a $d d p$ utilizada no modelo axissimétrico integrado ao método de otimização topológica. Além disso, verifica-se que o molde apresenta na sua superfície uma temperatura de aproximadamente $1550 \mathrm{~K}$.

Seguindo o procedimento de validação do MEF axissimétrico conforme indicado nas Figuras B.1 e B.2, foi desenvolvido um novo modelo de problema eletrotérmico para utilização no processo de otimização topológica. Este novo modelo foi inicialmente implementado e simulado no COMSOL considerando a radiação térmica não-linear e a diferença de potencial elétrico obtida através do modelo auxiliar. O objetivo deste modelo é para posterior comparação com as simulações que consideram radiação linearizada. A Figura B.10 ilustra como esse novo modelo foi desenvolvido. Na Figura B.10a estão molde com sua geometria original, os punções e uma região destacada, a qual é adotada como domínio físico do problema eletrotérmico indicado na Figura B.10b, onde também são apresentadas as condições de contorno.

Na Figura B.11 estão indicadas as dimensões do domínio físico consideradas para se realizar a verificação das implementações do MEF e a maneira pela qual ocorre o acoplamento do problema elétrico com o térmico. No problema elétrico $\Delta \phi$ representa a diferença de potencial elétrico e $\sigma_{a}, \sigma_{m}$ e $\sigma_{p}$ são as condutividades elétricas da amostra, molde e punção 


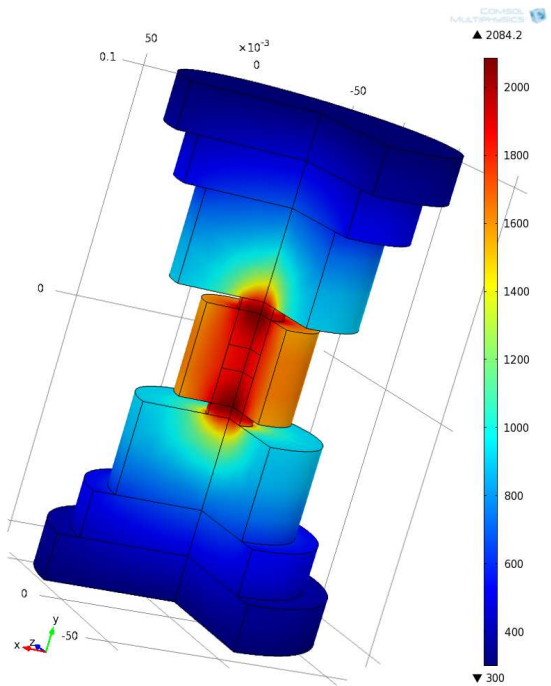

(a) Distribuição axissimétrica da temperatura

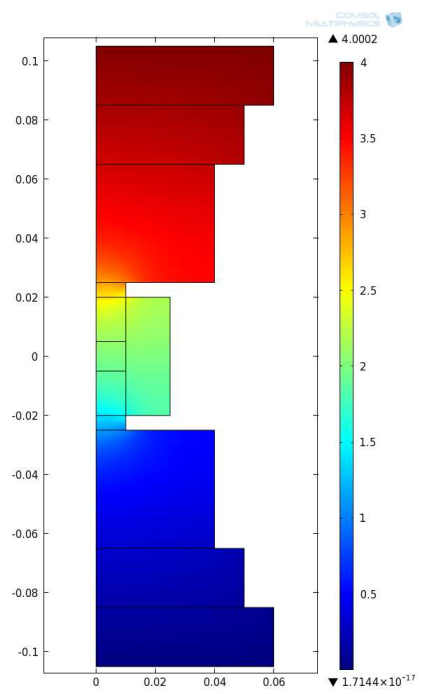

(b) Distribuição de potencial elétrico

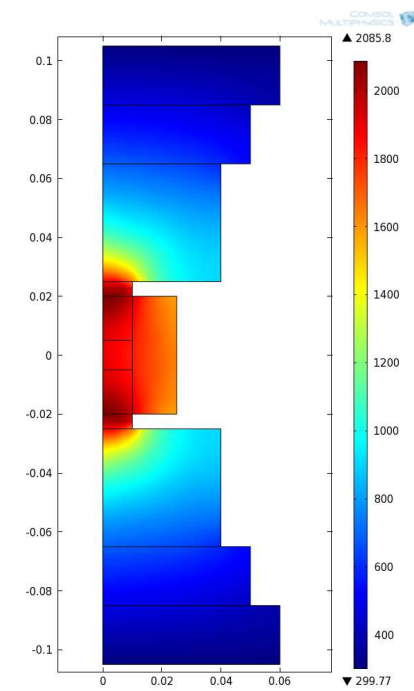

(c) Distribuição de temperatura

Figura B.9: Resultados do modelo auxiliar axissimétrico, com radiação não-linear implementado no COMSOL, para estimativa das condições de contorno a serem adotadas no modelo axissimétrico utilizado no problema de otimização.

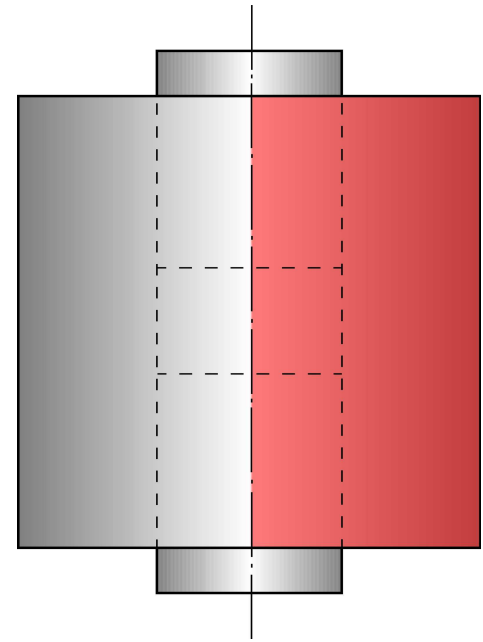

(a) Matriz de compactação Molde e punções

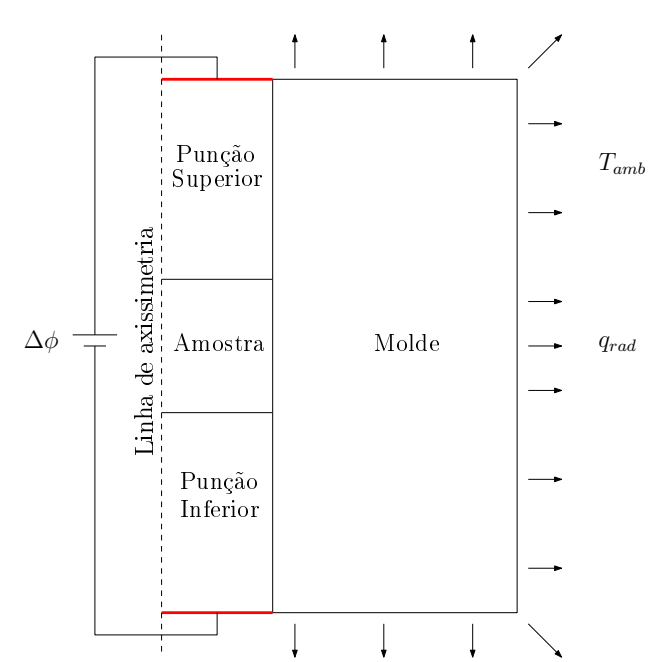

(b) Modelo físico adotado

Figura B.10: Modelo físico adotado e inserido no processo de otimização.

respectivamente. Para o problema térmico, $T_{a m b}$ é a temperatura ambiente, $q_{\text {rad }}$ o fluxo de calor causado pela radiação térmica, $\dot{q}(\phi(\mathbf{x}))$ a geração de calor em todo o domínio devido a passagem de corrente elétrica e $k_{a}, k_{m}$ e $k_{p}$ são as condutividades térmicas da amostra, molde e punção respectivamente.

Para a simulação do modelo indicado nas Figuras B.10 e B.11 foram utilizadas as seguintes condições de contorno e propriedades físicas: $\Delta \phi=1 \mathrm{~V}, \sigma_{a}=\sigma_{p}=\sigma_{m}=1,0 \times 10^{5} \mathrm{~S} / \mathrm{m}$, $T_{a m b}=300 \mathrm{~K}$ e $k_{a}=k_{p}=k_{m}=50 \mathrm{~W} / \mathrm{mK}$. Os resultados obtidos com esta simulação são 


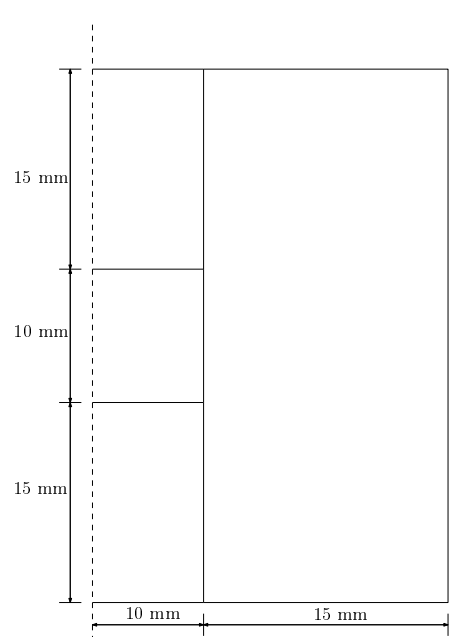

(a) Dimensões dos componentes ferramentais.

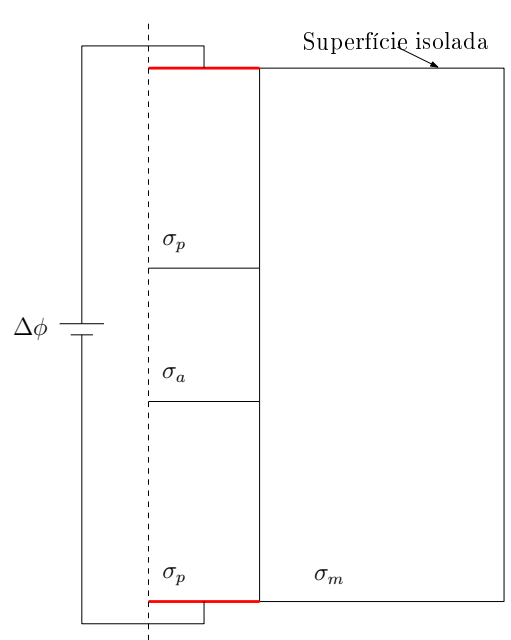

(b) Problema elétrico

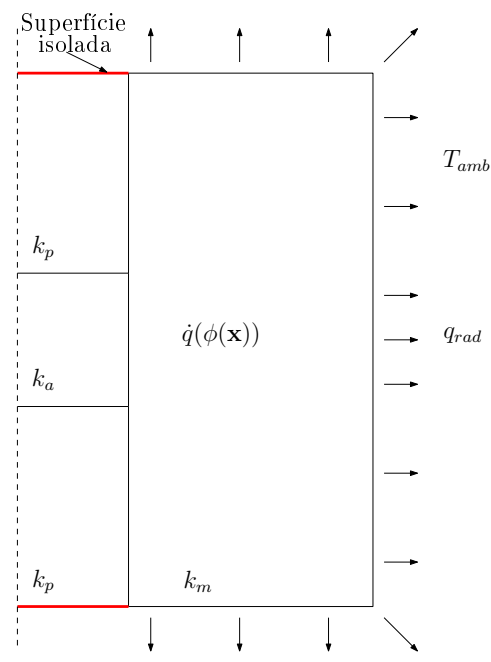

(c) Problema térmico

Figura B.11: Dimensões dos componentes ferramentais no modelo axissimétrico e condições de contorno no problema eletrotérmico utilizado no processo de otimização.

apresentados na Figura B.12.

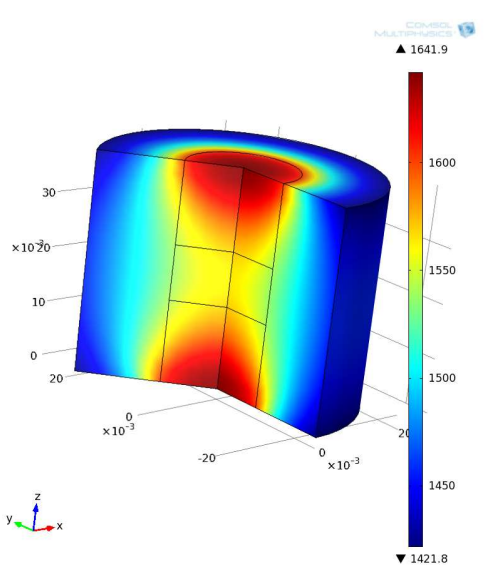

(a) Distribuição axissimétrica da temperatura

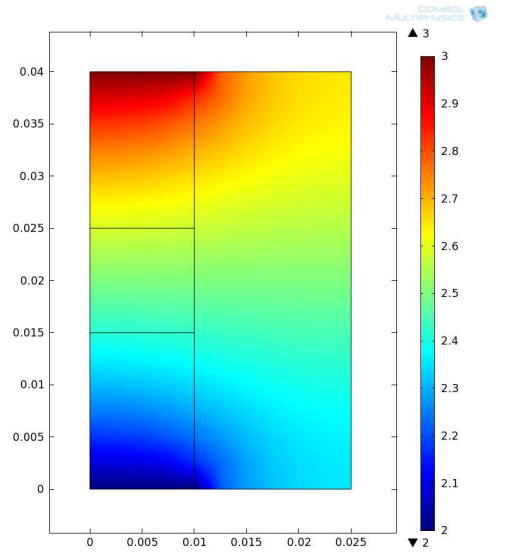

(b) Distribuição de potencial elétrico

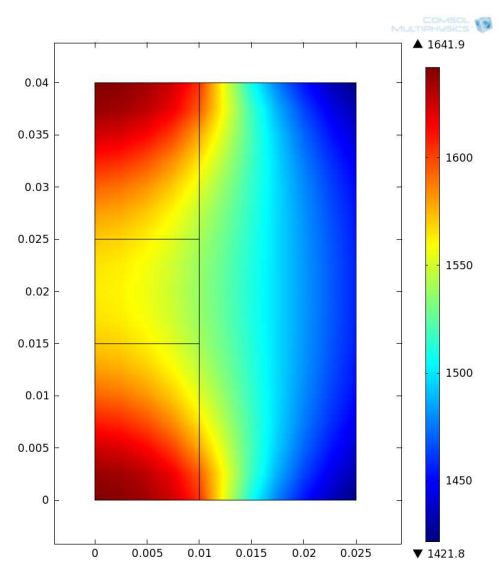

(c) Distribuição de temperatura

Figura B.12: Resultados do modelo axissimétrico simulado no Comsol considerando radiação não-linear.

De acordo com os resultados apresentados na Figura B.12, verifica-se a proximidade da temperatura superficial do molde obtida com o modelo auxiliar (ver Figura B.9) com a obtida com o modelo axissimétrico (cerca de $1.450 \mathrm{~K}$ ), que considera um $\Delta \phi$ aplicado entre os punções. Assim, esta temperatura de $1.450 \mathrm{~K}$ é tomada como a temperatura $T_{0}$ de linearização da radiação nos outros dois modelos que possuem radiação linearizada. A radiação é então linearizada utilizando as equações apresentadas na seção 2.3.2 e o problema eletrotérmico solucionado possui as mesmas condições apresentadas na Figura B.10. 
Os resultados obtidos com as implementações do problema eletrotérmico no Matlab considerando radiação linearizada foram comparados com o mesmo modelo implementado no Comsol (radiação linearizada). Tais resultados são apresentadas nas Figuras B.13, B.14, B.14, B.16, B.17 e B.18. Nessas figuras são apresentados os fluxo de corrente elétrica e a distribuição de temperatura, para o caso da simulação com grafite e alumina.

Na Figuras B.15 e B.18 estão indicados a distribuição de temperatura ao longo da direção radial, no centro da amostra para os três modelos, ou seja, Comsol não-linear (envolvendo radiação não-linear), Comsol linear (envolvendo radiação linearizada) e Matlab (envolvendo radiação linearizada).

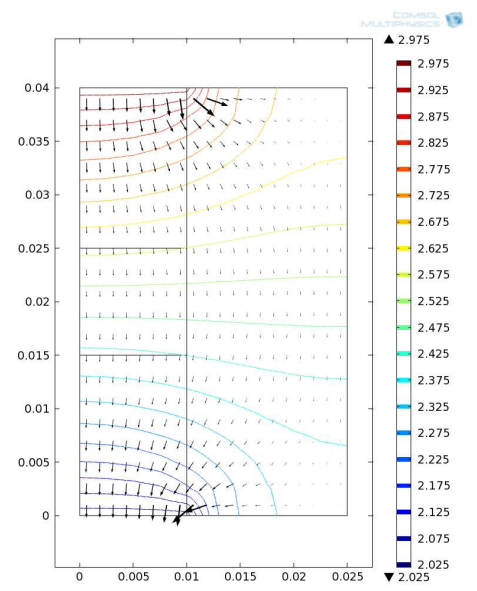

(a) Comsol

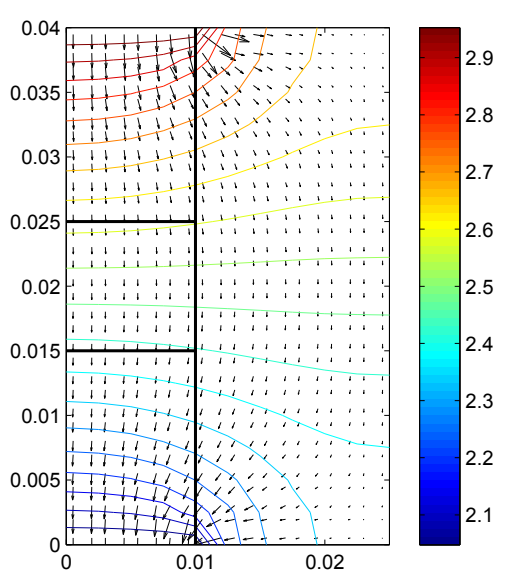

(b) Matlab

Figura B.13: Resultados do problema elétrico no modelo axissimétrico considerando radiação linear - Amostra de grafite.

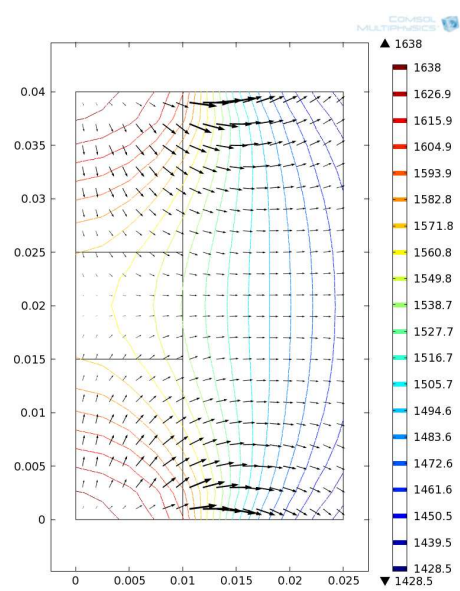

(a) Comsol

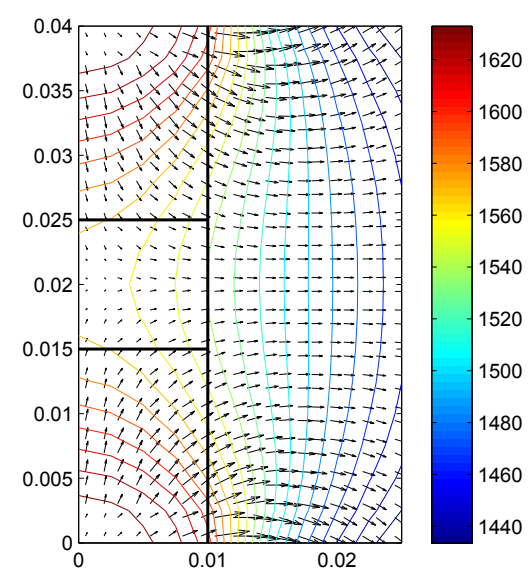

(b) Matlab

Figura B.14: Resultados do problema térmico no modelo axissimétrico considerando radiação linear - amostra de grafite. 
Na Figura B.15 são apresentadas as curvas da distribuição de temperatura na direção radial, tomada no centro da amostra, para as três simulações. Com isso é possível comparar os resultados com a simulação de radiação não-linear com os obtidos considerando radiação linearizada.

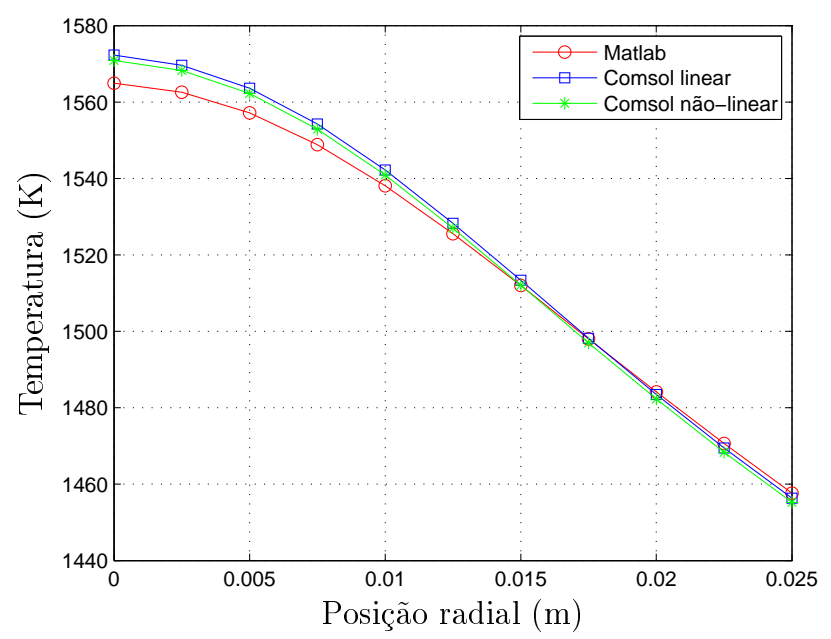

Figura B.15: Distribuição radial de temperatura para os três modelos axissimétrico. Amostra grafite.

\begin{tabular}{lcccc}
\hline Amostra & Malha & $T_{\text {linear }}[\mathrm{K}]$ & $\sigma_{0}(\mathrm{~S} / \mathrm{m})$ & $\kappa_{0}(\mathrm{~W} / \mathrm{mK})$ \\
\hline Grafite & $10 \times 16$ & 1450 & $10^{5}$ & 50 \\
Alumina & $10 \times 16$ & 1430 & $10^{-8}$ & 9 \\
\hline
\end{tabular}

Tabela B.2: Parâmetros adotados para validação do MEF.

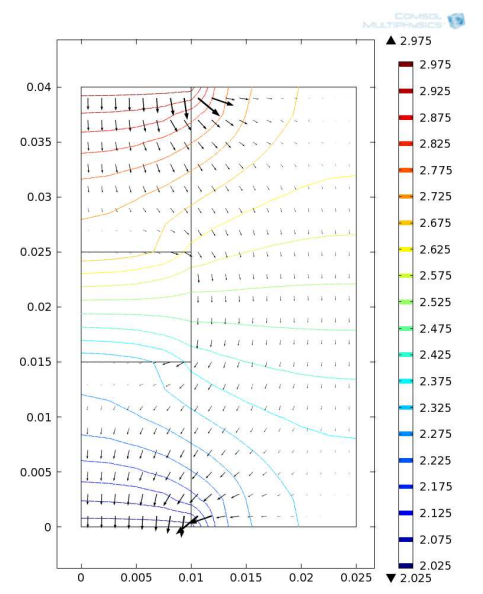

(a) Comsol

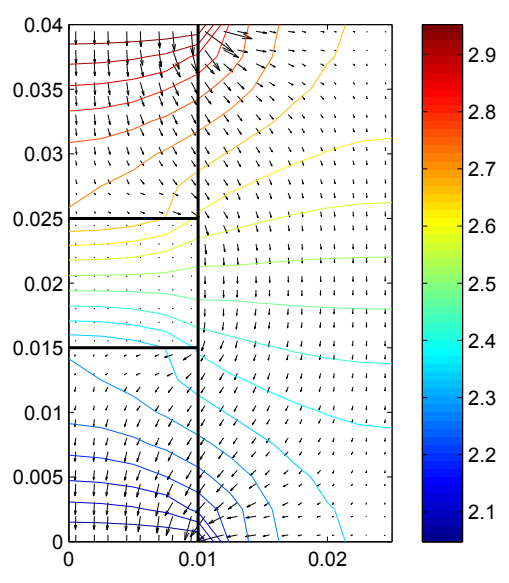

(b) Matlab

Figura B.16: Resultados do problema elétrico no modelo axissimétrico considerando radiação linear - Amostra de alumina. 


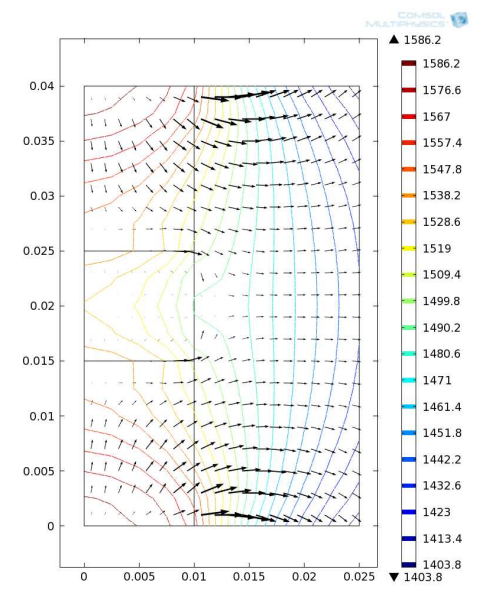

(a) Comsol

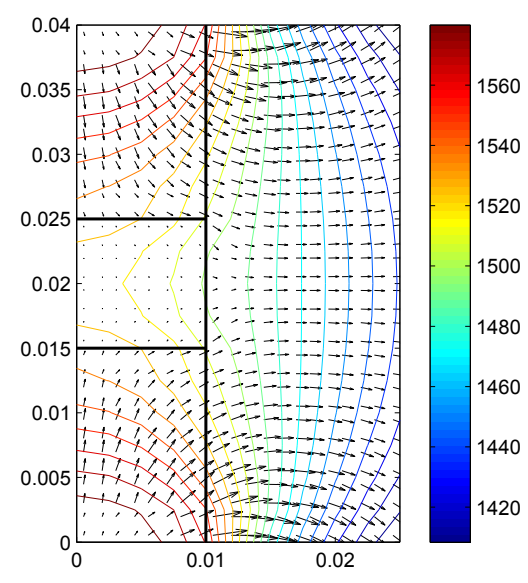

(b) Matlab

Figura B.17: Resultados do problema térmico no modelo axissimétrico considerando radiação linear - Amostra de alumina.

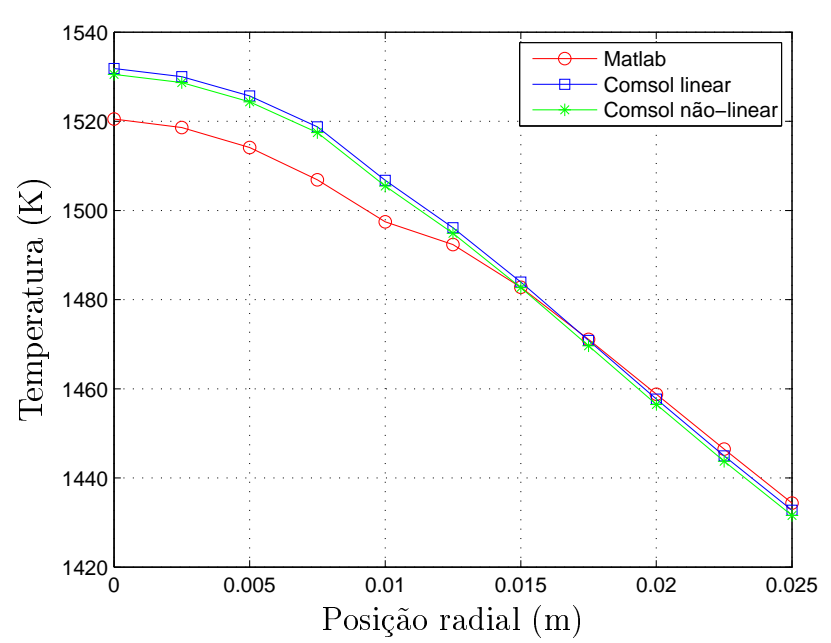

Figura B.18: Distribuição radial de temperatura para os três modelos axissimétrico. Amostra alumina.

\section{B.3 Propriedades dos materiais}

As propriedades dos materiais utilizados nas implementações basearam-se nas curvas indicadas nas Figuras B.19a e B.19b, que apresentam o comportamento da condutividade térmica e da resistividade elétrica em função da temperatura, para os materiais abordados neste trabalho (ALLEN; WALTER, 2012; WANG et al., 2007; BARLAK; GRZES; PIETRZAK, 1999).

Nos modelos computacionais implementados, conforme já citado, foram utilizados propriedades físicas constantes e independentes da temperatura do material. Os valores destas propriedades foram estimados para materias numa temperatura de $800 \mathrm{~K}$, a partir dos dados apresentados na Figura B.19. Embora não apresentado na Figura B.19b, a resistividade elé- 


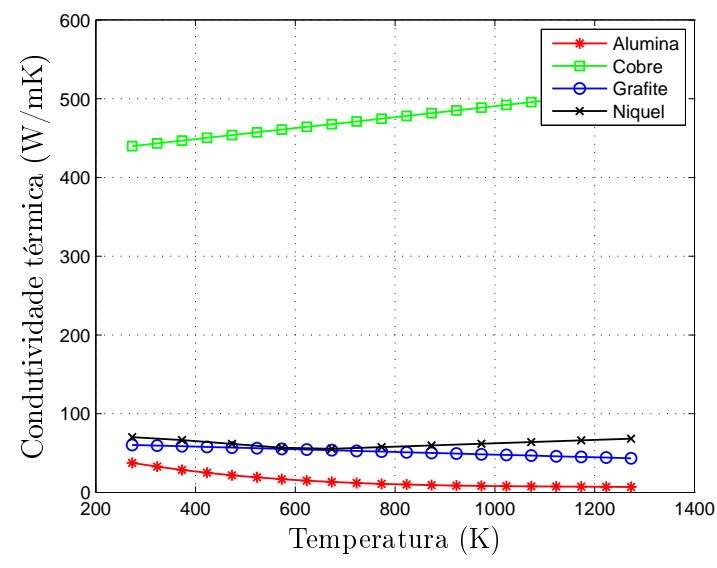

(a) Condutividade térmica

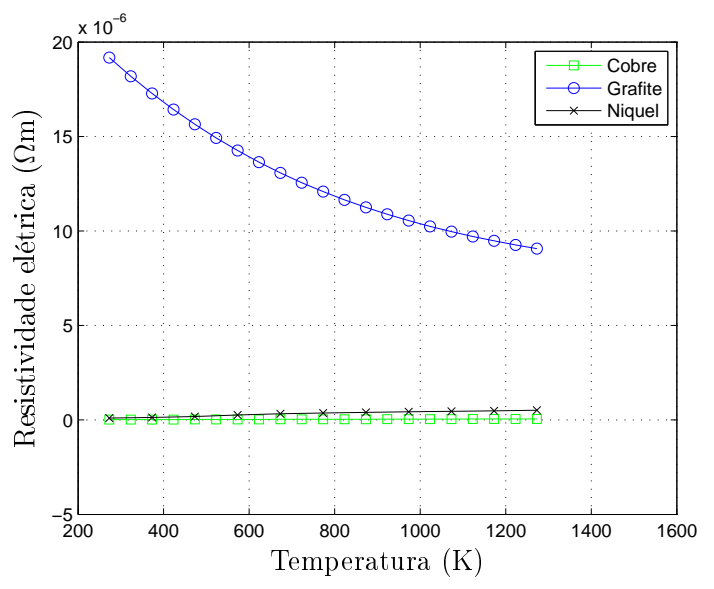

(b) Condutividade elétrica

Figura B.19: Propriedades elétrica e térmica, em função da temperatura, dos materiais utilizados nos modelos computacionais.

trica da alumina $\left(\mathrm{Al}_{2} \mathrm{O}_{3}\right)$ é constante e equivale a $1,0 \times 10^{8} \Omega \mathrm{m}$ (Não indicado na curva para evitar problema de escala numérica no gráfico).

\begin{tabular}{lcccc}
\hline Propriedade & Alumina & Cobre & Grafite & Níquel \\
\hline Condutividade elétrica $(\mathrm{S} / \mathrm{m})$ & $1,0 \times 10^{-8}$ & $4,0 \times 10^{8}$ & $1,0 \times 10^{5}$ & $2,0 \times 10^{6}$ \\
Condutividade térmica $(\mathrm{W} / \mathrm{mK})$ & 9 & 480 & 50 & 64 \\
\hline
\end{tabular}

Tabela B.3: Propriedades dos materiais adotadas e utilizadas nos modelos computacionais. Valores estimadas para materiais numa temperatura de $800 \mathrm{~K}$.

\section{B.4 Validação do cálculo de sensibilidades}

A seguir são apresentadas as curvas de sensibilidade das funções objetivos utilizadas nos problemas de otimização implementados neste trabalho. A validação das sensibilidades é realizada através da comparação entre o cálculo analítico e o MDF (Método das Diferenças Finitas), e com o filtro de projeção ativado ou desativo.

Na Figura B.20 é dada a sensibilidade da função objetivo no algoritmo de otimização para moldes prismáticos. Verifica-se a correta implementação pela concordância das curvas apresentadas, onde a sensibilidade da função objetivo é avaliada para cada variável de projeto.

Para moldes homogêneos, a Figura B.21 apresenta a curva de sensibilidades da função objetivo. Observa-se também a concordância das curvas de sensibilidade via método MDF e analítico.

Nas Figuras B.22 e B.23 são apresentadas as curvas de sensibilidades obtidas para otimi- 


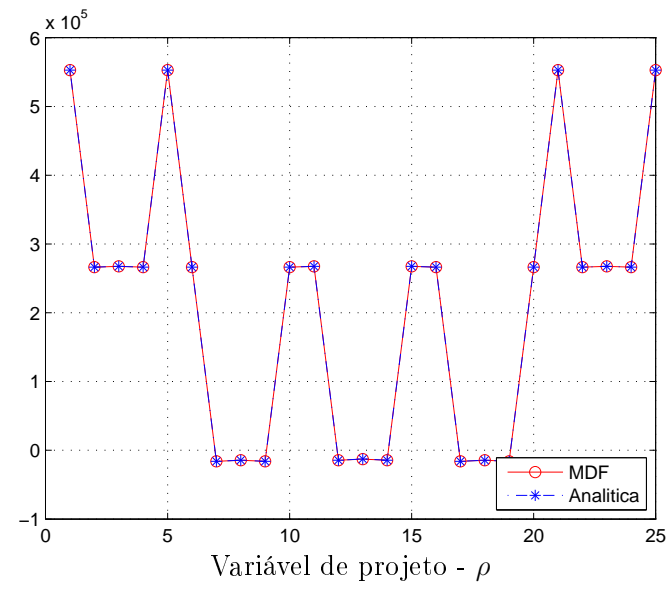

(a) Projeção desativada

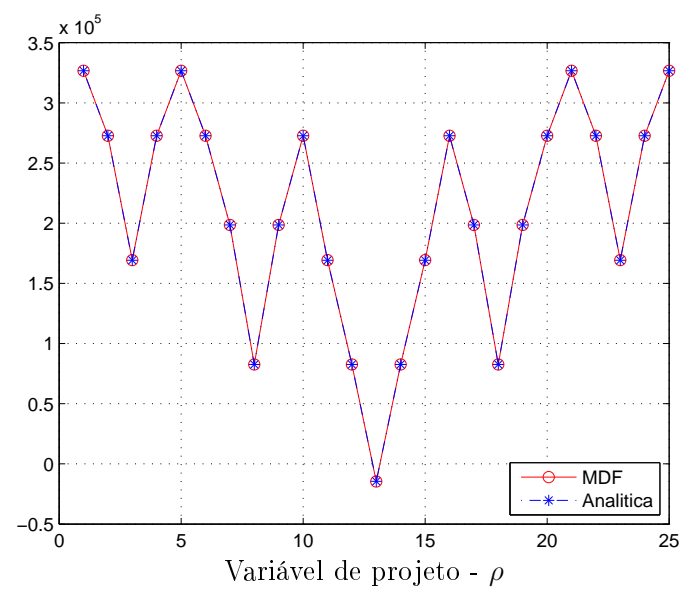

(b) Projeção ativada

Figura B.20: Validação da sensibilidade para molde prismático - formulação Q4/U. Curva avaliada para amostra quadrada, malha $5 \times 5, \rho$ inicial igual a $0,9, \Delta \rho=0,001$ e $R_{\min }=2 L_{e}$, sendo $L_{e}$ o comprimento da aresta de elemento finito.

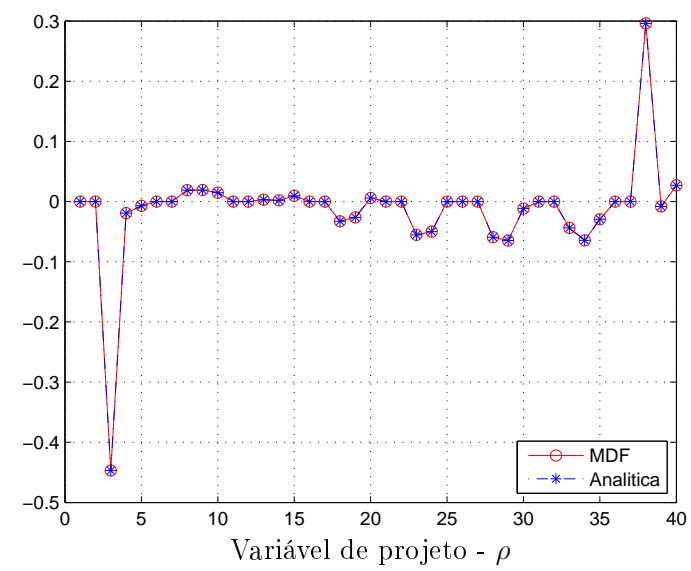

(a) Projeção desativada

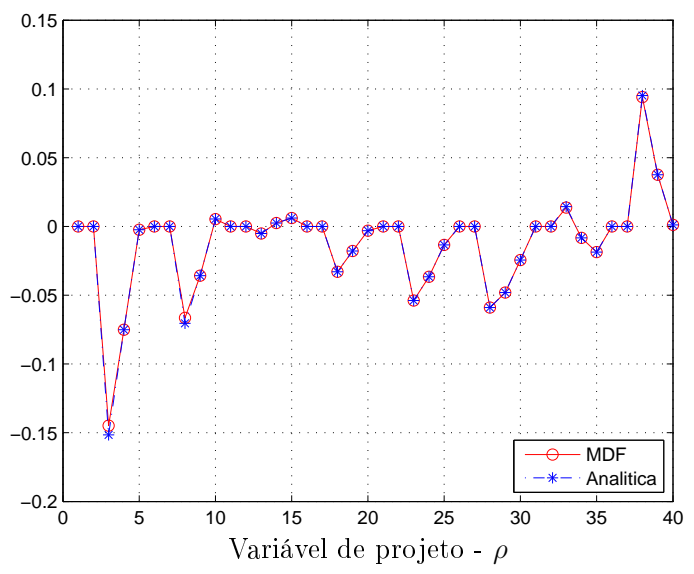

(b) Projeção ativada

Figura B.21: Validação da sensibilidade para molde axissimétrico homogêneo - formulação Q4/U. Curva avaliada para amostra de grafite, malha 5x8, $\rho$ inicial igual a $0,9, \Delta \rho=0,001$ e $R_{\min }=2 L_{e}$, sendo $L_{e}$ o comprimento da aresta de elemento finito.

zação de moldes compósitos para ambos os métodos de orientação das propriedades físicas. Na Figura B.22 tem-se a sensibilidade para a implementação utilizando a OMD, enquanto que na Figura B.23 é apresentada a sensibilidade para otimização sem a OMD, ou seja, com a variável $\theta$ assumindo valor contínuos. As curvas apresentadas nestas figuras também confirmam o correto cálculo para ambos os métodos.

Vale ressaltar que o filtro de projeção atua somente sobre as variáveis de projeto $\rho$ de pseudo-densidades, o que justifica a igualdade das curvas de sensibilidades para a variável $v$ com a projeção ativada e desativada, como pode ser observado na Figura B.23. Outro ponto a se destacar é a diferença na magnitude das sensibilidades para as variáveis $\rho$ e $v$. Devido a 


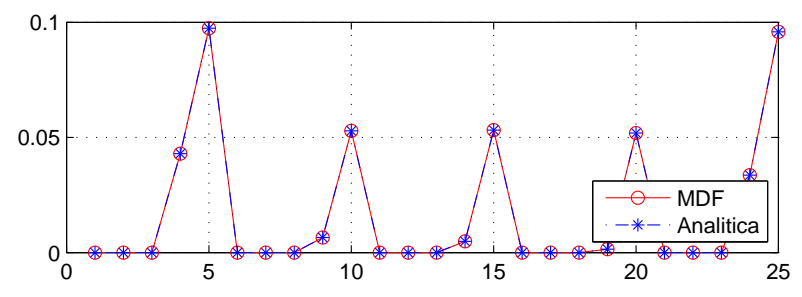

Variável de projeto - $\rho$

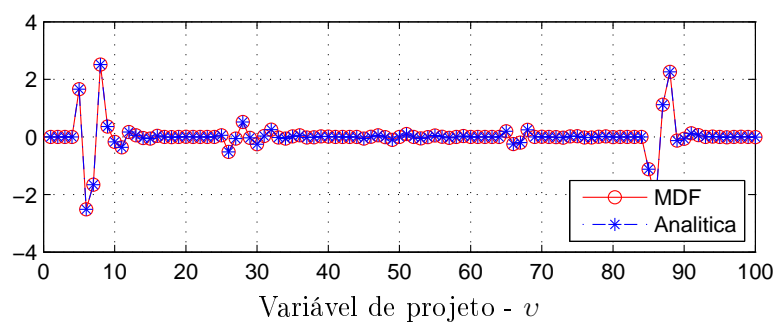

(a) Projeção desativada

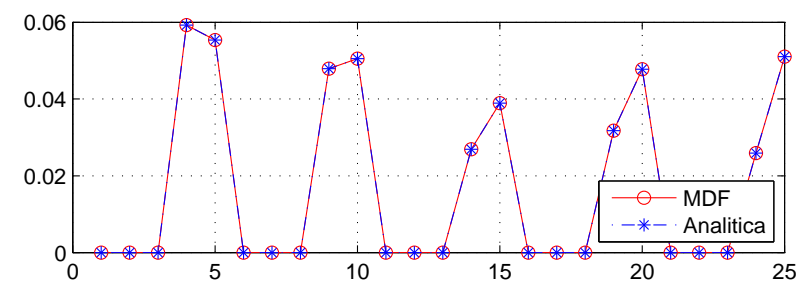

Variável de projeto - $\rho$

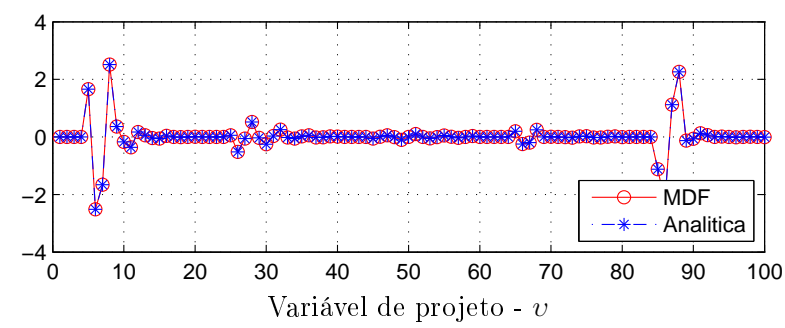

(b) Projeção ativada

Figura B.22: Validação da sensibilidade para molde axissimétrico compósito (com OMD) formulação Q4/U. Curva avaliada para amostra de grafite, malha 5x8, $\rho$ inicial igual a 0,9, $v$ inicial igual $0,01, \Delta \rho=\Delta v=1,0 \times 10^{-7}$ e $R_{\text {min }}=2 L_{e}$, sendo $L_{e}$ o comprimento da aresta de elemento finito.
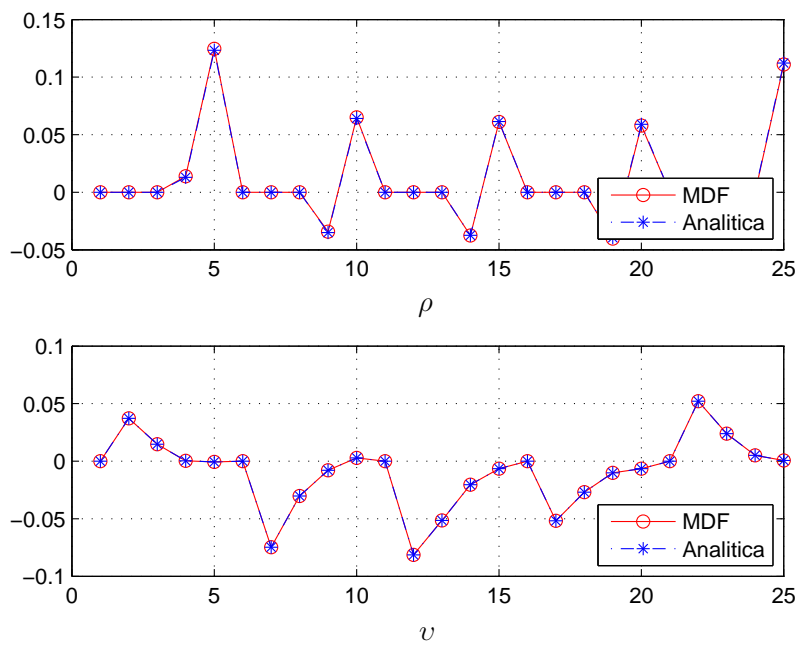

(a) Projeção desativada
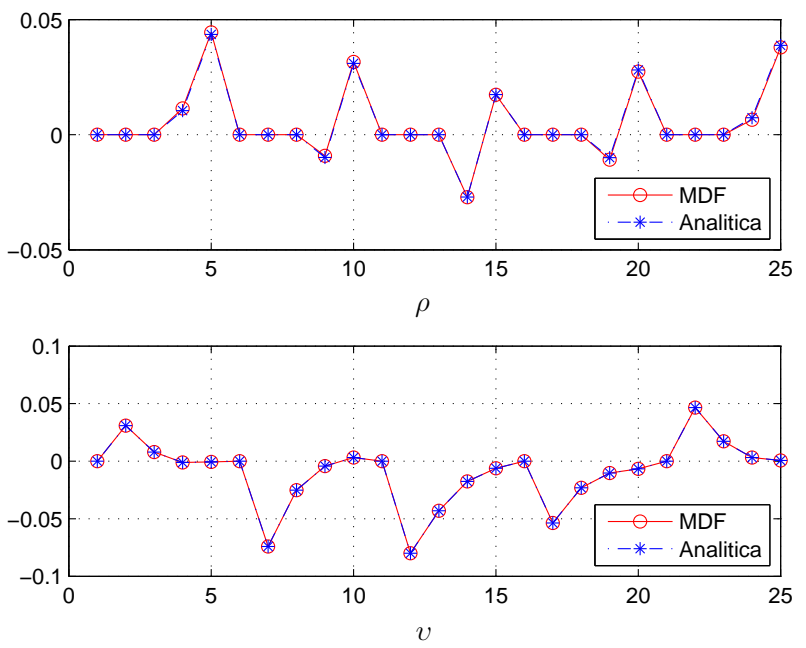

(b) Projeção ativada

Figura B.23: Validação da sensibilidade para molde axissimétrico compósito (sem OMD) formulação Q4/U. Curva avaliada para amostra de grafite, malha 5x8, $\rho$ inicial igual a 0,9, $v$ inicial igual $0,01, \Delta \rho=\Delta v=1,0 \times 10^{-7}$ e $R_{\min }=2 L_{e}$, sendo $L_{e}$ o comprimento da aresta de elemento finito.

esta diferença, as curvas de sensibilidades para estas variáveis foram apresentadas separadamente para evitar problemas de escala numérica, o que poderia dificultar a interpretação dos resultados. 


\section{Apêndice C - Método de Otimização Topológica aplicado a problemas térmicos}

Nesta seção são apresentadas aplicações da OT em problemas térmicos bidimensionais que envolvem as condições de fluxo de calor, geração interna de calor e convecção. Os exemplos numéricos aqui apresentados foram baseados em problemas analisados por Bendsøe e Sigmund (2003), Iga et al. (2009) e Gao et al. (2008). Em todos os exemplos numéricos apresentados foi implementada a formulação Q4/Q4 (variável de projeto pseudo-densidade aplicada nos nós do elemento finito). Nos exemplos que envolvem convecção utilizou-se a função degrau $H(\rho)$ (ver seção 4.2). Além disso, nos exemplos o material isotrópico possui condutividade térmica de $50 \mathrm{~W} / \mathrm{mK}$, a configuração do domínio fixo de projeto inicia-se com as variáveis de projeto $\rho_{i}=0,9(i=1, \ldots, n)$, a penalização máxima da condutividade é igual a 3 e não se utiliza o filtro de projeções, salvo indicações explícitas.

O problema de otimização solucionado em cada um dos problemas analisados é baseado na formulação indicada pela equação 4.21 utilizando o fator de ponderação $w$ igual a 1. Assim, a topologia ótima para cada caso estudado refere-se a uma estrutura que fornece a máxima dissipação térmica atendendo à restrição de volume imposta.

\section{C.1 Problemas envolvendo fluxo de calor prescrito}

Os exemplos numéricos a seguir ilustram o efeito do fluxo prescrito na fronteira do domínio. Estes exemplos foram extraídos do artigo publicado por Iga et al. (2009) e em geral, os resultados obtidos apresentam boa correlação com os apresentados no artigo.

Caso 1: O primeiro caso ilustra a situação do domínio $\Omega$ onde um fluxo de calor prescrito $q=1 \mathrm{~W} / \mathrm{m}^{2}$ em $\Gamma_{q}$ e temperatura prescrita $T=0{ }^{\circ} \mathrm{C}$ em $\Gamma_{u}$ representam as condições de contorno do problema e os demais trechos da fronteira do domínio encontram-se em condição adiabática (ver Figura C.1a). O objetivo neste problema é descobrir qual a distribuição de material condutor que maximiza a dissipação térmica que ocorre na estrutura em $\Gamma_{u}$. Neste caso, é o mesmo significado de maximizar a condutividade térmica para transferir ao meio 
externo a energia térmica inserida na estrutura em $\Gamma_{q}$. Com uma malha composta por 2500 elementos e restrição de volume de $50 \%$, a solução ótima deste problema (Figura C.1b) é uma estrutura que interliga as fronteiras $\Gamma_{q}$ e $\Gamma_{u}$. A Figura C.1d ilustra o histórico da função objetivo, indicando a sua convergência a partir da iteração de número 30 e a Figura C.1e ilustra a restrição de volume satisfeita.

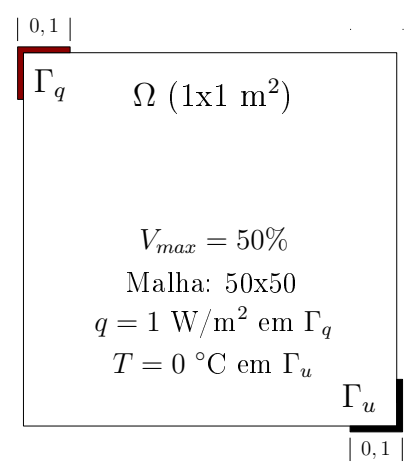

(a) Domínio de projeto

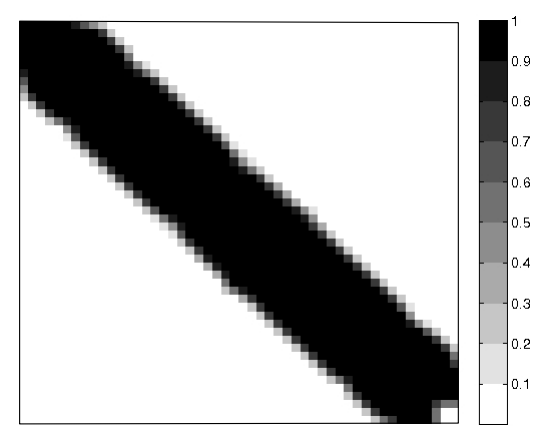

(b) Topologia ótima

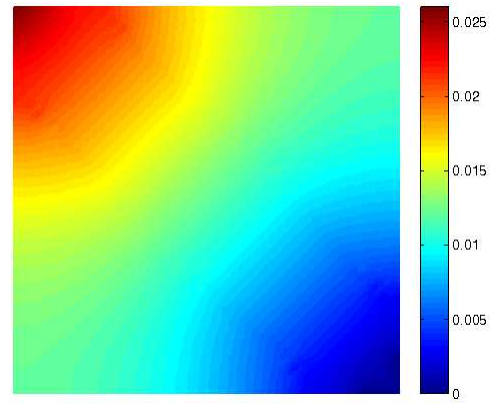

(c) Distribuição de temperatura

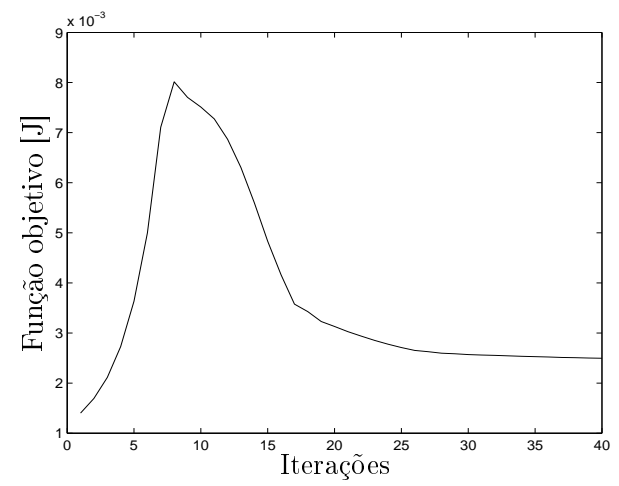

(d) Convergência da função objetivo

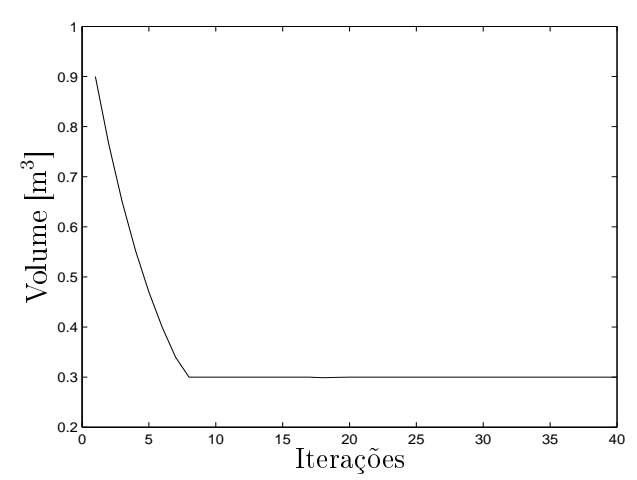

(e) Restrição volume

Figura C.1: Caso 1 para análise do fluxo de calor prescrito (dimensões em metros).

Caso 2: No segundo caso, também há um fluxo de calor prescrito $q=1 \mathrm{~W} / \mathrm{m}^{2}$, porém a fronteira com temperatura prescrita em $\Gamma_{u}$ é expandida para outras posições, conforme indicado na Figura C.2. A análise térmica é a idêntica ao do caso 1. A discretização é composta por 2500 elementos e uma restrição de volume de $50 \%$ é imposta no problema de otimização. A solução ótima, o campo de tensão, a curva de convergência e o histórico de volume da estrura são apresentados na Figura C.2. A solução ótima, embora parecida com a apresentada por Iga et al. (2009), somente foi obtida após reduzir o comprimento de $\Gamma_{u_{2}}$ e aumentar o $V_{\max }$ na restrição de volume (os valores fornecidos no artigo são $\Gamma_{u_{1}}$ medindo $0,1 \mathrm{~m}$ e $V_{\max }$ de $30 \%$ ). Simulação com os mesmos dados fornecidos no artigo resultava numa solução sem material condutor até a fronteira $\Gamma_{u_{2}}$. Isto, provavelmente se deve a diferença entre os modelos de material utilizado ou problema de mínimo local.

Casos 3 e 4: Os problemas térmicos analisados nos casos 3 e 4 são iguais, a menos do 


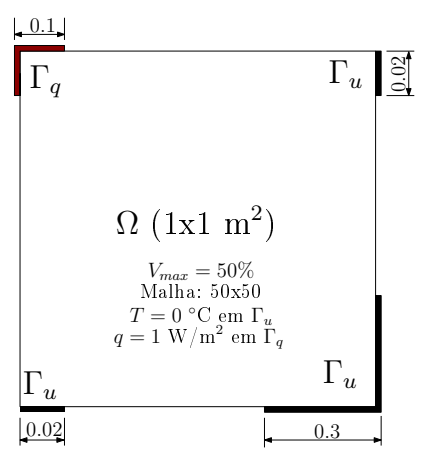

(a) Domínio de projeto

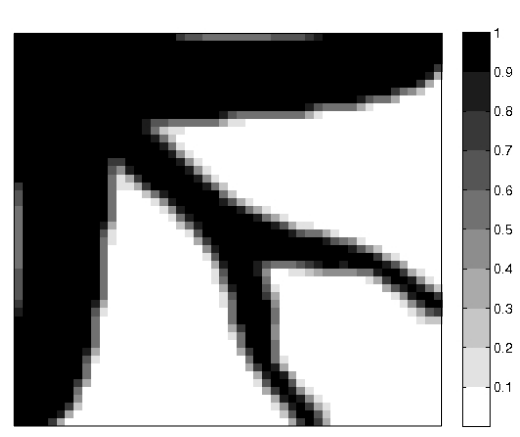

(b) Topologia ótima

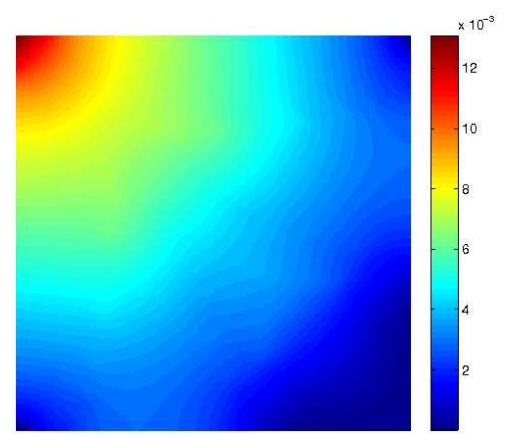

(c) Distribuição de temperatura

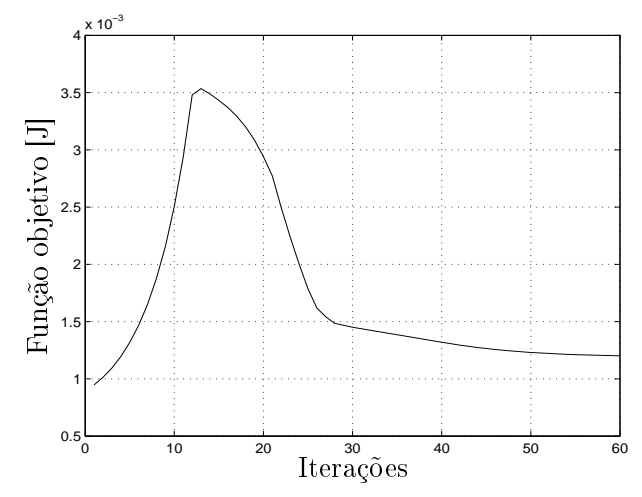

(d) Convergência da função objetivo

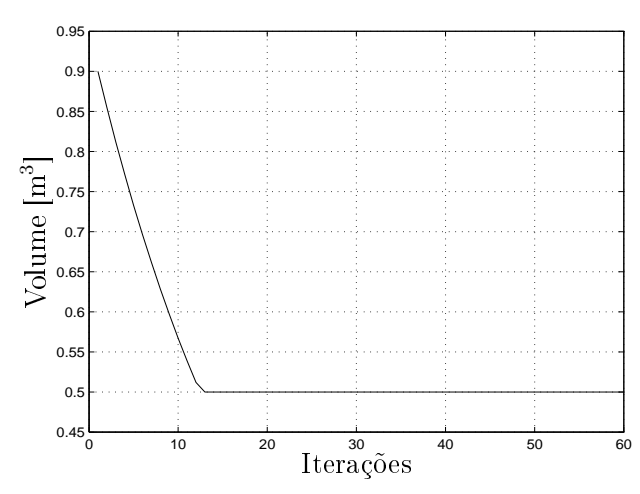

(e) Restrição volume

Figura C.2: Caso 2 para análise do fluxo de calor prescrito (dimensões em metros).

comprimento da fronteira $\Gamma_{q}$ e $\Gamma_{u}$, onde ocorre, respectivamente, as condições de contorno de fluxo de calor e temperatura prescritos, conforme pode ser visualizado nas Figuras C.3 e C.4. Em ambos os casos a discretização é composto por 2500 elementos e com restrição de volume de $30 \%$. Os resultados obtidos são coerentes com o publicados na literatura (IGA et al., 2009). 


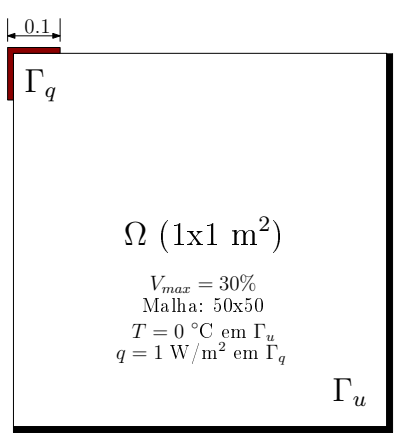

(a) Domínio de projeto

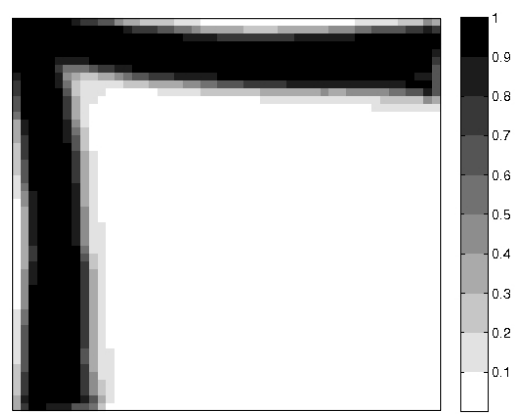

(b) Topologia ótima

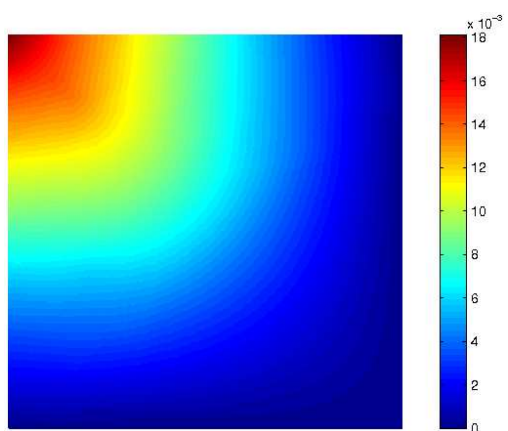

(c) Distribuição de temperatura

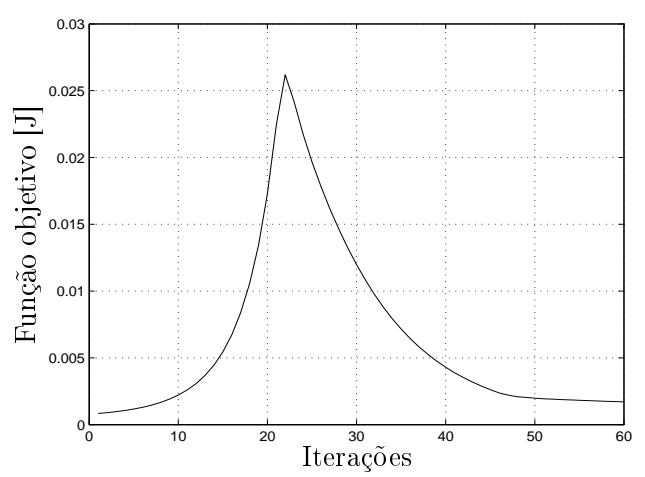

(d) Convergência da função objetivo

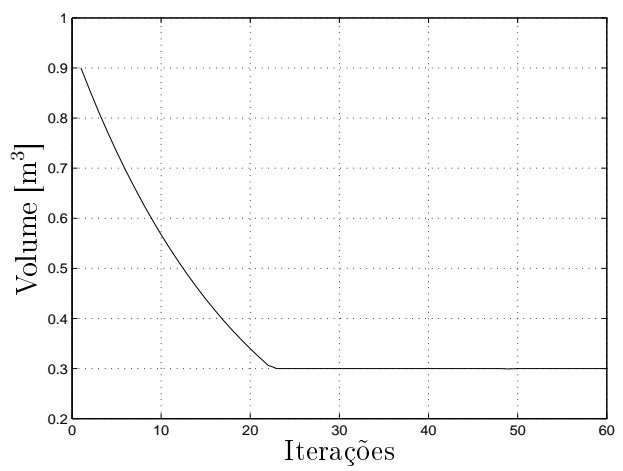

(e) Restrição volume

Figura C.3: Caso 3 para análise do efeito do fluxo de calor prescrito.

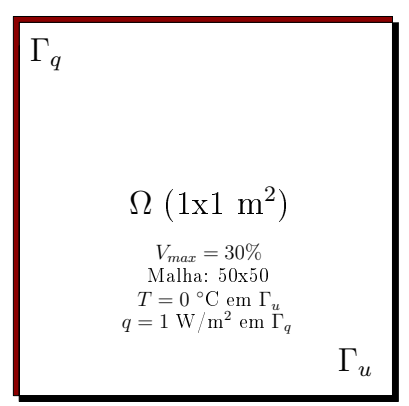

(a) Domínio de projeto

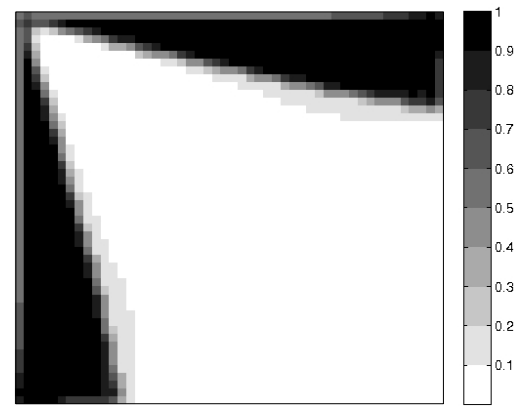

(b) Topologia ótima

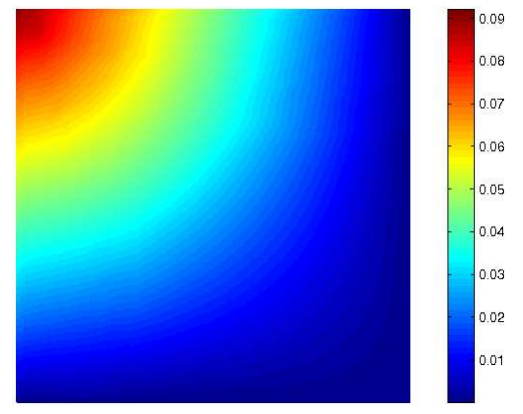

(c) Distribuição de temperatura

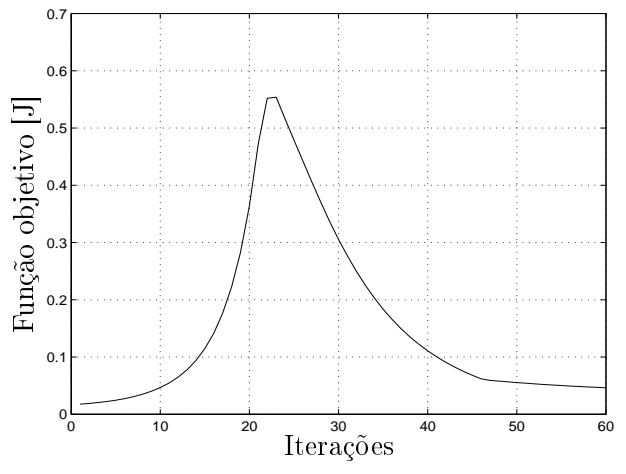

(d) Convergência da função objetivo

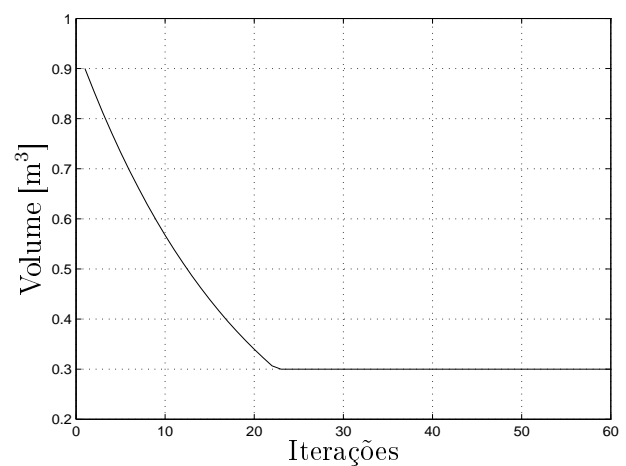

(e) Restrição volume

Figura C.4: Caso 4 para análise do efeito do fluxo de calor prescrito. 


\section{C.2 Problemas envolvendo geração interna de calor}

Nesta seção são apresentados problemas térmicos que envolvem geração interna de calor no domínio $\Omega$ e condição de Dirichlet (temperatura prescrita) na fronteira deste domínio. As curvas de convergência e restrição de volume, a partir desta seção não serão apresentadas, uma vez que apresentam comportamento semelhantes às apresentadas na seção anterior.

Caso 1: O primeiro caso (extraído de (BENDSøE; SIGMUND, 2003)) analisado, ilustra um domínio $1 \times 1 \mathrm{~m}^{2}$ com geração uniforme de calor $\dot{q}=0,01 \mathrm{~W} / \mathrm{m}^{3}$ e fronteira adiabática exceto em uma pequena região da fronteira esquerda (Figura C.5a) onde $T=0^{\circ} \mathrm{C}$ e que atua como um "dreno" (heat sink) por onde a energia térmica é dissipada. A discretização da malha é composta por 10.000 elementos finitos e a restrição de volume é de 40\%. A Figura C.5b apresenta topologia ótima para estas condições e na Figura C.5c tem-se a respectiva distribuição de temperatura.

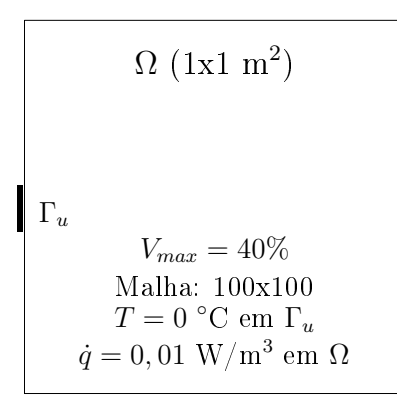

(a) Domínio de projeto

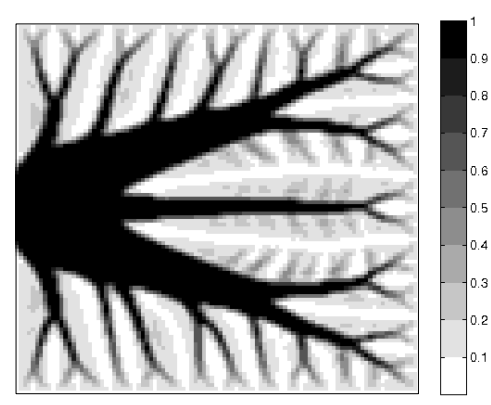

(b) Topologia ótima

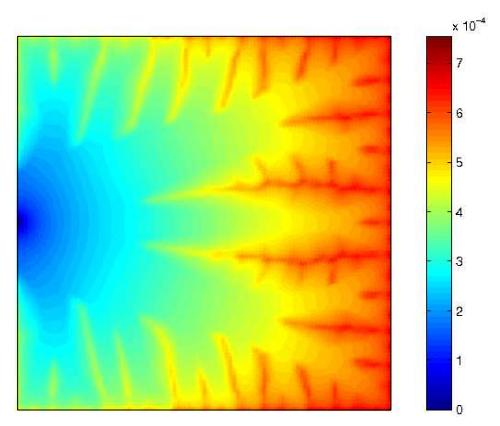

(c) Distribuição de temperatura

Figura C.5: Caso 1 para análise da geração de calor em $\Omega$. (a) Definição do problema, (b) Solução ótima coerente com resultado de Bendsøe e Sigmund (2003), (c) Distribuição de temperatura em ${ }^{\circ} \mathrm{C}$.

Caso 2: No segundo caso (extraído de Gao et al. (2008)), a geração de calor $\dot{q}=0,01$ $\mathrm{W} / \mathrm{m}^{3}$ ocorre de maneira pontual no centro da estrutura e em toda a sua fronteira a temperatura $T=0^{\circ} \mathrm{C}$ é prescrita (ver Figura C.6a). Neste caso tem-se um sorvedouro de calor e o objetivo do problema pode ser entendido como a minimização da temperatura máxima no centro do domínio, o que implica maximizar a condutividade térmica da estrutura. Para este caso, a discretização consistiu numa malha com 2500 elementos finitos e restrição de volume também de 40\%. A solução ótima para este caso está indicada na Figura C.6b, bem como a distribuição de temperatura na Figura C.6c.

Caso 3: O terceiro caso, extraído do artigo publicado por Iga et al. (2009), é semelhante aos anteriores (Caso 1 e 2), ou seja, geração de calor em $\Omega$ com condição de temperatura prescrita no seu contorno. Assim como nos casos 1 e 2, a geração de calor neste problema térmico ocorre sem depender da variável de projeto, isto significa que existe geração de energia 


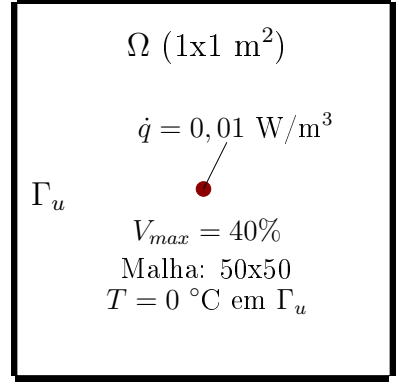

(a) Domínio de projeto

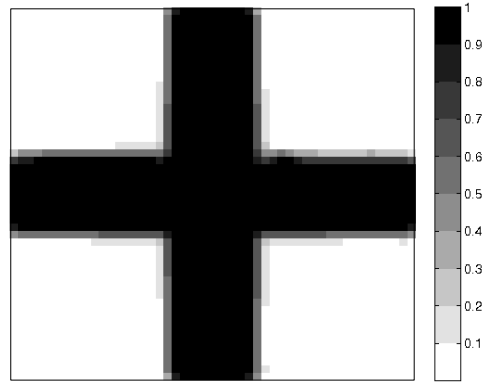

(b) Topologia ótima

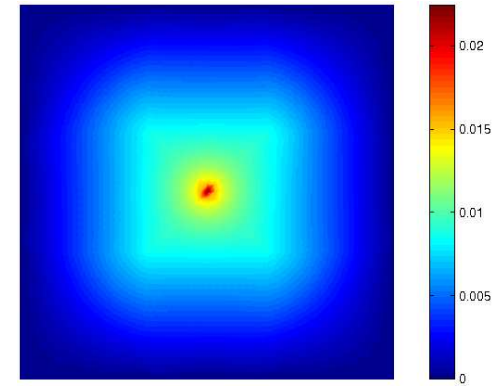

(c) Distribuição de temperatura

Figura C.6: Caso 2 para análise da geração de calor no domínioß. (a)Definição do problema, (b) Solução ótima coerente com a apresentada por Gao et al. (2008), (b) Distribuição de temperatura em ${ }^{\circ} \mathrm{C}$.

em todo o domínio independentemente da distribuição de material. O objetivo deste caso é comparar o resultado aqui obtido com o resultado do problema térmico do caso 4, onde é considerada a dependência estrutural. Então, a partir das condições apresentadas na Figura C.7a, obteve-se a estrutura ótima indicada na Figura C.7b juntamente com a distribuição térmica apresentada na Figura C.7c. Observa-se que aletas emergem, a partir da fronteira de temperatura prescrita, em direção à linha de simetria do domínio e se estendem até a região de maior concentração de calor (canto superior esquerdo).

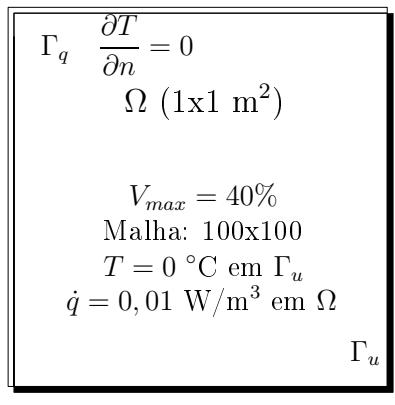

(a) Domínio de projeto

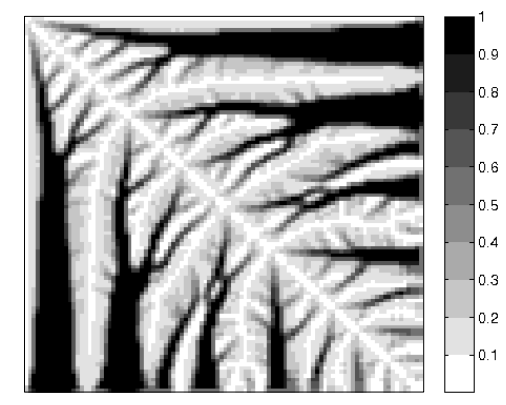

(b) Topologia ótima

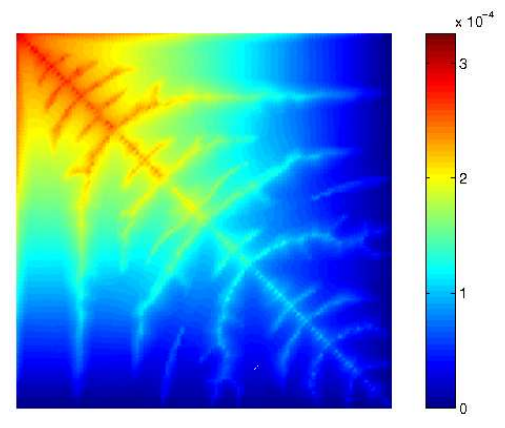

(c) Distribuição de temperatura

Figura C.7: Caso 3 para análise da geração de calor. (a) Definição do problema, (b) Solução ótima semelhante à apresentada por Iga et al. (2009), (c) Distribuição de temperatura em ${ }^{\circ} \mathrm{C}$.

Caso 4: No quarto caso, analisa-se praticamente o mesmo problema apresentado no caso 3 , exceto pela condição de dependência estrutural utilizada na formulação deste problema (caso 4). A dependência estrutural é estabelecida pela equação 4.4 (seção 4.1), tornando a geração de calor proporcional à densidade volumétrica do elemento. Na prática, este tipo de situação pode ocorrer em problemas cuja geração de calor é originada por efeito resistivo, por exemplo. Assim, considerando as informações indicadas na Figura C.8a, a solução ótima obtida é apresentada na Figura C.8b e a respectiva distribuição de temperatura na Figura 
C.8c. Observa-se que, embora aletas emirgam da fronteira com temperatura prescrita (assim como na solução ótima do caso 3), a disposição das aletas é sensivelmente diferente e se concentram próxima às fronteiras adiabáticas. Além disso, a temperatura média da estrutura no caso 4 é inferior àquela apresentada no caso 3 , isto por que a região clara na Figura C.8b praticamente não fornece energia ao sistema.

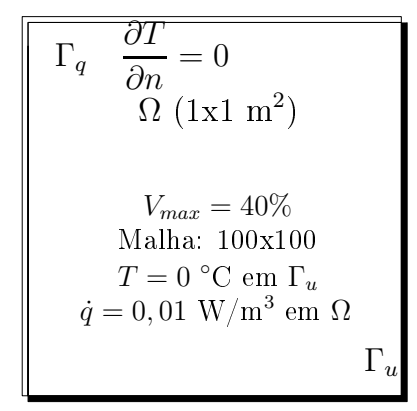

(a) Domínio de projeto

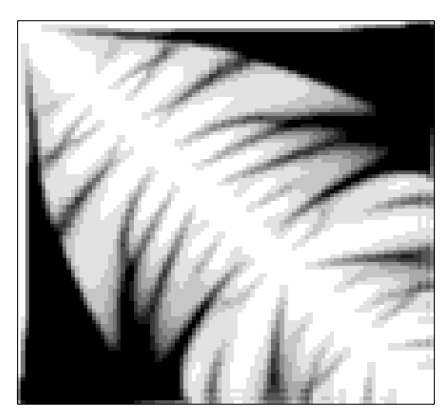

(b) Topologia ótima

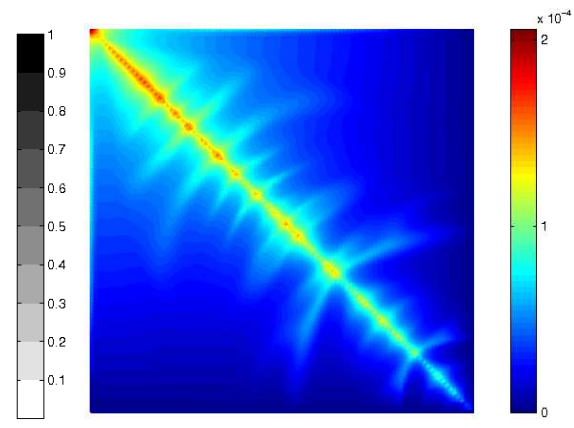

(c) Distribuição de temperatura

Figura C.8: Caso 4 para análise da geração de calor com dependência estrutural. (a) Solução ótima semelhante à apresentada por Iga et al. (2009), (b) Distribuição de temperatura $\mathrm{em}{ }^{\circ} \mathrm{C}$.

\section{C.3 Problemas envolvendo convecção na fronteira estru- tural}

Os efeitos da condição de convecção em problemas térmicos basearam-se no estudo do problema indicado na Figura C.9. Neste problema, um fluxo de calor é prescrito na fronteira $\Gamma_{q}$ e uma condição de contorno de convecção é imposta pela função "chapéu" (Equação 4.8), para dissipar a energia térmica inserida na estrutura. O coeficiente de convecção é então definido em cada nó da malha de elementos finitos e o problema de otimização inicia-se com $\rho_{i}=0.8$. Os valores de $\rho_{\text {inf }}$ e $\rho_{\text {sup }}$ são definidos como 0,3 e 0,9 , respectivamente. O objetivo desse problema, assim como nos demais, é de maximizar a condutividade térmica da estrutura e assim, favorecer a dissipação de calor. Conforme indicado na Figura C.9

Inicialmente foram analisados três casos, todos com uma malha de 2500 elementos, restrição de volume de $30 \%$, temperatura ambiente $T_{a m b}=0^{\circ} \mathrm{C}$ e fluxo de calor de $q=1 \mathrm{~W} / \mathrm{m}^{2}$, porém variando o valor do coeficiente de convecção $h$, com o intuito de avaliar a influência deste parâmetro na solução ótima obtida. Os resultados obtidos são apresentados nas Figuras C.10, C.11 e C.12, juntamente com a respectiva distribuição de temperatura em ${ }^{\circ} \mathrm{C}$.

Além disso, foi realizada uma simulação utilizando o filtro de projeção, uma vez que este introduz escala de cinza na distribuição de material, enquanto que a função "chapéu" atua diretamente sobre esta escala. Finalmente, foram realizadas duas simulações, considerando 


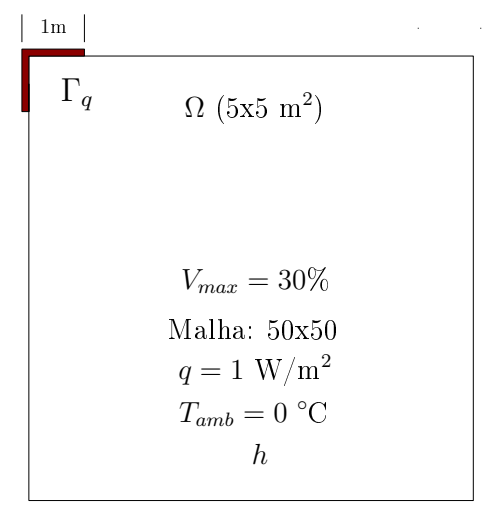

Figura C.9: Definição do problema para análise da convecção.

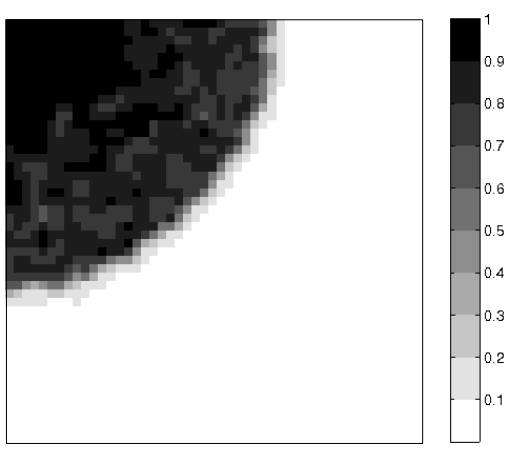

(a) Solução ótima

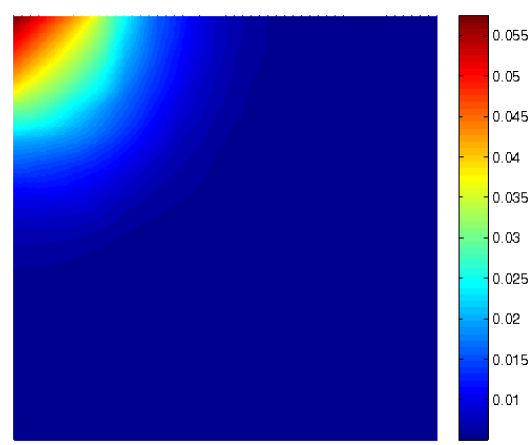

(b) Campo de temperatura $\left({ }^{\circ} \mathrm{C}\right)$

Figura C.10: Caso 1 para análise da convecção - $h=1 \mathrm{~W} / \mathrm{m}^{2} \mathrm{~K}$.

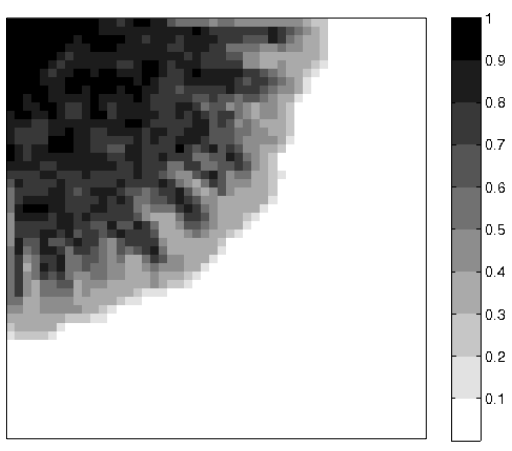

(a) Solução ótima

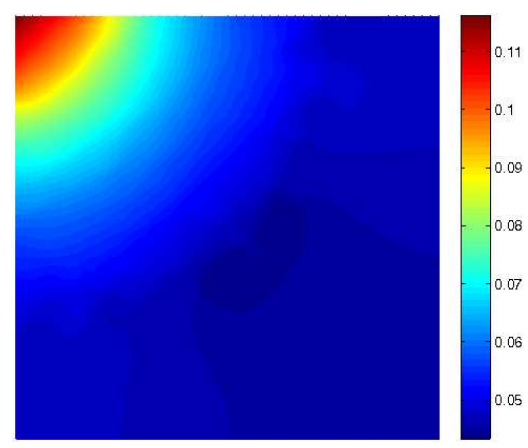

(b) Campo de temperatura $\left({ }^{\circ} \mathrm{C}\right)$

Figura C.11: Caso 2 para análise da convecção - $h=0,1 \mathrm{~W} / \mathrm{m}^{2} \mathrm{~K}$.

uma discretização mais fina da malha foram executadas, para avaliar a geometria da estrura ao se refinar a malha. Analisando os resultados apresentados pelas Figuras C.10, C.11 e C.12, observa-se que a medida em que o valor do coeficiente $h$ diminui a quantidade de aletas aumenta. Este aumento no número de aletas visa expandir a área de transferência de calor como forma de compensar a redução no coeficiente de convecção. Além disso, observa-se na Figura C.13 que ao utilizar o filtro de projeção, a solução ótima é sensivelmente alterada ao ser comparada com a Figura C.12. Verifica-se também que ao se refinar a malha de elementos 


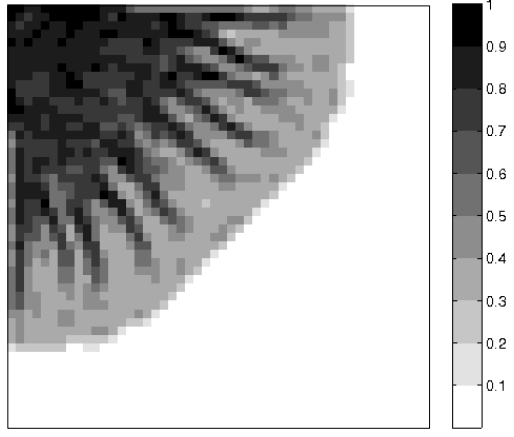

(a) Solução ótima

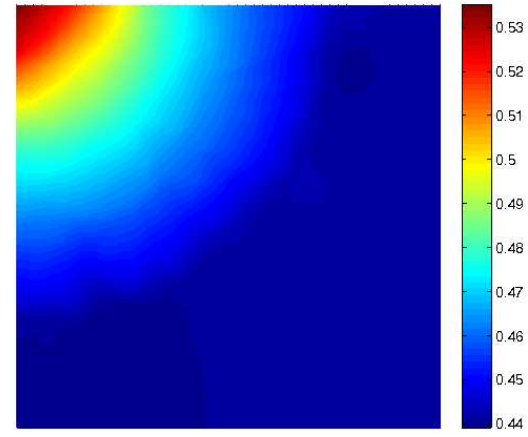

(b) Campo de temperatura $\left({ }^{\circ} \mathrm{C}\right)$

Figura C.12: Caso 3 para análise da convecção $-h=0,01 \mathrm{~W} / \mathrm{m}^{2} \mathrm{~K}$.

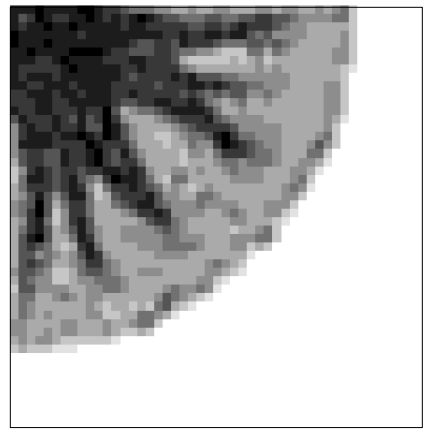

(a) Solução ótima

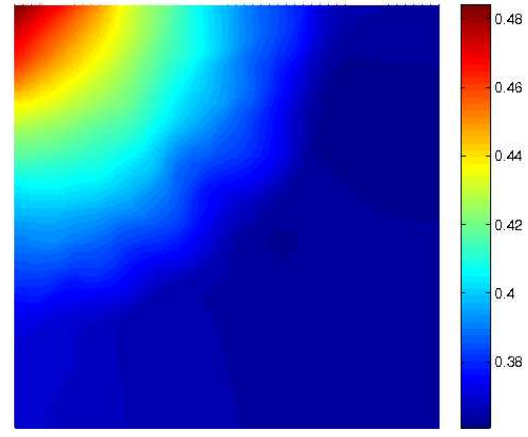

(b) Campo de temperatura $\left({ }^{\circ} \mathrm{C}\right)$

Figura C.13: Análise da convecção com filtro de projeção - $h=0,01 \mathrm{~W} / \mathrm{m}^{2} \mathrm{~K}$.

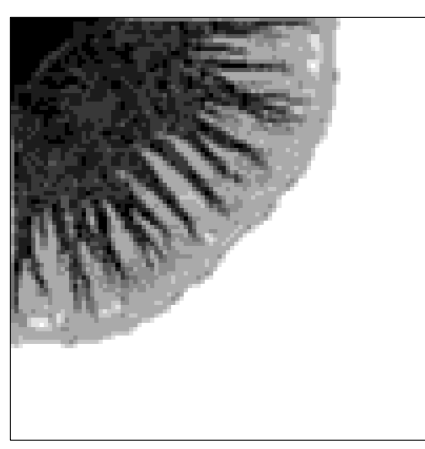

(a) Malha $100 \times 100$

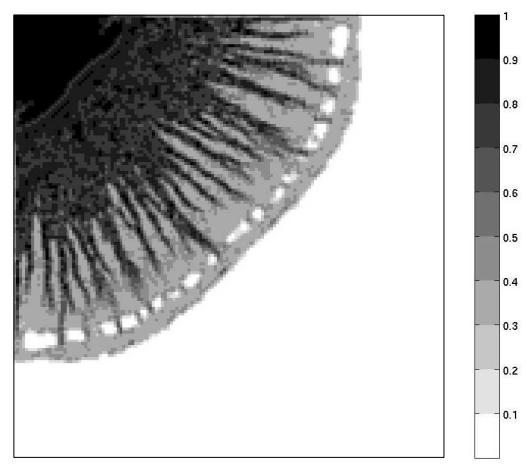

(b) Malha $150 \times 150$

Figura C.14: Análise da convecção com discretização refinada - $h=0,01 \mathrm{~W} / \mathrm{m}^{2} \mathrm{~K}$.

finitos a quantidade de aletas aumenta consideravelmente. 


\section{Apêndice D - Implementação Q4/U para condução térmica}

Neste Apêndice é apresentado um estudo relacionado à solução topológica obtida no exemplo numérico (Caso 1 - Fluxo prescrito) de condução térmica exposto na Figura C.1. Neste exemplo a solução obtida apresenta uma região sem material próximo à fronteira $\Gamma_{u}$. Para verificar o por quê desta ausência de material, o mesmo exemplo foi avaliado considerando a formulação Q4/U (pseudo-densidade por elemento) e utilizado não apenas a PLS como otimizador, mas também o Critério de Optimalidade (CO) (BENDSøE; SIGMUND, 2003).

Um primeiro resultado foi gerado considerando as mesma condições do exemplo Caso 1 Fluxo prescrito, porém considerando uma malha 20x20. A topologia obtida é apresentada na Figura D.1 e o campo de temperaturas gerado por esta topologia foi avaliada através do MEF implementado no MATLAB e comparada com a solução obtida através do software COMSOL, sendo os resultados apresentados na Figura D.2.

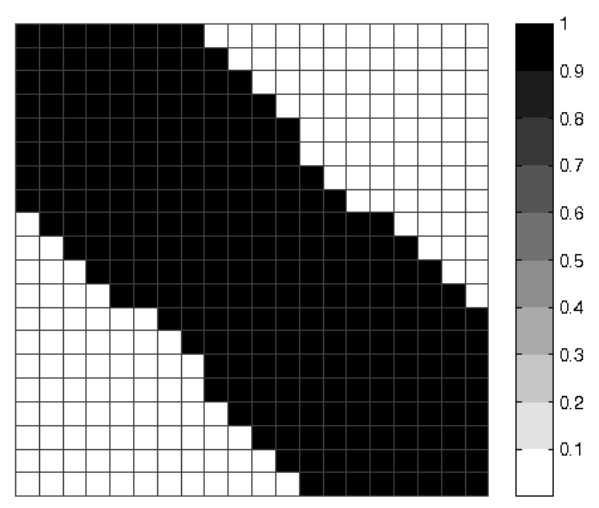

Figura D.1: Distribuição ótima de material condutor para o problema proposto - Malha 20

$$
\text { x } 20-V_{\max }=60 \% \text {. }
$$

Os resultados apresentados na Figura D.2 indicam a correta implementação do módulo de elementos finitos, o qual é introduzido no processo de otimização topológica.

Com a validação do MEF, outros resultados foram gerados e apresentados nas Tabelas D.1 e D.1. Os resultados apresentados nestas tabelas indicam que a solução topologia na Figura 


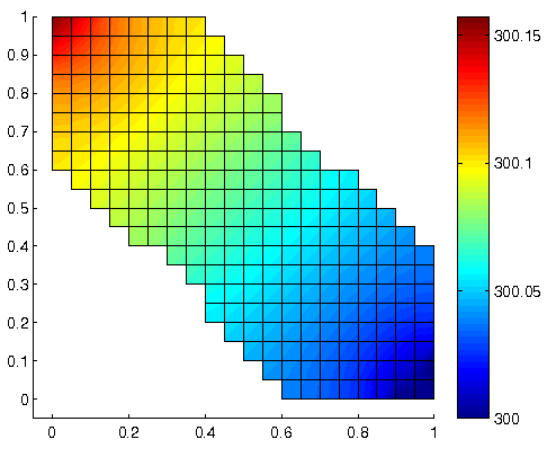

(a) MATLAB $-T_{\max }=300,1572 \mathrm{~K}$

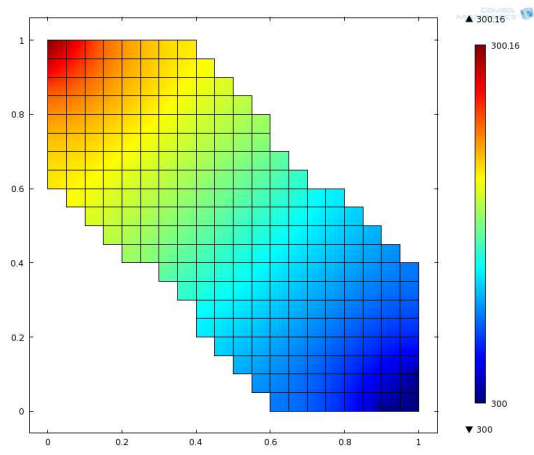

(b) COMSOL - $T_{\max }=300,1595 \mathrm{~K}$

Figura D.2: Distribuição de temperatura obtida através análise em elementos finitos com código implementado no MATLAB e COMSOL.

C.1 refere-se a um mínimo local obtido na otimização, pois as soluções para este problema variam de acordo com a malha de discretização e com otimizador.

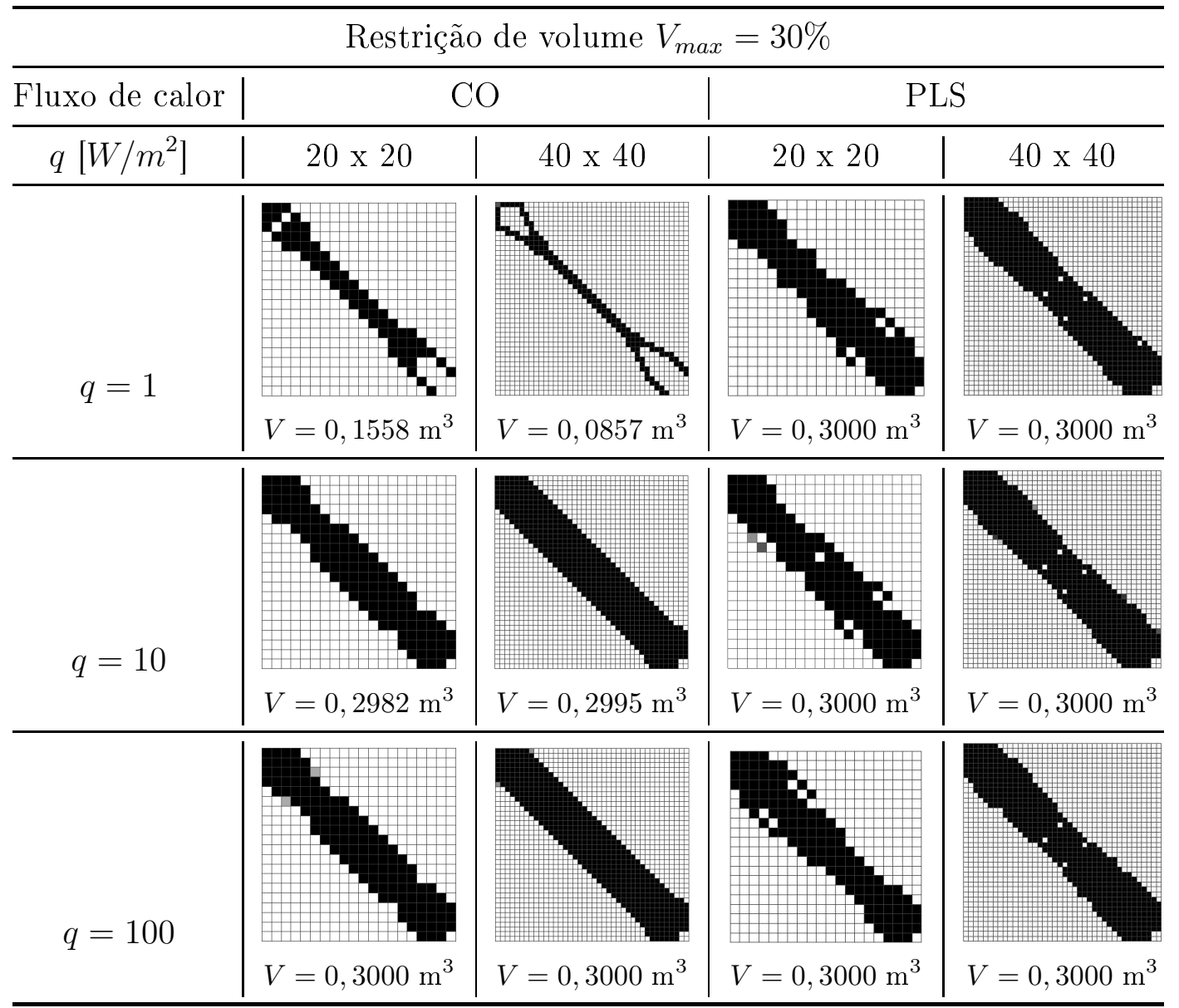

Tabela D.1: Comparação dos resultados considerando PLS, CO e restrição de volume de $30 \%$. 


\begin{tabular}{|c|c|c|c|c|}
\hline \multicolumn{5}{|c|}{ Restrição de volume $V_{\max }=60 \%$} \\
\hline Fluxo de calor & \multicolumn{2}{|c|}{$\mathrm{CO}$} & \multicolumn{2}{|c|}{ PLS } \\
\hline$q\left[W / m^{2}\right]$ & $20 \times 20$ & $40 \times 40$ & $20 \times 20$ & $40 \times 40$ \\
\hline$q=1$ & $V=0,1558 \mathrm{~m}^{3}$ & $V=0,0882 \mathrm{~m}^{3}$ & $V=0,6000 \mathrm{~m}^{3}$ & $V=0,6000 \mathrm{~m}^{3}$ \\
\hline$q=10$ & $V=0,5954 \mathrm{~m}^{3}$ & $V=0,5611 \mathrm{~m}^{3}$ & $V=0,6000 \mathrm{~m}^{3}$ & $V=0,5985 \mathrm{~m}^{3}$ \\
\hline$q=100$ & $V=0,6000 \mathrm{~m}^{3}$ & $V=0,5998 \mathrm{~m}^{3}$ & $V=0,6000 \mathrm{~m}^{3}$ & $V=0,6000 \mathrm{~m}^{3}$ \\
\hline
\end{tabular}

Tabela D.2: Comparação dos resultados considerando PLS, CO e restrição de volume de $60 \%$. 